Portland State University

PDXScholar

7-21-2021

\title{
Nesting Habits of Cavity Nesting Bees and Wasps in Portland, Oregon
}

Stefanie Kay Steele

Portland State University

Follow this and additional works at: https://pdxscholar.library.pdx.edu/open_access_etds

Part of the Biology Commons, and the Entomology Commons

Let us know how access to this document benefits you.

\section{Recommended Citation}

Steele, Stefanie Kay, "Nesting Habits of Cavity Nesting Bees and Wasps in Portland, Oregon" (2021). Dissertations and Theses. Paper 5779.

https://doi.org/10.15760/etd.7650

This Thesis is brought to you for free and open access. It has been accepted for inclusion in Dissertations and Theses by an authorized administrator of PDXScholar. Please contact us if we can make this document more accessible: pdxscholar@pdx.edu. 
Nesting Habits of Cavity Nesting Bees and Wasps in Portland, Oregon

by

Stefanie Kay Steele

A thesis submitted in partial fulfillment of the requirements for the degree of

\author{
Master of Science \\ in \\ Biology
}

Thesis Committee:

Susan E. Masta, Chair

Michael Murphy

Olyssa Starry

Portland State University

2021 
(C) 2021 Stefanie Kay Steele 


\section{Abstract}

Native bees are threatened by habitat loss through urbanization, however, there is increasing interest in creating bee nesting habitat in urban areas. Few studies have determined what species are present in the region, or examined the role of nest height or cavity size in attracting the approximate one-third of native bees that nest in cavities. To determine what species were present, and whether they showed preferences for nesting at a certain height or cavity width, we set up artificial wooden cavity nest blocks across fourteen locations in the greater Portland, OR area. Wooden posts were erected with nest blocks at three heights $(0.5,1.5$, and $2.3 \mathrm{~m})$, and to accommodate a diversity of bee species, cavity widths of $3.0,5.0,6.0,8.0$, and $10.0 \mathrm{~mm}$ were provided. The nests were retrieved at the end of the season and the bees and wasps reared in the lab. We found that bees occupied approximately $15 \%$ of the total available cavity nests, but when bees and wasps were combined, occupancy rates reached approximately 30\%. Sixteen species of bees used the nest blocks, including six nest building Megachilidae genera, two cleptoparasitoid Megachilidae genera, and nest building Colletidae genus. Bees built the greatest number of nests $(60 \%)$ in $5.0 \mathrm{~mm}$ cavity widths. Additionally, $5.0 \mathrm{~mm}$ cavity widths accommodated the greatest diversity of bee species (eight nest building species and one cleptoparasitoid species). Nest building wasps were also common in the nest blocks and occupied nearly $17 \%$ of the total available cavities. At least twelve species of wasps in four families built nests in cavities. Wasps most often used the $3.0 \mathrm{~mm}$ wide cavities (55\% of their nests). In addition to the nest building wasp taxa, at least six species of wasp in five families and one fly species parasitized cavity nests. Overall, all 
nest heights were used by at least some species, although heights at $1.5 \mathrm{~m}$ were the least used. Human constructed nest cavities provide an excellent opportunity to learn more about the various hymenopterans that use them. Nest descriptions and photos are included to be used as a pictural guide of cavity nesting species in the Portland area. Novel nest descriptions are provided for Megachile fidelis and a new record of introduced bee species Pseudoanthidium nanum is provided. Additionally, Megachile angelarum was documented as a new host species for the parasitoid bee fly, Anthrax irroratus. Nesting preference data will be used to better inform residents of greater Portland how best to provide nesting habitat for cavity nesting bees, and the solitary wasps that use similar nesting sites. Although this was not a comprehensive study of all of the cavity nesting species in Portland, we now have a much better understanding of the cavity nesting species and their nesting habits to promote conservation efforts. 


\section{Acknowledgements}

I first want to acknowledge Dr. Susan Masta for all of her support, encouragement, and opportunities she has provided over the years. I also would like to acknowledge the other two members of my committee, Dr. Olyssa Starry and Dr. Michael Murphy I appreciate your comments, enthusiasm, and participation in my research. Those that funded our project, PSU Forbes-Lea grant, Oregon Zoo Future for Wildlife Pacific Northwest Fund, Tim Wessels with Green Anchors, and the Oregon Bee Atlas for allowing me to use some of their nest blocks. I thank Dr. Zachary Portman for his email correspondence and confirmation of the Pseudoanthidium nanum specimens. Homeowners and other property managers for their cooperation in allowing me to place my nest blocks and for their participation monitoring nests while they were in the field. Past and present Masta Lab members who helped with my projects, you all were so valuable, and it was a pleasure getting to know you better. To my grad accountability buddies, you made this last year of quarantine less isolating and you helped me to stay on track (most days) and other days you reminded me that self-care is just as important. I am so thankful for the emotional support provided by my various friends and family members. I realize that joining me on my grad school journey has not always been an easy, but regardless, you stuck by me. To my mom, dad, and brother, you will forever be my favorite cheering squad.

Thank you all! 


\section{Table of Contents}

Abstract.............................

Acknowledgements...................................................... iii

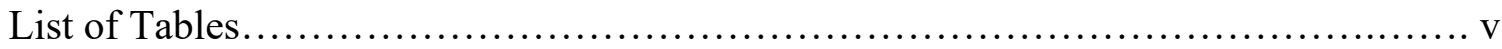

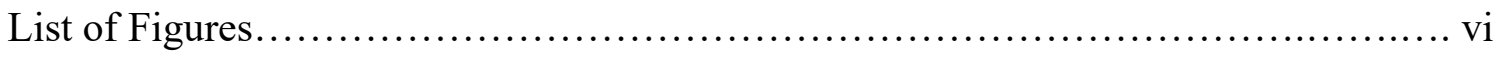

Chapter 1: Overview of Cavity Nesting Species and Their Cavity Width and Nest

Height Use in the Portland Area .......................................... 1

Introduction............................................................ 1

Methods............................................................... 10

Results............................................................ 28

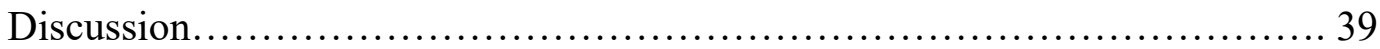

Chapter 2: Natural History of Cavity Nesting Bee and Wasp Species from the

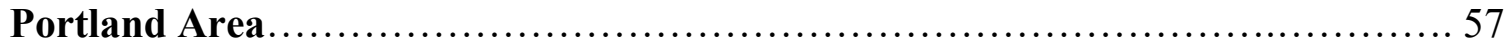

Introduction.......................................................... 57

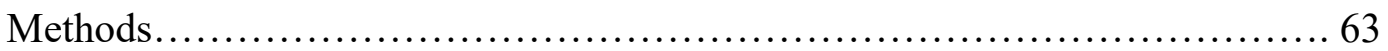

Results \& Discussion................................................. 70

Conclusions....................................................... 100

References............................................................ 165

Appendix: Nest Block Occupants ....................................... 176 


\section{List of Tables}

\section{Chapter 1}

Table 1.1a.

Nest block occupancy rates of cavity nest building bees and wasps for all 54 nest blocks.

Table $1.1 \mathrm{~b}$

Summary table of percent occupancy rates of nest blocks from Table 1.1a.

Table 1.2.

Bee species identified from nest blocks and their nest use. Use of nest materials, cavity width, nest height, total number of cavities, the number of post sites, and the months they were observed in the field are included.

Table 1.3.

Wasp and fly species identified from nest blocks and their nest use. Use of nest materials, the prey provisioned in brood cells, or the nest building bee or wasp host they parasitized, cavity widths, nest heights, total number of cavities, and number of post sites are included.

Table 1.4 112

Bee species abundance by location is shown by the sum number of species observed in each nest block.

\section{Chapter 2}

Table 2.1....

Resources used to identify nest block occupants.

Table 2.2.

Nest supersedure events. Nest block and cavity row information are provided for the nests where one species began nest building and one or more species built their nest using the same row, in front of the first builder.

Table 2.3. 118

Megachile angelarum and Osmia lignaria cavity width nest use, number of developed male and females, and their associated parasitoids.

Table 2.4

Megachile angelarum 3.0 and $5.0 \mathrm{~mm}$ cavity nest emergence results from cells provisioned with pollen.

Table 2.5.

Megachile fidelis nest measurements from $5.0 \mathrm{~mm}$ cavity in nest block 42 at the North Portland natural site, Baltimore Woods. 


\section{List of Figures}

\section{Chapter 1}

Figure 1.1

Linear nest arrangement of cavity nest building bees and wasps. From top: Wasp nest with mud partitions of Trypoxylon Trypargilum sp. from $6.0 \mathrm{~mm}$ cavity. Middle: Bee nest with plant resin partitions of Megachile angelarum from $5.0 \mathrm{~mm}$ cavity. Bottom: Bee nest with mud partitions of Osmia lignaria propinqua from $8.0 \mathrm{~mm}$ cavity.

Figure 1.2

Front view of nest block. The shortest measured width of the cavities corresponds with the cavity diameter measurement given. Column letters and row locations are provided to identify nest locations during field monitoring and rearing. Also note some of the irregularities in the cavities, due to the composition of plywood. A diversity of nesting used in the terminal/closing plugs are visible in some cavities as well.

Figure 1.3

Nest block locations across greater Portland, Oregon in the United States. Nest site codes are listed, and each location has a unique color. Residential garden locations are represented by a triangle shape and all other property types (education garden, community orchard, natural site, and organic farm) are represented by a circle shape.

Figure 1.4

Nine residential garden nest sites.

Figure 1.5.

Two Portland State University (PSU) Community Orchard nest sites in Downtown Portland. From left to right: PSU post 2, community orchard overview photo in early spring, and PSU post 1.

Figure 1.6.

Two Green Anchors (GA) education garden nest sites in North Portland. From left to right: GA post 1, overview of Green Anchors from the summer, GA post 2.

Figure 1.7

Two Bureau of Environmental Services nest sites. From left to right: South Ash Creek (SAC) natural site in Southwest Portland, overview of Baltimore Woods (BW) natural site in North Portland in summer. Baltimore Woods site in spring with BW post 1 near front and BW post 2 far in the distance.

Figure 1.8 126

Our Table Cooperative (OTC) organic farm nest sites in Sherwood. From left to right: OTC post 1 near flower garden and OTC post 2 near the orchard. Photo on right by Ann Christler. 
Figure 1.9.

A $5.0 \mathrm{~mm}$ cavity width nesting tray. Megachile angelarum is visible in the three cavity rows made with red plant resin nesting materials. Cream colored prepupa larvae of $M$. angelarum are visible in many of these cells.

Figure 1.10 127

Vinyl tubing attached to cavity width trays for occupant emergence during. Cavity nests occupied by Megachilidae bees; right tray: $3.0 \mathrm{~mm}$, left tray: $5.0 \mathrm{~mm}$.

Figure 1.11

Number of cavities occupied by bees per nest site post location.

Figure 1.12

Cavity widths used by all bee species.

Figure 1.13

Nest heights used by all bee species.

Figure 1.14.

Cavity width use by Megachile angelarum.

Figure 1.15

Nest height use by Megachile angelarum.

Figure 1.16

Cavity width use by Osmia lignaria propinqua.

Figure 1.17

Nest height use by Osmia lignaria propinqua.

Figure 1.18

Cavities used by bees and wasps per nest site post location, cavity widths (mm), and heights (m).

Figure 1.19

Number of cavities occupied by nest building wasps per nest site post location.

Figure 1.20.

Cavity widths used by all nest building wasp species.

Figure 1.21

Nest heights used by all nest building wasp species.

Figure 1.22. 
Cavity width used by common wasp genera: Pisonopsis sp., Trypoxylon spp., and Isodontia spp.

Figure 1.23 140

Nest heights used by common wasp genera: Pisonopsis sp., Trypoxylon spp., and Isodontia spp.

Figure 1.24

Parasitoid species nest use compared to nest building bee and wasp species. Cavity width and nest height for both occupant types is graphed for each location.

\section{Chapter 2}

Figure 2.1

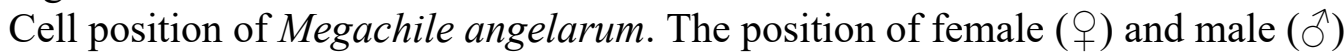

Megachile angelarum, and parasitoid flies, Anthrax irroratus are shown under each.

Figure 2.2.

Osmia lignaria propinqua superseded by Isodontia elegans in an $8.0 \mathrm{~mm}$ cavity of a 2.3 $\mathrm{m}$ nest block at organic farm site OTC.

Figure 2.3 143

Megachile angelarum superseded two wasp species. Wasp species, T. Trypoxylon sp. and Pemphredoninae resin sp., nested in the first 2/3 of the nest and Megachile angelarum in the final third, completing the $3.0 \mathrm{~mm}$ cavity nest in a 0.5 nest block at residential garden site $\mathrm{OSH}$.

Figure 2.4 143

Evidence of nest competition between Eumeninae sp. wasps and Megachile angelarum.

Figure 2.5. 143

Evidence of nest competition between Pemphredoninae resin sp. and Pisonopsis sp.

Figure 2.6.

Parasitoid fly pupa of Anthrax irroratus moving through the resinous cell partitions built by Megachile angelarum in a $5.0 \mathrm{~mm}$ cavity.

Figure 2.7 144

Parasitoid wasp larvae of Melittobia sp. on a Megachile fidelis larva in a $5.0 \mathrm{~mm}$ cavity.

Figure 2.8. 145

Parasitoid wasp adults, Melittobia sp. outside cavity nest entrances.

Figure 2.9 146

A.) Female Megachile angelarum returning to $5.0 \mathrm{~mm}$ cavity nest. Fresh green terminal plug material visible in cavity above this bee. B.) M. angelarum terminal nest plug 
showing innermost material plant resin, middle loose plant material, and outermost finely masticated leaves. C.) Female M. angelarum. D.) Male M. angelarum.

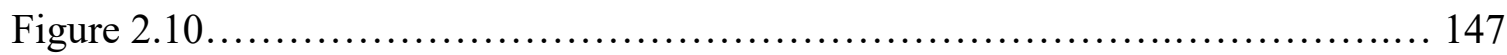

Megachile angelarum $3.0 \mathrm{~mm}$ cavity nests.

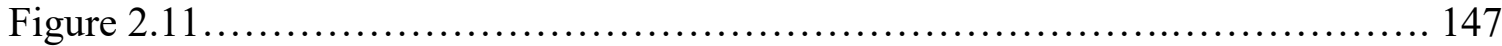

Megachile angelarum $5.0 \mathrm{~mm}$ cavity nests.

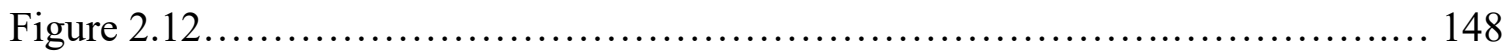

Osmia lignaria propinqua $8.0 \mathrm{~mm}$ cavity nest.

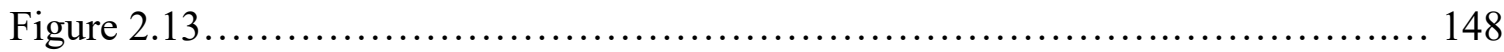

Osmia lignaria propinqua mud terminal plugs visible in 5.0 and 6.0 cavity widths.

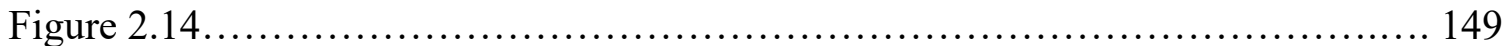

Parasitoid wasps, Monodontomerus sp. emerged from Osmia lignaria propinqua cocoons.

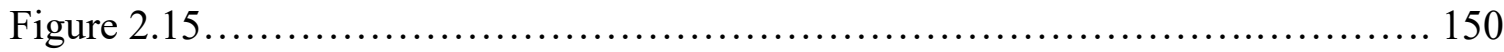

Megachile fidelis $5.0 \mathrm{~mm}$ cavity nest.

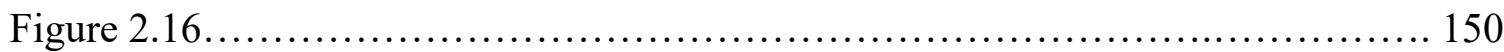

Close up of a Megachile fidelis brood cell with male in the cell.

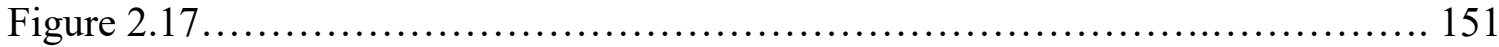

Finely masticated leaves and mud used for cell partitions and along edge of cavity row in Megachile fidelis nest.

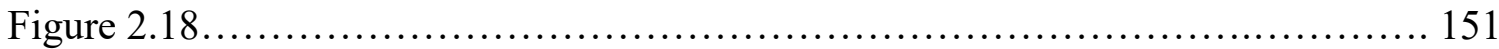

Megachile fidelis preliminary plug nest materials: brown toothed leaves partially coated with sticky resinous material.

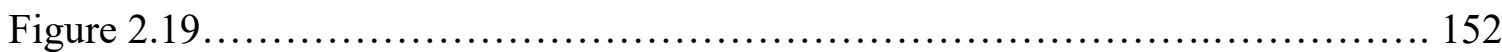

Megachile sp. A with overlapping cut green leaves in a $10.0 \mathrm{~mm}$ cavity nest. Fuzzy fungal growth visible on nest materials.

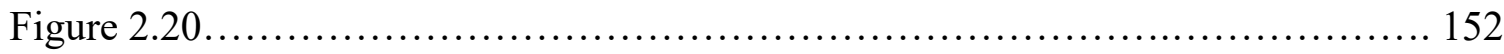
Megachile sp. A's encapsulated green leaf cocoon. Fuzzy fungal growth visible on nest materials.

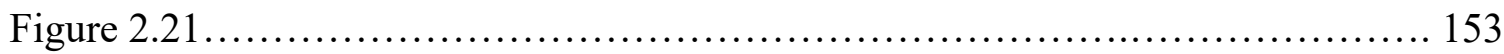

Megachile sp. B's rolled petal nest in $8.0 \mathrm{~mm}$ cavity.

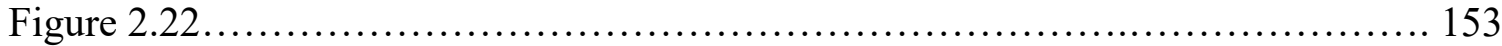


Cocoon of Megachile sp. B rolled petal nest in $8.0 \mathrm{~mm}$ cavity.

Figure 2.23.....

Megachile sp. C rolled leaf nest in $8.0 \mathrm{~mm}$ cavity.

Figure 2.24

Pseudoanthidium nanum in $5.0 \mathrm{~mm}$ cavity width nests.

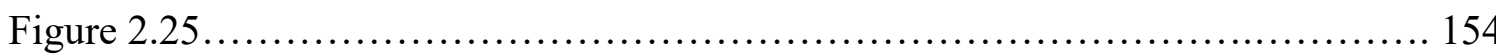

Melittobia sp. visible inside Pseudoanthidium nanum cocoon.

Figure 2.26

Heriades carinata $3.0 \mathrm{~mm}$ cavity nest.

Figure 2.27 155 Male Heriades carinata visible in brood cell with whiteish colored plant resin partitions.

Figure 2.28. 155 Ashmeadiella cactorum cactorum $3.0 \mathrm{~mm}$ cavity nest. Black staining evidence of fungal growth in this nest.

Figure 2.29 156

Hoplitis albifrons nest in $5.0 \mathrm{~mm}$ cavity.

Figure 2.30..... 156 Hoplitis albifrons collecting balls of dirt to use as nesting material on 13 July 2019.

Figure 2.31 157

Osmia proxima $5.0 \mathrm{~mm}$ nest cavities.

Figure 2.32 157

Close view of Osmia proxima brood cells, cocoons, cell partitions, and uneaten pollen ball mass.

Figure 2.33 158

Hylaeus sp. nest in $3.0 \mathrm{~mm}$ cavity.

Figure 2.34. 158

Close view of cellophane secretions from Hylaeus sp. nest.

Figure 2.35

Isodontia elegans nest in $6.0 \mathrm{~mm}$ cavities.

Figure 2.36

Isodontia elegans nest in $10.0 \mathrm{~mm}$ cavities. 
Figure 2.37

Isodontia elegans nest in $8.0 \mathrm{~mm}$ cavities with uneaten tree cricket prey visible.

Figure 2.38 160

Trypoxylon (Trypoxylon) frigidum nest $3.0 \mathrm{~mm}$ cavity. Two Eumeninae cells are visible closest to the nest entrance and terminal plug.

Figure 2.39 160

Trypoxylon (Trypargilum) sp. nest in $6.0 \mathrm{~mm}$ cavity. Uneaten spider prey provisions visible in center brood cell.

Figure 2.40 . 160

Pisonopsis sp. nests in $3.0 \mathrm{~mm}$ cavities.

Figure 2.41 160

Close up of Pisonopsis sp. cocoon and uneaten spider prey provision.

Figure 2.42

Resin Pemphredoninae sp. nest in $3.0 \mathrm{~mm}$ cavities.

Figure 2.43 161 Close up of resin Pemphredoninae sp. in brood cell with resin partitions visible and cellophane material cell cover.

Figure 2.44 162 Wood chewing Pemphredoninae sp. nest in $3.0 \mathrm{~mm}$ cavities.

Figure 2.45 162

Wood chewing Pemphredoninae sp. brood cells. Wood was chewed from the sides of the cavity row.

Figure 2.46 163

Eumeninae sp. nest in $3.0 \mathrm{~mm}$ cavities.

Figure 2.47 163

Eumenine sp. female returning to $5.0 \mathrm{~mm}$ cavity nest. Globular mud terminal plug is visible below female.

Figure 2.48

Eumeninae sp. nests in $6.0 \mathrm{~mm}$ cavities. Suspected multivoltine species with evidence of cell partitions broken and brood cells empty. Additionally, small holes visible in cell top linings from parasitism. 


\section{Chapter 1: Overview of Cavity Nesting Species and Their Cavity Width and Nest Height Use in the Portland Area}

\section{Introduction}

Recent studies have shown that bees and other insects across the world are in decline (Wratten et al., 2012; Mallinger, Werts and Gratton, 2015; Kopec and Burd, 2017; Sánchez-Bayo and Wyckhuys, 2019; Kline and Joshi, 2020). There are several contributing factors associated with their decline, including pesticide use, climate change, pathogens, and habitat loss associated with agricultural intensification and urbanization (Baldock et al., 2015; Sánchez-Bayo and Wyckhuys, 2019; Kline and Joshi, 2020). Bees require appropriate habitat for foraging and appropriate habitat in which to locate their nests, so the loss of habitat may be particularly devastating to bee populations. While there has been a growing public awareness of the need to conserve pollinators, often the emphasis has been on the importance of providing floral resources, with less emphasis on providing appropriate nesting sites. The majority of bees nest in the ground, and about 30 percent nest in cavities (Sheffield et al., 2011; Kline and Joshi, 2020). In an effort to conserve bees and other pollinators, and combat the effects of habitat loss, conservation efforts from organizations like the Xerces Society for Invertebrate Conservation are educating the public on how to recognize, develop, and maintain pollinator habitat in many types of landscapes (Vaughan and Skinner, 2008; Jordan et al., 2014, 2019; Williams et al., 2015). However, we lack information on the basic biology of most species of bees, and indeed in many regions, do not even know what species of bees are 
present. This makes it difficult to develop regional guidelines of best practices to promote bee conservation.

To effectively conserve bee communities in a given area, an understanding of what species are present, their biology, and resource requirements are necessary. Surveys are conducted to collect occurrence records and provide a baseline of the species present in an area through various sampling methods. The Oregon Bee Atlas (OBA), for instance, began an ongoing state-wide bee survey to catalog the state's species in 2018 (Oregon Bee Atlas, 2020). We, the Masta lab, at Portland State University (PSU) have surveyed the bees of Portland and their floral use at selected urban sites within the city over the 2017 - 2019 field seasons. Survey sampling methods vary in their effort, effectiveness, and type of data collected. Surveys occur through passive techniques (e.g. trap nests, bowl traps) or active techniques (e.g. netting, observations) (Portman, Bruninga-Socolar and Cariveau, 2020). Passive techniques require less effort from the surveyor after they are set-up and are easier for scientists to repeat without inserting their own survey bias. However, the different passive techniques themselves can be biased in the species that are attracted to them, and therefore do not accurately represent the overall bee composition or abundance of an area (Portman, Bruninga-Socolar and Cariveau, 2020). By contrast, active techniques require more effort in the field from the surveyor and effectiveness can vary based on the surveyors' experience (Portman, Bruninga-Socolar and Cariveau, 2020). However, active methods allow for phenology data to be collected, such as the species' seasonality, floral use, and other active behaviors that cannot be observed from other passive collections. The OBA uses a mix of both passive and active sampling 
methods, while the Masta lab uses active methods for our surveys. However, for our project, passive methods were primarily used to better understand Portland's cavity nesting bees.

Cavity nesting bees are solitary bees that seek pre-existing cavities for their nest. Cavity nesting females will then use these cavities to build and provision the brood cells for her nest. Cavities that are used by these types of bees occur as pre-existing holes, such as in our nest blocks. Alternatively, some cavity nesting species will chew the soft pith from plants or wood to create their cavity, and therefore may be unlikely to use pre-made cavities in nest blocks. Bees are herbivorous and forage floral resources to acquire most of their nutrition. The maternal females forage primarily on nectar for themselves and pollen for their developing young. Foreign materials, such as plants or mud are often used to construct nest cells within the cavity for their developing young. These foreign materials are sourced in the same general area as the nests. Alternatively, some bees use their own glandular secretions as their nesting material. Cavity nesting bees in the Pacific Northwest exist in different body sizes, with Hylaeus species being some of the smallest at about 4-6 $\mathrm{mm}$ in length and Heriades carinata between 6-8 $\mathrm{mm}$ long, while some of the largest species include Megachile which ranges from 10-18 mm in length (Ascher, 2009).

To better understand cavity nesting bees' basic natural history, human constructed nest boxes can be placed in the environment. These artificial nest cavities are sometimes called trap nests in the literature when they are used to collect the bees that nest in them. In a sense, these nests are trapping their offspring in the artificial nests where they can be 
subsequently reared in the laboratory. Other terms used for artificial cavity nests are bee hotel, bee block/box, and nest block. These terms have become popularized by community members in private and public gardens to refer to similar, but sometimes elaborate, human constructed cavity nest structures. Nest block is used throughout our project and is a more inclusive term that includes the other cavity nesting occupants that occur beyond the bee species, such as solitary wasps. Regardless of the term used, these nest blocks are widely accepted passive sampling tools used by researchers to study the biology of solitary cavity nest building bees, wasps, and their associated cleptoparasitoids, parasitoids, and predators (Fye, 1965b, 1965a; Krombein, 1967; O’Neill and O’Neill, 2010; MacIvor, 2017). Cleptoparasitoids feed on the hosts' food provisions and kill the host, while parasitoids feed directly on the host and eventually kill them. Predators, such as ants, beetles, and birds, can feed on nesting occupants.

Artificial nest cavities can be made to vary in cavity width or diameter, such that bees of different body size can select the cavity size that best suits them. Inside each cavity the female bees or wasps build a series of linear brood cells, in which they provision the egg in each cell (Figure 1.1). The female begins nest construction at the innermost end of the cavity, farthest from the entrance, with a preliminary plug. Preliminary plugs act as the inner most wall of the nest and partition of the first provisioned cell. They are typically made of the same nesting material (e.g. mud, plant resin, cut leaves, glandular secretions) as the cells but are often constructed thicker than the other cell partitions. Cells are provisioned with food by the female building the nest for the developing young to consume. Bees provide their developing young a pollen ball 
mass and wasps provide prey that they have paralyzed (e.g. spiders, aphids, tree crickets, caterpillars). Cell partitions then separate each successive cell and are sometimes curved in their shape, with the open side of the curve directed toward the cavity entrance. Commonly, before the terminal closing plug, an empty cell varying in length and called a vestibular cell is built. The terminal closing plug, typically made of the same nest building materials, is often constructed at the cavity nest entrance but can also be recessed inside the cavity.

Only a couple of cavity nesting bee taxa that reside in the Pacific Northwest have been well-studied. These include the native blue orchard mason bee Osmia lignaria (Megachilidae), and the introduced alfalfa leafcutter bee Megachile rotundata (Megachilidae). These two species readily use nest blocks, and have shown success in pollinating fruit trees early in the spring season (O. lignaria) and alfalfa in the summer (M. rotundata), making them economically important (Stephen and Osgood, 1965; Phillips and Klostermeyer, 1978; Kemp and Bosch, 2000; Pitts-Singer and Cane, 2011; Kraemer, Favi and Niedziela, 2014). It is known from published studies in North America, that $O$. lignaria is active early in the spring season, uses mud to build their brood cells, and has been recorded using cavity diameters sizes of 4.8, 6.4, 8.0, $12.7 \mathrm{~mm}$ with a preference for $6.4 \mathrm{~mm}$ diameter cavities, and will use nests heights from 1 to $2 \mathrm{~m}$ (Krombein, 1967; Kraemer, Favi and Niedziela, 2014). However, the preferred height of O. lignaria's nests have not been studied. Megachile rotundata is active in the summer season, uses cut leaves in an overlapping fashion to build their linear brood cells in cavity diameters ranging from 4 to $7 \mathrm{~mm}$ (Stephen and Osgood, 1965; Krombein, 1967; Kemp 
and Bosch, 2000; Pitts-Singer and Cane, 2011). From a previous study, Megachile rotundata readily accepted large domicile structures in agricultural fields that were $3 \mathrm{~m}$ tall and 2.4 to $6 \mathrm{~m}$ wide with cavities distributed throughout its entirety (Stephen, 1981; Richards, 1984). Richards found that cavities along the top and sides were occupied before those in the center and lower heights. The tops nests and those along the sides were believed to be preferred because they had the best light stimulation and visibility (Richards, 1984).

In addition to the life history information that has been gathered for these two commercially important bees, a few other studies of cavity nesting bees that live in the PNW have provided data on their nesting biology. The bee Megachile gentilis (Megachilidae), a summer-active resident bee of the PNW, is known to use $6.4 \mathrm{~mm}$ diameter cavities and build linear brood cells with circular cut leaves (Barthell, Frankie and Thorp, 1998). Another native summer-active bee Heriades carinata (Megachilidae), is known to use plant resin to build their linear brood cells in preferred diameters of $1 / 8$ inch $(\sim 3.175 \mathrm{~mm}), 9 / 64$ inch $(\sim 3.572 \mathrm{~mm})$ (Matthews, 1965$), 3.2 \mathrm{~mm}$, and $4.8 \mathrm{~mm}$ (Krombein, 1967). The above species have all been collected in surveys at sites in the urban core of Portland (Masta Lab Portland Bee Survey; unpublished, but see https://pdxscholar.library.pdx.edu/uerc/2020/posters/7/).

Even with the overall decline of available habitat, studies have shown that urban habitats can support a diverse number of bees if there is adequate habitat (Wojcik et al., 2008; Fortel et al., 2014, 2016). However, cavity nesting bees may have limited options of places to nest in urban habitats (Fortel et al., 2016). The cavities that bees generally 
occupy are hollowed plant stems, or abandoned cavities excavated by beetle in logs, stumps, or snags. Alternatively, some species will chew out the centers of pithy stemmed plants (Vaughan et al., 2009). Recognizing and preserving nesting locations is important, as most native bee species only live about one year, eleven months of which is spent developing within their nest and only approximately three to four weeks spent as an active adult (Moisset and Buchmann, 2011). Societal pressures may force a standard on homeowners and property managers to cut back stems, remove fallen branches, dead logs, or snags, and clean and tidy their lawns and properties, often by covering bare soil with mulch. Removing such "imperfect areas" may serve to remove habitat for these ecologically important pollinators. In addition to natural cavity nesting sites, human constructed, supplemental cavity nests may also be considered as alternative nesting sites.

Nest block design factors that have been well studied for some species of bees in eastern North America include cavity nest diameters, color and/or pattern of nest entrance, orientation, nest material, and nest placement (MacIvor, 2017). Nest dimensions are important because bees are selective of diameters based on their own body size and the need to ensure a tight fit for brood cells and minimize parasite access (MacIvor, 2017). Color and pattern around the outside of the nest entrance has been shown to increase nest recognition, particularly in nests with many cavities (Krombein, 1967; MacIvor, 2017). Southeastern orientations in full sun exposure have been found to yield the most occupants compared to other orientations (Budrienè et al., 2004; Everaars et al., 2011). Artificial nest materials vary from wood (blocks or stacked trays), cardboard tubes, plastic (tubes or stacked trays), glass tubes, or hollowed plant stems. Each style has 
its own benefits and limitations, but wood has been found to be the most attractive to bees (MacIvor, 2017). Nest placement factors include the substrate to which nests are attached, nest coverage, and habitat of nest placement. However, there have been very few studies examining height preferences of different nesting species. Instead, the majority of previous studies simply located nests at heights between 1-2 m above ground, most commonly at $1.5 \mathrm{~m}$, and it was not specified why these heights were chosen (Krombein, 1967; Torchio, 1976; Barthell, Frankie and Thorp, 1998; Loyola and Martins, 2008, 2011; Guisse and Miller, 2011; Kraemer, Favi and Niedziela, 2014; Rubene, Schroeder and Ranius, 2015; Araújo, Lourenço and Raw, 2016; O’Neill and O'Neill, 2018; Boyle and Pitts-Singer, 2019; Nether, Dudek and Buschini, 2019). If any reasoning for a height placement was stated in the above studies, it was because they were either replicating methods of a previous study or attempting to keep nest cavities above most vegetation. Additionally, instructions from retailers guide customers to install nests at eye level or $1.5 \mathrm{~m}$ for viewing enjoyment and to keep out of reach of pets (Hunter, 2020). Furthermore, there also have been no study of cavity nesting bees in the Portland, Oregon, region, therefore we do not even know what species are present let alone their nest preferences. Studies of the commercially important alfalfa leafcutter, Megachile rotundata, and the blue orchard mason bee, Osmia lignaria have shown that these two species use different sizes of cavities. In addition to the commercial use of these bees, their cocoons and nesting structures are also available for hobbyists to purchase from retailers. The blue orchard mason bees are advertised as utilizing $8 \mathrm{~mm}$ diameter nests while the summer leaf-cutter bees use $6 \mathrm{~mm}$ nests (Hunter, 2020). 
To effectively conserve the bees in this area, we first must know what species are present. Knowing which species accept the artificial nest blocks from our project will allow us to better understand the species in the area and which might use these nest structures. The nest blocks will also allow for further understanding of their nesting requirements, such as their nesting materials, seasonality, and the areas species are commonly found. Many lesser-known species may currently be excluded from most artificial nest block designs because their requirements fall outside of the popularized "mason or leafcutter bees" cavity diameter ranges. Knowing the cavity nesting parameters of the lesser-known species is especially important to accommodate the diversity of species present. Further investigation of preferred nest height will enable us to determine if the commonly used nest height of $1.5 \mathrm{~m}$ and cavity widths of 6 and $8 \mathrm{~mm}$ are preferred by the cavity nesting taxa in the PNW.

Supplemental cavity nest sites such as nest blocks can increase available cavity nesting habitat, and also provide excellent tools for education. However, in order to inform community members on how to provide the best artificial cavity-nest sites, the considerations of species-specific cavity nesting preferences must be addressed. Hence, our research investigated the following three questions by using specially designed nest blocks: (1) What cavity nesting species are present in the greater Portland, OR area? (2) What cavity nesting widths do species use? And (3) what nesting heights do species use? 


\section{Materials and methods}

\section{Nest block construction and assembly}

The nest blocks of our study consisted of 31 cavities, with five square cavity width sizes of $3.0 \mathrm{~mm}, 5.0 \mathrm{~mm}, 6.0 \mathrm{~mm}, 8.0 \mathrm{~mm}$, and $10.0 \mathrm{~mm}$, and a depth of $20.4 \mathrm{~cm}$ (Figure 1.2). These cavity width measurements were measured across the horizontal width of the squares, the shortest length of the cavity. The corresponding longest diagonal length, or hypotenuse of each cavity was calculated. These diagonal lengths are, from smallest to largest, approximately $4.2 \mathrm{~mm}, 7.1 \mathrm{~mm}, 8.5 \mathrm{~mm}, 11.3 \mathrm{~mm}$, and 14.1 $\mathrm{mm}$. Not all cavities fit these measurements perfectly as plywood is an imperfect and, at times, irregular material, making it difficult to cut precisely. Size variation most often occurred in the smallest, $3.0 \mathrm{~mm}$ cavities. Some of these cavities as a result were not quite square and their height was shorter than their width, creating more of a horizontal slit.

The $3.0 \mathrm{~mm}$ wide cavities had seven cavities per nest, and all other cavity width sizes had six cavities per nest (Figure 1.2). Fifty-four nest blocks were built, and each composed of seven pieces of $3 / 4$ or $5 / 8$ inch plywood that were cut so that they were 10.2 $\mathrm{cm}$ wide by $20.4 \mathrm{~cm}$ deep. Five of those plywood pieces were for each of the five cavity width sizes, which I will refer to as "trays". Another piece of plywood was used to act as the outer side to the largest cavity width, the $10.0 \mathrm{~mm}$ tray, and the last piece of plywood was used for the roof $11.1 \mathrm{~cm}$ by $26.8 \mathrm{~cm}$. The five different sized cavity tray widths were cut with a straight router, forming square cavities. Placed directly on top of the 
cavities was a sheet of acetate, followed by a sheet of $1 \mathrm{~mm}$ plastic foam underlayment. The nest blocks were then banded together by using two pairs of 11.8 inch $(\sim 30 \mathrm{~cm})$ long UV black pure nylon cable zip ties. The back side of the nest blocks were two layered, the inner layer was $1 \mathrm{~mm}$ plastic foam underlayment, and the outer layer was $4.0 \mathrm{~mm}$ corrugated plastic, such as what is used for sign making.

The original nest block design was created by the Oregon Bee Atlas (OBA), who donated 25 nests blocks made using $5 / 8$ inch plywood to our project. However, these donations were assembled so that each cavity tray was oriented horizontally, rather than vertically, with the $10.0 \mathrm{~mm}$ tray under the roof section, and the $3.0 \mathrm{~mm}$ tray on the bottom. To maintain standard design, these donated nests were rotated ninety degrees, and the extra length that overhung for the roof above the $10.0 \mathrm{~mm}$ tray was cut off, and a new roof was added on top of the vertically orientated trays. The remaining 29 nest blocks were built with the assistance of volunteers and with donated $3 / 4$ inch plywood provided by Green Anchors staff. Volunteers that assisted in building nest blocks included Portland State University (PSU) students and staff, Green Anchors staff, and my family members. Each nest block was assigned a number 1-54, and this identification number along with project contact information were printed, laminated, and stapled to the outer side of the $3.0 \mathrm{~mm}$ tray.

\section{Post and nest block installment.}

At the beginning of spring, during the week of 30 March to 7 April 2019, nest blocks and eighteen 4 inch by 4 inch by 10 foot tall fence posts were installed at fourteen 
locations across the Portland metro area (Figure 1.3). To install fence posts, post hole diggers were used to dig two feet deep holes, which left eight feet of the post above ground. Soil was then backfilled around the posts and tampered down until the post was stable with minimal movement.

Nest blocks were attached to posts by drilling an 8 by $13 \mathrm{~cm}$ piece of plywood to the outer side of the $10.0 \mathrm{~mm}$ tray, which was then drilled into the post facing southeast because Burdrience et al. (2004) found that a southeast orientation was most attractive to bees. To determine nest height preferences of cavity nest building bees (and wasps), nest blocks were attached to posts at heights of $0.5 \mathrm{~m}, 1.5 \mathrm{~m}$, and $2.3 \mathrm{~m}$ above ground. These heights were selected based on several factors. First, a height of $1.5 \mathrm{~m}$ is the most commonly used height in research and is the height suggested by commercial vendors of mason bees to place "mason bee" nests. This height is also the approximate height of eye level for many people and allows easy observation of nest building and occupancy. A height of $1.5 \mathrm{~m}$ is also generally above vegetation that may block the nest entrances (MacIvor, 2017) and out of reach of residential pets (e.g. dogs) that may disturb nests. Second, a height of $2.3 \mathrm{~m}$ is approximately the height of eaves of a house or a garage. This height is another nest block placement recommendation for hobbyists as the eave also provides additional protection from weather (Hunter, 2020). Heights of $2.3 \mathrm{~m}$ do require a three-step stool to view and access, but this is a common tool many people already have in their homes. Lastly, because our goal was to determine if $1.5 \mathrm{~m}$ was actually the preferred height for all of the bees in the Portland region, we also selected a lower height, $0.5 \mathrm{~m}$. A height of $0.5 \mathrm{~m}$ was selected as the lowest height because it was 
not too close to the ground that nests will be infiltrated by rain, but still close enough to the ground to act as a lower contrast. This low height would be similar to that of a tree stump, log, or hollow stemmed plants. At this height nests would also be above most low growing vegetation, but some maintenance around nests was occasionally necessary to prevent nest entrances from being obscured by vegetation (uncut grass), or to minimize easy access of arthropod predators (e.g. spiders, ants, dermestid beetle larvae, earwigs etc.).

\section{Field sites}

Fourteen properties were selected to host nest blocks for the 2019 April to October spring, summer, and fall season, with each property given a unique two to three letter code (Table 1.1a, Figure 1.3). Each of the 14 nest locations had either one or two posts with nest blocks conformed to the three heights. The number of posts with nests per location depended on the size of the land available and cavity nesting bees previously observed. The nests were secured to the 10 -foot tall wooden posts and erected in agreed upon locations with the landowner. A total of 18 posts and 54 nests were installed. The properties encompassed three counties in the greater Portland area: Multnomah, Clackamas, and Washington counties. The spread of nest locations from each other when measured on Google Earth was approximately 165 square miles (427 square kilometers) of urban, residential, and rural landscapes. The plants and other natural environmental features at the property sites were not analyzed. However, brief overall descriptions of the field sites are provided below. Property managers and homeowners reported that 
pesticides were not used at the locations while nest blocks were on site, but they may have been used in previous years at some sites. All sites had a mix of perennial, annual, native, and ornamental plants/shrubs, which varied in their composition. Additionally, grass and bark chips were common as the ground substrates and typically areas of bare ground and dead wood were minimal.

Nine of the locations were residential gardens (EBH, OSH, TWH, OH, NH, MMH, EKH, ERH, DHH) (Figure 1.4). Residential gardens had one nest post each and were spread across all three counties. Owners of these residences dedicated a portion of their yards to attract native pollinators and were interested in learning what bees were found residing in their yards. Two of the sites were locations where we, the Masta Lab, had previously conducted preliminary native bee surveys. These two surveyed sites were Portland State University Community Orchard (PSU) in Downtown Portland (Figure 1.5), and Green Anchors (GA) an educational garden in North Portland (Figure 1.6). The community orchard and education garden sites both had two nest posts installed per location due to the abundance and diversity of cavity nesting bees collected from previous surveys. The PSU community orchard is located on the far west side of the campus, bordering a highway on-ramp. The Green Anchors education garden borders a city park to the south, a Port of Portland site to the north, and the Willamette River to the west. Two other sites were Bureau of Environmental Services (BES) natural sites, Baltimore Woods (BW) in North Portland and South Ash Creek (SAC) in Southwest Portland (Figure 1.7). These BES natural sites were primarily open fields, but also had mature trees that lined the edge of the properties and also shared a border with residential 
yards. Most of the trees at Baltimore Woods were part of a corridor of Oregon white oak. Additionally, there was also a small orchard on site. Two nest posts were installed at Baltimore Woods due to the bee activity and site productivity I observed from the previous two summers. The last site was a certified organic farm in Sherwood, Our Table Cooperative Farm (OTC) (Figure 1.8). The organic farm had two nest posts on site, one near the main farmhouse and flower garden and the other was on the other side of the property near the farm owners house and small orchard.

\section{Field monitoring}

Volunteers (homeowners, property managers, PSU students) and I conducted field observations of nest blocks every other week to monitor them for any kind of activity. Signs of occupancy from bees or wasps included observing them flying in or out of the cavity, or presence of nesting material inside of the cavities. The presence of non-target invertebrates such as spiders or ants nesting in the cavities was also noted. Volunteers were instructed to remove any spider webs that were found around nest blocks, so they would not deter targeted occupants, but were not to interfere with any spiders inside of the cavities. Volunteers used an observation log to record the nest block identification number, day, month, and details of that day's observations. If the nest cavities were empty, "empty" or "no activity" was notated. If there was activity to record, locations were identified by the associated row location number and column letter (Figure 1.2). A flashlight was used to help determine if cavities were occupied or not. Due to the partially transparent nature of the plastic backings of the nest blocks, light would not pass through 
if cavities were occupied. With these observations at the start of nest building, more accurate seasonality was determined. As nest building progressed, the nest material used by the host was recorded in the observation log.

In May 2019, ants in the genus Camponotus were observed inhabiting all three nests on one of the posts at PSU. Due to the level of infestation, bees that had started nests at this location were destroyed. The ants were sprayed out of the cavities with water, and then a sticky sap barrier, tanglefoot, was applied to the post to prevent the ants from inhabiting the nest blocks again. To apply tanglefoot, the tanglefoot guard tree wrap was wrapped around the base of the post (about $10 \mathrm{~cm}$ above the ground) and secured with a piece of twine. A thick layer of tanglefoot was then applied to the wrap to serve as a sticky insect barrier. This process was repeated on all 18 posts to prevent further ant infestations. Volunteers were instructed to keep vegetation off the posts and nest blocks, as this could provide easy access for non-targeted invertebrates to occupy cavities, but also to keep vegetation from blocking nest entrances to not deter bees from utilizing the net blocks. Throughout the field season, email check-ins were periodically sent to volunteers to provide examples of bees and wasps they might observe, reiterate instructions, and to provide time for feedback and questions.

Nest block retrieval and diapause: $4^{\circ} \mathrm{C}$ cold storage

All nest blocks were collected from the field between September 30 and October 6, 2019. Upon retrieval, nest block entrances were photographed and then the nests, still bound, were placed into cold storage. Temperatures were kept between $4{ }^{\circ} \mathrm{C}$ (MacIvor \& 
Salehi, 2014) or a maximum $8{ }^{\circ} \mathrm{C}\left(\mathrm{O}^{\prime}\right.$ Neill \& O'Neill, 2018) and about $50 \%$ relative humidity (Richards, 1987) to mimic winter temperatures during their diapause period. Relative humidity fluctuated and maintained about an average of $30 \%$ in the chamber used. Bee and wasp occupants experienced a shortened diapause period that ended between 14 January and 24 March 2020 when they were placed in warm growth chambers. A typical diapause period in the Portland area would last until March for spring bees and late May through July for summer bees. Shortened diapause lengths for many bee species has not been studied, but my preliminary data from rearing summer 2018 nest contents were successful with this shortened diapause period.

\section{Photography and disassembly}

Nest block entrances and cavity nests were photographed using an iPhone and Android cellular phone. However, prior to disassembling each nest block, a photograph was taken of the entire nest block entrance to document if there were terminal plugs on the exterior and what the nest material consisted of. To disassemble the nests, the zip ties binding the nest blocks together were cut, which allowed each individual cavity tray to be viewed. The plastic foam underlayment sheet easily slipped off when nests were disassembled, but the acetate sheet typically remained on top of the cavity tray. The acetate was removed to take photographs unless it would cause damage to the cells, such as with some nests that sticky tree resin was used as the nest material (Figure 1.9). A photograph of each cavity tray was taken, and then each individual row was given a label and photographed with a metric ruler. Labels were made listing the county, state, and 
country followed by an identification code:

SiteCode_NestIDNumber_PostNumber_NestHeight_RowLocation_ColumnLetter (e.g. BW_14_2_1.5_2_B), then GPS decimal degree coordinates and elevation (m), and lastly, my name, Stefanie Steele, and October 2019, when nests were retrieved.

Each occupied row was examined under a dissecting microscope to determine contents of nesting material, the physical appearance of the larva (when possible), and if hosts appeared to be parasitized. Nesting material was recorded as mud, cut leaves or petals, masticated leaves, resin: red/orange/white, grass, loosely packed detritus, pebbles, cellophane, cottony fibers. The number of cells were counted and a description of their contents or lack of contents: cocoon presence/appearance, food provisions (pollen/arthropods), and if a vestibule cell was present. Damage to a cocoon, such as a pin sized hole, was a good indicator that that cell was parasitized. Nests that were parasitized were placed into a Ziplock bag to prevent parasites from invading other nests. Isolating these parasitized nests was important to minimize the risk that the parasitoids would spread to nests that were thought to have not been parasitized. Parasitoid species kill their host, and if an entire nest is affected, the chance of determining the host species is severely impacted. Earwigs, ants, spiders, beetles, and social vespid wasps were removed from nests when found. However, many of these previously mentioned nontarget taxa were active in cold storage, so their original location was not confirmed as they were seen moving between nests. Lastly, the presence of any fungal growth - chalky or fuzzy white, dark black staining, fuzzy green, was also noted at this time. Some of the cavity trays appeared visibly damp when disassembled, and this dampness seemed to be 
associated with the fungal growth. Fungal growth can contribute to the mortality of the developing nest occupants, which is why nests were designed to have an overhanging roof to help protect them from weather. Those that were impacted were noted, but no other intervention was made. However, in the future the wooden nests could be given time to dry before placing in cold storage.

Sealing cavity trays for diapause

After nests were labeled, photographed, and contents recorded at the start of diapause, each cavity tray was sealed by using double sided Scotch tape. The doublesided tape was placed along the length of the flat ridges of the trays between the cavity rows, and then adhered to the acetate sheet. The function of the double-sided tape was to adhere the acetate so tightly that it would greatly minimize the movement of occupants between the cavity rows, in particular the movement of parasitoids. A small piece of cardboard was cut to fit along the back end of the tray. The cardboard was adhered to the tray using heavy duty Scotch shipping tape that was placed wrapping around the sides, underneath, and on top of the tray. The shipping tape was also used along the length of the perimeter edges of the cavity trays to secure the sides of the acetate sheet. The cavity nest entrances of the trays were left open for diapause, unless parasitism was detected. If parasitism was detected, another piece of cardboard was used to seal off the entrance cavities as well. 


\section{Cocoon extraction}

Cocoon structure and composition varied across the different nesting species. Some cocoons were composed of what appeared to be multiple woven silk layers that were firm in composition, while some cocoons were very thin and delicate with silk-like fibers, while others were hard and brittle. Cocoons from occupants including Osmia spp., Trypoxylon (Trypargilum) sp., Isodontia spp., and Pisonopsis sp. were some of the sturdier cocoons that were extracted. The extracted cocoons were removed and placed into their own 5-dram plastic vial with a parafilm lid that allowed for gas exchange. The parafilm was monitored closely for tearing. Cocoons from the previously listed genera were thick enough to be removed without damage, unlike those of Megachile spp., Hylaeus sp., or Heriades carinata, whose cocoons were composed of a very thin and fragile semi-transparent silk type material and were left in their cavity nest. A unique identifier label was placed into the vial of the individual cocoon with the same information as the rows of the trays. Additionally, the cell number of the cocoon was recorded after the column letter on the label. Cell numbers were counted starting from the back of the cavity and increased as they neared the cavity entrance. The purpose of cocoon extraction was to isolate individuals to better protect those who were not parasitized from becoming parasitized in the lab setting as this was an issue in our preliminary study in 2018 and from other studies (Krombein, 1967; MacIvor, 2019). Cocoon extraction of bees also allowed for the most accurate information on the emerging individual because individuals could move from their original cell position after completing development. Often all of the cocoons from a single wasp nest were 
extracted and placed into one vial and stored together. Wasps were our secondary focus and combining cocoons saved space. For these reasons, cell position of these wasps is not known.

Rearing: $27^{\circ} \mathrm{C}$ growth chamber

After a shortened diapause period in cold storage, all nest occupants were moved into warm growth chambers (Fischer Scientific Isotemp Incubator and Adaptis CMP 6010 by Conviron). Growth chambers were kept at temperatures of $26-28^{\circ} \mathrm{C}$ with a relative humidity ranging between 55-60\% (MacIvor \& Salehi, 2014). There was insufficient space for all occupants to fit into the warm growth chamber at the same time. Additionally, processing all specimens at once would have been difficult, so multiple rounds of nests were placed in the warm incubator as space allowed. Therefore, occupants were moved into growth chambers in rounds beginning on 11 January 2020, with the last round beginning on 23 March 2020. Osmia species were expected to require fewer days in the growth chamber for their emergence, so they were started first. Nest building wasp species were started next, and as room allowed other bee species were started. The last trials of occupants included those that were known to have been parasitized, to minimize their spread to nests that were not afflicted. A growth chamber monitoring log was used to record the date nest occupants started in the warm growth chamber, temperature, relative humidity, development notes, and the date of emergence/the date determined the individual was no longer viable. The first trial of nest occupants to enter the warm growth chamber were the individual cocoons in $27^{\circ} \mathrm{C} 5$ - 
dram plastic vials. Initially, vials were in a horizontal position to view easier, but due to space constraints, they were positioned vertically, or standing. Growth chamber nest occupants were checked daily, as able, and were monitored for signs of emergence, such as chewing through the cocoon, and the parafilm was checked for tears. Eventually all parafilm was replaced with plastic snap lids, as more tearing was occurring, and as more and more individuals were added to the warm growth chamber. The plastic snap lids also reduced the chance of occupants escaping, however, the parasitoid wasps, Melittobia sp., were sometimes able to escape through the miniscule space between the vial and snap lid in the preliminary study. To further limit escape of any occupants, any cocoons in vials that had evidence of parasitism had parafilm wrapped around the outside of the plastic snap lid.

\section{Cavity tray and vinyl tubing set-up}

A unique rearing design was used to accommodate the nest occupants whose cocoons were too fragile to remove and were left in their nest cell in the cavity tray. The design created was important as it allowed us to determine the specific nests the species were reared from; thus, we could match unique nest architecture with each nesting species. This unique rearing design adhered four different diameter sizes of clear PVC vinyl tubing to the corresponding cavity width of the cavity entrance using hot glue and removable adhesive putty. The internal diameters of the vinyl tubing measured 3.0, 4.0, 5.0, 6.5, and $9.0 \mathrm{~mm}$. At the other end of the tubing, a plastic 5-dram vial was attached to collect the nest occupants as they emerged from their cavity. To attach the vials to the 
vinyl tubing, the plastic snap lids were scored to allow the tubing to push through, and any crack and gaps remaining around the tube were sealed with the putty (Figure 1.10). When nest occupant(s) entered the vial at the end of the vinyl tubing, this vial was removed and capped, a unique label given to the specimen(s), and a new vial replaced the one that was removed with the collected specimen(s). Additionally, the trays with vinyl tubing and vials were placed in a shallow box to further support them while occupants were being reared in the growth chambers.

\section{Euthanasia}

Once nest occupants completed their development to adulthood, they were placed into a vial labeled with all nest identifying information. The emergence information was recorded in the growth chamber monitoring log, including: the date, sex, and family and/or genus taxonomic identification. After recording this information, occupants were euthanized by freezing in a $-80{ }^{\circ} \mathrm{C}$ freezer, which killed them quickly. Euthanasia in a -20 ${ }^{\circ} \mathrm{C}$ freezer was not sufficient to euthanize some of the early spring season species (i.e. Osmia lignaria). $O$. lignaria adults were still alive after being exposed to $-20{ }^{\circ} \mathrm{C}$ temperatures for several days, so a $-80{ }^{\circ} \mathrm{C}$ freezer was used to ensure a quick euthanasia process and to best maintain the specimens until they could be further processed. The cocoons of occupants that failed to emerge, when applicable, were manually opened to assess and identify the contents. 


\section{Identification}

Bees were identified to the lowest taxonomic level possible, using available morphological species keys, species descriptions, and correspondence with expert taxonomists. Wasps were identified using available morphological descriptions, consulting papers where wasps were reared from nest blocks, and correspondence with taxonomic experts. Morphological keys and reference papers I used are listed in the second chapter with the corresponding nest descriptions and photographs. When no adult bees or wasps emerged from the nests, identifications were determined from their unique nest architecture.

\section{Curation and photography}

Specimens were stored in the freezer until they were either pinned or sorted into $80 \%$ ethanol jars. Cocoons, if available and space permitting, were kept with the emerged specimens. Some cavity nest trays were frozen after adults emerged and will also be dried and resealed to use as reference and for education. All curated specimens were labeled with the unique identifying code they received when they emerged, however some labels were damaged by the occupant and were replaced. A series of photographs of specimens were taken with a Leica S6D dissecting microscope and stacked with Zerene Stacker software of the all the species with their corresponding male and females if available. Adult specimens and select cocoons will be deposited to the PSU Invertebrate Museum as historical records and educational displays. 


\section{Oregon State Arthropod Collection}

A selection of the reared adult Megachile fidelis and Pseudoanthidium nanum specimens will be deposited at Oregon State Arthropod Collection (OSAC) with an accompanying note on their nest use and nest description. The $M$. fidelis note will be the first published nest description of the species and the $P$. nanum note will be the first published description of a nest in the New World of the species. A sample of the foreign nest materials each species used as well as the associated parasitoid wasps will also be deposited at OSAC.

\section{Statistical analysis}

Nest use data were analyzed using chi square contingency tables and Poisson regression. Chi square was analyzed in Excel (version 16.46) and confirmed with a chi square test of independence calculator (Stangroom, 2018). The chi square test of independence was performed to determine the significance of the relationship between nest height use or cavity width use of the different nest block occupants. Nest height use of all nest block occupants, collectively, was analyzed by the sum number of cavities occupied $(n=514)$ against the unoccupied cavities $(n=1160)$. The null hypothesis $(p>$ 0.05) was that there was no significant difference in use of the three nest heights, while the alternate hypothesis $(p<0.05)$ was that there was a significant differential use of the three nest heights. Cavity width use was measured similarly for the five cavity sizes for all nest block occupants. 
Nest height and cavity width use were further analyzed by the cavities that were occupied by bees or wasps independently of each other. The total number of cavities occupied by bees $(n=253)$ was analyzed against the sum total available cavities not occupied by bees $(n=1421)$. Cavities occupied by bees were analyzed a second time, against the occupied cavities used by wasps only $(n=261)$. If a cavity was used by both bees and wasps, it was counted as bee occupied and subtracted from the wasp occupied cavities. These two analysis methods were conducted for the sum number of cavities occupied by wasps $(n=281)$. Both analysis methods yielded similar significant results, and the latter method, comparing only the used cavities was reported in the figures. Cavity width and height analysis were also conducted for the five most abundant occupants. Each of these abundant species or genera occupied more than 50 cavity nests, which was sufficient for these analyses. The most abundant species included two nest building bee species: Megachile angelarum $(n=171)$ and Osmia lignaria $(n=52)$ and three nest building wasp genera: Isodontia spp. $(n=69)$, Trypoxylon spp. $(n=84)$, and Pisonopsis sp. $(n=86)$. Chi-square analysis was also conducted for parasitized cavity nests. The number of parasitized bee cavity nests $(n=100)$ and the number of parasitized wasp nests $(n=59)$ were analyzed against the number of bee and wasp cavity nests that were not parasitized.

Poisson regression was used analyze these count data to determine if there was an association between the number of cavities occupied by the different species and three predictor variables (nest block height, cavity width, and post site location). RStudio version 1.2.5033 was used to conduct the Poisson regressions. The total number of 
occupied cavities for the different nest occupants (all occupants, only bees, only wasps, M. angelarum, O. lignaria, Pisonopsis sp., and Trypoxylon spp.) were analyzed along with the three predictor variables. The Poisson regression compared the results of the height variable to the lowest height, $0.5 \mathrm{~m}$, the smallest cavity width, $3.0 \mathrm{~mm}$, and the first post site location, BW1. 


\section{Results}

\section{Nest occupancy}

Nest blocks were occupied by solitary cavity nest building bees and wasps, and parasitoid bees, wasps, and flies that parasitized their host nests. Of the study's 54 nest blocks, all but two blocks located in residential gardens had at least one cavity occupied (Table 1.1a; 1.1b). Of the occupied nest blocks, $30.7 \%$ of cavities had evidence of being occupied by the complete or incomplete nests constructed by cavity nest building bees or wasps. An average total occupancy rate of 9.5 of 31 cavities per nest block indicates that the majority of cavities in each nest block were left unoccupied. Solitary nest building bees occupied at least one cavity in $79.6 \%$ nest blocks. Additionally, bees occupied $49.2 \%$ of the cavity nests that were occupied. On average, bees occupied approximately $15.1 \%$ of cavities per nest block (Table 1.1a). Solitary nest building wasps occupied at least one cavity nest in $83.3 \%$ of the nest blocks. Additionally, wasps occupied $54.7 \%$ of the cavity nests that were occupied. On average, wasps occupied approximately $16.8 \%$ of the cavities per nest block (Table 1.1a).

Sixteen species of bees nested in the blocks, with the majority of species (14) in the family Megachilidae (Table 1.2) and the others in the family Colletidae. Two of these taxa were cleptoparsitoid bee species, utilizing the nests and resources of other bees. Only one introduced bee species was reared from the nest blocks, Pseudoanthidium nanum, a species native to Europe, western Asia, and northern Africa (Michener, 2000). It is worth noting that this is the first documented record of $P$. nanum in a nest block in 
the Americas. Eleven bee species were successfully reared to adulthood and identified. In nests where bees did not successfully develop into adults, morphospecies designations were assigned based on their unique nest architecture. The most abundant species, of both nesting bees and wasps, was Megachile angelarum, who occupied 33.3\% of the occupied cavities. Osmia l. propinqua was the second most abundant bee species and occupied $10.1 \%$ of the occupied cavities. All other bee species used fewer than ten cavity nests each and combined, their occupancy made up $6.8 \%$ of the occupied cavities.

Through observations of nest blocks in the field, the general nest building seasonality of some of the bee species was determined. Instances when bees were observed flying into or out of the cavities, or dates when completed terminal/closing plugs were observed were included as observed field activity months (Table 1.2). For some species, because there were no confirmed field sightings or recorded nest activity, months were not listed in Table 1.2. There were three species observed in the first two months the nest blocks were in the field: Osmia l. propinqua, Osmia proxima, and Heriades carinata. Both of the Osmia species also overwintered as adults in cocoons, however $H$. carinata overwintered as a prepupa larva. The month where the greatest number of species were observed was July, with six species observed nest building: Megachile angelarum, Megachile fidelis, Pseudoanthidium nanum, Ashmeadiella c. cactorum, Hoplitis albifrons, and Hylaeus coloradensis. In September, the last month before nests were retrieved, M. angelarum and M. fidelis were observed to have constructed new terminal/closing plugs on their cavity nests. 
In addition to bees, there were approximately twelve species of solitary, predatory cavity nest building wasps in four families. These wasps built brood cells in the nest blocks, and provisioned these cells with prey they hunted and paralyzed as food for their developing young. Half of the wasp species are members of the Crabronidae family (Table 1.3). The second most abundant species that occurred, of both bees and wasps, were the Trypoxylini wasps, who were similar to morphological descriptions of Pisonopsis sp. and will be referred to as such. The Pisonopsis sp. wasps used $16.7 \%$ of the occupied cavities. Trypoxylon spp., including two genera, were the third most abundant species ( $16.3 \%$ cavities), followed by Isodontia spp. (13.4\% cavities), and then wasps in the subfamily Eumeninae (6.8\% cavities). At least six additional parasitoid wasp species in five families were also reared from bee and/or wasp cavity nests. These parasitoid species found nests of their target bee and wasp host species and laid their eggs on the developing hosts, killing the hosts as the larva developed. The most abundant of these parasitoid wasps were the tiny Eulophidae wasps, Melittobia sp. In addition to hymenopterans, the parasitoid fly, Anthrax irroratus, was a common bee parasitoid and was found to be a specialist of Megachile spp. (Table 1.3).

\section{Bee nest occupancy: Location}

Bee occupancy rates (i.e. the total number of cavities occupied by bee species) varied across the 18 nest site locations (Table 1.1a; Figure 1.11). The site with the greatest number of cavities occupied by bees was the community orchard on Portland State University's campus in downtown Portland. Approximately 13\% of the cavities 
occupied by bees were collected from nest blocks on one post at that nest site.

Additionally, two of these nest blocks, had bee occupancy rates greater than 38\% (Table 1.1a). Surprisingly, the nest blocks of this post were previously overrun with ants. Therefore, the bee occupants must have begun nest building after the ants were eliminated at the end of May. The other nearby post at that same location had much lower occupancy (Table 1.1a, Figure 1.11). The site with the second highest bee occupancy, and the only site where bee nest block occupancy rates were greater than $50 \%$, was from the highest, $2.3 \mathrm{~m}$ nest block at a post from one of the natural sites in North Portland, Baltimore Woods (Table 1.1a). Almost 10\% of the cavities occupied by bees were collected from this North Portland natural site post (Figure 1.11). Interestingly, bees did not occupy any of the cavities in the middle $1.5 \mathrm{~m}$ height nest block of this post. The other post at this natural site had $8.3 \%$ of bees, whereas the two posts at the education garden site, Green Anchors, had 7.9\% and 7.5\% of the bees, followed by a residential garden with $7.1 \%$ of bees. All other nest post sites, primarily residential gardens, each contained less than $6 \%$ of bee nests (Figure 1.11). Overall, at least one species of bee occurred at all of our study locations.

Nest occupancy: Species richness

The greatest richness of bee species present in one nest block was four species, and this occurred in the nest block from the natural site, Baltimore Woods, in North Portland (Table 1.4). The four bee species in this block were Osmia lignaria, Megachile angelarum, Megachile fidelis, and Hoplitis albifrons (Table 1.4). Six nest blocks, all at 
different nest site posts, had three different species of nesting bees: two nest blocks at natural site, and one nest block at each of the education garden site, community orchard site, organic farm site, and a residential site. The most abundant species in the nest blocks, Megachile angelarum, was found at all nest sites except for two residential gardens (Table 1.4). Both of these residential gardens were located outside of Portland's city limits in Washington and Clackamas counties, respectively (Figure 1.3) Osmia lignaria was found at half (nine) of the nest site posts (Table 1.4). Megachile fidelis was found at only two of the natural sites, and Heriades carinata was found at only three of the residential gardens (Table 1.4). Pseudoanthidium nanum was the only introduced bee species and was found in one nest block. This introduced bee was found in the educational garden site, Green Anchors, located adjacent to the Willamette River in North Portland. Megachile species that used large cut pieces of leaves of petals were found in one nest block at a residential garden site, both community orchard posts, and on post at the educational garden (Table 1.4). Colletid bee occupants Hylaeus were found only at two sites, the community orchard downtown and a residential garden in Sherwood. Cleptoparasitoid bee species were found at five nest sites, encompassing all of the five site types (Table 1.4). Stelis laticincta was the most abundant of these cleptoparasitoid species and specialized in parasitizing M. angelarum.

Nest use: Bee species

Although all five cavity widths were used by bees, there was differential use of cavities of different widths $\left(X^{2}\right.$ test, $\left.\mathrm{p}<0.001\right)$. In fact, the $5.0 \mathrm{~mm}$ width had the greatest 
and most significant association (Poisson regression, $\mathrm{p}<0.001$ ), with about $60 \%$ of nests in this size cavity (Figure 1.12). The $5.0 \mathrm{~mm}$ cavity width also had the greatest bee richness with eight species. These bees used a variety of materials to construct their cells, including plant resin, mud, small pebbles, masticated leaves, and cottony plant fibers. Only one bee species, Megachile sp. A, used the largest $10.0 \mathrm{~mm}$ width and built cells out of multi-layered overlapping leaves. Osmia l. propinqua, Megachile sp. B, and Megachile sp. C all used $8.0 \mathrm{~mm}$ cavities. The two Megachile spp. that used multi-layered rolled leaves or petals to construct their linear cells used 6.0 and $8.0 \mathrm{~mm}$ cavities. Three of the five species that nested in the smallest width cavity used plant resin to construct their cells, and the others, Hylaeus spp., used their own glandular secretions.

All three nest heights were used by bees, but not equally $\left(X^{2}\right.$ test, $\left.\mathrm{p}=0.0004\right)$. Cavities at heights of $1.5 \mathrm{~m}$ had a significant negative association with bee use (Poisson regression, $\mathrm{p}=0.0095)$ (Figure 1.13 ). Although nests at $1.5 \mathrm{~m}$ had lower occupancy rates, species richness across the nests heights did not seem to be impacted. Nine species were found to use both the 0.5 and $1.5 \mathrm{~m}$ heights, and eight species at the highest, $2.3 \mathrm{~m}$. There were four species recorded using all three heights: Osmia l. propinqua, Osmia proxima, Megachile angelarum, and Megachile fidelis.

Nest use: Megachile angelarum

Megachile angelarum was the most common nest occupant of all bee and wasp species. They used only two cavity sizes, 3.0 and $5.0 \mathrm{~mm}$, and the differential use was significant $\left(X^{2}\right.$ test, $\left.\mathrm{p}<0.001\right)$. The greatest number of occupied cavities were in the 5.0 
mm sizes, and Poisson regression confirmed that there was a significant association with this size (Poisson regression, $\mathrm{p}<0.001$, Figure 1.14). Megachile angelarum used all three experimental nest heights (Figure 1.15). However, the greatest number of occupied cavities occurred at the $0.5 \mathrm{~m}$ nest height, followed by $2.3 \mathrm{~m}$. There was a significant differential in nest height use $\left(X^{2}\right.$ test, $\left.\mathrm{p}<0.001\right)$. A significant negative association was found in M. angelarum's use of nests at $1.5 \mathrm{~m}$ compared to those at $0.5 \mathrm{~m}$ (Poisson regression, $\mathrm{p}=0.0003)$. Megachile angelarum was found nesting in 35 nest blocks across all field locations except two residential sites (Table 1.4).

\section{Nest use: Osmia lignaria propinqua}

Osmia lignaria propinqua was the second most common bee species that occupied the nest blocks. They used three widths of nest cavities, 5.0, 6.0, and $8.0 \mathrm{~mm}$ (Figure 1.16) There was a significant differential in use ( $X^{2}$ test, $\left.p=0.012\right)$, where the 6.0 mm cavities were used the most. Osmia l. propinqua used all three nest heights (Figure 1.17). A declining trend in nest height use was observed as height decreased to $0.5 \mathrm{~m}$. The difference in nest height use was significant $\left(X^{2}\right.$ test, $\left.\mathrm{p}=0.023\right)$. Compared to nest heights of $0.5 \mathrm{~m}$, a strong association was found in nests used at heights of $2.3 \mathrm{~m}$ (Poisson regression, $\mathrm{p}=0.003$ ). Osmia l. propinqua was found at all property types and nested in 20 nest blocks at nine nest site posts. They used the greatest number of nests at Baltimore Woods, the North Portland natural site. (Table 1.4). 
Nest use: All species

Cavity nest building bee and wasp species used all five cavity widths and three nest heights across the different 18 post locations (Figure 1.18). The difference in cavity use by all species was found to be significant $\left(X^{2}\right.$ test, $\left.p<0.001\right)$. However, the two smallest cavity sizes, 3.0 and $5.0 \mathrm{~mm}$ were the most heavily used. Bee species dominated the $5.0 \mathrm{~mm}$ cavity size, and wasps dominated the $3.0 \mathrm{~mm}$ size. The three largest cavity width sizes, 6.0, 8.0, and $10.0 \mathrm{~mm}$, were all used significantly less (Poisson regression, $\mathrm{p}$ $<0.001$ ). Additionally, nest height use was not found to be significantly different and was more evenly distributed across the three heights. Nest blocks at the $2.3 \mathrm{~m}$ height had the greatest number of occupied cavities and $1.5 \mathrm{~m}$ the least.

\section{Wasps nest occupancy: Location}

Nest building wasp species were found at all locations (Figure 1.19). A significant association was found in nest building wasps at the two organic farm posts in Sherwood, OR, Our Table Cooperative (Poisson regression, $\mathrm{p}=0.001$ ). More than $30 \%$ of wasps occupied cavities came from these nest blocks (Figure 1.19). Wasp occupancy rates exceeded $50 \%$ in five of the six nest blocks at the organic farm, meaning wasps occupied more than 15 cavities per nest block at these sites (Table 1.1a). The post location with the third highest wasp occupancy rates occurred at a residential garden in Hillsboro with $7.5 \%$ of wasps found in these nest blocks, closely followed by the North Portland natural site, Baltimore Woods (Figure 1.19). Post locations where wasps occurred the least were at the educational garden in North Portland, and residential garden in Southeast Portland. 
In addition to low wasp occupancy, the residential garden in Southeast Portland had the lowest overall occupancy of all sites (Table 1.1a).

Nest use: Nest building wasp species

All five cavity widths were used by nest building wasp species (Figure 1.20), but not equally ( $X^{2}$ test, $\left.\mathrm{p}<0.001\right)$, as the smallest cavity $(3.0 \mathrm{~mm}$ width) was used the most frequently. The smallest cavity was also found to attract the greatest richness of nesting wasps, as seven species used this size. Eumeninae wasps used all cavity widths except the largest, $10.0 \mathrm{~mm}$ cavity. All three nest heights were used equally by wasps (Figure 1.21; $X^{2}$ test, $\mathrm{p}=0.052$ ). Six nest building wasp species or morphospecies groups used all three nest heights including, both Trypoxylon spp., Pisonopsis sp., wood chewing Pemphredoninae sp., Eumeninae spp., and Isodontia elegans (Table 1.3).

Nest use: Crabronid wasps

The most common wasp and second most common of all nest occupants were the Pisonopsis sp. wasps. These wasps used almost exclusively only one cavity width, 3.0 $\mathrm{mm}$, with minimal use of $5.0 \mathrm{~mm}\left(X^{2}\right.$ test, $\mathrm{p}<0.001$; Table 1.3, Figure 1.22). All three nest heights were used by this species. The greatest and most significant use in nest height occurred at $1.5 \mathrm{~m}\left(X^{2}\right.$ test, $\mathrm{p}=0.0004$; Figure 1.23). A significant association was found with nests built at heights of $1.5 \mathrm{~m}$ compared to those at $0.5 \mathrm{~m}$ (Poisson regression, $\mathrm{p}=0.020$ ). 
The two Trypoxylon species used 3 cavity widths: 3.0, 5.0, and $6.0 \mathrm{~mm}$ : Trypoxylon frigidum, nested in the $3.0 \mathrm{~mm}$ cavities, whereas $T$. Trypargilum sp. used the two larger cavities (Figure 1.22). The differential in use of the three cavity widths was significant $\left(X^{2}, \mathrm{p}=0.0004\right)$. Compared to the $3.0 \mathrm{~mm}$ use, the use was significantly less in $5.0 \mathrm{~mm}$ and in $6.0 \mathrm{~mm}$ due to the greater occurrence of T. frigidum (Poisson regression, $\mathrm{p}<0.001$; Figure 1.22). Trypoxylon species used all three nest heights (Figure 1.23). Nest height use at 0.5 and $1.5 \mathrm{~m}$ were equal, and this was not significantly greater than that in $2.3 \mathrm{~m}\left(X^{2}, \mathrm{p}>0.10\right)$.

Nest use: Sphecid wasps

The two Isodontia species used three cavity widths, 6.0, 8.0, and $10.0 \mathrm{~mm}$ (Figure $1.22)$, but almost exclusively the two larger sizes of $8.0 \mathrm{~mm}$ and $10.0 \mathrm{~mm}\left(X^{2}, \mathrm{p}<0.001\right)$. All three nest heights were used by Isodontia spp. (Figure 1.23). Preferred nest height was trending towards the tallest height, $2.3 \mathrm{~m}$, but the difference was not significant $\left(X^{2}\right.$, $\mathrm{p}>0.05)$. Isodontia mexicana was only reared from nests at a residential garden in North Portland. Although there were no adults successfully reared from the natural site in the same neighborhood, these failed nests were suspected to be I. mexicana based on the close proximity. Whereas Isodontia elegans, the more abundant species, occurred at five post locations, including three residential gardens and both organic farm posts, most of which occurred outside of Multnomah county. 
Nest use: Wasp and fly nest parasitoids

Parasitoid species were common in nest blocks. At least nine parasitoid morphospecies were reared from nest blocks, including two bee species, one fly species, and six wasp species (Table 1.2 and 1.3). Out of the 514 total cavities occupied, 150 (29.2\%) cavities had at least one parasitoid species occur in the nest. The most abundant nest block occupant, Megachile angelarum, had almost half ( $48.0 \%, 82$ cavities) of their cavities parasitized. The nine parasitoid morphospecies parasitized the greatest number of hosts' nests in the $5.0 \mathrm{~mm}$ cavities, followed by the $3.0 \mathrm{~mm}$ cavities (Figure 1.24). Nest heights at $0.5 \mathrm{~m}$ had the greatest occurrence of parasitism, and this declining trend continued as height increased. A greater proportion of bee hosts were parasitized (100 cavities, $19.5 \%$ ), compared to wasp hosts (59 cavities, $11.5 \%$ ) and this difference was significant $\left(X^{2}, \mathrm{p}<0.001\right)$. Supersedure events occurred in eleven of the parasitized bee and wasp cavity nests and appeared to have affected both nest building species. Often when parasitoids occurred within one cavity nest, they were also found elsewhere at the site, whether in another cavity of the same nest block or a different nest block on the same post. 


\section{Discussion}

Although nest blocks are commonly used as tools in research and by hobbyists, species specific nesting preferences, cavity width or diameter and nest height use, had not been studied in the greater Portland, OR area. In an effort to attract the greatest number of nest occupants, a diverse portion of the region was sampled with the fourteen locations. These diverse locations included nine residential gardens, one community garden and orchard, one educational garden, two natural areas, and one organic farm. This choice of sites should enhance our chances of sampling the bee and wasp community broadly to assess species richness and species nest site preferences. Our findings suggest that, overall, cavity nest building wasps occupied nest blocks at higher occupancy rates than bees, and at similar occupancies as what has been reported in other studies (Krombein, 1967; Budriene, Budrys and Nevronyte, 2004; Macivor, 2015). To summarize, our main findings indicate that a variety of cavity nest building species were present in nest blocks. Of the bees that occupied cavities, occupancy was dominated by two species: Megachile angelarum and Osmia lignaria. The majority of bee species reared from nest blocks were indigenous, relatively small bodied (used $5.0 \mathrm{~mm}$ cavities), and in the Megachilidae family. Although the largest $10.0 \mathrm{~mm}$ cavity width was used the least by nest building species, this does not mean that bees did not use this size. These larger cavities were often observed in the field as sites of refuge by male cavity and ground nesting bee species. Nest blocks used in research and by hobbyists are most commonly placed at heights of $1.5 \mathrm{~m}$, however, bees from our study used this height significantly less. 
Although, when all nest building species are considered, there was no significant difference observed in their nest height use. Lastly, occupancy rates of bees and wasps were found to vary across field locations.

Wasps were common nest occupants and used the same cavity nests as cavity nesting bees. The greater number of wasps observed here was anticipated based off previous studies that also found the abundance of solitary, predatory cavity nest building wasp species on average, exceeded that of the solitary cavity nest building bee species (Krombein, 1967; Budriene, Budrys and Nevronyte, 2004; O'Neill and O'Neill, 2010; Macivor, 2015; MacIvor and Packer, 2015). Wasps who built nests in the blocks collected more general, non-specific materials to build their brood cells (e.g. mud, mixed dried grass, other small detritus debris materials) than did the bees. Therefore, due to their ability to use these more accessible nesting materials, cavity nest building wasp species may have been better able to nest in a greater proportion of locations compared to bees. Cavity nest building wasps provisioned their brood cells with aphids, caterpillars, tree crickets, and spiders. Often, many gardeners and farmers would welcome this wasp behavior, as these prey species are generally considered as garden pests. Perhaps unsurprisingly, the most abundant occurrences of nest building wasps were at the two organic farm post sites in Sherwood. Wasps were possibly important in biocontrol pest management at the farm, as other studies have also found them to be important predators (Budriene, Budrys and Nevronyte, 2004; MacIvor, 2019).

In contrast to wasps, bees collected and provisioned pollen for developing young to feed on and often require plant specific nesting materials as well. The Megachile 
species observed in nest blocks of our project used plant materials varying from plant resin, cut leaves, and petals. Therefore, because bees required a variety of plants for both food and shelter, it may be that plant resources were limited and caused bees to occur less frequently in nest blocks. We could also infer that bees could be nesting in other available cavity nesting sites. Anecdotal field observations from one residential garden, OSH, reported that bees entered small holes within their wooden fence, less than $15 \mathrm{~m}$ from the nest post site. Bees were also observed nesting in alternative cavity nests at education garden, Green Anchors. These alternative cavity nesting sites included driftwood garden bed borders, the wooden eave of a yurt, and in stems of Symphyotrichum sp. and Fallopia japonica.

Although there were several species of bees occupying nest blocks, Megachile angelarum was undoubtedly the most abundant occupant. Results from the Masta lab's Portland bee survey and a blog post on Gail Langellotto's work on Portland bees (Langellotto, 2019) both support that M. angelarum is a common species in the Portland area. Additionally, the Masta lab study and information provided on Discover Life define M. angelarum as a non-pollen specialist, a generalist or polylectic species (Ascher, 2009). As a polylectic species, they are able to use a greater number of plant resources to adapt to more locations, thus likely contributing to their greater abundance. However, these bees do require sites where plant resin is available to construct their brood cells, as well as plant leaves to masticate for their terminal plug. We concluded that M. angelarum used predominantly $5.0 \mathrm{~mm}$ cavities, but $3.0 \mathrm{~mm}$ cavities also used possibly because the preferred $5.0 \mathrm{~mm}$ cavities were already occupied in a nest block. 
To better understand if Megachile angelarum used $3.0 \mathrm{~mm}$ cavities because 5.0 mm cavities were already occupied, the nest blocks where $M$. angelarum used these smaller cavities must be investigated further. $M$. angelarum used the smallest, $3.0 \mathrm{~mm}$ cavities in ten out of the sixteen nest blocks that they were observed nesting in. For example, all of the 3.0 and $5.0 \mathrm{~mm}$ cavity widths were occupied in nest block 42 at $2.3 \mathrm{~m}$, from the North Portland natural site Baltimore Woods. Importantly, M. angelarum used both of these cavity sizes in this nest block. One wasp, Pisonopsis sp., used these $3.0 \mathrm{~mm}$ cavities as well. Furthermore, two other bee species used M. angelarum's preferred 5.0 mm size: Megachile fidelis and Hoplitis albifrons. Interspecific competition between these three bee species was suspected to have occurred over the preferred $5.0 \mathrm{~mm}$ cavities due to the seasonal overlap when they were observed actively nest building. $M$. angelarum was observed nest building beginning 13 July 2019 in both cavity sizes, 3.0 and $5.0 \mathrm{~mm}$. H. albifrons was also observed on 13 July 2019 in $5.0 \mathrm{~mm}$ cavities, whereas M. fidelis was observed on 3 August 2019, in $5.0 \mathrm{~mm}$ cavities. All six of the $5.0 \mathrm{~mm}$ cavities in nest block 41 at $1.5 \mathrm{~m}$, on the same post, were unoccupied. Additionally, two $5.0 \mathrm{~mm}$ cavities were also unoccupied in nest block 40 at the lowest height. From these unoccupied nearby cavities, we infer that $M$. angelarum chose to nest in smaller cavity widths of nest block 42 instead of using cavities of their preferred sizes in the nest blocks below on the same post.

In all but two of the nine other nest blocks in which $M$. angelarum used $3.0 \mathrm{~mm}$ cavities, there were also unoccupied $5.0 \mathrm{~mm}$ cavities available within the same block. It is not clear why M. angelarum chose to nest in the smaller cavities when $5.0 \mathrm{~mm}$ cavities 
were available. However, another hypothesis could be to conserve resources in nest building and partitioning, as these smaller sizes would not require as much material. There are few studies published on M. angelarum, so further investigation in nest use would be beneficial.

M. angelarum and M. fidelis nest use were recorded as common occupants from a study in California (Barthell, Frankie and Thorp, 1998; Frankie et al., 1998). Their study placed nests at $1.5 \mathrm{~m}$ and used round shaped cavities. M. angelarum most often used their smallest experimental diameter, $5.0 \mathrm{~mm}$, but also accepted $6.5 \mathrm{~mm}$. Interestingly in my study, there was no evidence that $M$. angelarum attempted nests in widths greater than $5.0 \mathrm{~mm}$, but instead they used the smaller size of $3.0 \mathrm{~mm}$. Barthell et al.'s study also found M. fidelis used diameters of 6.5 and $8.0 \mathrm{~mm}$, larger than $5.0 \mathrm{~mm}$ we observed. (Barthell, Frankie and Thorp, 1998). However, perhaps the square shaped cavities affected nest use. With the longest calculated lengths taken into consideration, it is possible that the $6.5 \mathrm{~mm}$ diameters from the two previously mentioned studies could also fall into the range of the $5.0 \mathrm{~mm}$ cavity widths of our study. Also observed from our study, $M$. angelarum did accept nests at $1.5 \mathrm{~m}$, but this was at a significantly lower rate. Therefore, smaller cavity widths and diameters should be available at both lower and higher heights to provide nesting for M. angelarum.

Osmia lignaria propinqua, was the second most abundant bee occupant. This is likely due to the rise in popularity of hobbyists keeping "mason bees" as this is the species that is sold commercially. However, with more residents hosting this species on their properties, it was surprising that more were not found nesting in nest blocks in 
residential yards around the greater Portland sites. O. l. propinqua is also known as a polylectic species (Ascher, 2009) and requires mud to use as their nest material to build their brood cells and terminal plug. These bees, who over-winter as fully developed adults, are known as some of the first species to begin flying at the end of winter/beginning of spring, in March (Krombein, 1967). Since our nest blocks were not installed at sites until April, O. l. propinqua may have established nests elsewhere in the month or so before nest blocks installation. However, O. l. propinqua in our project were observed nesting through the month of June, so nesting opportunities were available during most of their nesting season. The natural site in North Portland, Baltimore Woods, was where this species was most abundant in the nest blocks. This natural site was located directly west of a residential street, where residential backyards met the eastern property border. Perhaps this convergence of residential and natural landscapes provided an optimal habitat for nesting O. l. propinqua.

From previous surveys, we knew that $O$. l. propinqua occurred at multiple sites where we installed the nest blocks. Despite the lower number of cavities occupied, the sites used in our study where we had previously identified $O$. l. propinqua are Green Anchors, the education garden along Willamette River in north Portland and Portland State University (PSU) Community Orchard in downtown Portland. Only one nest block at Green Anchors was occupied, and four of the six nest blocks at PSU were occupied. Contrary to the $8.0 \mathrm{~mm}$ cavities retailers advertise for "mason bees" (Hunter, 2020), O. $l$. propinqua in our study showed a significant preference for $6.0 \mathrm{~mm}$ cavities. Based on observational field notes, there were two instances where $O$. l. propinqua built nests in 
$5.0 \mathrm{~mm}$ cavities after they built nests in either 6.0 or $8.0 \mathrm{~mm}$ cavities. These nest blocks were from nest block 6 at the organic farm in Sherwood and nest block 15 at the natural site, Baltimore Woods. As females age, they may opt to build nests in smaller cavity sizes where fewer resources are required (Torchio and Tepedino, 1980). With regard to height, there was a significant preference by $O$. l. propinqua to nest at heights of $2.3 \mathrm{~m}$, thus, again differing from the commonly suggested and used $1.5 \mathrm{~m}$ height. This suggests that a greater number of $6.0 \mathrm{~mm}$ cavities, but also a range of cavity widths and diameter sizes $(5.0,6.0,8.0 \mathrm{~mm})$ should be provided at heights of $2.3 \mathrm{~m}$ in greater proportions to accommodate the preferences of $O$. l. propinqua. Additionally, because of $O . l$. propinqua seasonality, cavity nests should be made available beginning around the start of March or as cherry, apple, and red bud trees begin to bloom.

There were several cavity nesting bee species with too few occurrences to draw conclusions as to whether they had any preference in nest width or height. These included Ashmeadiella c. cactorum, Hoplitis albifrons, lesser Osmia spp., Hylaeus spp., Megachile morphospecies, etc. This lack of data indicates that further replication of our study on a larger spatial and temporal scale should be conducted to determine if these other species do have nesting height and cavity diameter preferences. Such a study would also likely increase the number of species that use artificial cavity nests in the region. Additionally, in our study, some of these species' nests did not yield adults, so we cannot determine what species they were. However, even with limited data, our study clearly supports the recommendation that nesting cavities should be made available at different diameters and heights. 
The sites where bees would naturally nest, including stumps, logs, trees, snags, hollowed plant stems, all occur at varying diameters and heights. Therefore, providing cavities should also reflect this variation to support the diversity of nesting bees and other species. It should be noted that the $1.5 \mathrm{~m}$ height from our study was used significantly less by bee species, although these results were likely biased by the overwhelming presence of Megachile angelarum. Additionally, the Oregon Bee Atlas (OBA), an ongoing survey project, has deployed nest blocks across the state to gather data on cavity nest occupants (Oregon Bee Atlas, 2020). The OBA study will provide more information on species-specific cavity width preferences. However, they have not documented or standardized nest height with the placement of their nest blocks. It should also be noted that the cavity widths used by the OBA and our study are the same and will provide valuable data for the state.

Habitat requirements of the nesting species and the ecology of nest sites would be important factors to consider with the observed variation that occurred amongst nest locations. For nesting bees or wasps to occur at a site, they themselves first must be in the area, but also resources for food and shelter must be present as well. We did not survey or measure ecological differences across the different field sites, but from observations and findings of previous studies, we can make inferences on trends that impacted nest occupancy. From field observations, residential gardens in particular had varying amounts and composition of plant resources available for bees. These sites also often had neighboring properties that were primarily grass lawns, thus further decreasing the resources available for bee occupants. Based on field observations, nest locations at two 
residential gardens (DHH and ERH) had fewer observed floral resources available throughout the season, both bordered coniferous forests, and appeared to be more heavily shaded. Results from a study investigating habitat preferences of Osmia lignaria and other cavity nesting species in California found that oak woodland habitat was preferred over coniferous forests and could in part explain the low bee abundance at these sites (Guisse and Miller, 2011). Overall, all sites could improve upon their floral resources to incorporate a diversity of successional blooms throughout the spring through fall seasons Another factor that can positively influence the abundance of cavity nesting species is the presence of pre-existing cavities at a site (Hobbs and Lilly, 1954; Sheffield et al., 2011). For example, the two post sites at the education garden, Green Anchors, located adjacent to the Willamette River, not only provided a variety of blooming plants throughout the season, but they also incorporated driftwood into their garden bed borders. From field observations, much of the driftwood garden borders had small holes, presumably created by beetle larva, and hollow and pithy stemmed plants were minimally pruned. These conditions provided increased sites of pre-existing cavities for resident occupants. In contrast, the lack of pre-existing cavities at nest locations may have contributed to the low abundance in some of the nest blocks at other locations.

Another factor that could have affected occupancy rates was nest block competition. Since bees and wasps use the same types of cavity nests, competition for these sometimes-limited resources can occur. My data supports that competition likely occurred between nesting bees and wasps within some of the two smallest cavity sizes, 3.0 and $5.0 \mathrm{~mm}$. One resolution to decrease nest competition would be to increase nest 
recognition by making nest entrances more distinct. Wooden human constructed cavity nests often are often charred around the outside of the nest entrance. This pattern increases nest recognition so that females do not mistakenly enter the wrong nest (MacIvor, 2017). Possible evidence of interspecific competition was seen when more than one species built their nests in the same cavity row. However, Krombein also observed instances where more than one species would nest in a single cavity, but he did not necessarily conclude competition occurred (Krombein, 1967). Krombein recorded intraspecific competition in leaf-cutting Megachile spp. when the species of plant material changed midway through the nest, because most often, females will use the same plant species throughout an entire nest. Additionally, interspecific competition was thought to have occurred when the nesting materials of different species overlapped, for example when resin and mud materials overlapped and mixed within a nest. In the earlier Baltimore Woods nest block 42 example, competition over $5.0 \mathrm{~mm}$ cavity widths was thought to have occurred between Megachile angelarum and multiple species. All 5.0 $\mathrm{mm}$ cavity widths of this nest block were occupied, and it seems safe to conclude that this cavity size was highly sought after by multiple species at this site.

Cavity nests sites can be limited in in many areas. Since both bee and wasp species use the same or similar cavity nesting sites, cavities that people intend to use for bees are often used by wasps. Therefore, wasp occupancy further reduces the already limited cavity nesting sites of bee species. However, community members and land managers should not be deterred by nesting wasps. Wasps are beneficial insects, as they are also pollinators and are beneficial predators of common garden pests. 
Nest parasitoid wasps and flies also affected the host nest bee and wasp occupants in our study ( $28.6 \%$ of occupied cavities). Few studies have investigated parasitoid rates of cavity nesting bees in natural nesting sites (Michener, 1953), so further studies are needed to make comparisons. However, there are limited published findings from nest block studies. A parasitism rate of less than the $36.2 \%$ was found in a study in Germany (von Königslöw et al., 2019), about 20\% from a study in New York (O’Neill and O’Neill, 2013). Additionally, a metadata analysis including 22 studies worldwide found that cavity nesting bee genera had an average parasitism rate of $30.5 \%$, cavity nesting wasp genera $22.1 \%$, and pooled rate of $27.0 \%$ (Wcislo, 1996). Parasitism rates from our study were comparable to what have been reported as they fell just above the $27 \%$ cited pooled average from Wcsilo. Interestingly, a previous study found that as host diversity increased, parasitism rates decreased (Veddeler et al., 2010). Baltimore Woods natural site had the greatest species richness of cavity nesting occupants with four bee species and three wasp species. Only 4 of the 93 cavities $(0.04 \%)$ of these Baltimore Woods nest blocks were parasitized, and M. angelarum was the recorded host species in $75 \%$ of these parasitized cavities. On the other hand, post 2 at the Portland State University community orchard site had only two species of nesting bees and two species of nesting wasps that occupied these nest blocks. Additionally, this was where the highest abundance of $M$. angelarum occurred at one post site. Approximately $15 \%$ of the cavity nests on this post were parasitized, and M. angelarum was the host of $93 \%$ of the parasitized cavities. Overall, these parasitism results are consistent with what has been previously reported (Veddeler et al., 2010), in that greater host diversity yields lower parasitism rates, 
demonstrating this to be the result of a dilution effect. The species richness of nest building species at Baltimore Woods was nearly double that at PSU. Additionally, parasitism at PSU post was nearly 4 times greater than at the Baltimore Woods post.

There are several factors that can contribute to nest parasitism. Parasitism rates observed in our project and in general could be explained in part by the variability that occurs in regions over time (Groulx and Forrest, 2018). Another factor could be due to the host being vulnerable during a longer developmental time (MacIvor, 2019). Particularly, nest aggregation may also be considered as a factor (Pitts-Singer and Cane, 2011; MacIvor and Packer, 2015). Most solitary nest building species do not necessarily form dense nest aggregations in the wild. When artificial nest cavities are aggregated, such as in the form of artificial nest blocks, this can create higher nesting densities than that what would occur naturally. As a result of nest aggregations, increased rates of parasitism above 20\% (Pitts-Singer and Cane, 2011), and above those from the metaanalysis (Wcislo, 1996), and Groulx's study increased from 18\% to 25\% (Groulx and Forrest, 2018) have been reported. Each of our nest blocks had 31 cavities available, although on average, approximately less than $1 / 3$ of these cavities were occupied. With nearly half of all cavities used by Megachile angelarum parasitized, this summer-active species proved to be quite susceptible to parasitism. On the contrary, a study on nesting aggregations of Osmia spp. from May to July found that nests built later in the season were parasitized less (Groulx and Forrest, 2018). We found that early season species like Osmia were parasitized less often compared to summer species. However, it is important to note that all nests from our study remained in the field considerably longer (October) 
than in the aforementioned study. Previous research has also concluded that the influence of host nest aggregation density on parasitism can be both positive and negative (Groulx and Forrest, 2018). Significant positive associations concluded that nesting aggregations can attract a greater number of parasitoids. Whereas negative associations concluded the opposite, that denser populations of hosts nests can deter, confuse, and allow hosts a greater defense against parasitoids (Groulx and Forrest, 2018). However, this area is still not well understood due to these conflicting results. Despite lack of conclusive evidence, there is general agreement in the literature (MacIvor and Packer, 2015; Groulx and Forrest, 2018; C. Satyshur et al., 2020) that nests would benefit from smaller bundles of stems or nest blocks with fewer cavities. However, a greater amount of research agrees that limiting cavity nest densities is valid, as opposed to actively encouraging dense aggregations.

Records of a new cleptoparasitoid fly, commonly referred to as the Houdini fly (Cacoxenus indagator) have been documented in Washington in 2020 (WSDA, 2020) and anecdotally in Oregon at least since 2021 (Natter, 2021). These flies specialize in parasitizing Osmia, or "mason bee" nests. Houdini flies lay multiple eggs on one pollen provision of bee brood cells. Like bee cleptoparasitoids, the fly larvae will feed on the pollen ball, thus starving the developing bee of that cell. Since Houdini flies are cleptoparasitoid, they will be easily seen in the bees' brood cell and not within the mason bee cocoons. Washington State Department of Agriculture recommends that community members with cavity nests be proactive in intervening with Houdini flies and destroying adults or larvae when found to reduce their populations. Human intervention can occur 
two ways. First if nests can be opened at the end of the season to view occupants and their nests, then the fly larvae can be easily found and destroyed. If nests cannot be opened, then WSDA recommends that entire cavity nests be placed into a fine mesh bag to control the emergence of mason bee occupants the following spring. This type of controlled emergence allows human observers to monitor for mason bee emergence and Houdini fly emergence in the mesh bag. When mason bees are observed they can be released from the bag, but when Houdini flies are observed they should be squashed and destroyed within the mesh bag. Now, more than ever community members must perform increased maintenance and management of their cavity nests. Since this introduction is early, intervention and destruction can decrease populations and their spread. These flies were not observed in our study, but a colleague in NE Portland informed me that they observed Houdini flies emerging from their Osmia lignaria nests this year.

Moisture, predation, and nest block design often contribute to the likelihood of nest use and occupant mortality. Moisture and fungal growth within brood chambers could be factors that contributed to increased mortality rates. Arthropod predators such as earwigs, ants, and dermestid beetle larvae were also noted among the nest blocks. Although once nests were retrieved from the field and put into cold storage, these predators were still active and moved to different nest blocks, and ultimately most of their nest block origins were undetermined. Ants were not only predators of cavity nesting species, but were also observed to use nest block cavities for their own nests as they might in a natural cavity. Their nests often extended to multiple nest cavities or nest blocks at a single post site. Similarly, spiders were also observed using cavities to nest 
during field observations. Though it is not clear if they depredated/deterred occupants or just occupied space. Other contributions also include social vespid wasp queens and solitary male non-cavity nesting bees. These taxa were occasionally observed seeking shelter in the larger 6.0, 8.0, and $10.0 \mathrm{~mm}$ cavities during field observations, and again, it is not clear what effect they had on nesting individuals.

Nest block design improvements such as using non-engineered wood instead of plywood wood likely increase the attractiveness to occupants and longevity (MacIvor, 2017). Nest blocks have been found to be successful made with pine (Pinus) wood. Pinus has also been reported as the most cited species of wood used over the years (MacIvor, 2017). The use of plywood in nest block construction created several irregularities including broken plywood layers resulting incomplete cavities and nonuniform sizes. Additionally, some plywood warped during the field season, creating gaps between cavities and nest block roof. The way the cavity trays were designed also allowed for greater parasitoid and predator access from the back of the nest. Instead of drilling completely through to the back of the cavity trays, approximately $2 \mathrm{~cm} \mathrm{(3/4} \mathrm{inches)} \mathrm{of}$ wood should be left undrilled to provide greater protection to the back of the nest from the elements and predators/parasitoids and minimize light in the cavity nest (Stephen, 1962). An additional board along the bottom of nest trays would also minimize moisture and parasitoid access. Leucospis affinis was observed ovipositing through the bottom wood layer into the $6^{\text {th }}$ row of a $5.0 \mathrm{~mm}$ cavity where $M$. angelarum was nesting at the Green Anchors site. An additional bottom board would likely greatly minimize this occurrence and further increase bee survival rates. When monitoring nest activity and 
progress in the field, an otoscope can be used for more accurate observations inside nest cavities (Satyshur et al. 2020). This otoscope method was proven successful in a Minnesota project, and when working with community scientists, this would likely help empower them, increase their confidence, and maintain interest in the project.

Knowledge of preferred cavity nest diameters and heights are important to attract and promote the survival of the diverse indigenous cavity nesting bee species, as well as nesting wasps who use these structures. Abundance rates of some occupants were low, and their preferred nesting parameters were not determined, but what they did choose to use can be applied. Since bees and wasps were observed using all cavity width sizes provided, my results support that a range of cavity widths (from 3.0 to $10.0 \mathrm{~mm}$ ) should be provided to accommodate cavity nesting species diversity. However, a trend was observed in cavity width use and as width increased above $5.0 \mathrm{~mm}$, use drastically decreased. Most importantly, the smallest cavity widths, $3.0 \mathrm{~mm}$ and $5.0 \mathrm{~mm}$, had the greatest occupancy rates and species richness. Therefore, a greater percent of smaller cavity sizes should be provided in order to improve the cavity nesting habitat for the bees and solitary wasps in the Portland Metro region. Many of the bee and wasp species that used these smaller cavities were active later in the summer season, so it is important that these nests are available in June. It is important to mention that these recommended diameter sizes are smaller than those than can be found at most retailers that supply nest block materials. However, some retailers do advertise nesting for "wild bees" and offer cavity diameter sizes of 4-10 mm, but this is far less common (Hunter, 2020). Additionally, drill bit sizes including 1/8,3/16, 1/4, 5/16, and 3/8 inch correspond to the 
cavity widths we used. Most of the focus on providing habitat for cavity nesting species is still very narrow and primarily targets only two species: the mason bee Osmia lignaria, using $8 \mathrm{~mm}$ cavities or "leafcutter bees," Megachile rotundata, using $6 \mathrm{~mm}$. In addition to human constructed cavities, there are other ways we can contribute to nesting habitat as well. Often what is viewed as "messy" gardening, such as leaving dead wood in place (e.g. logs, snags), not cutting vegetation down to the ground (e.g. pithy stemmed and hollow stemmed plants), planting natives, providing areas of bare soil, and minimizing grass lawns is not socially accepted. Instead, communities need to learn to appreciate messy gardens that include these natural cavity nesting sites as these are also important sites (Vaughan and Black, 2007).

In conclusion, much remains to be learned about Oregon's native bee species, as our work was not a comprehensive study of all of the cavity nesting species in the area. However, we do need to change our perspective on the way we manage our lands and be more inclusive of the habitat we provide. More inclusive habitat will support a greater diversity of bees and wasps that also use this habitat. Often this type of inclusive habitat would be considered "messy gardening" by our society's standards. This means, the way we provide habitat does not necessarily need to be expensive. However, it is important to note that wood cavities have been found to be the most attractive to bees, whether they are provided naturally by beetles or with human constructed cavities (MacIvor, 2017). Most importantly, smaller cavity sizes accommodated a greater variety of bees. Small bees often get overlooked by the public, and these pollinators require small cavities. So, to accommodate a variety of bee species, provide a range of cavity sizes, but provide a 
greater proportion of holes of smaller sizes. Additionally, nests should be made available at different heights to allow bees and wasps a choice. In habitat undisturbed by humans, bees and wasps nest in stumps, logs, trees, snags, hollowed plant stems. All of these potential nest sites occur at varying heights, so we need to be accommodating of their needs and preferences. 


\section{Chapter 2: Natural History of Cavity Nesting Bee and Wasp Species from the Portland Area}

\section{Introduction}

Life history data for many of North America's more than 4,000 bee species and Oregon's estimated more than 630 bee species are still largely unknown (Moisset and Buchmann, 2011; Oregon Bee Atlas, 2020), except for a handful of well-studied species. For example, Osmia lignaria, the common cavity nesting blue orchard mason bee is only one of more than 130 described species of Osmia or "mason bees" in North America (Krombein, 1967; Kraemer, Favi and Niedziela, 2014). Basic life history data is lacking for many of the other mason bee species. Life history data, such as nesting habits and the type of nesting materials used, is time consuming to collect, as it requires thorough field observations over the course of the nesting season. In general, nest locations and substrates that cavity nesting species will use in nature vary from pre-existing cavities or they might excavate some of the pith or wood to form a cavity. The substrates species will use vary as well, and include the species of wood or plant stems, rock crevices, or human constructed cavities.

Some of the most extensive multi-year studies and detailed accounts of nest architecture, offspring development, parasitoids, and other nest behavior of cavity nesting bees and wasps were conducted by Krombein in the 1960's (Krombein, 1967). His study sites were primarily in the eastern states (New York, Washington D.C., North Carolina, Florida) with some nest blocks also in Arizona. The occupants found using these nests 
consisted of 43 non-parasitoid bee species, 75 predaceous wasp species, and 83 species of parasitoids and predators (Krombein, 1967). Nest block design parameters used in Krombein's study included white pine as the wooden nest substrate, nest heights approximately 1-2 $\mathrm{m}$ above the ground and cavity diameters of 3.2, 4.8, 6.4, 9.5, and 12.7 $\mathrm{mm}$. Comparatively, the bee species in western states have been far less studied, and we are still learning what species are present and their associated natural history, including nesting preferences. There have been no published comprehensive studies in the Pacific Northwest (Washington, Oregon, northern California) on the cavity nesting species that are found here and their preferred nesting parameters, such as the cavity nest widths or diameters and heights used by the different species.

Man-made nest structures (e.g. nest blocks, trap nests) have long been used to study the natural history of solitary, cavity nesting bees and wasps (Peckham and Peckham, Elizabeth, 1898; Krombein, 1967). Though the use of nest blocks are on the rise in communities, we still do not know all of the species that use them, their nesting preferences, and natural history. Artificial nest blocks are also excellent tools to collect natural history information on the species that live on site, as well as environmental information on the habitat and resources the occupants use (Grixti and Packer, 2006; MacIvor, 2017). The provisioned food—pollen for bees, arthropod prey for wasps, can be identified to better understand how the surrounding habitat was being used. Cell partitions, brood cells, and other cells can be counted and measured to learn about the bees that develop from the nest. Additionally, sex ratios and position of offspring in cells can be determined. Other natural history information that can be collected is the 
seasonality of nest construction and emergence, developmental biology of nest occupants, and the associated nest parasites, predators, and disease. Other nest associates include bees, wasps, and flies that parasitize and ultimately kill the host bee or wasp species. Nest blocks also allow the pairing of male and female species who are undescribed or difficult to identify (Michener, 1953; Fye, 1965a; Matthews, 1965; Krombein, 1967). The reproductive biology of Hymenopterans is also very interesting as many they have haplodiploid sex determination (Torchio and Tepedino, 1980; O'Neill and O'Neill, 2010). Thus, the female chooses what sex the egg is that she lays in the nest as fertilized eggs are female and unfertilized eggs are male. Since sex determination the females' choice, we can use this information to better understand what factors influence sex ratios. In North America, many cavity nesting bee occupants include species in the family Megachilidae, as well as members of Colletidae and Apidae (Krombein, 1967; Michener, 2007). Nesting materials that species use to construct nests vary amongst taxa. Megachilid bees often collect foreign materials from the environment (e.g. mud, pebbles, leaves, plant resin) to partition the cells of their nests with instead of secreted glandular materials common with other species (e.g. some Colletid species) (Cane, Griswold and Parker, 2007; Michener, 2007; Sheffield et al., 2011). Leafcutter bees in the genus Megachile vary greatly in both nesting behaviors and morphology. With more than 500 species in the Western Hemisphere, there is still much to be learned about this diverse group (Michener, 1953, 2007; Klostermeyer and Gerber, 1969). The mandibles of Megachile species can offer clues as to the types of foreign materials they collect for building the cell partitions of their nests. The presence and size of a cutting edge on the 
mandible of Megachile provides evidence that these bees cut leaves, to some extent, for use in their nests and brood cells (Michener, 2007; Sheffield et al., 2011).

Bees in the genus Osmia, often referred to as "mason bees", are overall, a highly understudied genus. The lack of knowledge about taxa within Osmia may come as a surprise since Osmia lignaria, the blue orchard mason bee, is one of the most well-known species. With popularity in keeping "mason bees" on the rise, most everyday community members/hobbyists are familiar with $O$. lignaria, but few other species, and it is likely that there are still a number of undescribed species of Osmia in Western North America. Additionally, morphological species keys are not available for most Osmia in Western North America. Species descriptions have not been updated for decades, and species descriptions are often completely lacking for males (Sandhouse, 1939). General nesting information is available for some Osmia species, but many of the referenced studies only provided the general substrate the bees have been documented to nest in, (i.e., soil, stem, wood, etc.) and brief details on nest structure (Cane, Griswold and Parker, 2007). Therefore, rearing bees in nest blocks allows for difficult to identify male and female species who emerge from the same nest to be identified as the same species. Additionally, nesting habits can be described in more detail.

Solitary cavity nesting bee species are not the only species using nest blocks. Nest blocks also attract many species of solitary, predatory, cavity nest building wasps. Thus, nest blocks can also be used as a tool to study wasps (Medler, 1967b; O'Neill and O’Neill, 2007; Fateryga, Protsenko and Zhidkov, 2014). Similar to bees, wasp species will construct their brood cells using specific foreign nesting materials (e.g. mud, dried 
grass, plant resin, small pieces of wood/stems, pebbles, and plant seeds). The female wasps will then provision those cells with prey they have hunted and paralyzed for their developing young to eat. Examples of provisioned prey for developing wasps include arthropods such as spiders, tree crickets, aphids, and caterpillars.

The use of nest blocks from our study allowed for the collection of a variety of natural history data, and the main goal of this chapter is to describe the observed natural history of the nesting occupants, particularly the bee species. This work also provides a pictorial guide of the nest block occupants in the greater Portland, Oregon area, as photographs were taken of the occupants and the diverse materials they used to construct the nests. This photographic documentation is important because it is not known what taxa will nest in cavities in the Portland area or what their nests look like. Even relatively well studied taxa such as Osmia lignaria have not been systematically studied and new aspects of their nesting biology could likely be discovered.

My photographs of the nest architecture of species found in the nest blocks will help aid in their identification. Nest architecture is not currently known for all cavity nesting species and novel discoveries are still being made. In our study I used photos to describe detailed nest use by Megachile angelarum, and describe for the first time the nests of Megachile fidelis and Pseudoanthidium nanum. Additionally, photos can be a good tool for community members to access and compare their observations.

For each nest, additional data was gathered, including the position of males and females within the nest, their sex ratios, and if more than one species built a nest within the same row. Factors that led to mortality of the larva, such as parasitism and fungal 
growth, were documented. Recognizing and addressing factors that could contribute to mortality can decrease the impact they have on nesting occupants. For example, parasitoids can be both generalists and specialists in the hosts they effect, while moisture within nests from improperly sealed nests can be a common cause of fungal growth. 


\section{Methods}

To collect natural history data on cavity nesting species, as outlined in Chapter 1, we used 54 human constructed wooden nest blocks. Each nest block had 31 square cavities with 5 different cavity width sizes $(5.0,6.0,8.0$, and $10.0 \mathrm{~mm})$. Nest blocks were attached to eighteen 10 -foot tall wooden posts at three treatment heights $(0.5,1.5,2.3 \mathrm{~m})$. Fourteen locations across three counties in the greater Portland area were selected to host nest blocks. Locations included residential gardens, natural areas, an education garden, a community orchard, and an organic farm. To better understand the natural history of the nest block occupants of our study, the occupants were first identified using morphological keys and descriptions.

\section{Bee identification}

Bees are easily differentiated from other Hymenopterans (wasps, ants, sawflies) by the modified branched hairs found on their bodies. Most female bees use these branched hairs to collect pollen. However, some bee species use other techniques to collect pollen such as an internal crop, or they are cleptoparasites and their larva feed on the pollen collected by the host bees that they parasitize. Morphological keys, species descriptions, and references from past nest block projects were used to identify occupants (Table 2.1). Upon emergence from the nest, bee species were sexed and then identified using available morphological keys and species descriptions. Email correspondence with taxonomic expert, Zachary Portman, confirmed Pseudoanthidium nanum's identification, 
a newly introduced species (Portman et al., 2019). Photographs of female and male $P$. nanum and their key morphological features were emailed to Portman. Osmia proxima was identified by Susan Masta who used the beta version of a key to Osmia of the western United States found on Discover Life (Ascher, 2009), along with original species descriptions.

Bees of the family Megachilidae were easily identified to genus based on their morphological features (Jackson, 2019). All Megachilids have large mandibles, two submarginal cells on their wings, and nest building females have pollen collecting hairs (scopa) on the underside of their abdomen (Michener, 2007; Jackson, 2019). Identification to genus was accomplished by using these same keys, with each genus displaying a unique suite of morphological characters. In Osmia species for example, arolia are present between their tarsal claws, the parapsidal lines on their thorax do not appear as a true line, and their integument is often metallic (Jackson, 2019). On the other hand, in Megachile species, arolia are absent, their integument color is non-metallic, and often their abdomen has bands of hair (Jackson, 2019). Heriades species are small bodied and their integument is black and largely covered in deep pits (Jackson, 2019). For nests where no bees successfully emerged, genus was determined based of their nest architecture and nest descriptions from "Bees of the World" (Michener, 2007) or other resources as outlined in Table 2.1. Two megachilid cleptoparasitoid bees were identified. Cleptoparasitoids often appear very wasp-like in their colorations (black, yellow, red) and have fewer branched hairs than bees that collect pollen to provision their nests. The cleptoparasitoid Stelis was identified by the lack of scopa, two submarginal cells, and 
red/yellow/pale markings on their body. Similarly, Coelioxys was identified by its two submarginal cells and its posteriorly tapered abdomen.

Hylaeus species in the family Colletidae, are very small-bodied bees with yellow and black integument. They are also often referred to as masked bees because of the yellow markings on their face. Hylaeus have far fewer hairs on their body because they use an internal crop to collect pollen instead of scopae. These bees are easily differentiated from the Megachilids, but an untrained eye could mistake them for wasps due to their yellow and black markings and lack of pollen-collecting hairs.

\section{Wasp identification}

Nesting behavior and identification of bees was prioritized over the wasp occupants. However, keys to species for most wasps are lacking, and therefore morphological identifications were made to the best of my ability. Wasps and their nests are generally easily differentiated from bees. For many wasp nests, uneaten prey/parts of prey, such as a spider leg, are often visible. In general, wasps have few, simple, hairs on their bodies, which are usually silver in color. Many wasps have a traditional thin, "wasp waist", and spiny legs, although these features vary across species.

To identify wasps that used nest blocks in our project, I first became familiar with previous studies in which wasps had accepted nest blocks. Published nest block research that included wasp identifications and nest descriptions were reviewed and compared to my findings (Table 2.1). There is a large database of bee and wasp nest images on the University of Toronto's website. This resource was very helpful to better understand 
cavity nesting wasps (Hallett, 2011). Genera descriptions were also carefully reviewed to identify some of the more abundant occupants. Taxonomic determination levels varied amongst the wasps that were reared from nest blocks of our study. Wasps were identified to species, genus, subfamily, family, and suborder. For example, the margins of the compound eyes of Trypoxylini wasps are medially emarginate, antennal sockets sit low on the face, and head is in general a blocky square shape (Bohart and Menke, 1976). Community science nature application program, iNaturalist, was used to assist with identification of the most abundant wasps, Pisonopsis sp. (Stefaniesteele, 2020). However, I am reserved in my Pisonopsis sp. determination and therefore say they are similar to this genus based on some of their distinct morphological features. The mandible of Pisonopsis sp. had a proximal notch and the apex of the marginal cell appeared to be faintly rounded and only slightly surpassed the outer vein of the third submarginal cell (Bohart and Menke, 1976). The large grass-carrying wasps, Isodontia were easily identified by their use of long, dried grass in their nest architecture. Species descriptions were used to differentiate the black bodied I. mexicana from the gold bodied I. elegans (Table 2.1). The use of resin in the nest architecture of some Pemphredoninae species was recognized from previous studies and aided in their identification (Hallett, 2011). Wasps were not sexed for the purpose of our study, and their nest arrangements were not analyzed. 


\section{Fly identification}

Dipterans were separated from the Hymenopteran taxa based on the presence on one pair of wings. Their large bulbous eyes, short antennae, and thin legs are also good characteristics. The Bombyliidae flies were identified as Anthrax irroratus based on the dark markings on their wings (Kits, Marshall and Evenhuis, 2008). Their wings were covered in small and large black spots. Some of these smaller spots were not touching a vein on the wing and were instead inside the cell. Also, along the upper wing margin there was a very distinct alternating small dark and clear spot pattern.

\section{Nest materials}

Nest material descriptions were made from observations after nests blocks were brought in from the field and were initially opened. Alternatively, some nest materials were further analyzed after nest occupants emerged. General nest descriptions were recorded in a spreadsheet where nest location, height, cavity size, row number, etc. were also included. The colors of the nesting material (e.g. resin, leaves, petals) were also documented in the notes.

Nest materials and architecture of Megachile fidelis were further analyzed. The nesting materials used to create the nest plugs and cell partitions from the M. fidelis nest that reared adults were measured. Photographs of the nest were taken with a metric ruler using a Leica S6D dissecting microscope. Nest images were downloaded and opened in Apple Preview Version 11.1 and the measuring tool was used to approximate the widths of cell partitions and nest plugs by using the millimeter markings as reference. Due to the 
curved nature of the cell partitions, the widths were measured at the thickest point, the apex of the curve. Cell lengths were also measured from the apex of the partition to where the nesting materials began for the following cell.

Nest arrangement of bees

The position of cells that contained male and female bees within a nest were recorded. One cavity row was defined as one nest and sex was determined after the adults completed their development. From these data, sex ratios of bee species could also be determined. If a bee failed to emerge from their cell (e.g. the egg or larvae died), then the sex was not determined. However, for some species, the sex of the species can be determined based on the size of the brood cell (Rau, 1937). In general, female cells are larger/longer and located towards the back of the nest. Whereas male cells are generally smaller/shorter and located closest to the nest entrance. Sex ratio data were also gathered from bee nests where the majority of males and females successfully developed.

Detailed nest analyses were conducted for M. angelarum nests. When sex ratios of $M$. angelarum were determined, only cells created by M. angelarum were counted. Cells created by another nesting species were excluded, such as events when a different nest building bee or wasp species nested in front of another species in the same cavity row. Additionally, I was not able to determine if more than one $M$. angelarum female laid eggs in the same cavity nest. However, any larger vestibule cells that often occurred behind the terminal plug and occasionally in the middle of a nest row were excluded. The sum total cells provisioned included emergent cells of $M$. angelarum males, females, and 
parasitoids, and cells with deceased larva/pupa and empty aside from the collected pollen provisions were non-emergent cells.

I also recorded when more than one species used the same cavity row to build their nest. The term supersede is commonly used in reference to honey bees when a new queen takes the place of an old queen. However, supersedure is also applicable here, when cavity nest building bees and/or wasps nest within the same cavity and one species takes over the nest of the other (Krombein, 1967; Delphia and O'Neill, 2012; MacIvor, 2017). One species began building their nest in the back of the row with their unique nesting materials, and then another species took over that cavity row and built their nest in front of the original builder, thus superseding them.

Parasitism, predation, and fungal growth in nest blocks

Nests were considered parasitized when there were confirmed sightings of parasitoid bee, wasp, or fly adults, larvae, exuvia, or frass within host brood cells or nest cavities. Ants and dermestid beetle larvae within cavity nests were documented as predators. Any fungal growth on the wood of the cavity trays and/or within the nests themselves were documented. The color and texture of the growths were described and what part of the nest they impacted. 


\section{Results and Discussion}

Sixteen bee species, including two cleptoparasitoid bee species, used the nest blocks (Table 1.2). Although most of these species had previously been recorded in North American to accept nest blocks, not all had recorded nest descriptions. Bee species of our study that have been known to accept nest blocks from previous research include: Osmia lignaria (Medler, 1967a), Osmia proxima (Fye, 1965a), Megachile angelarum (Matthews, 1965; Barthell, Frankie and Thorp, 1998), Megachile fidelis (Barthell, Frankie and Thorp, 1998; Frankie et al., 1998) Hoplitis albifrons (Michener, 1947; Fye, 1965a; Guisse and Miller, 2011), Heriades carinata (Matthews, 1965; Krombein, 1967). The two cleptoparasitoid bee species have also been documented from studies using nest blocks were Stelis laticincta (Frankie et al., 1998) and Coelioxys sp. (Fye, 1965a; Krombein, 1967). Additionally, novel nest descriptions for two bee species, Megachile fidelis and Pseudoanthidium nanum are described later in this chapter.

At least twelve nest building wasp species and at least six species parasitoid wasps and one parasitoid fly species used the nest blocks (Table 1.3). Although a few of the wasps are only identified to subfamily, previous studies show wasps of these subfamilies and genera have been known to accept nest blocks including Trypoxylon (Trypargilum) (Krombein, 1967; Medler, 1967b; Musicante and Salvo, 2010), Trypoxylon (Trypoxylon) frigidum (Krombein, 1967; Medler, 1967b; O’Neill and O’Neill, 2013), Pemphredoninae species (Fye, 1965b; Krombein, 1967; O’Neill and O’Neill, 2013), Eumeninae species (Krombein, 1967; Frankie et al., 1998; Budriene, 
Budrys and Nevronyte, 2004; Taki et al., 2008; O’Neill and O’Neill, 2010), Isodontia mexicana (Krombein, 1967; O’Neill and O’Neill, 2010; Fateryga, Protsenko and Zhidkov, 2014), Isodontia elegans (Krombein, 1967; O’Neill and O’Neill, 2007), and sawfly species (Fye, 1965b).

Nest architecture: Materials used to construct nests

Nesting materials used by cavity nest building bee and wasp species were diverse. Both bees and wasps were observed using mud, including Osmia lignaria propinqua, Trypoxylon wasps, and Eumeninae wasps, however the size, shape, and texture of their mud partitions and terminal plugs varied. For example, some mud was coarser in appearance with gaps in between the layers as found in Osmia lignaria nests, while the mud Eumeninae wasps plastered in their nests was very smooth and uniform in texture. Both bees and wasps were observed using plant resin, including Megachile angelarum, Heriades carinata, Ashmeadiella cactorum cactorum, and some Pemphredoninae wasps. For example, the resin that $M$. angelarum used occurred in colors ranging from pale, deep red, and black and partitions were often much thicker than in the other species. Cut leaves were only used by Megachile species and dried blades of grass were used only by Isodontia wasps. Small balls of dirt and pebbles were used by the bee Hoplitis albifrons and the wasps Pisonopsis sp. In addition to dirt and pebbles, Pisonopsis sp. also used a variety of other loosely packed small debris like bark, sticks, and seeds. Nesting materials used less frequently were overlapping pieces of larger cut leaves, rolled flower petals, and rolled leaves, all used by the three unidentified Megachile species. Cotton-like plant 
fibers were only used by the bee Pseudoanthidium nanum, and chewed wood from the sides of the cavity row were found in some Pemphredoninae wasps and sawfly nests. Even less common was nesting material secreted by the host, like that in the Hylaeus species.

\section{Cell position: Location of males and females}

The position of male and female cells within nests generally followed a similar pattern. Female cells are most often in the back, innermost nest cells, whereas male cells are most often towards the front, closest to the entrance (Figure 2.1) (Stephen and Osgood, 1965; Yocum, Rinehart and Kemp, 2014). Females of the abundant bee, Megachile angelarum, occurred the most in cells in the back of the nest, but were also found in cells near the entrance and in the middle of the nest. Only two $3.0 \mathrm{~mm}$ cavity nests reared female M. angelarum. In both of these nests, females were found in the first two cells at the back of the nest. In the preferred $5.0 \mathrm{~mm}$ nests, female $M$. angelarum emerged from 46 out of the 90 successful nests. Forty out of the 46 cavity nests $(87.0 \%)$ had females develop from cells in the first half of the nests. However, in seven of these nests, females were also found dispersed throughout the middle cells and closer to the nest entrance. Additionally, male M. angelarum and parasitoids often developed from cells in the first half of the cavity nests (Figure 2.1). In $5.0 \mathrm{~mm}$ cavity widths, male $M$. angelarum emerged from these first few brood cells in 29 (32.2\%) out of the 90 cavities nests and parasitoids in 48 (53.3\%) out of the 90 cavities. These results support that cavity size was an important factor in determining the sex of nesting occupants, but sex 
the presence of parasitoids in the nest could also influence sex. The length of a brood cell can sometimes be used to determine the sex of the occupant because often female cells are longer than males. Unfortunately, cell length in our project was not a reliable measurement because of the thick nature of the plant resin nesting material M. angelarum used to build their cells. The resin made it difficult to determine when one cell ended and the next began.

Additionally, females from Megachile fidelis, Pseudoanthidium nanum, and Hoplitis albifrons nests also emerged in the first half of brood cells. Overall, bee emergence data does support that most females developed from the innermost cells. In a similar study investigating the cell position of another Megachile species, M. rotundata, they found that the majority ( $82 \%$ ) of females also emerged from the first three innermost cells (Yocum, Rinehart and Kemp, 2014). Again, bees seem to generally follow this male and female position rule, but it is not always true. In contrast, it is known that Vespidae cavity nesting wasps do strictly follow the sex position pattern of females found at the back of the nest and males towards the front (Krombein, 1967).

\section{Nest arrangement}

There were some cavities where more than one species used the same cavity to build their nests. In these situations, a solitary bee or wasp began to build its nest in the back of the cavity, but then another species built their nest in front of those nest cells, superseding them. Superseding means that one species started building their nest in a cavity that the same or different species had previously occupied (Krombein, 1967). 
Cavity nests where supersedure events occurred were easily recognized by the different and unique nest architecture of the nest building species (Figure 2.2-2.5). There were 33 cavity nests in 18 nest blocks where these superseding events occurred (Table 2.2). Solitary wasps were the original builders in $24(72.7 \%)$ of these cavity nests. In six of these, solitary wasps were the original occupant and another species of wasp superseded them. In 18 cavity nests, wasps were the original occupant and a bee species superseded them. Interestingly, there were two cavity nests that had three different species nesting, indicating two supersedure events and one cavity nest that had four different nesting species, indicating three supersedure events. Trypoxylon spp. were the most common wasps in these nests and was the original builder in 11 of the nest cavities and was the superseding builder in two others. Megachile angelarum was the most common bee species in these supersedure nests. Megachile angelarum were observed in 24 nests (72.7\%) cavities, and were only observed to be the superseding occupant, most often (21 nests) superseding a wasp species (Table 2.2). Bees were superseded by another bee species less often than as seen with wasps. There were three nests where a bee superseded another bee, most notably in the two Pseudoanthidium nanum nests.

The supersedure data also showed that Megachile angelarum superseded Trypoxylon spp. in 11 nest cavities, with nine of those cavities being from T. Trypoxylon, the smaller of the two observed subgenera. The majority of T. Trypoxylon brood cells did not yield adults. In many of T. Trypoxylon's nests, the cocoons were open and mud partitions broken as though the wasps had already emerged. These empty cocoons indicated that these wasps are a multivoltine species (Medler, 1967b). With $T$. 
Trypoxylon species emerged, M. angelarum may have opportunistically reused old, empty nests. Alternatively, a study on supersedure of Isodontia mexicana by Megachile rotundata found that $M$. rotundata damaged some of the wasp's cells and cocoons, perhaps in an attempt to clean the nest before she used it (Delphia and O'Neill, 2012). This nest cleaning behavior by the superseding occupant is interesting, but it was not observed in our superseded nests. Superseding occupants appeared to have built their nests without interfering with the previous occupants. Another study also reported that nest supersedure did not significantly impact nest mortality. For many of the superseded nests from our study, it was not always clear what affected the mortality of one or both occupants' nests.

\section{Nest failure}

There were 252 (49.0\%) of the 514 occupied cavity nests that failed to produce any adults, and these nests made it more difficult to confidently identify which species occupied the nest. Nests can fail for a variety of reasons. Factors contributing to nest failure were parasitism, fungal growth, and unidentifiable cause. There were 74 (29.4\%) failed nests that were confirmed to have been parasitized, 65 (25.8\%) with fungal growth/moisture, and ants and/or dermestid beetle predators were observed in $24(9.5 \%)$ of these failed cavity nests. Additionally, for 120 (47.6\%) cavity nests, the cause for egg or larvae failure was unknown, aside from that some nests were incomplete with only minimal nesting material and terminal plug. 
A metadata analysis study found that the average rate of brood mortality in cavity nesting species was about 36.9\% (Minckley and Danforth, 2019). Natural enemies (parasitoids, predators, and fungi) contributed to about $16.6 \%$ of brood mortality, and unknown factors also about 20\% (Minckley and Danforth, 2019). Fungal growth/mold have been reported commonly in both ground and cavity nests of bee species (Minckley and Danforth, 2019). Nest mortality rates from our study compared to the averages reported from this metadata analysis were greater overall. Parasitoids and predators from our study could easily move to other cavity nests or travel up and down a post to access other nest blocks, so nest aggregation had negative implications in our study.

There were three species of Megachile that were designated morphospecies identifications based off their unique nest architecture because there were no adults successfully reared from any of their nests (Table 1.2). Megachile sp. B, who cut and rolled flower petals to use as their nest material in cavities of 6.0 and $8.0 \mathrm{~mm}$, was parasitized by two species, the bee Coelioxys sp., and Bombyliidae fly, Anthrax irroratus. When the petal materials were opened in the lab, the insides of some of the cells had evidence of fungal growth on the pollen provisions and larvae had white spots on them. Evidence of parasitism and fungal growth were also found in nests of Megachile sp. A, who cut large pieces of green leaves and positioned them in an overlapping fashion. These nests occurred in the largest cavity size, $10.0 \mathrm{~mm}$, and the outside of the leaves had a fuzzy green fungal growth, and the insides of the cells had a similar occurrence of the remaining pollen provisions covered in a fungal growth. A single underdeveloped male Megachile was also found within the cells, however his body was covered in fungal 
spores. Megachile sp. C who cut and rolled green leaves in a similar manner of Megachile sp. B, failed from unknown causes. When this nest was opened after nothing emerged, the three cells of this nest had the original, normal appearing pollen provisions and nothing else, suggesting that failure occurred very early on, and was not due to mold.

Bombyliidae bee fly, Anthrax irroratus, was a common ectoparasitoid of bees from our study. Anthrax irroratus (Figure 2.6) was found to be Megachile parasitoid specialist, with a particularly great impact on Megachile angelarum. There have been no published studies on rates of $A$. irroratus parasitism in M. angelarum. In fact, our study provides M. angelarum as a new host record (Ávalos-Hernández et al., 2014). These flies parasitized approximately $32.7 \%$ of $M$. angelarum's nests. In addition, $89.3 \%$ of those nests, A. irroratus parasitized the first half of the cells, those farthest from the entrance. The cells in the back half of the nest, are constructed first and are typically where the female lays the female eggs. This high rate of parasitism is likely why the observed male bias was so high in M. angelarum. Although M. angelarum has not previously been recorded as a host species, other bee species have, including here in Oregon (ÁvalosHernández et al., 2014). Parasitism rates of Bombyliidae flies in general vary. One study showed that rates varied between less than $5 \%$ and more than $90 \%$ based on the year and location (Bohart, Stephen and Eppley, 1960). Overall, A. irroratus is a common parasitoid fly of several bee species (Krombein, 1967; Yeates and Greathead, 1997; Kits, Marshall and Evenhuis, 2008; Minckley and Danforth, 2019).

Parasitoids: Generalists vs. specialists 
Cleptoparasitoid and parasitoid species that parasitized cavity nest building species were found to be both generalists and specialists in their hosts. Bombyliidae ectoparasitoid flies, Anthrax irroratus, were Megachile specialists in our nests. Anthrax irroratus were only found to have parasitized bees in the genus Megachile, particularly M. angelarum. Previous studies also report Megachile species as hosts for A. irroratus (Krombein, 1967; Marston, 1970; Scott and Strickler, 1992; MacIvor, 2019). However, several other cavity nesting species of bees, including those outside of Megachilidae, and wasps have also been reported as hosts (Marston, 1970; Scott and Strickler, 1992; Kits, Marshall and Evenhuis, 2008). When A. irroratus oviposits, they hover near the hosts' nest entrance and flip their eggs inside the cavity. Anthrax larva will then search for a host larva in the nest to feed on. Since A. irroratus flips their eggs into the cavities of the hosts nest, we can infer that the Megachile nests that were parasitized by A. irroratus occurred before Megachile sealed nests with terminal plugs. From our nests, terminal plugs were observed during the summer months of July, August, and September. A study on Megachile in Michigan found A. irroratus were actively ovipositing in the field in summer months of June, July, and August. (Scott and Strickler, 1992). That study also found that the greatest proportion of cavity nests impacted by A. irroratus were those most occupied by Megachile, their $11.0 \mathrm{~mm}$ cavities. In contrast, we found cavity widths of $5.0 \mathrm{~mm}$ were occupied the most, both by Megachile and A. irroratus. Scott and Strickler suspected that $A$. irroratus preferred larger $11.0 \mathrm{~mm}$ cavities over the $5.5 \mathrm{~mm}$ because they were more accessible for ovipositing. However, we observed host abundance to be the greatest factor to impact the cavities A. irroratus oviposited in. 
Anthrax irroratus parasitized 59 cavity nests used by bees in all three nest heights and three cavity widths including 3.0, 5.0, and $8.0 \mathrm{~mm}$.

Other common ectoparasitoids of cavity nest building species were the Melittobia sp. wasps. The behavior and morphology of these tiny wasps were similar to other studies (Table 2.1), but their genus was not confidentially determined. On the basis of our study, these wasps were generalists in the hosts they chose. Melittobia $\mathrm{sp}$. wasps parasitized cavity nests of eight bee species in the Megachilidae family (Figure 2.7) and at least five wasp species in Crabronidae and Vespidae families. These parasitoid wasps were about 1 $\mathrm{mm}$ or less in size and were found in all five cavity nest widths and three nest heights. Adult Melittobia sp. wasps were observed on nest blocks in the field at the end of July and beginning of August (Figure 2.8). The mud terminal plugs of Eumeninae wasp nests had visible holes in the terminal plug, both pin sized and larger, like the size of the host. When nests were opened, all brood cells were empty except for tiny exuviae and frass of Melittobia sp. in many of the cells. Another discovery was that were large holes in mud cell partitions that appeared to be size of the host wasps. We can infer that because the brood cells were empty, that the host Eumeninae wasps created the large holes in the cell partitions when they emerged after completing their development. We can further conclude that these wasps were multivoltine since they, and the parasitoid wasps, emerged during the summer. Additionally, there were other eumenid nests with the same architecture that did have wasp larvae when the nest were retrieved in October. We can also infer that Melittobia sp. parasitoid wasps were also multivoltine since several other hosts were also parasitized by these wasps when the nests were retrieved. In a review of 
Melittobia species biology, females were found to produce several clutches (Matthews et al., 2009). The offspring, primarily females, either continued to feed and oviposit on the host they developed on, reaching numbers from 10 to more than 100 individuals from potentially more than one female (Figure 2.7). Or females could chew through the nest and disperse to a new nest. After chewing through the nest they emerged from, to save energy, they will often crawl to find a nest nearby (Matthews et al., 2009). Based on the proximity of cavity rows within a nest block and nest blocks on the same post used in our project, we can infer that these wasps nest gregariously and that female Melittobia sp. from separate clutches likely parasitized nearby cavity nests. For example, 17 cavities from the three nest blocks at natural site South Ash Creek (SAC) were parasitized by these tiny wasps. Thirteen of those parasitized cavities were from one nest block and two each from the other two nest blocks on that post. Four bee species and three wasp species nested in these cavities is further evidence of their generalist behavior.

\section{Bees: Megachilidae}

Megachile (Chelostomoides) angelarum Cockerell, 1902

Megachile (Chelostomoides) angelarum (Figures 2.9-2.11) is a common generalist, polylectic species of western North America and their range extends from British Columbia to Baja California and New Mexico (Snelling, 1990; Ascher, 2009). Bees in this subgenera, Chelostomoides, are considered masons since they collect and use plant resins for their cavity nest cell partitions (Figure 2.10-2.11) (Michener, 2007; Sheffield et al., 2011). The lack of a cutting edge on the females' mandibles of $M$. 
angelarum is further evidence that cut leaves are not incorporated, or incorporated very minimally, in their nest architecture (Figure 2.9A-B). Megachile angelarum females created linear nests within the cavities of the nest blocks they occupied (Figure 2.102.11). Each brood cell under undisturbed conditions, yielded one bee and was provisioned with a ball of pollen, partitioned with a wall of plant resin on either side ( $\sim 2$ $3 \mathrm{~mm})$, and a thin layer of resin along the edges of the cavity row $(<1 \mathrm{~mm})$. Most of these nests began with a preliminary plug of plant resin $(<10 \mathrm{~mm})$ at the very back of the nest, which served as the interior partition of the first brood cell. Nest plugs, or terminal plugs, when present consisted rarely of only resin, instead many were tri-layered with the inner portion made with resin, the middle with loose plant materials (e.g. seeds, bark pieces, small twigs), and the outer most portion was finely masticated leaves (Figure 2.9A). A vestibule cell, an elongated and empty cell, was often built between the last provisioned cell and directly behind the terminal plug. Vestibule cells varied in their length, with some of the longest more than $4.5 \mathrm{~mm}$. The greatest number of cells built within one cavity row was 17 cells, including the vestibule, and this nest occurred in 5.0 mm cavity.

Megachile angelarum nested in 171 nest diameter rows, but only 115 were reared out in warm incubators after the shortened diapause period (Table 2.3). On average, $M$. angelarum emerged as fully developed adults after approximately 31.9 days from the warm $27^{\circ} \mathrm{C}$ incubator. The other 57 nest rows had cells that were either empty or occupants had died during diapause in cold treatment. Deceased larvae were visibly desiccated and/or with darkened necrotic tissue. Of the 115 nests, 25 were from $3.0 \mathrm{~mm}$ 
and 90 from $5.0 \mathrm{~mm}$ width nest rows (Table 2.4). A total of four females and 45 males successfully emerged from the $3.0 \mathrm{~mm}$ cavity nests (Table 2.3 ), while a total of 78 females and 148 males emerged from $5.0 \mathrm{~mm}$ nests. From these successfully emerged adults, observed sex ratios in $3.0 \mathrm{~mm}$ cavity widths were approximately $11.3: 1$, males. From these successfully emerged adults, observed sex ratios in $5.0 \mathrm{~mm}$ cavity widths were approximately 1.9:1, males. The differential in Megachile angelarum's sex ratios in the two diameter sizes was significant $\left(X^{2}, \mathrm{p}<0.001\right)$. Sex ratios of $M$. angelarum have not been previously reported, but from data collected from Osmia l. propinqua, sex ratios in preferred cavity diameters have been reported as 2:1 (Torchio and Tepedino, 1980). This 2:1 ratio is similar to the observed data in the $5.0 \mathrm{~mm}$ cavity widths of our project. However, the smaller, $3.0 \mathrm{~mm}$ width cavities, very clearly biased male M. angelarum offspring. Cavity size has been found in other studies to influence the sex of the nesting occupants (Krombein, 1967; Torchio and Tepedino, 1980; O’Neill et al., 2010). In general, bees are sexually dimorphic, with males being the smaller sex. Due to their smaller size, often male brood cells are smaller/shorter in length. Studies have found that provisioning males brood cells is less energy expensive of the female, as males generally require a smaller mass of pollen to feed on while they are developing (Phillips and Klostermeyer, 1978; Torchio and Tepedino, 1980). Seasonality can also impact the sex of offspring the female lays (Torchio and Tepedino, 1980). As nest building females age, they can become senescent. Additionally, nest building and provisioning resources can become more limited as the season progresses. 
Megachile angelarum chose to provision $14.5 \%$ of brood cells in the smaller, 3.0 mm cavity widths (Table $2.3-2.4$, Figure 2.10 ). In addition, $36.0 \%$ of the provisioned cells yielded male $M$. angelarum, 3.2\% yielded females, $23.2 \%$ yielded parasitoids, and $37.6 \%$ of cells the bee failed to develop (Table 2.4). There were three different taxa of parasitoids to emerge from these nests: Bombyliidae flies Anthrax irroratus, Leucospidae wasps Leucospis affinis, and Eulophidae wasps Melittobia sp. Anthrax irroratus was the most abundant parasitoid of $M$. angelarum. The majority, $60.8 \%$, of provisioned $M$. angelarum cells in $3.0 \mathrm{~mm}$ cavities yielded parasitoids and non-emergent/failed bee cells. Megachile angelarum chose to provision $83.7 \%$ of brood cells in the larger 5.0 mm cavity widths (Table $2.3-2.4$, Figure 2.11 ). Of these provisioned cells, $20.8 \%$ of cells yielded male $M$. angelarum, 10.1\% yielded females, $23.8 \%$ yielded parasitoids consisting of Anthrax irroratus fly, Melittobia sp. wasps, Megachilidae cleptoparasitoid Stelis laticincta, and Leucospis affinis wasps (Table $2.3-2.4$ ). Nearly half, $45.9 \%$, of the provisioned cells in $5.0 \mathrm{~mm}$ cavities yielded non-emergent/failed bee cells. Parasitoid species were found in the first half of provisioned cells in more than half of the 905.0 mm cavity nest rows used by $M$. angelarum. The cells in the innermost first half of the nest, farthest from the entrance, are traditionally where the majority of females develop. The presence of parasitoids and non-emergent cells can begin to explain the much greater proportion of male cells. Additionally, males were found in the first half of approximately one-third of the 90 nests. A previous study on Megachile rotundata found that the females' decision on the sex of the egg she chose to lay is influenced by the sex of the egg the she laid in the previous cell (Yocum, Rinehart and Kemp, 2014). If the 
female lays an unfertilized egg in the first cell, farthest from the nest entrance, it will develop as a male. Thus, the chance that the following cells will also be male is greater than if a fertilized female egg was laid first. This pattern in the females' decision could also explain the greater number of male Megachile angelarum observed from our study.

\section{Osmia lignaria propinqua}

The nesting biology of Osmia lignaria has been well documented (Rau, 1937; Krombein, 1967; Phillips and Klostermeyer, 1978; Torchio and Tepedino, 1980; Torchio, 1989; Bosch, Kemp and Peterson, 2000; Guisse and Miller, 2011; Kraemer, Favi and Niedziela, 2014; Sgolastra et al., 2016). Osmia l. propinqua's common name, blue orchard mason bee, comes from their early spring seasonality that is timed with fruit trees blooming and the females' use of mud as their nesting material. Similar to Megachile angelarum, O. lignaria built linear cells that they provisioned with a pollen ball for a single bee to consume as it developed. However, $O$. lignaria used mud to partition their cell walls (Figure 2.12). Osmia lignaria also used mud along the cavity row edges of many of the cells, although the amount varied depending on the cavity nest and nest width. Terminal plugs were also built solely with mud (Figure 2.13). The mud O. lignaria partitioned in nest building had rough edges. When mud occurred in multiple layers within the nest, there was a visible space between layers, as if two sheets of mud were lightly pushed up against each other.

Osmia lignaria propinqua used all three nest heights and three cavity width sizes, 5.0, 6.0, $8.0 \mathrm{~mm}$ (Table 2.3). The majority terminal plugs observed in the field were recorded the first two weeks of May. It took $O$. lignaria approximately 7.8 days to 
emerge from their cocoons in the warm $27^{\circ} \mathrm{C}$ growth chamber. Overall, O. lignaria partitioned a range of 2 to 15 cells per cavity row. The average number of cells built were 6.2 cells in $5.0 \mathrm{~mm}$ nests, 8.0 cells in $6.0 \mathrm{~mm}$ nests, and 7.4 cells in $8.0 \mathrm{~mm}$ nests. Male O. lignaria emerged, almost exclusively, emerged from the $5.0 \mathrm{~mm}$ in a $7: 1$ ratio. A greater number of males emerged from $6.0 \mathrm{~mm}$ than females, in a 2.6:1 ratio. Slightly more females emerged from $8.0 \mathrm{~mm}$ cavity nests than males, in a 1.2:1 ratio. There was a significant differential $\left(X^{2}, \mathrm{p}=0.0001\right)$ in $O$. lignaria's sex ratios from our study. In previous studies, strong associations between cavity diameter size and sex ratios have been found (Rau, 1937; Krombein, 1967; Torchio and Tepedino, 1980; O'Neill et al., 2010). Although overall, sex ratios were found to generally favor males 2:1 (Rau, 1937; Krombein, 1967; Torchio and Tepedino, 1980). Krombein found that cavity sizes of 4.8 mm yielded almost entirely males, whereas both sexes developed in larger sizes such as $6.4 \mathrm{~mm}$ (Krombein, 1967).

Parasitism was not common in Osmia lignaria nests. Parasitoid species were only observed in four cavity nest rows. Monodontomerus wasps parasitized cells within two $O$. lignaria cavity nests (Figure 2.14). Additionally, a couple of individual adult Melittobia sp. wasps were observed in two O. lignaria nests, though none seemed successful in parasitizing these bees, so it is not clear what affect they had. In an overview of the life history of $O$. lignaria, they also determined that $O$. lignaria is parasitized less frequently (Rau, 1937). Due to the bee's spring seasonality, many hymenopteran and dipteran parasitoids are not active while O. lignaria is nest building (Rau, 1937). 
Megachile fidelis Cresson, 1878

Megachile (Sayapis) fidelis have been recorded accepting artificial nest blocks from previous studies (Barthell, Frankie and Thorp, 1998; Frankie et al., 1998). However, their unique nest architecture has not yet been described. We observed, females using a mix of roughly cut leaves, finely masticated leaves, and mud for the cell partitions of their nests. The distinct, but incomplete cutting edge on the females' mandible allows them to incorporate some cut leaves in their nests (Figure 2.15) (Michener, 2007), however the leaves do not fully encapsulate the cell (Figure 2.16) as in Megachile rotundata (Krombein, 1967). Instead, the masticated leaves and mud are used as partitions between brood cells and a thin portion $(\sim 0.5 \mathrm{~mm})$ continued along the wooden cavity row edge (Figure 2.17). Brown, toothed, roughly cut leaves were used to construct the preliminary plug (Figure 2.18). These leaves also appeared to have produced a sticky resin-like material. The nest occupied $16.8 \mathrm{~cm}$ of the $20.5 \mathrm{~cm}$ cavity and ended about 1 $\mathrm{cm}$ inside the cavity with green roughly cut leaves that had visible hairs. The maternal female built and provisioned eight cells, followed by a ninth, elongated vestibule cell. Only one female was reared from this nest, from cell 2, whose cell length was $1.85 \mathrm{~cm}$ in length (Table 2.5). Cell 1 was also suspected to contain a female due to its length of 1.80 $\mathrm{cm}$ and position in the back of the nest, but this larva failed to develop after 38 days and had desiccated and turned more and more yellow. Males emerged from all other provisioned cells, 3 through 8 , and on average these cells were $1.38 \mathrm{~cm}$ in length. Cell partitions were curved with the concave portion facing towards the nest entrance. The thickness of the mud and finely masticated green leaf partitions were measured at the 
apex of their curve and were on average $0.15 \mathrm{~cm}$ thick. The preliminary, vestibule, and terminal plugs all incorporated larger pieces of roughly cut leaves.

Based off this unique nest architecture, two additional Megachile fidelis nests were suspected from both natural site locations, Baltimore Woods and South Ash Creek. Although no viable bees developed from these nests due to larvae failure in diapause or parasitism from Melittobia sp. wasps. Megachile fidelis used all three available nest heights, but only used cavity width, $5.0 \mathrm{~mm}$. The one female emerged after 30 days in 27 ${ }^{\circ} \mathrm{C}$ incubator, and males emerged between 27 and 30 days. These bees were active late in the summer and were observed nest building from August to September. Parasitoid wasps, Melittobia sp. were also observed at the start of their nest building in August.

\section{Megachile morphospecies}

Brood cells did not successfully rear any adults from the unidentified Megachile spp. A, B, and C. There were four incomplete and unidentified Megachile sp. A nests in $10.0 \mathrm{~mm}$ cavities at nest block 38 in a Northeast Portland residential garden (Figure 2.19). The leaves of these nests were constructed with large pieces of overlapping and nestled cut green leaves. The cocoons were fully encapsulated by the leaves used to construct them (Figure 2.20). This nest architecture was similar to how Krombein described Megachile rotundata nests (Krombein, 1967). Megachile sp. B constructed a nest in a $6.0 \mathrm{~mm}$ cavity using rolled pink flower petals in nest block 16 at the Portland State University site. Less than two meters from this nest, was a small garden plot with Clarkia sp. flowers. The Clarkia sp. petals were also pink and had evidence that they had 
been cut by a Megachile species. Megachile sp. B also occurred at the education garden site in North Portland, Green Anchors, and used yellow rolled petals (Figure 2.21). Megachile sp. B's cocoons were also constructed with flower petals and were fully encapsulated (Figure 2.22). Megachile sp. C also occurred at Portland State University, in an $8.0 \mathrm{~mm}$ cavity in nest block 19 . Nest construction was similar to the rolled pink flowers of Megachile sp. B but was made with rolled green leaves (Figure 2.23). Megachile brevis is known to nest in pre-existing cavities and use rolled leaves as nesting material (Sheffield et al., 2011). Within 50 meters of this site, Fragaria chilloensis leaves and Hydrangea quercifolia sepals were found cut in a pattern that was consistent with those made by Megachile. Leaf-cutting bees collected from our Portland bee survey included one female M. rotundata from 29 June 2019 and one female M. centuncularis from 16 August 2019, both on Hydrangea quercifolia. Megachile rotundata nests include large pieces of overlapping and nestled cut leaves, which do not resemble either of these unidentified nests.

Pseudoanthidium nanum (Mocsáry, 1881)

We documented the first time in the New World nesting by Pseudoanthidium nanum in a nest block. Pseudoanthidium nanum occupied two $5.0 \mathrm{~mm}$ cavities within nest block 53 (Figure 2.24), at the educational garden, Green Anchors, in North Portland. Both of the P. nanum nests were superseded by Megachile angelarum by 3 August 2019 . Megachile angelarum later completed the nests with a masticated leaf terminal plug by 14 September 2019. Pseudoanthidium nanum used cotton plant fibers/dry plant wool to 
construct nest cells and preliminary plug within the wooden cavities of the trap nest (Figure 2.24). Three cells from the cavity row 5 were parasitized by what are believed to be Melittobia sp. (Westwood, 1848) (Figure 2.25). Both living and dead adult Melittobia sp. were observed on top of cotton nest fibers (Figure 2.24), between nest fibers and cocoon at the time of nest retrieval October 2020. The Melittobia sp. adults were frozen and transferred to $70 \%$ ethanol. A pin sized hole was found in the cocoons that revealed more (desiccated) Melittobia sp. adults, exuvia, and frass.

Pseudoanthidium nanum are native to the Old World-Europe (north to Germany), western Asia, and northern Africa (Michener, 2000). Nest material records document plant fibers from mullein (Verbascum sp.) have been used in their nests from the Old World (Litman, 2012). However, they have been documented as an introduced species to several regions of the United States - the Northeast (Ascher et al., 2014; Droege \& Shapiro, 2011; Matteson et al., 2013), Midwest (Portman et al., 2019; Kilpatrick et al., 2020), and more casually from photos in the Pacific Northwest (Laurelby, 2018; Morris, 2018; Portman et al., 2019; Ascher, 2020). It is not sure how P. nanum was introduced to the Portland area, however it is suspected to be separate from the event Portman et al. documented. The Green Anchors site is located near a Port of Portland site along the Willamette River. Perhaps this port could be an entry point of nonnative species. 
Heriades carinata Cresson, 1864

Heriades carinata only used the smallest diameter size, $3.0 \mathrm{~mm}$ (Figure 2.26). A total of three nests were built, and they all occurred at different residential gardens in North and Northeast Portland. Heriades carinata used a whiteish plant resin as their nesting material (Figure 2.27) to construct both their brood cells (each provisioned for one bee) and terminal plug. Between all three nests, a total of 15 cells were built, though only 11 yielded occupants, two females and nine males. The two females emerged from cells 1 and 2, the innermost cells of nest block 29. The nesting biology of Heriades (Neotrypetes) carinata was well documented in 1965 from nests in Michigan (56 nests) and Oregon (33 nests) (Matthews, 1965). Matthews found that $H$. carinata used 1/8 inch $(\sim 3.2 \mathrm{~mm})$ cavity diameters the most. This cavity size is consistent with our findings.

Ashmeadiella cactorum cactorum (Cockerell, 1897)

Ashmeadiella cactorum cactorum only used one of the smallest, $3.0 \mathrm{~mm}$ wide cavities. This nest was built at the education garden site in North Portland, Green Anchors. In our study, a light-colored plant resin was observed as the main nesting material for this species brood cell partitions, but a small amount of mud was also observed. Krombein reported similar cavity nesting use in A. c. cactorum. He found that they nested in cavity diameters of 3.2 and $4.8 \mathrm{~mm}$ in two desert locations in Arizona (Krombein, 1967). Larvae of these bees were visible through a transparent cellophanelike material that covered the length of each cell, but unfortunately this nest suffered extensive damage due to fungal growth (Figure 2.28). The sides of the wood were stained 
black, and some cells turned black and/or hazy and contents could not be determined. Eleven cells were suspected to have been provisioned, though only five had a visible larva from which a single female A. c. cactorum emerged after 24 days in the $27^{\circ} \mathrm{C}$ incubator. On 13 July 2019, a resin and leaf mixture terminal plug was observed in the field, however, when the nest was disassembled in the lab, this plug was no longer present. Pisonopsis sp. wasps superseded A. c. cactorum and they occupied about $5.5 \mathrm{~cm}$ of the cavity directly behind the nest entrance. Perhaps these two species were competing for this nest before the terminal plug and the mud I observed mixed in the resin of the bee cells was secondarily brought in by the nesting wasps.

Hoplitis albifrons (Kirby, 1837)

Hoplitis albifrons nested in two $5.0 \mathrm{~mm}$ cavities within nest block 42 at the North Portland natural site, Baltimore Woods. They used small pebbles and balls of dirt as the nesting materials for their cell partitions (Figure 2.29). On 13 July 2019, a female $H$. albifrons was observed flying in and out of nest block 42. She flew down to the ground and laid flat on the bare ground, presumably collecting dirt for nesting material (Figure 2.30). Total adults to emerge from the two nests were three females and seven males. The females all emerged from the same nest cavity from cells 1,2 , and 4 . These females emerged from the $27^{\circ} \mathrm{C}$ incubator after 16 days and males emerged between 14-16 days. In a previous study, Fye described Hoplitis (Alcidamea) albifrons albifrons nests in 6.4 and $8.0 \mathrm{~mm}$ cavities taken from Ontario (Fye, 1965a). Fye found H. a. albifrons used both pebbles and macerated green leaves to build brood cells and the terminal plug. In 
contrast, Hoplitis albifrons from our nests did not use any macerated green leaves in their nests. This difference in nesting materials could be due to variation among species use or variation that can occur regionally.

Osmia proxima Cresson, 1864

Osmia proxima nested in seven $5.0 \mathrm{~mm}$ cavities across three nest block sites (Figure 2.31). The nest blocks were located at a residential garden in Sherwood and South Ash Creek, the natural site in Southwest Portland. They finely masticated green and yellow plant material to use as nesting material for both their cell partitions (Figure 2.32) and terminal plug. These bees completed their nests with terminal plugs by mid-late June 2019, and then they overwintered as fully developed adults in cocoons. It should be noted that all 7 nest cavities were parasitized by the tiny Melittobia sp. wasps. Although, these tiny parasitoid wasps were not observed on any of $O$. proxima's nest blocks while they were in the field, Melittobia sp. were observed throughout August 2019 on a different nest block at South Ash Creek site. These parasitoids were found both inside and outside of the $O$. proxima's cocoons when the nest block was disassembled. When nests were transferred into the $27^{\circ} \mathrm{C}$ incubator, adults emerged from cocoons after four days, which is not consistent with what was previously reported (Medler, 1967a). In contrast to our study, Medler reported that $O$. proxima emerged from cocoons after one month in a warm growth chamber (Medler, 1967a). Other sources note that Osmia (Melanosmia) proxima can also be known as Osmia sericea (Mitchell, 1962; Ascher, 2009). Osmia proxima has previously accepted cavity diameters of 6.4 and $8.0 \mathrm{~mm}$ (Fye, 
1965a; Medler, 1967a). Medler described O. proxima's nesting materials for both the brood cell partitions and terminal plug as finely masticated plant material, consistent with our findings (Medler, 1967a).

Bees: Colletidae

Hylaeus species

Hylaeus bees used two $3.0 \mathrm{~mm}$ cavities, but only one nest was successful. Hylaeus coloradensis (Cockerell, 1896) were reared and identified from nest block 20 at Portland State University in Downtown Portland. However, the Hylaeus individual who built its nest in nest block 3 in Sherwood did not develop past the prepupa stage, and therefore could not be identified to species (Figure 2.33). Nest failure in nest block 3 may have been caused by a malfunction in the incubator in which temperatures intermittently rose above $30^{\circ} \mathrm{C}$. Unlike nest building Megachilid bee species discussed thus far, these bees did not gather foreign materials to use as nest materials. Instead, they used their own glandular secretions to build their brood cell partitions and terminal plug. These secretions resembled cellophane - a delicate, clear plastic type material, which allowed the larvae to be easily viewed within the nest (Figure 2.34). The cavity tray from which H. coloradensis emerged was severely impacted by moisture. The wood was visibly wet, ants were seen crawling through the cavities, and the contents of cells 1-3 were not clearly visible due to fungal growth. However, the larva in the $4^{\text {th }}$ cell was visible, and one female and one male successfully developed. Both the male and female emerged 
after 14 days at $27^{\circ} \mathrm{C}$. Nest activity for this cavity in nest block 20 was observed in the field on 6 July 2019.

Wasps: Sphecidae

Isodontia species

Isodontia (Murrayella) species were the largest cavity nest occupants and used 6.0, 8.0, and $10.0 \mathrm{~mm}$ cavities. Dried brown grass was used as their nesting material for both their brood cells and terminal plug (Figure 2.35-2.37). Nest building females captured tree crickets, which they paralyzed and carried back to their nests and placed multiple crickets per cell (Figure 2.37) upon which she would lay an egg. The developing wasp would then consume these crickets and then spin its cocoon. Two species used my nest blocks, Isodontia elegans (Smith, 1856) and Isodontia mexicana (Saussure, 1867), the former occurred more frequently. Isodontia elegans was confirmed nesting at four nest sites and eight nest blocks, all of which occurred in the areas surrounding Portland. Residential garden in Gresham and Hillsboro, and organic farm in Sherwood reared $I$. elegans. Isodontia mexicana was confirmed nesting in two nest blocks at a residential garden in North Portland. The unviable nests from the North Portland natural site, Baltimore Woods, were also suspected to be I. mexicana due to field observations and proximity to the confirmed site. Isodontia emerged from their cocoons after an average of 36 days in the $27^{\circ} \mathrm{C}$ incubator. Nest descriptions for both species are available, however I. elegans has been far less studied in comparison to I. mexicana. Isodontia elegans and mexicana have been recorded using 7.5, 8.0, 9.0 mm cavities from Montana, (O’Neill and 
O’Neill, 2003, 2007), and $12.7 \mathrm{~mm}$ in Arizona (Krombein, 1967) which is similar to the use we found.

\section{Wasps: Crabronidae}

Trypoxylon species

At least two species of Trypoxylon were observed using nest blocks, $T$.

Trypoxylon and T. Trypargilum. Both subgenera used mud in building their cell partitions and terminal plugs and female nest builders depredated on spiders to provision the brood cells of their nests for their developing young to feed upon. The mud used as their cell partition was rounded and cradled the cocoon end that was closest to the rear of the cavity nest. The two subgenera created cocoons that were distinctly different from each other and the cavity diameters each used varied as their size varied. Trypoxylon (Trypoxylon) used $3.0 \mathrm{~mm}$ cavities and their cocoons were pale yellowish in color, cylindrically shaped, and a thin tissue paper-type consistency (Figure 2.38). Trypoxylon (Trypargilum) used 5.0 and $6.0 \mathrm{~mm}$ cavities and their cocoons were very dark, almost black in color, cylindrically shaped, and a stiff brittle consistency (Figure 2.39). Trypoxylon (Trypargilum) emerged from their cocoons on average after 27 days in the $27^{\circ} \mathrm{C}$ incubator. Several of the T. Trypoxylon cocoons were open and empty, or were full of frass and exuvia left by Melittobia sp. parasitoid wasps when nests were disassembled in the lab at the start of diapause. These cocoons are empty because the T. Trypoxylon already completed their development and emerged while the nests were still in the field. From these results, we can conclude that this species is multivoltine and were from an 
earlier generation that year. The Melittobia sp. parasitoid wasps emerged from the cocoons of both subgenera, whereas Chrysididae cleptoparasitoid wasps only emerged from T. Trypargilum.

\section{Pisonopsis species}

Our most abundant nest building wasp occupant was a member of the genus I believe to be or is similar to Pisonopsis sp. These wasps almost exclusively used $3.0 \mathrm{~mm}$ cavities (Figure 2.40) aside from one occurrence in a $5.0 \mathrm{~mm}$ cavity. The females did not build distinct brood cells with clear partitions, but instead brood chambers. Dirt, sand, grass seeds, bark pieces, and other similar vegetative materials were used to construct the brood chambers and terminal plugs. These materials were loosely distributed throughout the cavity space and were not cemented together like that of Trypoxylon spp., Osmia lignaria, or even the balls of dirt from Hoplitis albifrons. Cocoons were cylindrical in shape and brittle/crumbly in consistency. They were a brown dirt color that resembled the texture of plastered sand and dirt, as though they incorporated the nesting material into their cocoons. Most cocoons were not evenly distributed throughout the cavity, and were found partially buried under the nesting material or sitting on top of it. Very few food provisions were observed, but when they were found, they were spiders (Figure 2.41). These wasps emerged from there cocoons after 24-52 days, or an average of about 35 days at $27^{\circ} \mathrm{C}$.

Previous studies have not reported Pisonopsis spp. to accept wooden nest blocks, but $P$. burkmanni have accepted "trap stems" (Parker and Bohart, 1966). Sambucus sp. 
stems were placed individually, directly into the ground or bundled and placed in bushes in California. Stems were cut to 18 inches and diameters from $1.5 \mathrm{~mm}$ to $6.4 \mathrm{~mm}$ were drilled into the stems. Individual stems placed into the ground had higher acceptance rates than those bundled and placed in bushes (Parker and Bohart, 1966). Another study from California found that a different species, P. clypeata, instead nested in ground (Evans, 1969). Pisonopsis clypeata used pre-existing ground nests of bees like Diadasia consociata, and also dug their own nests. Both species were recorded to have hunted Thomisidae crab spiders to use as their prey provisions and nest materials for ground and stem nesting species included small balls of dirt, wood, and other plant materials (Williams, 1954; Evans, 1969).

\section{Pemphredoninae species}

At least three nest building wasp species from this subfamily were found in the nest blocks. All Pemphredoninae sp. were small, black bodied wasps and used only 3.0 $\mathrm{mm}$ cavities. However, the materials they used to build their linear brood chambers differed. At least two of the species used plant resin to build their cell partitions (Figure 2.42). Passaloecus and Psenulus are the suspected genera of the resin-using wasps, but these identifications were not confidently determined. Observed prey of the Pemphredoninae wasps included aphids and spiders. The length of the suspected Passaloecus wasps' brood cells were covered in a cellophane-like material (Figure 2.43) and their terminal plugs were also plant resin. The third Pemphredoninae species used the wood they chewed off the sides of the cavity row as their cell partitions (Figure 2.44). 
Their cocoons were boxy in shape and resembled an amber leather/paper type material (Figure 2.45). Aphids were the observed prey of these wood chewing wasps. The Pemphredoninae sp. wasps were almost entirely observed at the residential garden in Hillsboro, EKH and the organic farm in Sherwood, OTC. Field notes from this residential recorded nest activity late July through August. The wood chewing species emerged after 27 days in the warm $27^{\circ} \mathrm{C}$ growth chamber, and the resin species emerged after a minimum of 11 days and maximum of 30 days. Previous records show that Passaloecus species used smaller diameter cavities between 3 to $6 \mathrm{~mm}$ (O’Neill and O’Neill, 2013) and are known to use resin and provision aphids (Fye, 1965b). Amazingly, these wasps have been known to provision between 50 to 200 aphids per nest and as many as 63 in one brood cell (Fye, 1965b). Gardeners and farmers should welcome these fierce aphid predators in their yards as a natural biocontrol alternative.

Wasps: Vespidae

\section{Eumeninae species}

At least three species of Eumeninae wasps likely built nests within the nest blocks. These wasps used all three nest heights and four cavity widths of 3.0, 5.0, 6.0, and $8.0 \mathrm{~mm}$. They used mud for their brood cell partitions and in their terminal plugs. The mud was very smooth like plaster and of uniform consistency (Figure 2.46). The mud in the terminal plug was also very smooth, but appeared in convex globs, instead of as a wall or sheet with Osmia lignaria (Figure 2.47). Caterpillars were also believed to be the sole prey collected for all of the Eumeninae wasps. However, prey was not seen often 
and was very desiccated when it was found. At least some of the Eumenids were suspected to be multivoltine as some nests were found to have no developing wasps in the brood cells (Figure 2.48). For instance, some of the mud partitions had eumenid size holes in the cell partitions and terminal plug. From this, it can be inferred that the nest building wasps completed their development and chewed their way out of the nest. Additionally, when the cavity trays were opened, many of the brood cells were empty, or empty aside from the tiny frass and exuvia left by the parasitoid wasps Melittobia sp. These parasitoid wasps were observed in the field at the natural site South Ash Creek, near the entrance cavity of these Eumenid wasps on 3 August. Some mud terminal plugs had a pin-sized-hole, thought to have been made by the Melittobia sp. wasps. Field notes also recorded that on August $18^{\text {th }}$, a large hole was found in two of these cavities. 


\section{Conclusions}

Human constructed cavity nest blocks provide an excellent opportunity to learn more about the hymenopteran species that use them. The design I used allowed for the nests to be opened and for the diverse and unique architecture to be viewed. It also allowed me to observe the occupants and what remained of their pollen or prey. Using this design allowed me to describe nest architecture for the first time for some of the species. Although our study was not comprehensive of all cavity nesting species in the Portland area, we now have a much better understanding on what cavity nesting species are present and their nesting habits. These new discoveries are not only important to fill in the paucity of natural history information, but also to inform the Portland community.

From my study, we learned that what was most important for cavity nesting bees was cavity width/diameter size, "good" site conditions, and artificial nest block design. My data showed that the diverse species found in our study accepted a range of artificial wood cavity widths including 3.0 to $10.0 \mathrm{~mm}\left(1 / 8^{\text {th }}\right.$ to $3 / 8^{\text {th }}$ inch). However, the smaller cavity widths were in high demand because smaller bodied bees were more abundant than larger bodied bees. In all likelihood, we can infer that they would nest in natural cavities of these or similar sizes. Holes created by beetle larvae in dead wood (i.e. stump, $\log$, tree branch, or snag) are excellent nesting sites. Non-native and more importantly native plants can be resources for nesting sites as well. Some hollow or pithy stemmed plants that are used as stem nesting sites include species of Acer negundo, Agastache spp., Asclepias incarnata, Cirsium spp., Echinacea spp., Eutrochium spp., Helianthus 
spp., Hydrangea spp., Monarda fistulosa, Panicum spp., Rhus spp., Rosa spp., Rubus spp., Sambucus spp., Silphium perfoliatum, Solidago spp., Symphoricarpos spp., Symphyotrichum spp., and Veronia spp. (Vaughan and Black, 2007; Vaughan et al., 2015; C. Satyshur et al., 2020). For many, the hollow or pithy stems of these plants are exposed when the stems with dead flower heads are cut back in the spring to about 8 to 24 inches $(21$ to $60 \mathrm{~cm})$. The cut stems can remain in place as the new plant growth comes in around them. Eventually, overtime, the cut stems will decompose naturally (C. Satyshur et al., 2020), so providing nesting stems requires little maintenance.

Although we cannot confidently define a "good" cavity nesting site because our study did not analyze the ecological factors of the sites, but in general, we do know what bees require. In addition to cavity nesting sites, bees require floral resources including pollen and nectar for food and nesting materials, which many gather from the environment. Inadequate resources at the sites might explain why some nest sites had few cavity nests occupied (i.e. residential garden of DHH) and some sites had many cavity nests occupied (i.e. Baltimore Woods natural site). We could infer that "good" sites had adequate floral resources and nesting materials throughout the spring to fall seasons, whereas other sites did not. Successional flowering native plants are optimal floral resources for attracting native bee species, but many will also use non-native plants as well. Nesting materials used by nest building occupants varied, but the most commonly used material was mud. At least nine species, including both bees and wasps, were found to use mud in some manner in their nests, so it is important to have moist dirt available as a resource for these species. Additionally, other bee species collected various plant 
materials including resin, leaves, or flower petals. In the future, pollen and nest material analysis should be conducted to confirm what resources are being used so that we can better understand how they are using the environment and what qualifies as a "good" site.

With overall brood mortality greater than the reported average, my data supports that there are factors in the nest block design from our project that could be improved to help decrease these rates. At the end of the season gaps were observed between some of the cavity trays, roof, and back of nests. If these gaps were reduced, this would minimize parasitoid, predator, and moisture access to the nests, all leading causes contributing to brood mortality. Due to the design of the experiment, the nests were aggregated, and my data supports that nest aggregation made it easier for parasitoid and predator species to find the cavity nests. We could infer that if nests were not clustered and distributed further apart, they would be more difficult for parasitoids and predators to find. Additionally, nest aggregation may have also contributed to confusion in nest builders, resulting in some of the incomplete nests from our project. Most importantly, more research is needed on brood mortality rates of nesting species in natural cavity nests so that we can compare them to what has been reported in human constructed cavity nests. This research would allow us to better conclude the impact of human constructed cavity nests.

Bees and wasps are both integral elements of healthy ecosystems. It is common knowledge that bees provide the important ecosystem service of pollination, but wasps are incidental pollinators as well. Of course, wasps do not actively collect pollen, and they do not have the specialized pollen collecting hairs most bees do. However, when 
they visit flowers and drink nectar, they are still passively pollinating. Additionally, wasps also provide a biocontrol service with the insects and other arthropods they hunt, as their prey species, include common garden pests (aphids, caterpillars, and crickets) and predators (spiders).

Overall, many community members are invested in "saving the bees" and want to contribute to conservation efforts, but are unaware of the diversity of solitary bee species that use cavities for nesting. The majority of the public only associate blue orchard mason bees (Osmia lignaria) with cavity nesting bees. Osmia lignaria is an excellent spring pollinator of early blooming trees (e.g. cherry, apple, etc.) and other flowering plants, but as my data showed, there are a variety of other species that nest in cavities. Many of the other bee species are active later in the summer season, therefore they are some of the species that will pollinate summer crops (e.g. squash, beans, etc.), not $O$. lignaria. Additionally, information on solitary cavity nest building wasps that use these same cavities is not necessarily known by the public or readily accessible. The publics' lack of basic bee and wasp life histories can then further perpetuate the stigma many have, particularly towards wasps, that they should be feared and excluded from their cavity nests. However, solitary, non-social insects do not display the same defensive behavior that can be seen with social bees and wasps. Solitary cavity nest building occupants do not have a colony to guard and protect and will likely not pay attention to a human observer. Additionally, many of these species are quite small and are not capable of harming our much larger human bodies. 
Instead of fear and misunderstanding, we want community members to feel empowered to know more about the insects residing on their properties, as bees and wasps should both be welcomed garden residents and visitors. Additionally, bees and wasps are valuable members of the ecosystem and can occupy similar nesting sites whether in natural or human constructed cavities. In addition to building a deeper respect for insects, new natural history discoveries of these species are still occurring, whether in your own home garden habitat, or at your school, community, or farm. There are also opportunities for community members to actively contribute to these new life history discoveries as well. Bee Atlas projects including Oregon (Oregon Bee Atlas, 2020) and Minnesota (Minnesota Bee Atlas, 2021) are initiatives that rely on community (or citizen) science volunteers for the exciting discoveries they are making. Life is happening all around us, and there are lots of opportunities to contribute to observational science. Natural history data collected from these observations can be used to better inform scientists, land managers, and homeowners on the best conservation efforts for these species. 


\section{Tables}

\section{Chapter 1}

Table 1.1a: Nest block occupancy rates of cavity nest building bees and wasps for all 54 nest blocks. This table shows the post site (PS) of each nest block (NB), the nest height (NH), the total number of occupied cavities (TOC), the bee occupied cavities (BOC), the wasp occupied cavities (WOC), and percent of cavities occupied for all occupants combines, bee occupants, and wasp occupants. The sum cavities that were occupied and their averages are listed below.

Table 1.1 Legend

\begin{tabular}{|c|c|}
\hline & $\begin{array}{c}>50 \% \text { of nest block } \\
\text { occupied }\end{array}$ \\
\hline & $\begin{array}{c}<50 \% \text { and }>30 \% \text { of } \\
\text { nest block occupied }\end{array}$ \\
\hline & $\begin{array}{c}<30 \% \text { and }>10 \% \text { of } \\
\text { nest block occupied }\end{array}$ \\
\hline $\begin{array}{c}<10 \% \text { and }>0 \% \text { of } \\
\text { nest block occupied }\end{array}$ \\
\hline $\begin{array}{c}0 \% \text { of nest block } \\
\text { occupied }\end{array}$ \\
\hline
\end{tabular}

$\begin{array}{rlllllll}\begin{array}{r}\text { Site } \\ \text { Type }\end{array} & \text { PS } & \text { NB } & \begin{array}{l}\text { NH } \\ (\mathrm{m})\end{array}\end{array}$ TOC BOC $\quad$ WOC $\%$ All $\%$ Bee $\%$ Wasp

\begin{tabular}{|c|c|c|c|c|c|c|c|c|c|}
\hline \multirow{9}{*}{ 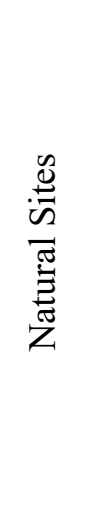 } & \multirow{3}{*}{$\bar{m}$} & BW_40 & 0.5 & 14 & 8 & 6 & $45.2 \%$ & $25.8 \%$ & $19.4 \%$ \\
\hline & & BW_41 & 1.5 & 5 & 0 & 5 & $16.1 \%$ & $0.0 \%$ & $16.1 \%$ \\
\hline & & BW_42 & 2.3 & 21 & 17 & 5 & $67.7 \%$ & $54.8 \%$ & $16.1 \%$ \\
\hline & \multirow{3}{*}{$\sum_{\infty}^{N}$} & BW_13 & 0.5 & 12 & 7 & 6 & $38.7 \%$ & $22.6 \%$ & $19.4 \%$ \\
\hline & & BW_14 & 1.5 & 15 & 8 & 7 & $48.4 \%$ & $25.8 \%$ & $22.6 \%$ \\
\hline & & BW_15 & 2.3 & 13 & 6 & 7 & $41.9 \%$ & $19.4 \%$ & $22.6 \%$ \\
\hline & \multirow{3}{*}{ 崫 } & SAC_10 & 0.5 & 2 & 2 & 0 & $6.5 \%$ & $6.5 \%$ & $0.0 \%$ \\
\hline & & SAC_11 & 1.5 & 15 & 5 & 11 & $48.4 \%$ & $16.1 \%$ & $35.5 \%$ \\
\hline & & SAC_12 & 2.3 & 3 & 3 & 0 & $9.7 \%$ & $9.7 \%$ & $0.0 \%$ \\
\hline \multirow{3}{*}{ 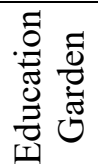 } & \multirow{3}{*}{ 『 } & GA_52 & 0.5 & 15 & 15 & 0 & $48.4 \%$ & $48.4 \%$ & $0.0 \%$ \\
\hline & & GA_53 & 1.5 & 4 & 4 & 0 & $12.9 \%$ & $12.9 \%$ & $0.0 \%$ \\
\hline & & GA 54 & 2.3 & 5 & 1 & 4 & $16.1 \%$ & $3.2 \%$ & $12.9 \%$ \\
\hline
\end{tabular}




\begin{tabular}{|c|c|c|c|c|c|c|c|c|c|}
\hline & \multirow{3}{*}{$\underset{\mho}{\mathbb{2}}$} & GA_49 & 0.5 & 12 & 9 & 5 & $38.7 \%$ & $29.0 \%$ & $16.1 \%$ \\
\hline & & GA_50 & 1.5 & 14 & 9 & 5 & $45.2 \%$ & $29.0 \%$ & $16.1 \%$ \\
\hline & & GA_51 & 2.3 & 7 & 1 & 6 & $22.6 \%$ & $3.2 \%$ & $19.4 \%$ \\
\hline \multirow{6}{*}{ 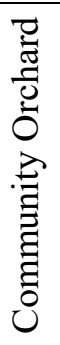 } & \multirow{3}{*}{$\vec{\Omega}$} & PSU_19 & 0.5 & 8 & 6 & 2 & $25.8 \%$ & $19.4 \%$ & $6.5 \%$ \\
\hline & & PSU_20 & 1.5 & 4 & 1 & 3 & $12.9 \%$ & $3.2 \%$ & $9.7 \%$ \\
\hline & & PSU_21 & 2.3 & 11 & 7 & 4 & $35.5 \%$ & $22.6 \%$ & $12.9 \%$ \\
\hline & \multirow{3}{*}{$\stackrel{\Upsilon}{\curvearrowright}$} & PSU_16 & 0.5 & 14 & 14 & 2 & $45.2 \%$ & $45.2 \%$ & $6.5 \%$ \\
\hline & & PSU_17 & 1.5 & 13 & 6 & 7 & $41.9 \%$ & $19.4 \%$ & $22.6 \%$ \\
\hline & & PSU_18 & 2.3 & 12 & 12 & 0 & $38.7 \%$ & $38.7 \%$ & $0.0 \%$ \\
\hline \multirow{6}{*}{ 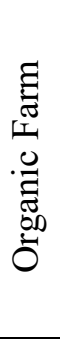 } & \multirow{3}{*}{$\begin{array}{l}\bar{U} \\
\stackrel{0}{0}\end{array}$} & OTC_4 & 0.5 & 20 & 4 & 14 & $64.5 \%$ & $12.9 \%$ & $45.2 \%$ \\
\hline & & OTC_5 & 1.5 & 19 & 2 & 17 & $61.3 \%$ & $6.5 \%$ & $54.8 \%$ \\
\hline & & OTC_6 & 2.3 & 17 & 8 & 11 & $54.8 \%$ & $25.8 \%$ & $35.5 \%$ \\
\hline & \multirow{3}{*}{$\begin{array}{l}\text { Uै } \\
\text { O }\end{array}$} & OTC_7 & 0.5 & 9 & 6 & 9 & $29.0 \%$ & $19.4 \%$ & $29.0 \%$ \\
\hline & & OTC_8 & 1.5 & 20 & 2 & 18 & $64.5 \%$ & $6.5 \%$ & $58.1 \%$ \\
\hline & & OTC_9 & 2.3 & 17 & 0 & 17 & $54.8 \%$ & $0.0 \%$ & $54.8 \%$ \\
\hline \multirow{21}{*}{ 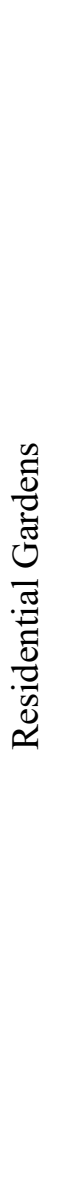 } & \multirow{3}{*}{ 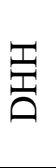 } & DHH_22 & 0.5 & 5 & 0 & 5 & $16.1 \%$ & $0.0 \%$ & $16.1 \%$ \\
\hline & & DHH_23 & 1.5 & 0 & 0 & 0 & $0.0 \%$ & $0.0 \%$ & $0.0 \%$ \\
\hline & & DHH_24 & 2.3 & 9 & 4 & 5 & $29.0 \%$ & $12.9 \%$ & $16.1 \%$ \\
\hline & \multirow{3}{*}{$\begin{array}{l}\vec{D} \\
\underset{I}{\mid r}\end{array}$} & EBH_34 & 0.5 & 2 & 0 & 2 & $6.5 \%$ & $0.0 \%$ & $6.5 \%$ \\
\hline & & EBH_35 & 1.5 & 3 & 0 & 3 & $9.7 \%$ & $0.0 \%$ & $9.7 \%$ \\
\hline & & EBH_36 & 2.3 & 17 & 9 & 8 & $54.8 \%$ & $29.0 \%$ & $25.8 \%$ \\
\hline & \multirow{3}{*}{$\frac{\vec{I}}{I}$} & EKH_43 & 0.5 & 19 & 4 & 15 & $61.3 \%$ & $12.9 \%$ & $48.4 \%$ \\
\hline & & EKH_44 & 1.5 & 4 & 3 & 1 & $12.9 \%$ & $9.7 \%$ & $3.2 \%$ \\
\hline & & EKH_45 & 2.3 & 6 & 2 & 5 & $19.4 \%$ & $6.5 \%$ & $16.1 \%$ \\
\hline & \multirow{3}{*}{$\frac{\mathbb{a}}{\mathbb{I}}$} & ERH_1 & 0.5 & 0 & 0 & 0 & $0.0 \%$ & $0.0 \%$ & $0.0 \%$ \\
\hline & & ERH_2 & 1.5 & 3 & 3 & 0 & $9.7 \%$ & $9.7 \%$ & $0.0 \%$ \\
\hline & & ERH_3 & 2.3 & 11 & 3 & 8 & $35.5 \%$ & $9.7 \%$ & $25.8 \%$ \\
\hline & \multirow{3}{*}{$\sum_{\Sigma}^{\mathbb{I}}$} & MMH_31 & 0.5 & 12 & 9 & 4 & $38.7 \%$ & $29.0 \%$ & $12.9 \%$ \\
\hline & & MMH_32 & 1.5 & 4 & 0 & 4 & $12.9 \%$ & $0.0 \%$ & $12.9 \%$ \\
\hline & & MMH_33 & 2.3 & 10 & 6 & 4 & $32.3 \%$ & $19.4 \%$ & $12.9 \%$ \\
\hline & \multirow{3}{*}{ 㐏 } & NH_46 & 0.5 & 9 & 7 & 2 & $29.0 \%$ & $22.6 \%$ & $6.5 \%$ \\
\hline & & NH_47 & 1.5 & 1 & 0 & 1 & $3.2 \%$ & $0.0 \%$ & $3.2 \%$ \\
\hline & & NH_48 & 2.3 & 12 & 4 & 8 & $38.7 \%$ & $12.9 \%$ & $25.8 \%$ \\
\hline & \multirow{3}{*}{$\frac{\pi}{0}$} & OH_25 & 0.5 & 1 & 0 & 1 & $3.2 \%$ & $0.0 \%$ & $3.2 \%$ \\
\hline & & OH_26 & 1.5 & 7 & 4 & 3 & $22.6 \%$ & $12.9 \%$ & $9.7 \%$ \\
\hline & & OH_27 & 2.3 & 4 & 4 & 0 & $12.9 \%$ & $12.9 \%$ & $0.0 \%$ \\
\hline
\end{tabular}




\begin{tabular}{|c|c|c|c|c|c|c|c|c|}
\hline \multirow{3}{*}{$\begin{array}{l}\mathbb{W} \\
\widetilde{0}\end{array}$} & OSH_28 & 0.5 & 6 & 5 & 3 & $19.4 \%$ & $16.1 \%$ & $9.7 \%$ \\
\hline & OSH_29 & 1.5 & 11 & 7 & 6 & $35.5 \%$ & $22.6 \%$ & $19.4 \%$ \\
\hline & OSH_30 & 2.3 & 10 & 6 & 4 & $32.3 \%$ & $19.4 \%$ & $12.9 \%$ \\
\hline \multirow{3}{*}{$\sum_{F}^{I}$} & TWH_37 & 0.5 & 6 & 0 & 6 & $19.4 \%$ & $0.0 \%$ & $19.4 \%$ \\
\hline & TWH_38 & 1.5 & 15 & 9 & 7 & $48.4 \%$ & $29.0 \%$ & $22.6 \%$ \\
\hline & TWH_39 & 2.3 & 6 & 1 & 5 & $19.4 \%$ & $3.2 \%$ & $16.1 \%$ \\
\hline & & Sum: & 514 & 253 & 281 & & & \\
\hline & & Avg: & 9.5 & & & $30.7 \%$ & $15.1 \%$ & $16.8 \%$ \\
\hline
\end{tabular}

Table 1.1b: Summary table of percent occupancy rates of nest blocks from Table 1.1a.

\begin{tabular}{cccc}
$\begin{array}{c}\text { Percent Nest Block } \\
\text { Occupancy }\end{array}$ & $\begin{array}{c}\text { Nests with Total } \\
\text { Occupants (n) }\end{array}$ & $\begin{array}{c}\text { Nests with Bee } \\
\text { Occupants (n) }\end{array}$ & $\begin{array}{c}\text { Nests with Wasp } \\
\text { Occupants (n) }\end{array}$ \\
\hline \hline$>50 \%$ & 8 & 1 & 3 \\
$<50 \%>30 \%$ & 19 & 3 & 4 \\
$<30 \%>10 \%$ & 18 & 27 & 27 \\
$<10 \%>0 \%$ & 7 & 12 & 11 \\
$0 \%$ & 2 & 11 & 9 \\
\hline & Sum: $\mathbf{5 2}$ & $\mathbf{4 3}$ & $\mathbf{4 5}$
\end{tabular}




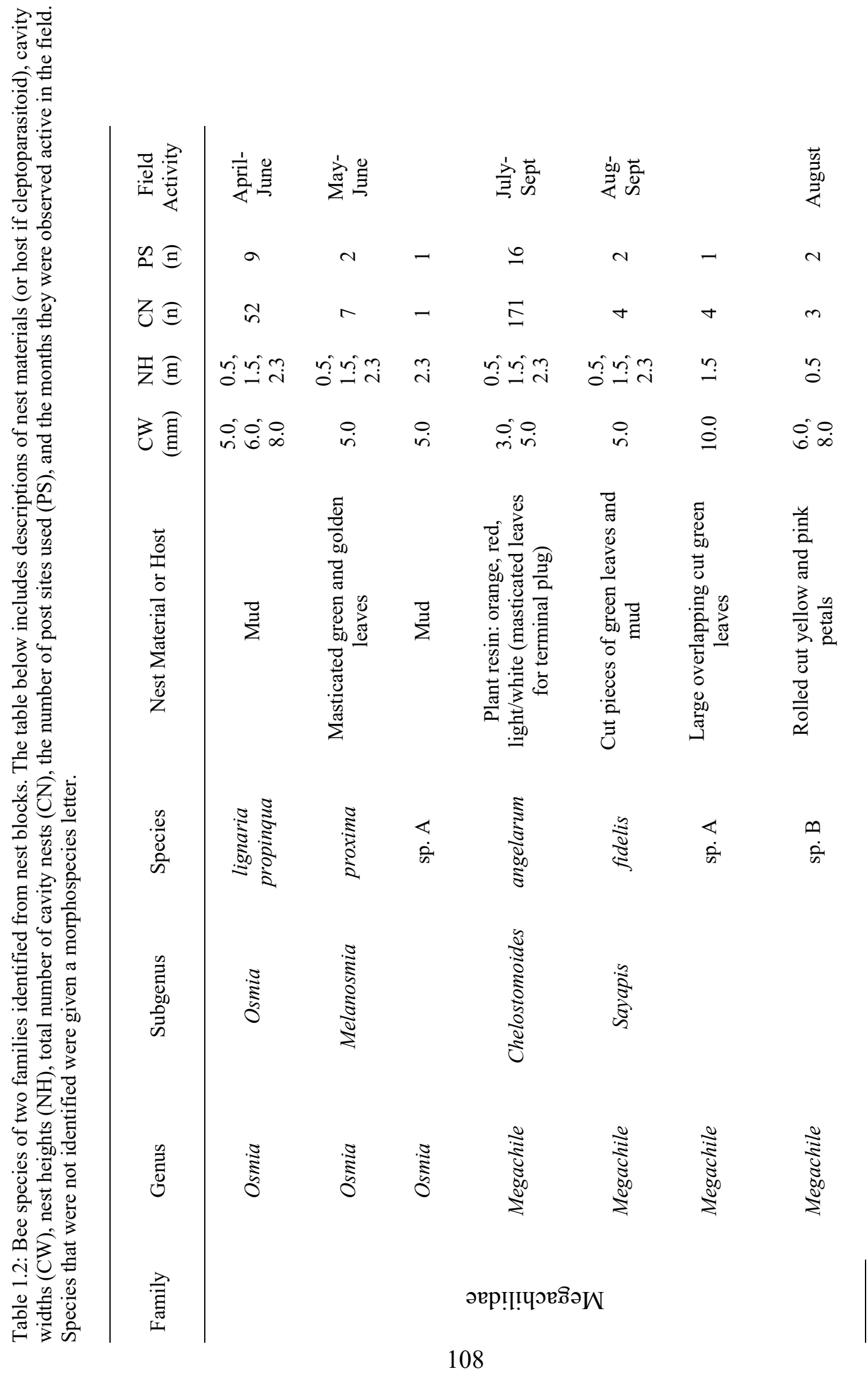




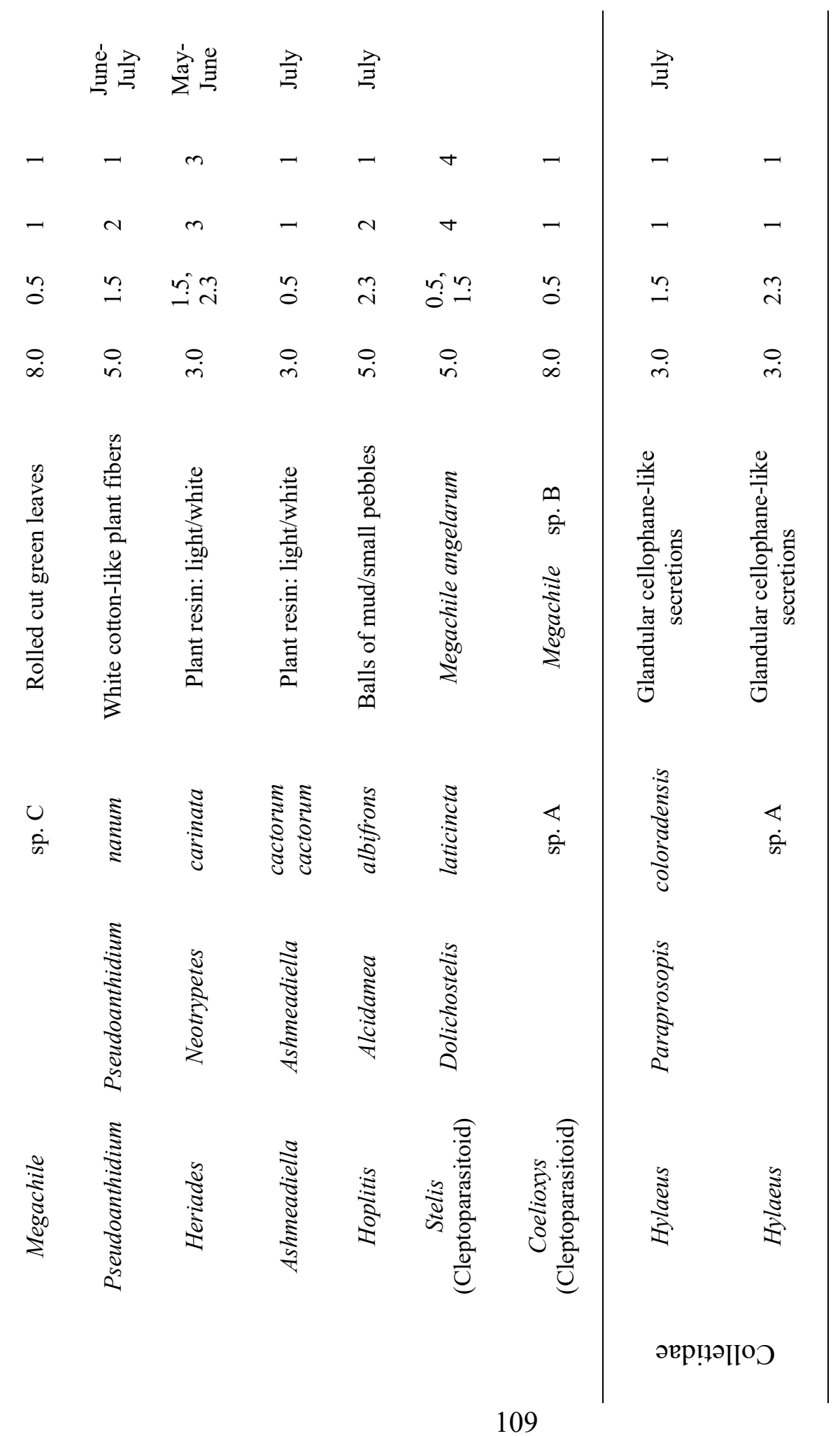




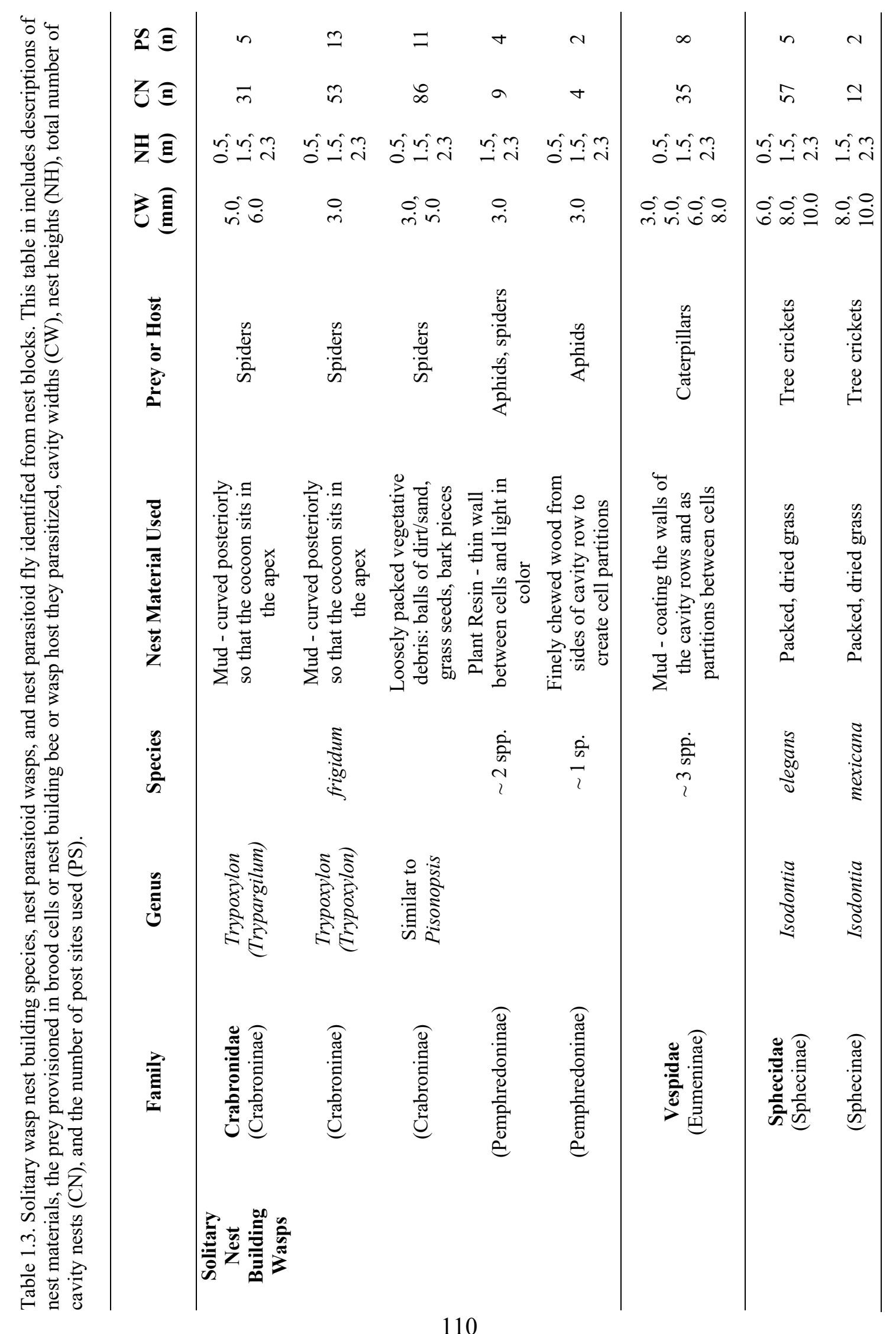




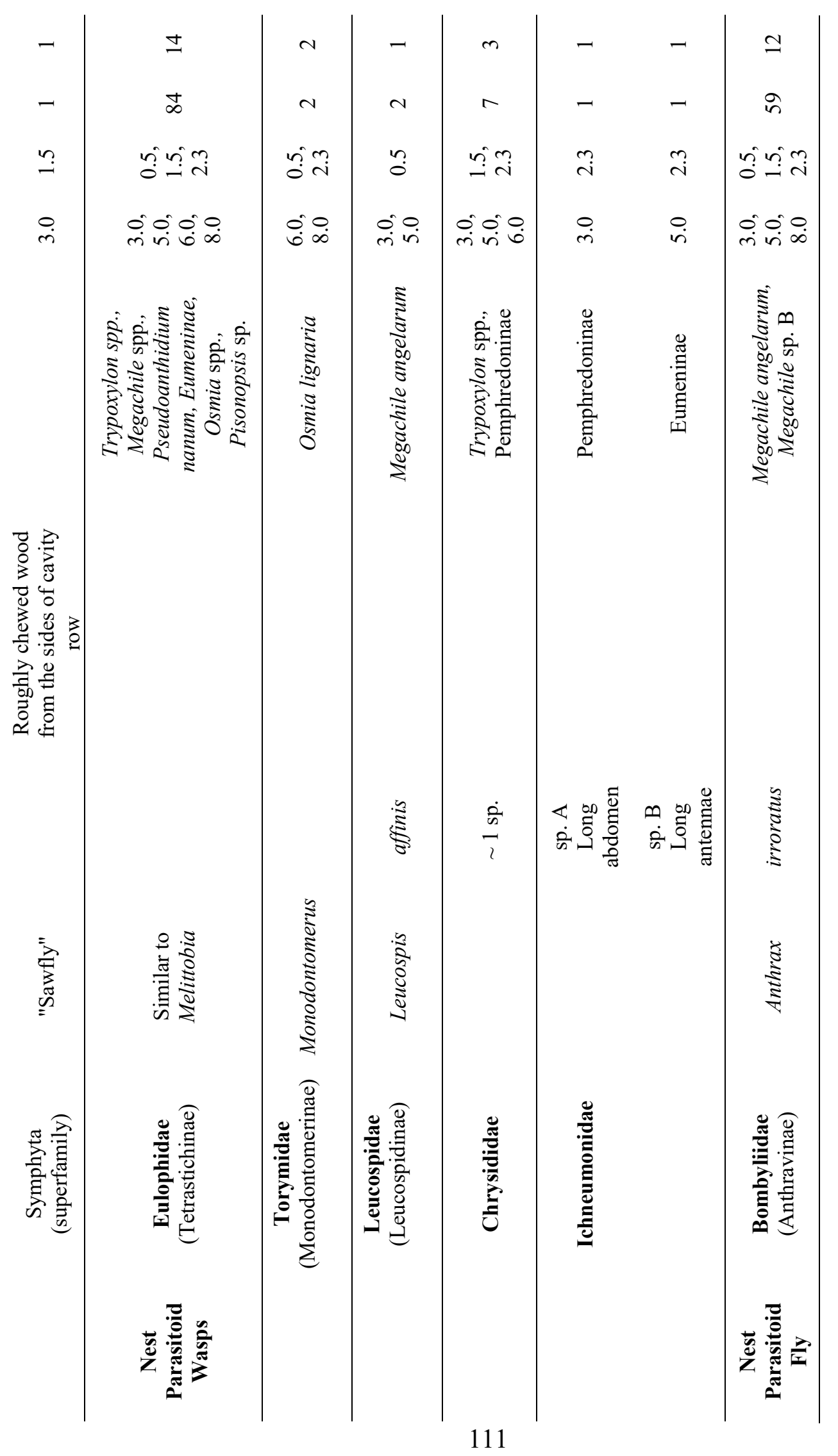


Table 1.4: Bee species richness and abundance by nest block site. Each bee species is represented by a letter along the top row, and the number below each species represents the number of cavities per nest block that species occupied. All identified species, Osmia lignaria (a), Osmia proxima (b), Osmia sp. A (c), Megachile angelarum (d), Megachile fidelis (e), Megachile sp. A (f), Megachile sp. B (g), Megachile sp. C (h), Pseudoanthidium nanum (i), Heriades carinata (j), Ashmeadiella c. cactorum (k), Hoplitis albifrons (1), Hylaeus coloradensis (m), Hylaeus sp. A (n) are indigenous to the area except P. nanum (i). Two cleptoparasitoid species include Stelis laticincta (o), and Coelioxys sp. A (p).

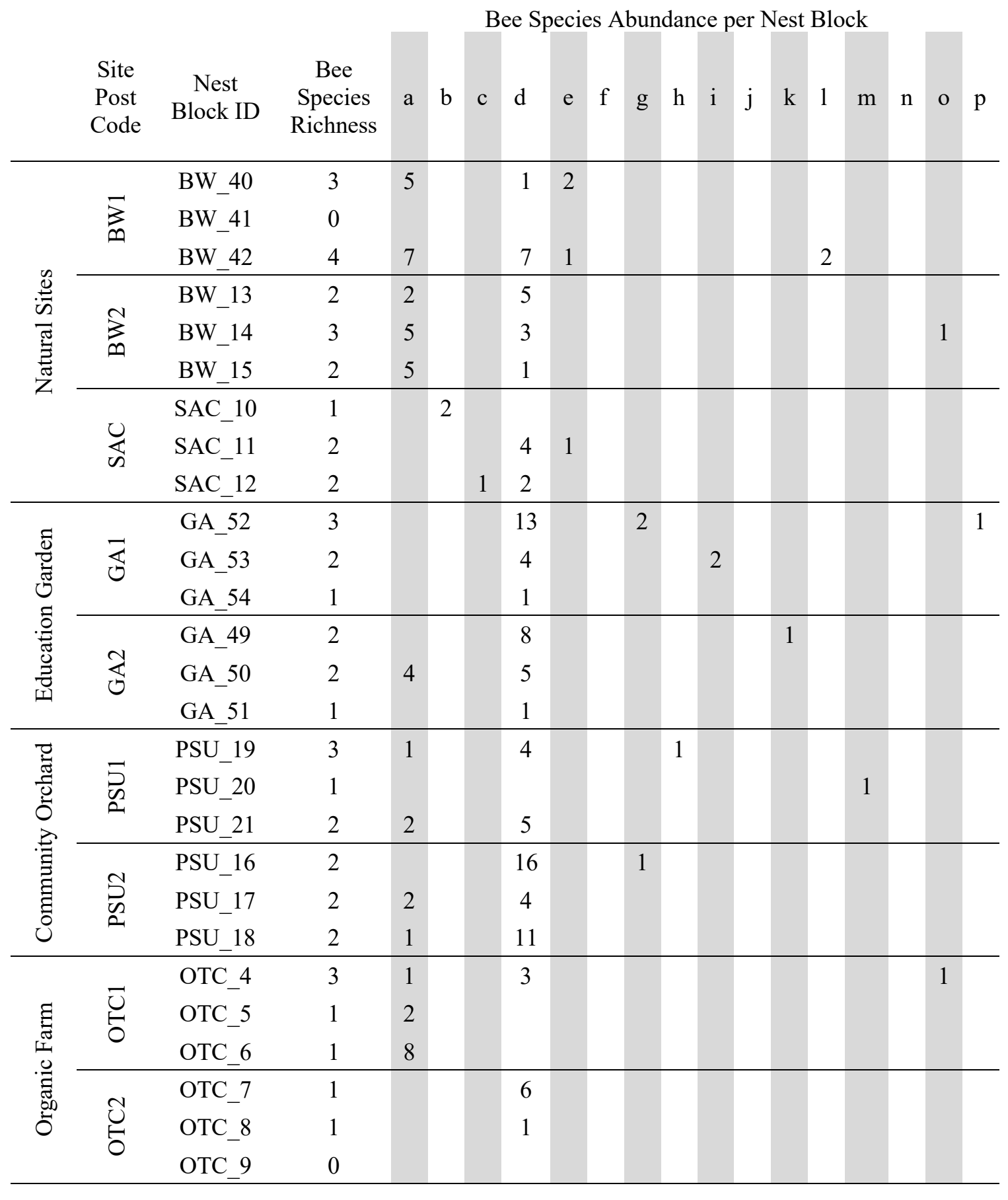




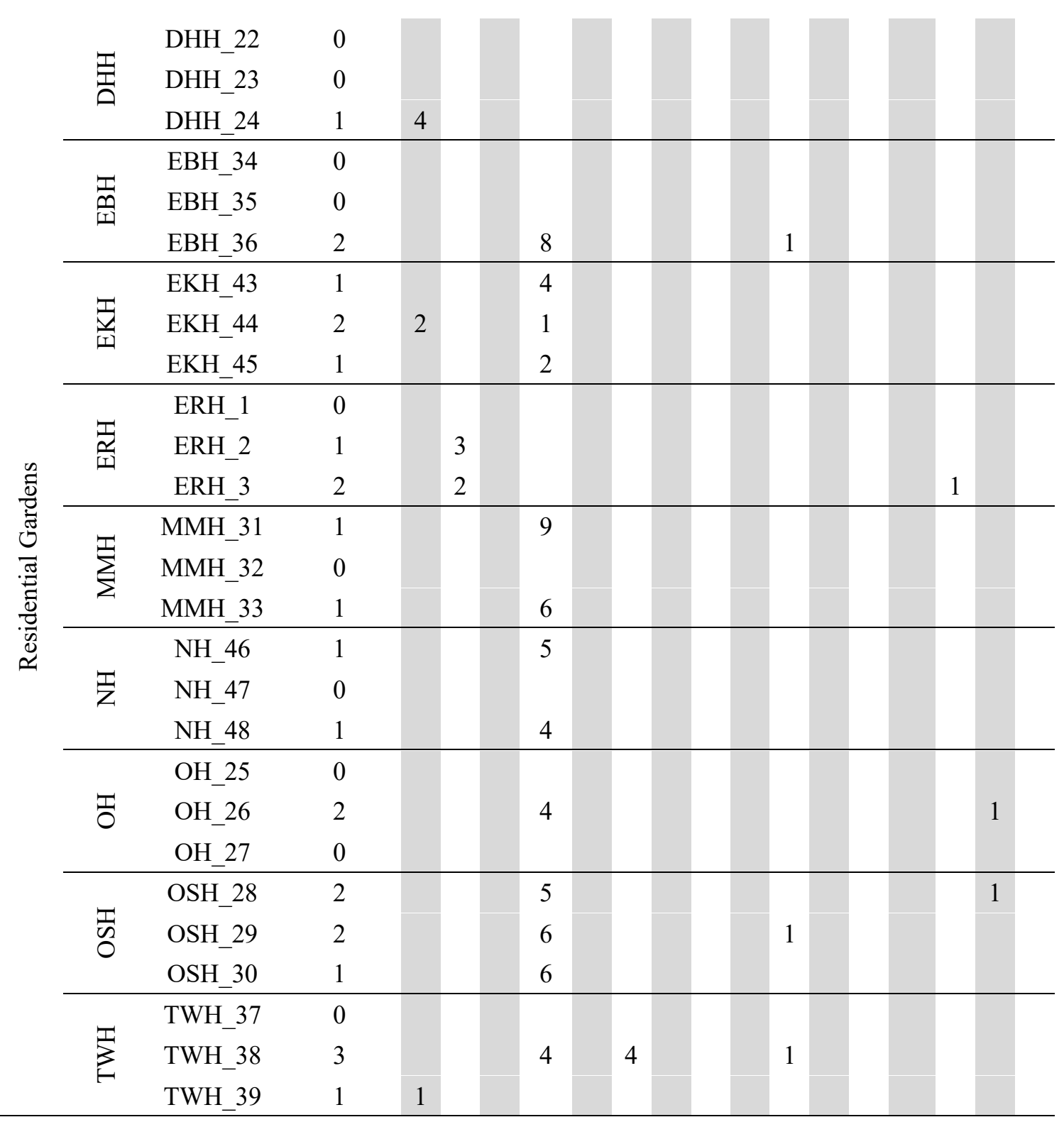




\section{Chapter 2}

Table 2.1: Identification resources for nest block occupants.

\begin{tabular}{|c|c|c|}
\hline & Nest Block Occupant & es Used for Identification \\
\hline Bees & $\begin{array}{l}\text { Osmia lignaria propinqua (Cresson, } \\
1864 \text { ) } \\
\text { Osmia proxima } \\
\text { Osmia sp. A } \\
\text { Megachile angelarum (Cockerell, } \\
\text { 1902) } \\
\text { Megachile fidelis (Cresson, 1899) } \\
\text { Megachile sp. A } \\
\text { Megachile sp. B } \\
\text { Megachile sp. C } \\
\text { Pseudoanthidium nanum (Mocsáry, } \\
\text { 1881) } \\
\text { Heriades carinata (Cresson, 1864) } \\
\text { Ashmeadiella cactorum cactorum } \\
\text { (Cockerell, 1897) } \\
\text { Hoplitis albifrons (Cresson, 1864) } \\
\text { Stelis laticincta (Cresson, 1878) } \\
\text { Coelioxys sp. A } \\
\text { Hylaeus coloradensis (Cockerell, 1896) } \\
\text { Hylaeus sp. A }\end{array}$ & $\begin{array}{l}\text { (Ascher, 2009; Krombein, 1967; Mitchell, 1962; } \\
\text { Sandhouse, 1939) } \\
\text { (Ascher, 2009; Mitchell, 1962; Sandhouse, 1939) } \\
\text { (Michener, 2007) } \\
\text { (Sheffield et al., 2011) } \\
\text { (Sheffield et al., 2011) } \\
\text { (Krombein, 1967; Michener, 2007; Sheffield et al., } \\
\text { 2011) } \\
\text { (Krombein, 1967; Michener, 2007; Sheffield et al., } \\
\text { 2011) } \\
\text { (Krombein, 1967; Michener, 2007; Sheffield et al., } \\
\text { 2011) } \\
\text { (Michener, 2007; Portman et al., 2019) } \\
\text { (Hurd, Jr. and Michener, 1955; Matthews, 1965; } \\
\text { Krombein, 1967) } \\
\text { (Hurd, Jr. and Michener, 1955) } \\
\text { (Hurd, Jr. and Michener, 1955) } \\
\text { (Parker and Bohart, 1979) } \\
\text { (Michener, 2007) } \\
\text { (Oram, 2018) } \\
\text { (Krombein, 1967; Michener, 2007) }\end{array}$ \\
\hline Wasps & $\begin{array}{l}\text { Trypoxylon (Trypargilum) } \\
\text { Trypoxylon (Trypoxylon) } \\
\text { Pisonopsis sp. } \\
\text { Pemphredoninae spp. } \\
\text { Eumeninae } \\
\text { Isodontia mexicana } \\
\text { Isodontia elegans } \\
\text { Sawfly } \\
\text { Melittobia sp. } \\
\text { Monodontomerus sp. } \\
\text { Leucospis affinis } \\
\text { Chrysididae spp. } \\
\text { Ichneumonidae spp. }\end{array}$ & $\begin{array}{l}\text { (Krombein, 1967; Medler, 1967; Sandhouse, 1940) } \\
\text { (Krombein, 1967; Medler, 1967; Sandhouse, 1940) } \\
\text { (Williams, 1954; Evans, 1969; Ratzlaff, 2015) } \\
\text { (Budriene et al., 2004; Fye, 1965; Krombein, 1967) } \\
\text { (Fye, 1965b; Krombein, 1967; Budriene, Budrys } \\
\text { and Nevronyte, 2004; Hallett, 2011) } \\
\text { (Krombein, 1967; Bohart and Menke, 1976; } \\
\text { Pickering, 2009) } \\
\text { (Bohart and Menke, 1976; Pickering, 2009) } \\
\text { (Fye, 1965b) } \\
\text { (Krombein, 1967; Matthews et al., 2009; MacIvor, } \\
\text { 2019) } \\
\text { (Krombein, 1967; Macivor and Salehi, 2014) } \\
\text { (Medler, 1967a; O’Neill and O’Neill, 2018) } \\
\text { (Krombein, 1967; O’Neill and O’Neill, 2010) } \\
\text { (Fye, 1965b) }\end{array}$ \\
\hline Fly & Anthrax irroratus & $\begin{array}{l}\text { (Krombein, 1967; Kits, Marshall and Evenhuis, } \\
\text { 2008; MacIvor, 2019) }\end{array}$ \\
\hline
\end{tabular}




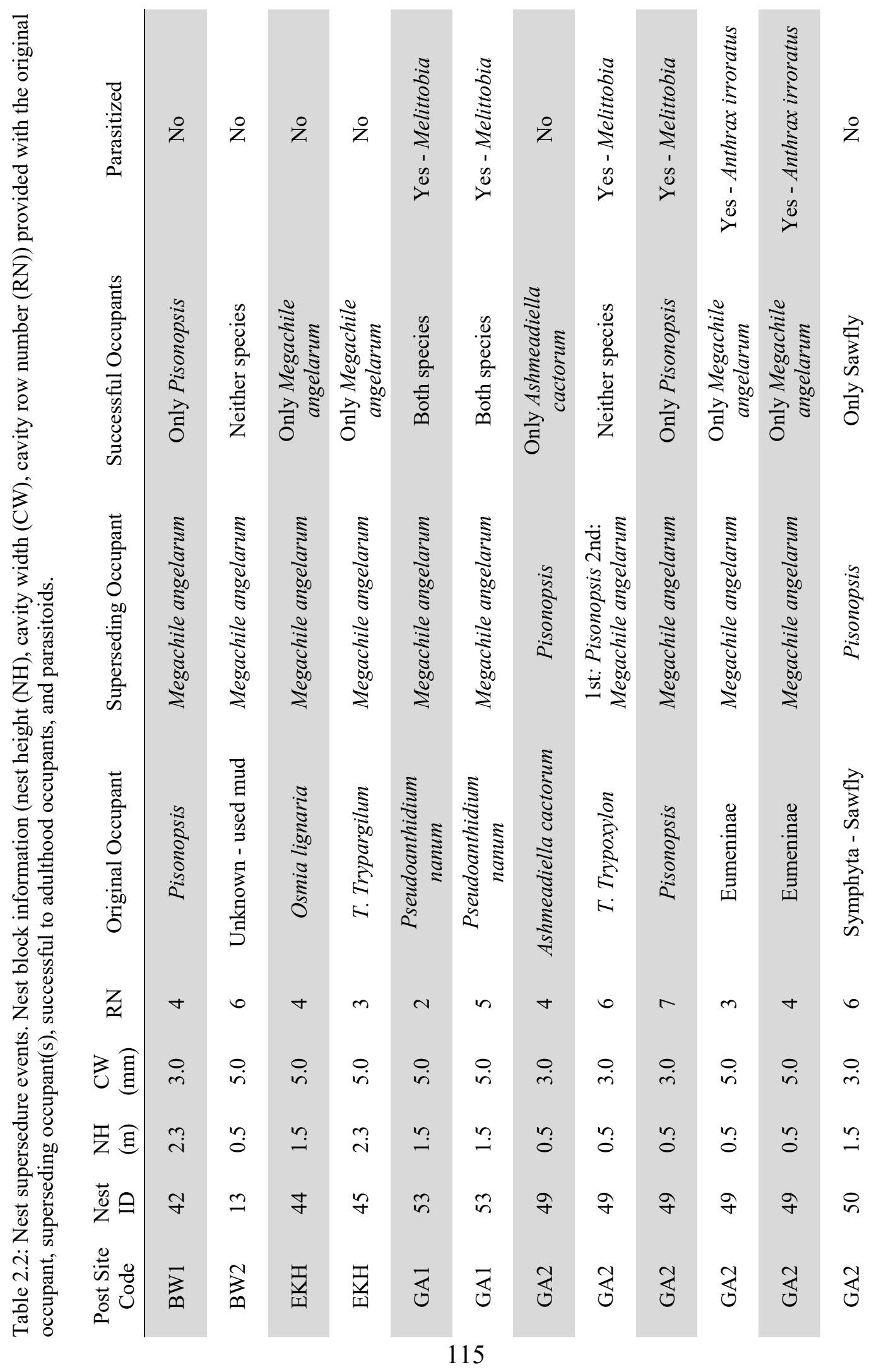




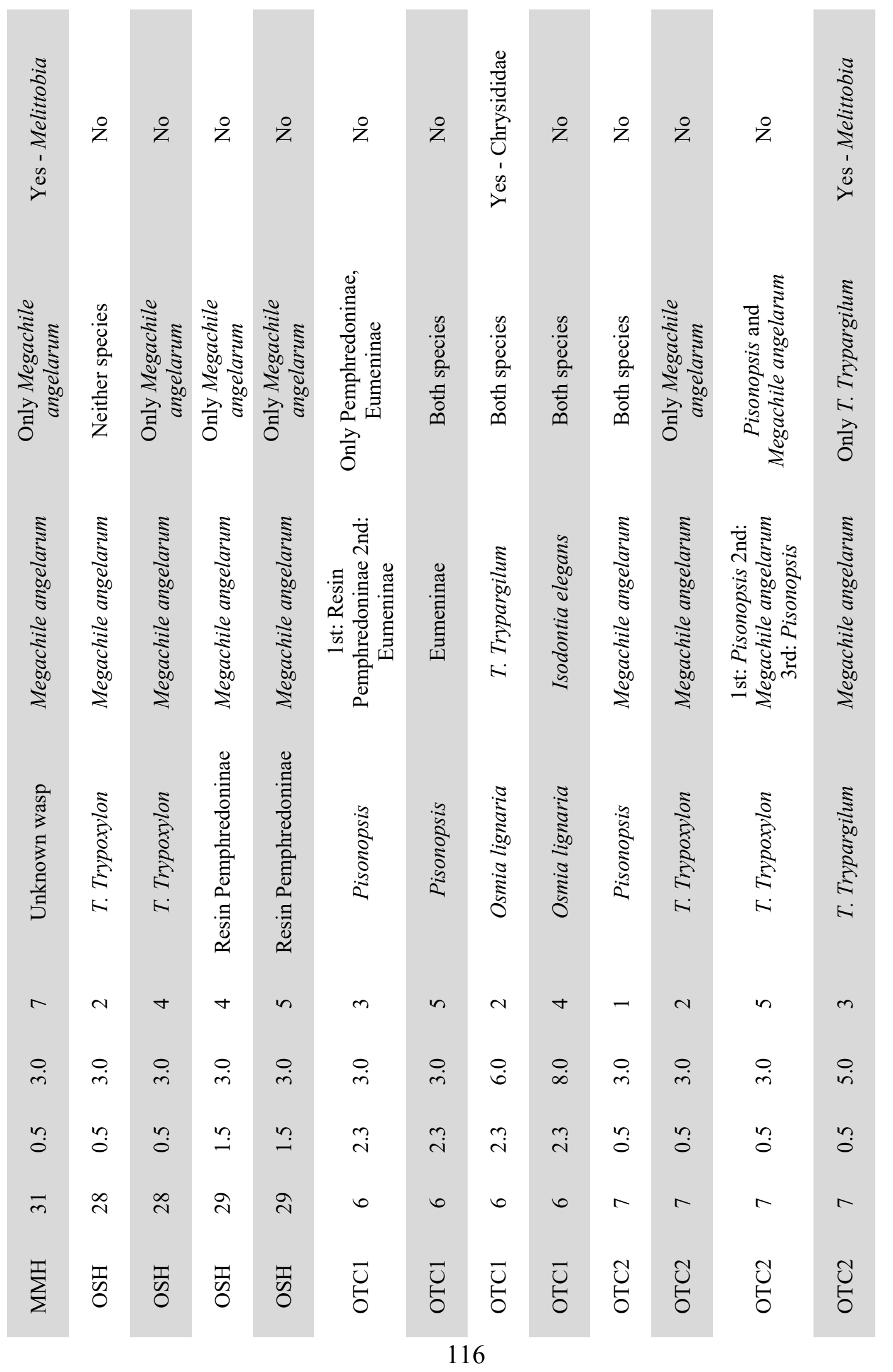



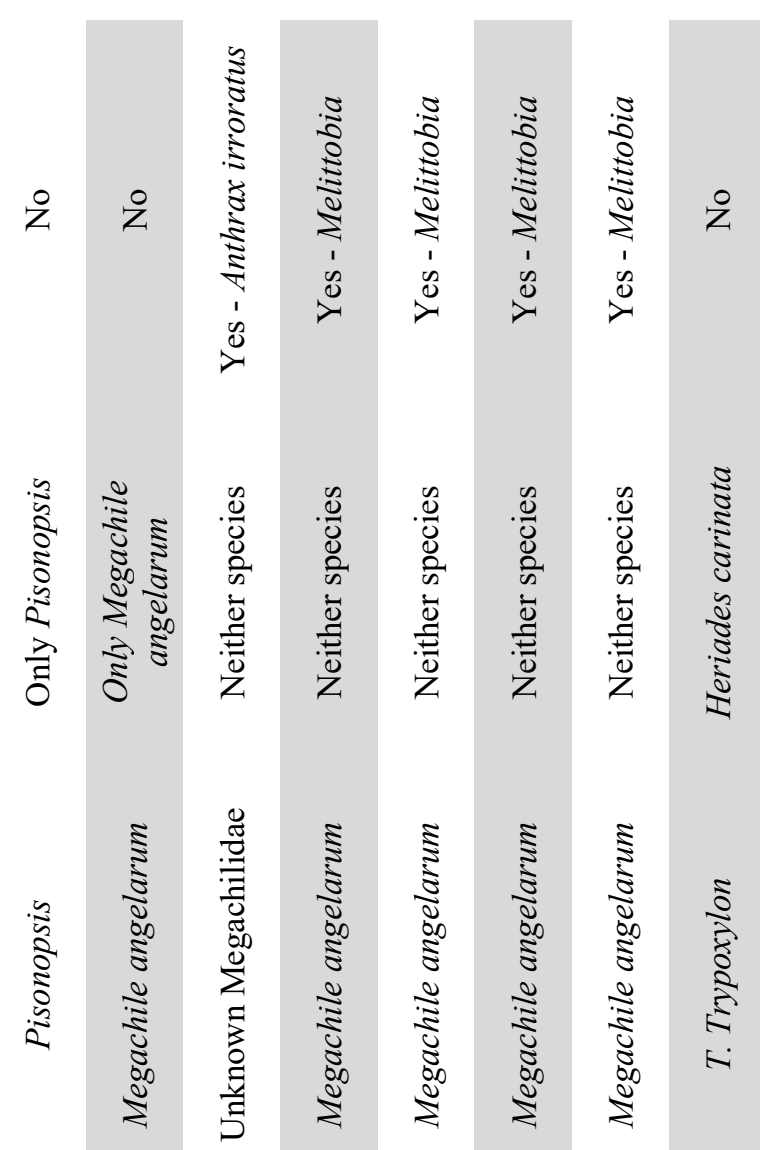

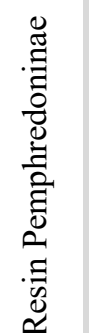

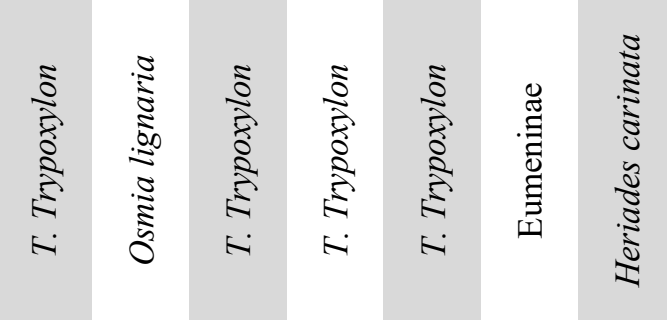

in $n d$ a 4 in 6

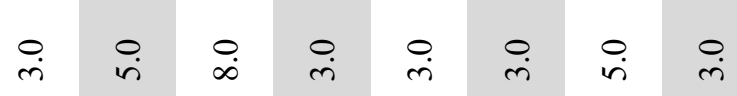

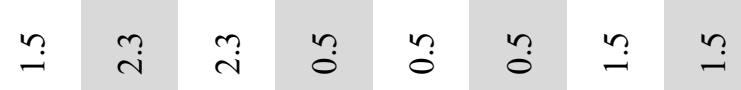

$\infty \bar{\sim} \vec{\sim} \stackrel{\bullet}{0}=\infty$

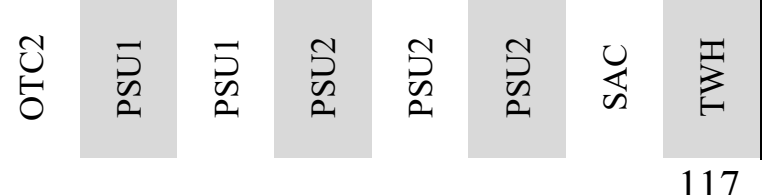




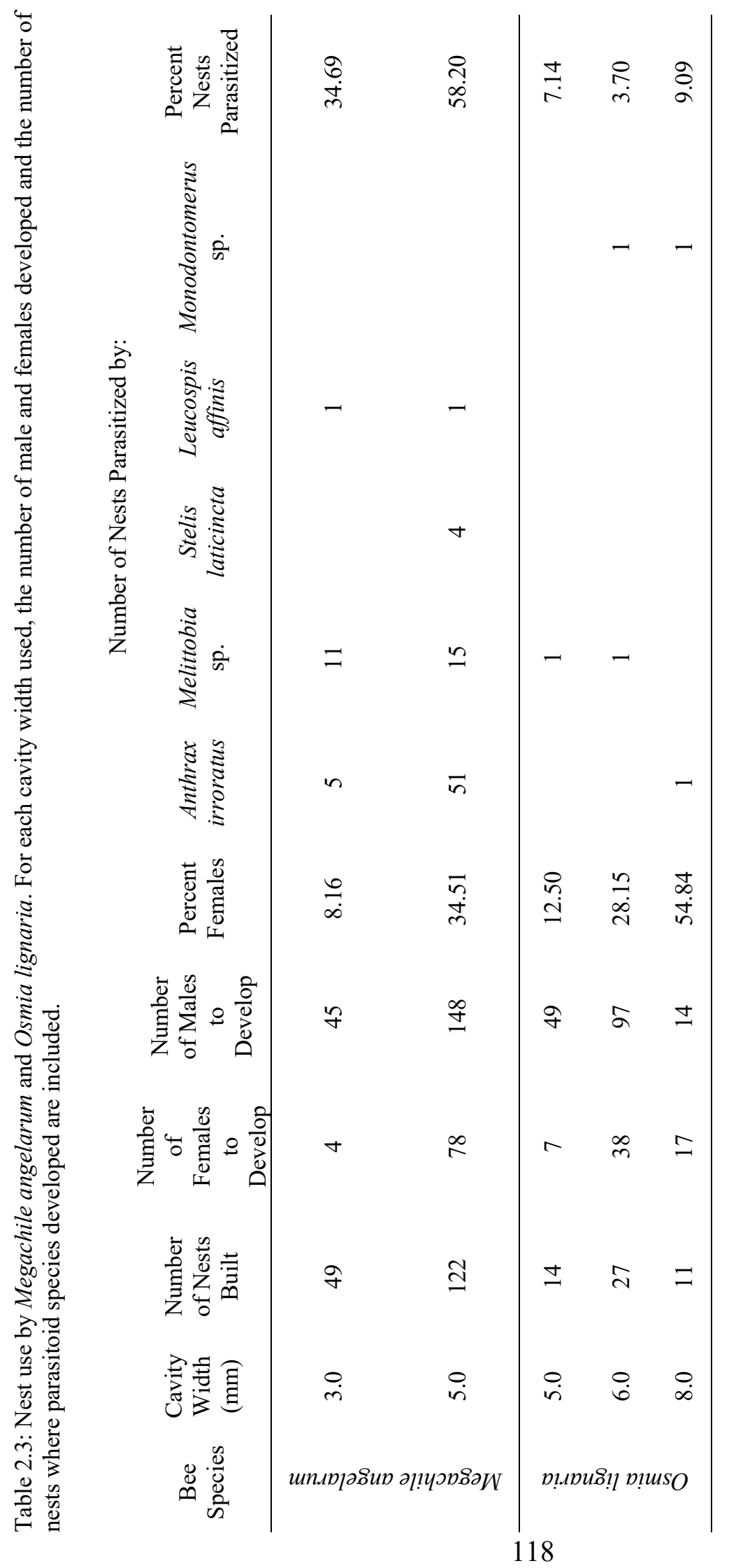


Table 2.4: Results of Megachile angelarum's provisioned cells in 3.0 and $5.0 \mathrm{~mm}$ cavity widths.

\begin{tabular}{|c|c|c|}
\hline 3.0 Nest Cavity Rows Used $(n=25)$ & Number of Cells & Percentage of Cells \\
\hline Sum total $3.0 \mathrm{~mm}$ cells provisioned & 125 & $14.5 \%$ \\
\hline Sum total $3.0 \mathrm{~mm}$ occupants emerged & 78 & $62.4 \%$ \\
\hline Sum $3.0 \mathrm{~mm}$ emerged males & 45 & $36.0 \%$ \\
\hline Sum $3.0 \mathrm{~mm}$ emerged females & 4 & $3.2 \%$ \\
\hline Sum $3.0 \mathrm{~mm}$ emerged parasitoids & 29 & $23.2 \%$ \\
\hline Sum $3.0 \mathrm{~mm}$ cells no emergence & 47 & $37.6 \%$ \\
\hline \multicolumn{3}{|l|}{$5.0 \mathrm{~mm}$ Nest Cavity Rows Used $(\mathrm{n}=90)$} \\
\hline Sum total $5.0 \mathrm{~mm}$ cells provisioned & 720 & $83.7 \%$ \\
\hline Sum total $5.0 \mathrm{~mm}$ occupants emerged & 402 & $54.7 \%$ \\
\hline Sum $5.0 \mathrm{~mm}$ emerged males & 153 & $20.8 \%$ \\
\hline Sum $5.0 \mathrm{~mm}$ emerged females & 74 & $10.1 \%$ \\
\hline Sum $5.0 \mathrm{~mm}$ emerged parasitoids & 175 & $23.8 \%$ \\
\hline Sum $5.0 \mathrm{~mm}$ cells no emergence & 337 & $45.9 \%$ \\
\hline
\end{tabular}


Table 2.5: Megachile fidelis cell contents and measurements. M. fidelis nested in a $5.0 \mathrm{~mm}$ cavity of nest block 42 at the North Portland natural site, Baltimore Woods.

\begin{tabular}{cccc} 
Cell Position & Cell Contents & $\begin{array}{c}\text { Cell } \\
\text { Length }(\mathrm{cm})\end{array}$ & $\begin{array}{c}\text { Apex of Cell Partition } \\
\text { Thickness }(\mathrm{cm})\end{array}$ \\
\hline \hline Preliminary Plug/1 & Deceased larva & 1.8 & 0.3 \\
2 & Female & 1.85 & 0.15 \\
3 & Male & 1.35 & - \\
4 & Male & 1.4 & 0.16 \\
5 & Male & 1.4 & - \\
6 & Male & 1.3 & 0.15 \\
7 & Male & 1.3 & 0.15 \\
8 & Male & 1.5 & 0.15 \\
Vestibule & & 4.3 & 0.3 \\
Terminal Plug & & & 0.3 \\
\hline
\end{tabular}




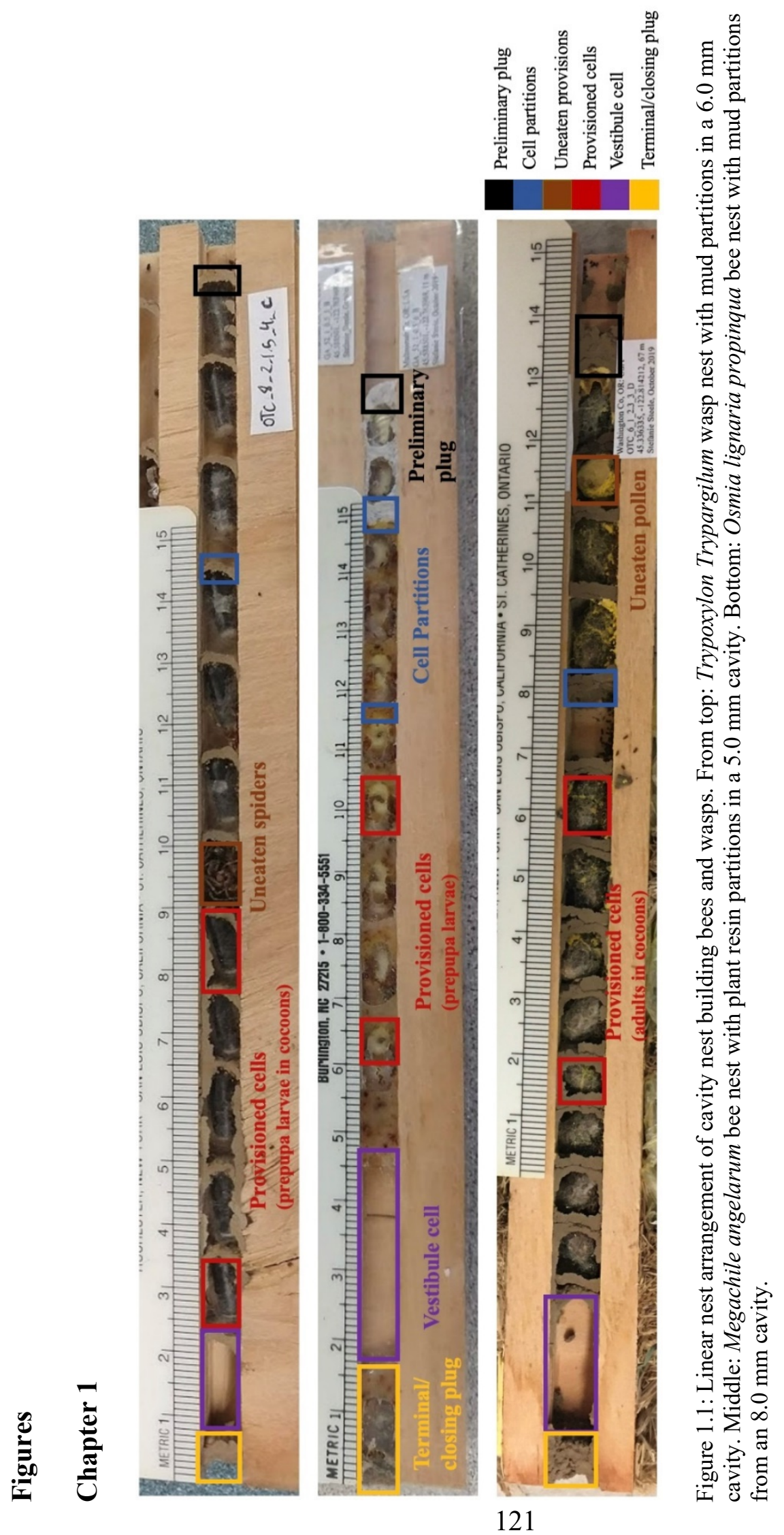




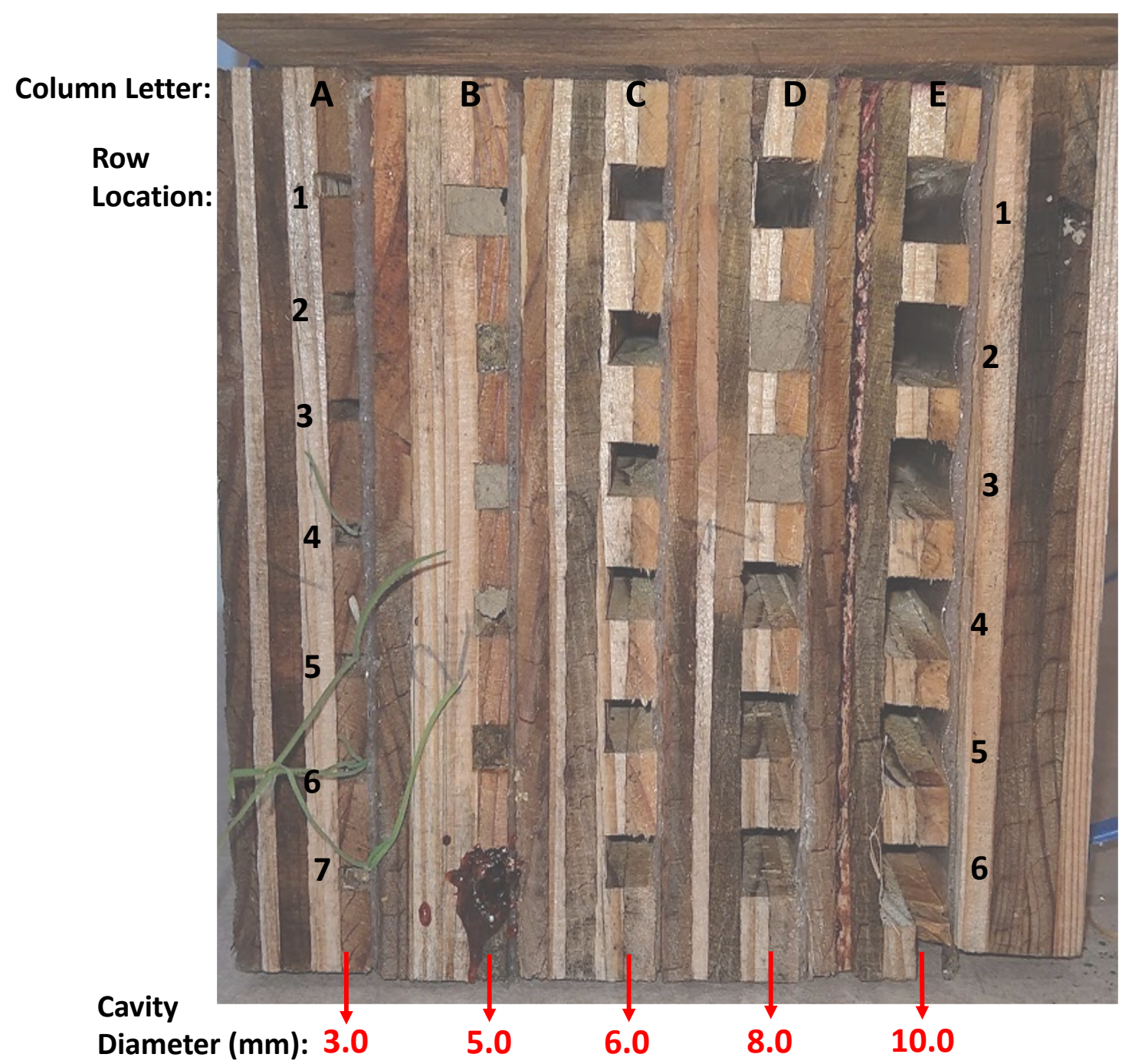

Figure 1.2: Front view of nest block. The shortest measured width of the cavities corresponds with the cavity diameter measurement given. Column letters and row locations are provided to identify nest locations during field monitoring and rearing. Also note some of the irregularities in the cavities, due to the structure of plywood. A diversity of nesting used in the terminal/closing plugs are visible in some cavities as well. 


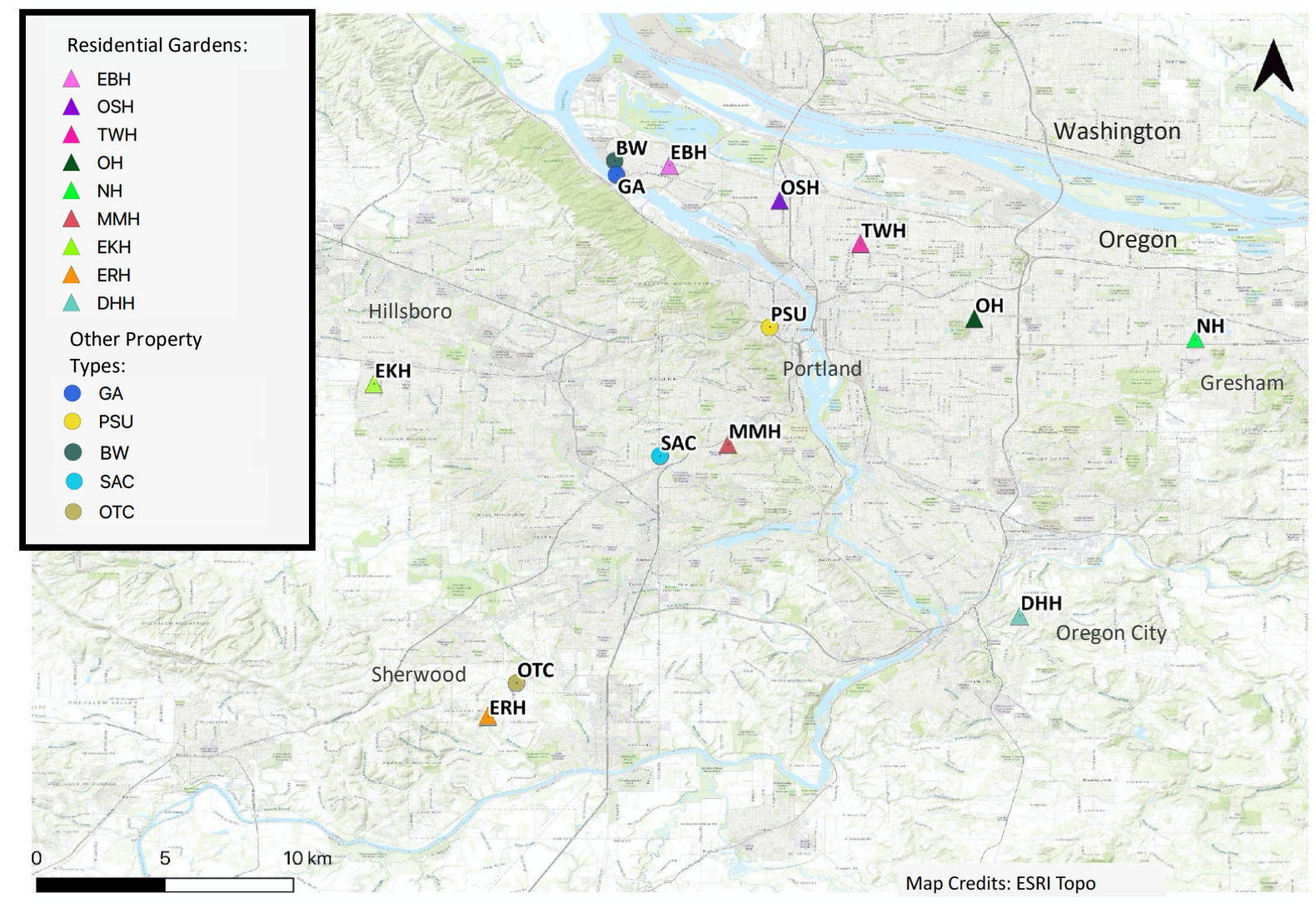

Figure 1.3: Nest block locations across greater Portland, Oregon in the United States. Nest site codes are listed, and each location has a unique color. Residential garden locations are represented by a triangle shape and all other property types (education garden, community orchard, natural site, and organic farm) are represented by a circle shape. 


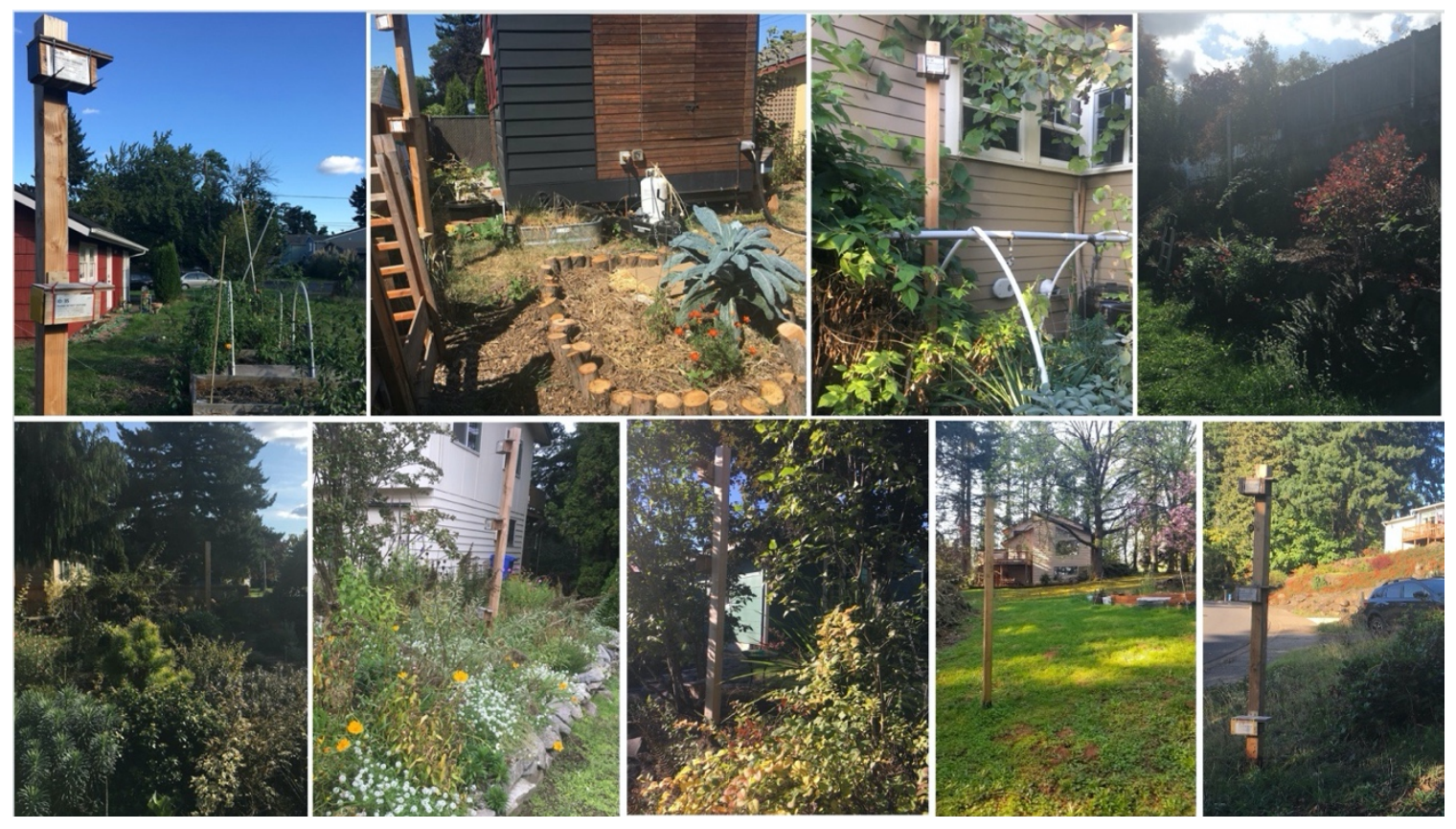

Figure 1.4: Residential garden nest sites. Top from left to right: EBH, OSH, TWH, and OH. From bottom left to right: $\mathrm{NH}, \mathrm{MMH}, \mathrm{EKH}, \mathrm{ERH}$, and DHH.
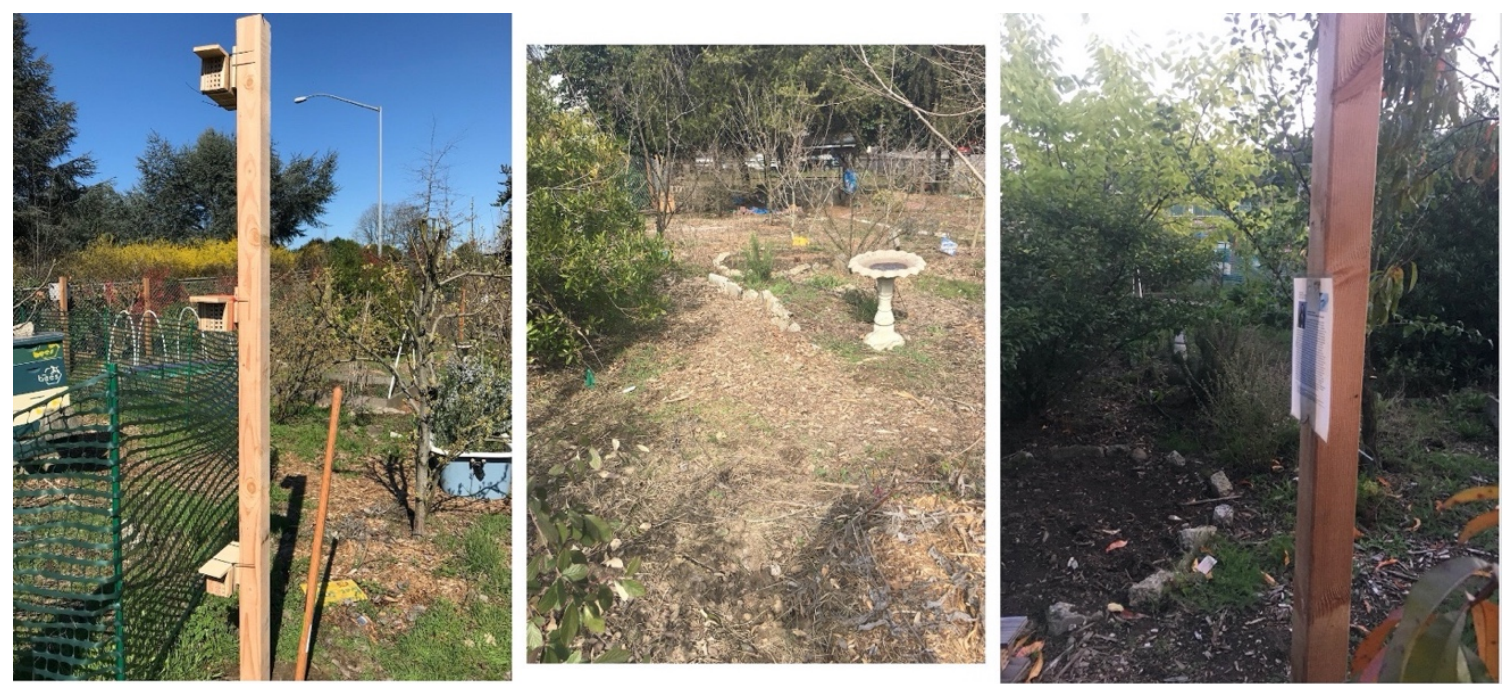

Figure 1.5: Portland State University (PSU) Community Orchard nest sites in Downtown Portland. From left to right: PSU post 2, community orchard overview photo in early spring, and PSU post 1. 

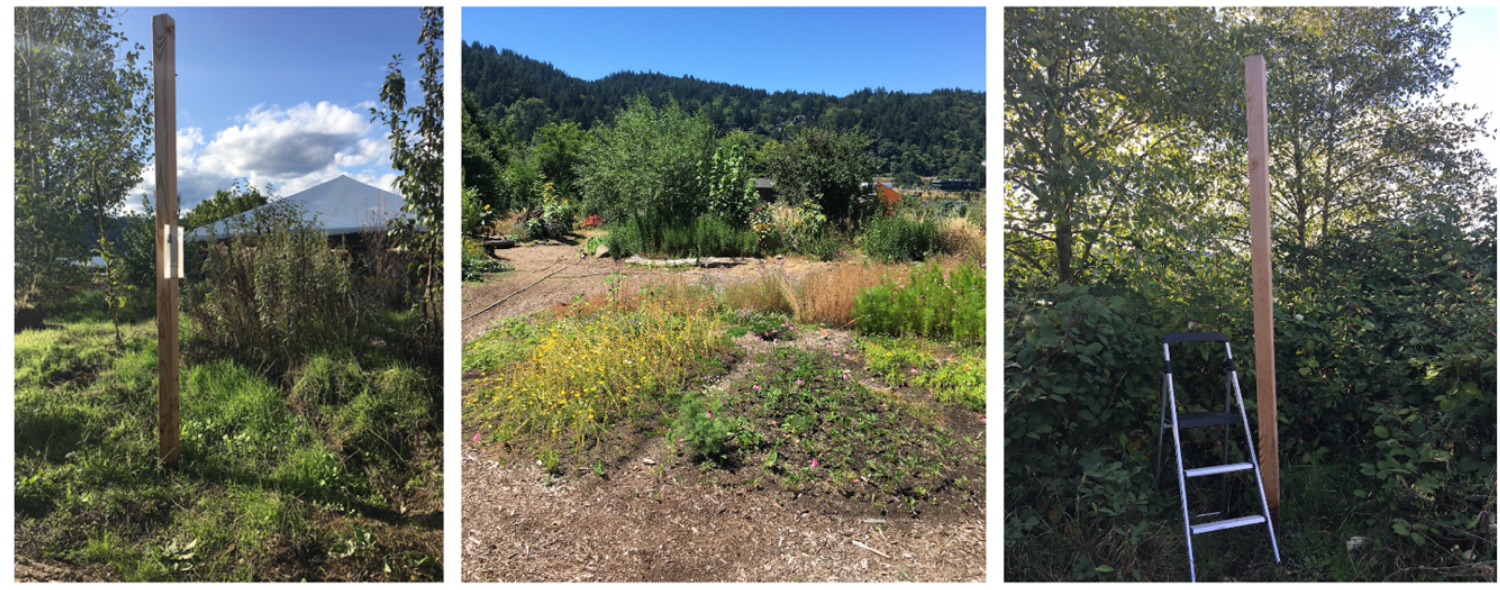

Figure 1.6: Green Anchors (GA) education garden nest sites in North Portland. From left to right: GA post 1, overview of Green Anchors from the summer, GA post 2.
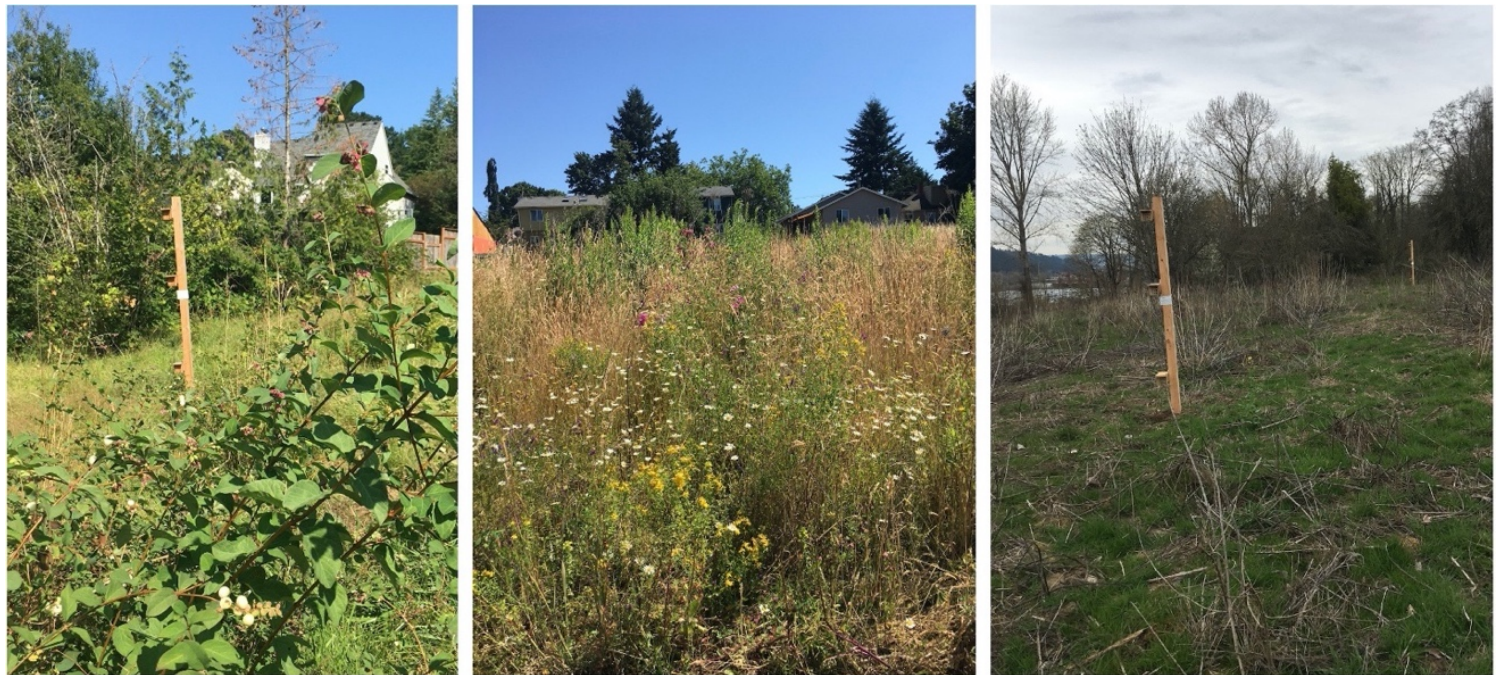

Figure 1.7: Bureau of Environmental Services nest sites. From left to right: South Ash Creek (SAC) natural site in Southwest Portland, overview of Baltimore Woods (BW) natural site in North Portland in summer. Baltimore Woods site in spring with BW post 1 near front and BW post 2 far in the distance. 

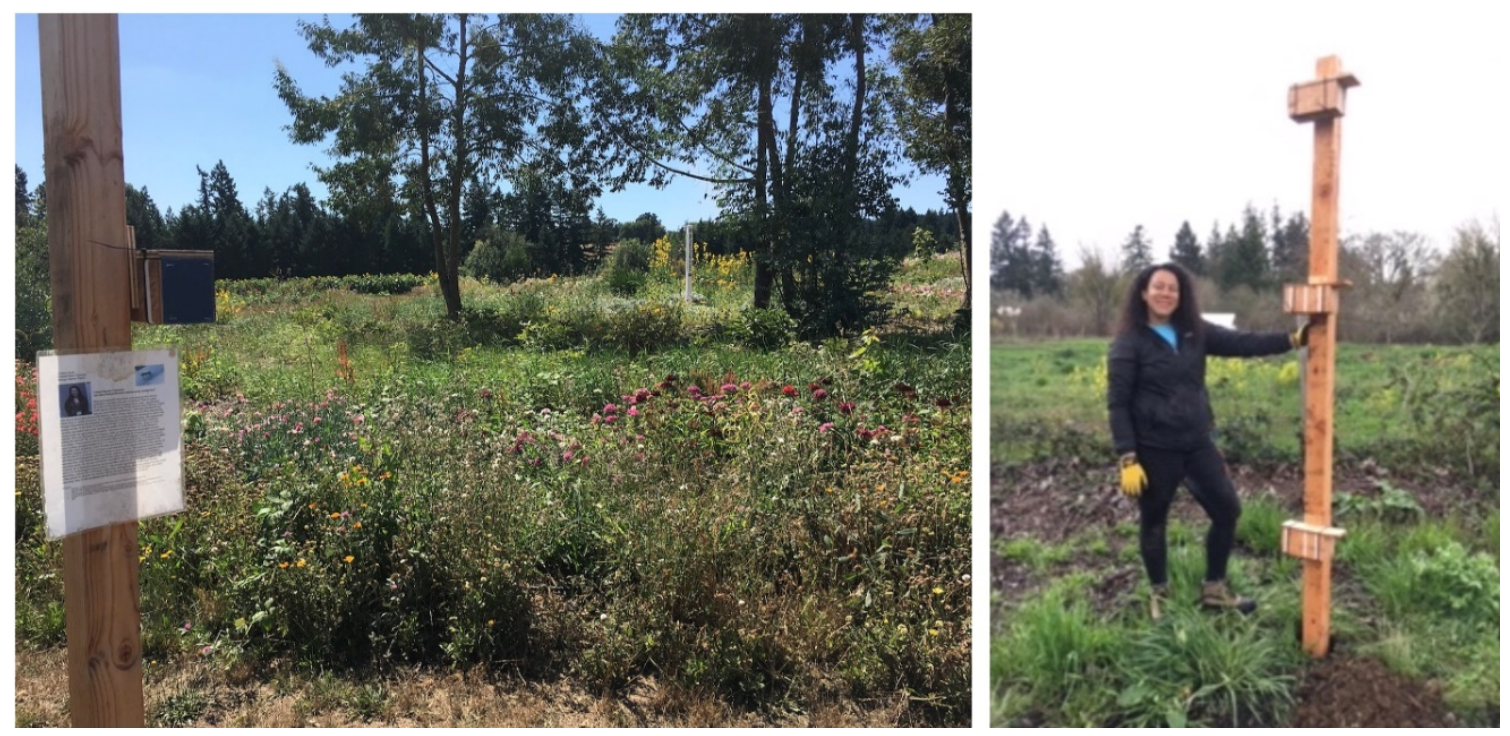

Figure 1.8: Our Table Cooperative (OTC) organic farm nest sites in Sherwood. From left to right: OTC post 1 near flower garden and OTC post 2 near the orchard. Photo on right by Ann Christler.

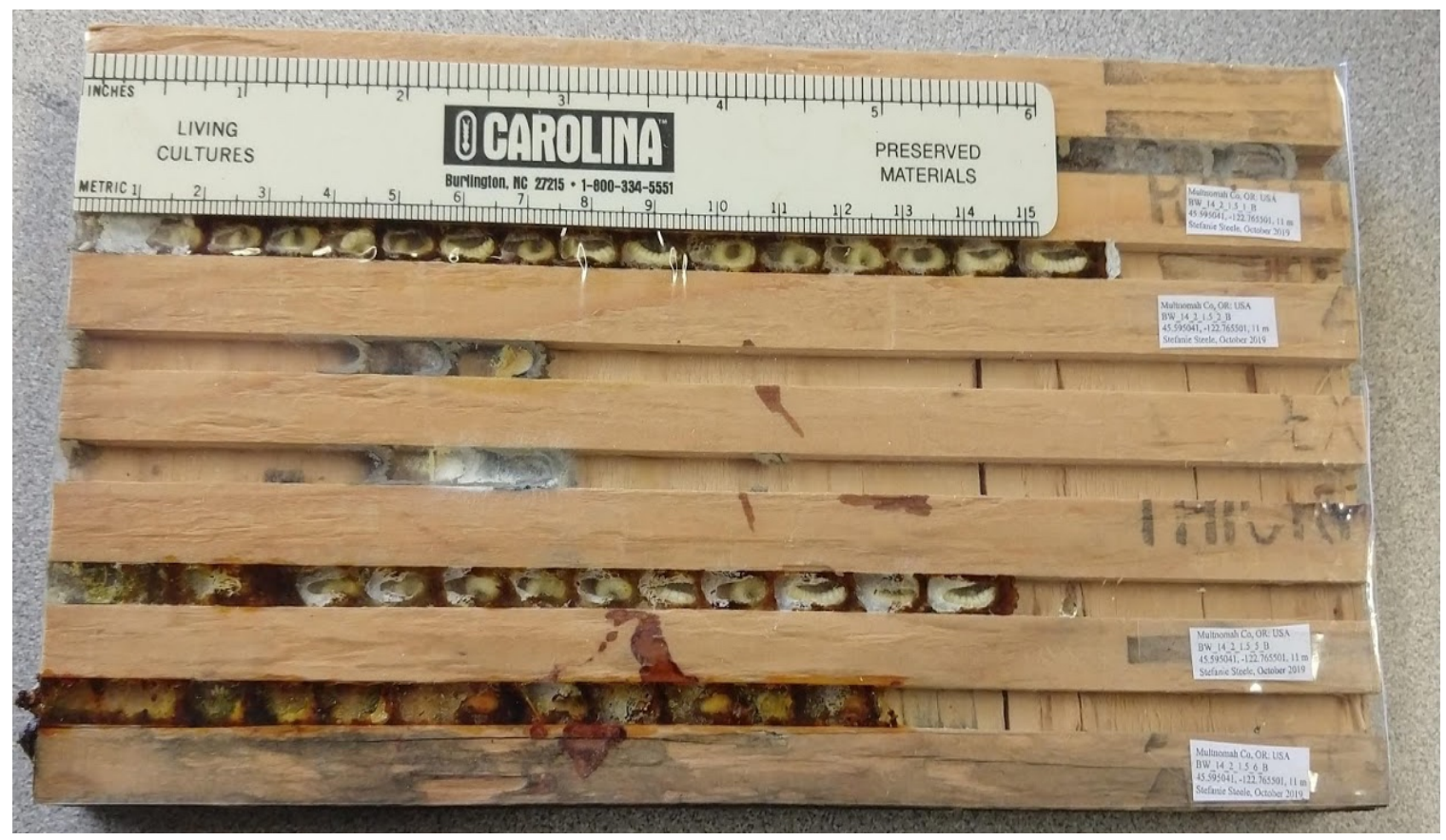

Figure 1.9: A $5.0 \mathrm{~mm}$ cavity width nesting tray. Megachile angelarum is visible in the three cavity rows made with red plant resin nesting materials. Cream colored prepupa larvae of $M$. angelarum are visible in many of these cells. 


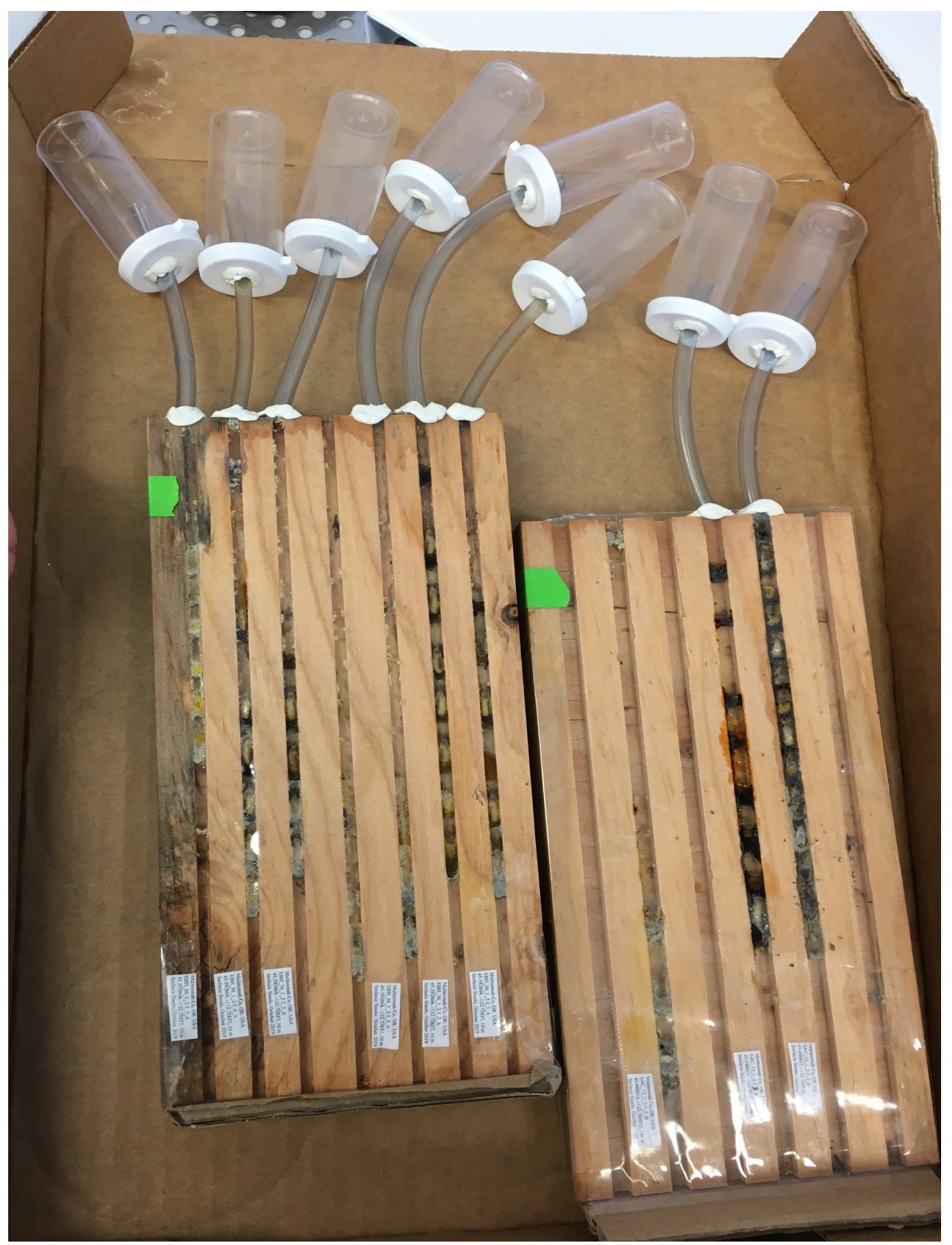

Figure 1.10: Vinyl tubing attached to cavity width trays for occupant emergence during. Cavity nests occupied by Megachilidae bees; right tray: $3.0 \mathrm{~mm}$, left tray: $5.0 \mathrm{~mm}$. 


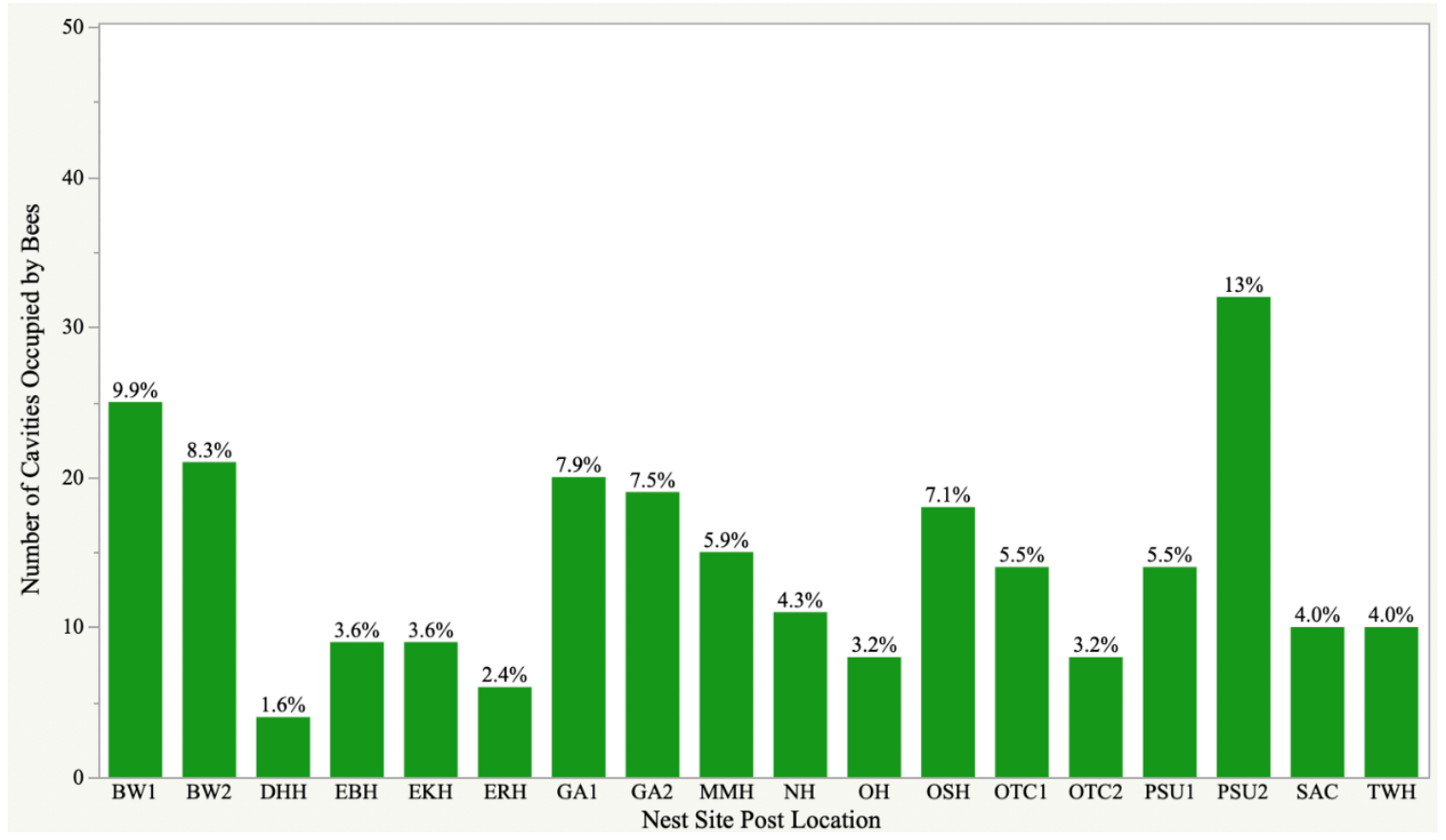

Figure 1.11: Number of cavities occupied by bees per nest site post location. The sum number of cavities bees used are graphed and the percentages above are calculated out of the 253 cavities that bees occupied. Community orchard site in downtown Portland, PSU2, had the greatest number of cavities occupied by bees. Residential garden in Oregon City, DHH, had the fewest cavities occupied by bees. 


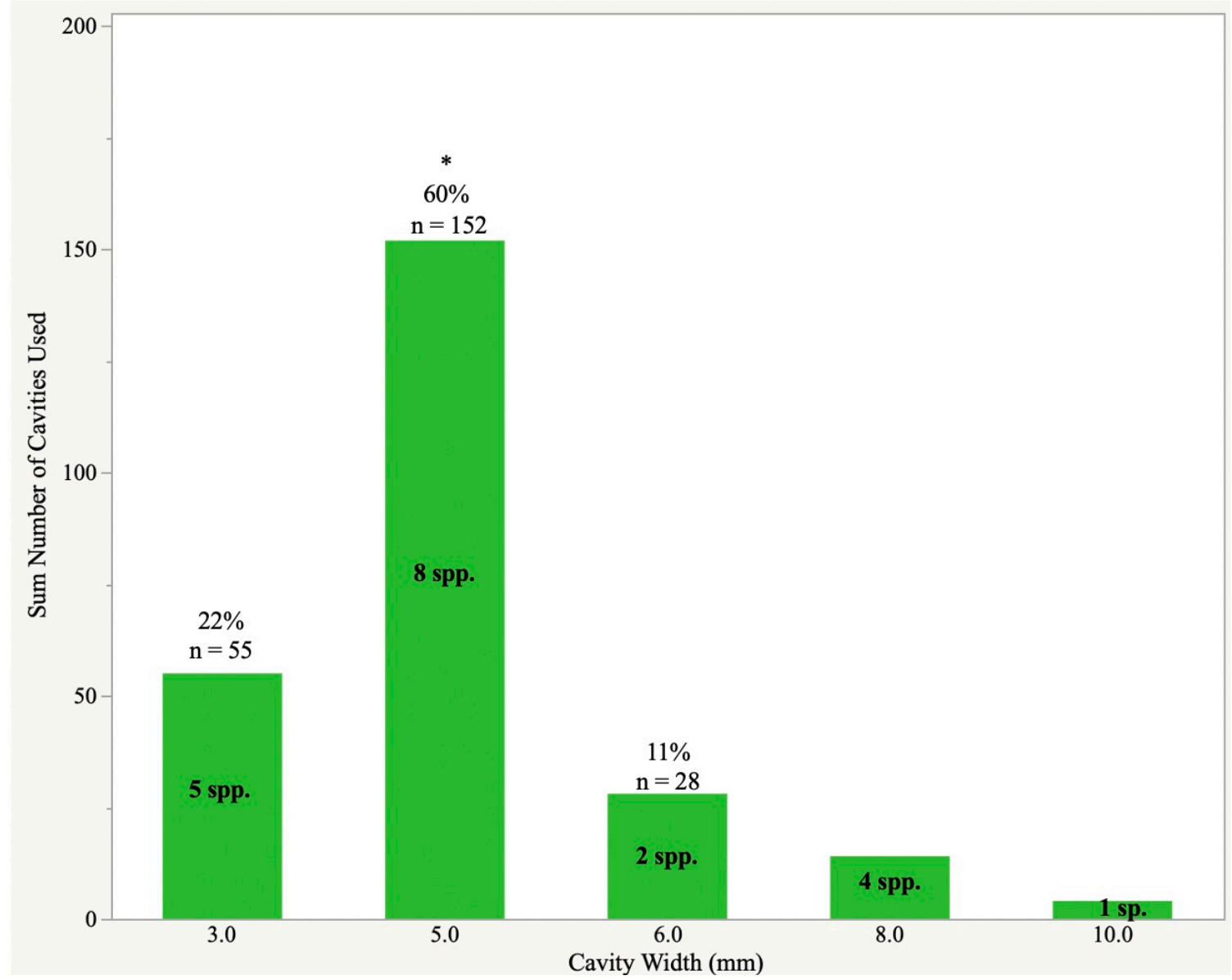

Figure 1.12: Cavity widths used by all bee species. Cavity width analysis using Poisson regression shows that compared to $3.0 \mathrm{~mm}$, cavities of $5.0 \mathrm{~mm}(\mathrm{p}<0.001$; slope $=1.017)$ were occupied significantly more. All other cavities were occupied significantly less than $3.0 \mathrm{~mm} ; 6.0 \mathrm{~mm}(\mathrm{p}=0.004), 8.0 \mathrm{~mm}(\mathrm{p}<0.001)$, $10.0 \mathrm{~mm}(\mathrm{p}<0.001)$. Chi square test of independence supports that there was a significant difference in use between cavity widths $X^{2}(4, n=253)=142.638, \mathrm{p}<0.001$. 


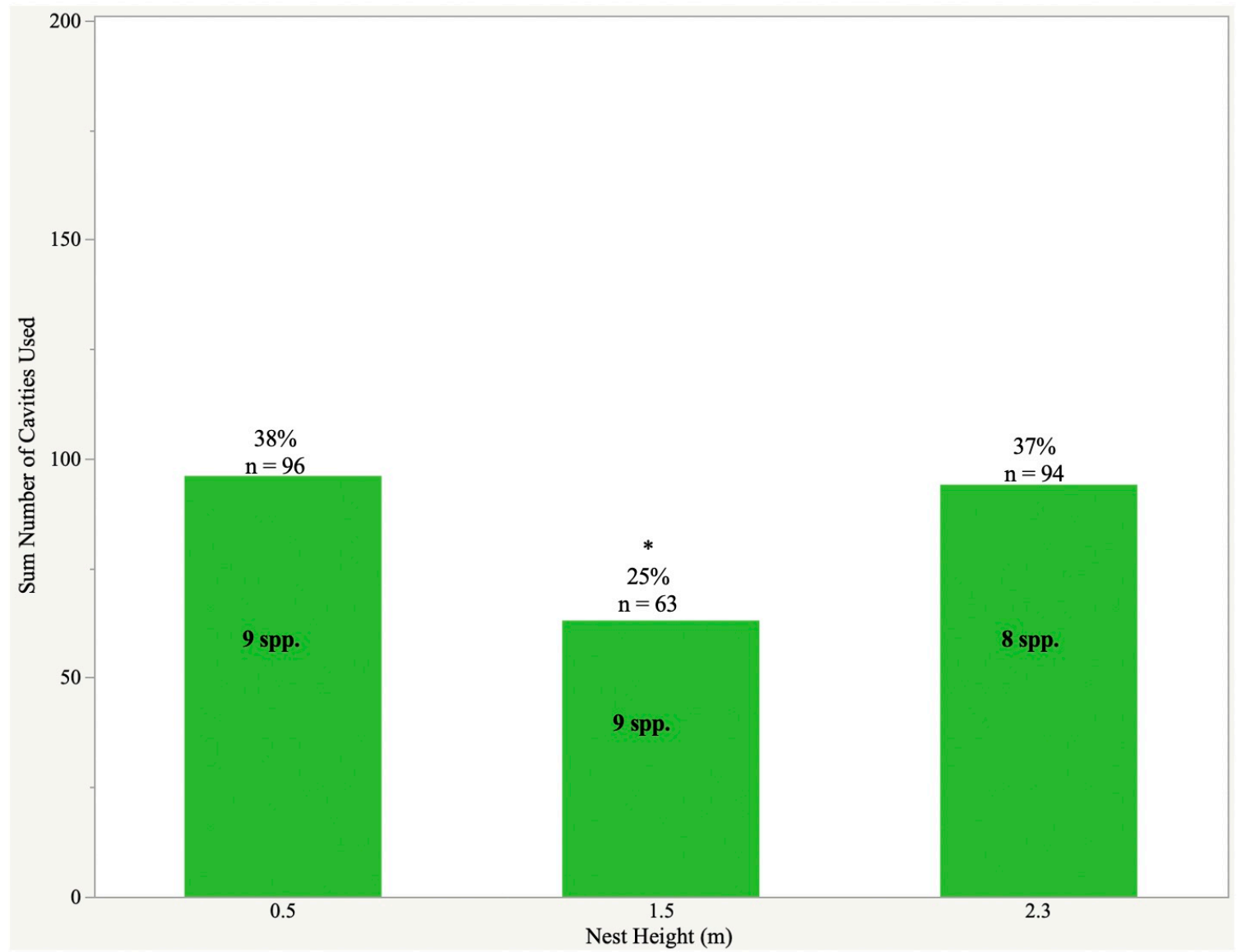

Figure 1.13: Nest heights used by all bee species. Nest height analysis using Poisson regression shows that compared to $0.5 \mathrm{~m}$, nest blocks at heights of $1.5 \mathrm{~m}(\mathrm{p}=0.009$; slope $=-0.421)$ were occupied significantly less. Chi square test of independence supports that there was a significant difference in use between heights $X^{2}(2, n=253)=63.211, \mathrm{p}<0.001$. 


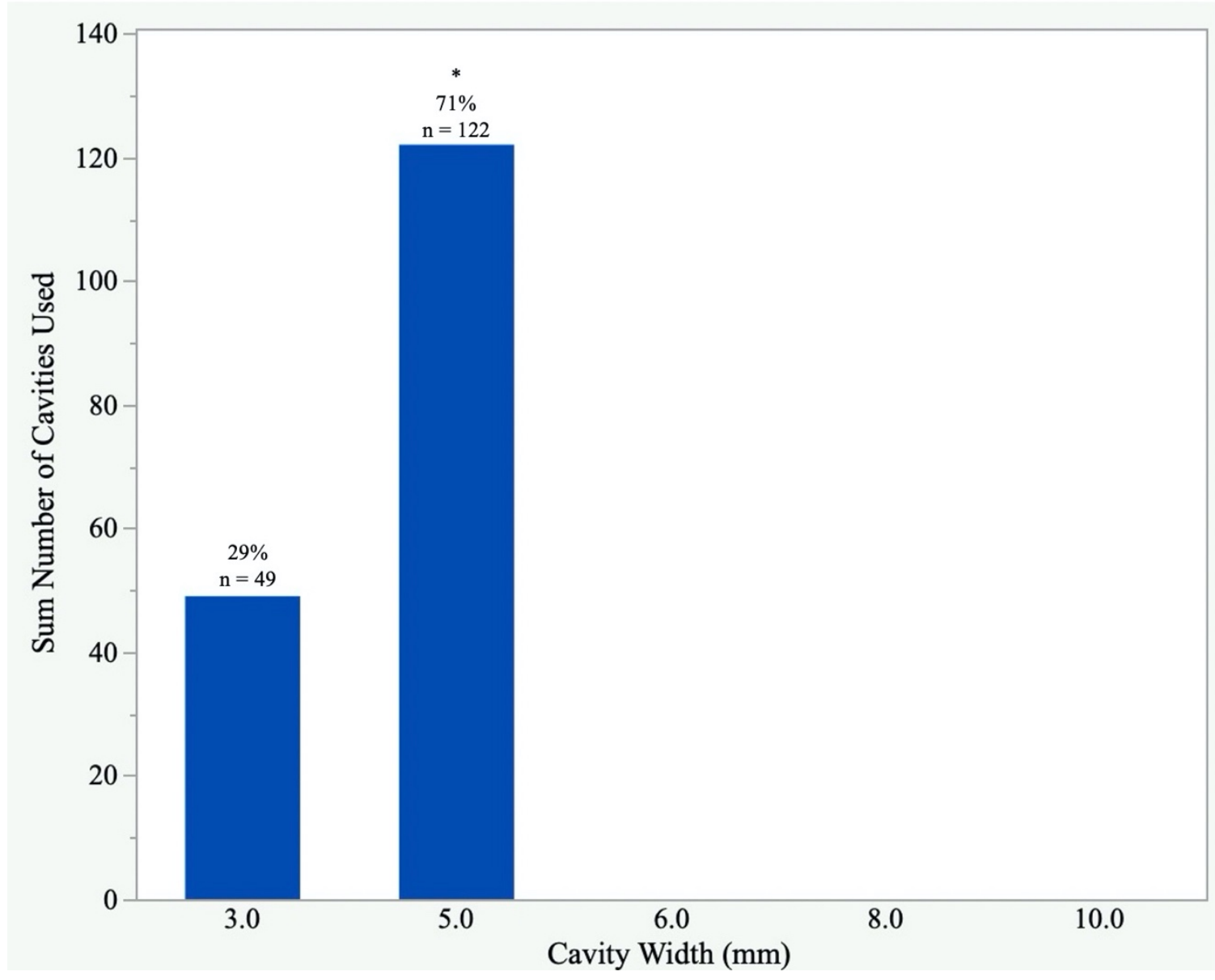

Figure 1.14: Cavity width use by Megachile angelarum. Cavity diameter analysis using Poisson regression shows that compared to $3.0 \mathrm{~mm}$, cavities of $5.0 \mathrm{~mm}(\mathrm{p}<0.001$; slope $=0.912)$ were occupied significantly more. Chi square test of independence supports that there was a significant difference in use between these two cavity widths $X^{2}(1, n=171)=57.723, \mathrm{p}<0.001$. 


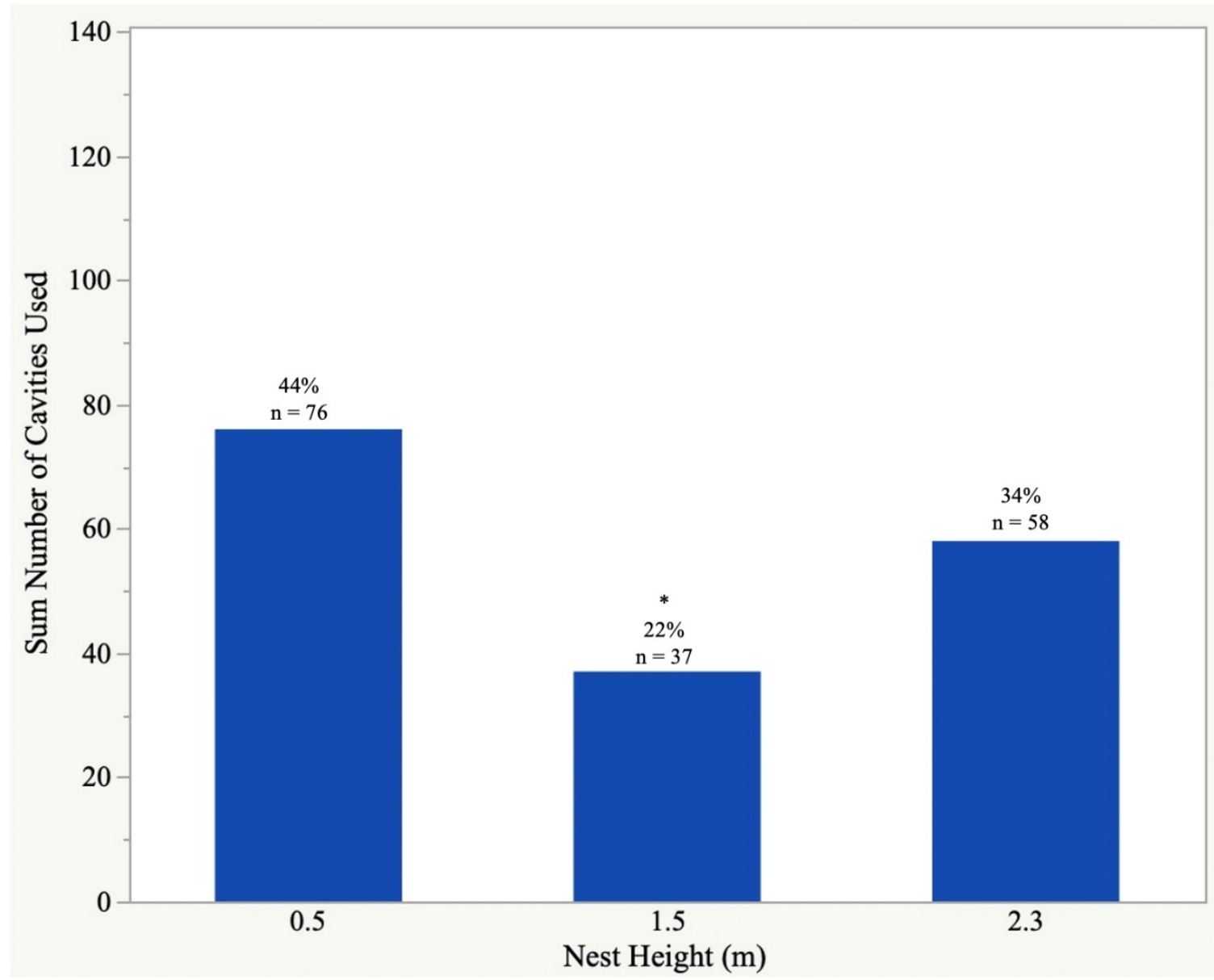

Figure 1.15: Nest height use by Megachile angelarum. Nest height analysis using Poisson regression shows that compared to $0.5 \mathrm{~m}$, nest blocks at heights of $1.5 \mathrm{~m}(\mathrm{p}=0.0003$; slope $=-0.720)$ were occupied significantly less. Chi square test of independence supports that there was a significant difference in use between heights $X^{2}(2, n=171)=23.638, \mathrm{p}<0.001$. 


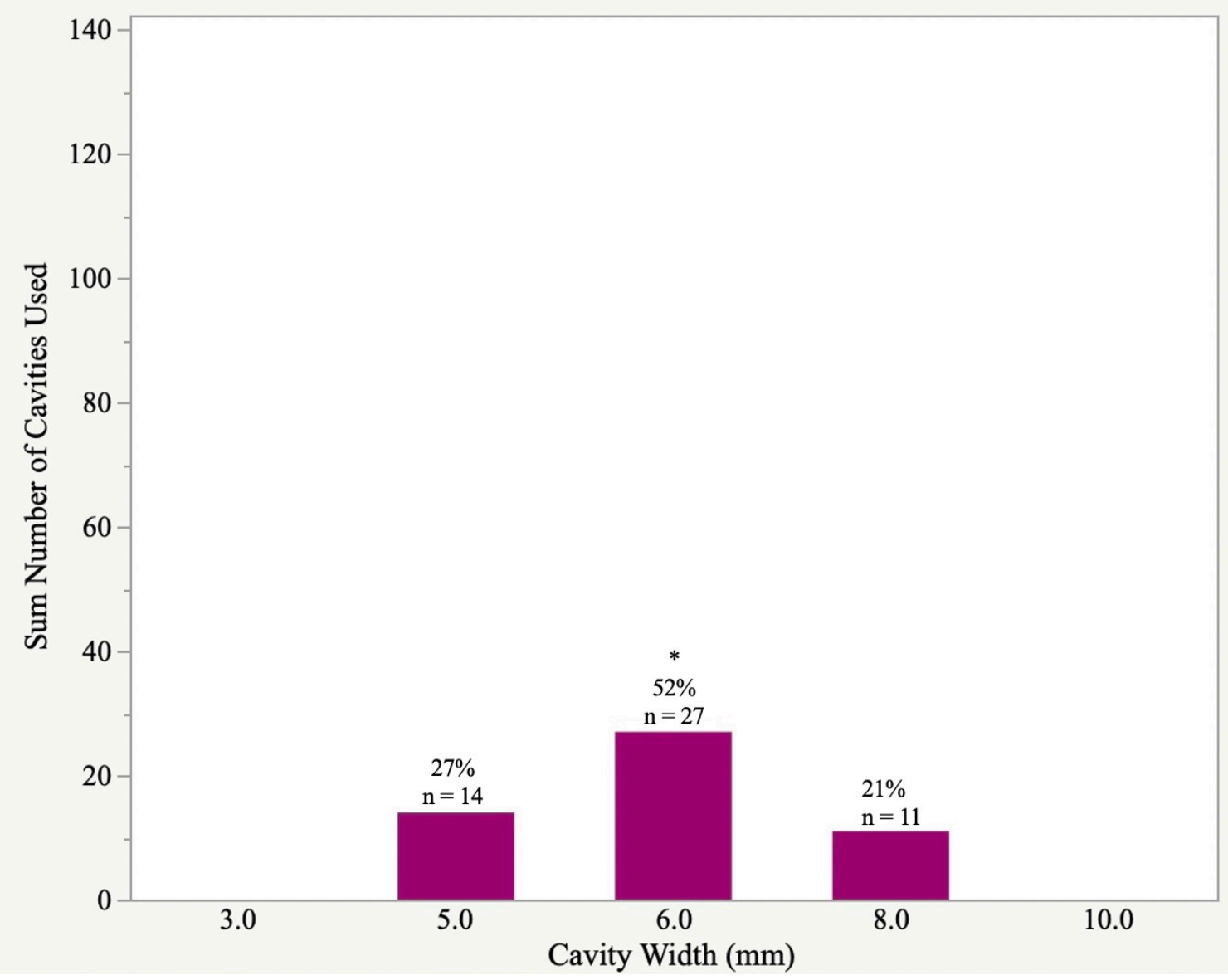

Figure 1.16: Cavity widths used by Osmia lignaria propinqua. Cavity width analysis using Poisson regression shows that there was no significant difference in occupancy between $5.0,6.0$, and $8.0 \mathrm{~mm}$ cavities, $p>0.05$. However, Chi square test of independence shows that there was a significant difference in use between these three cavity widths $X^{2}(2, n=52)=8.818, \mathrm{p}=0.012$. 


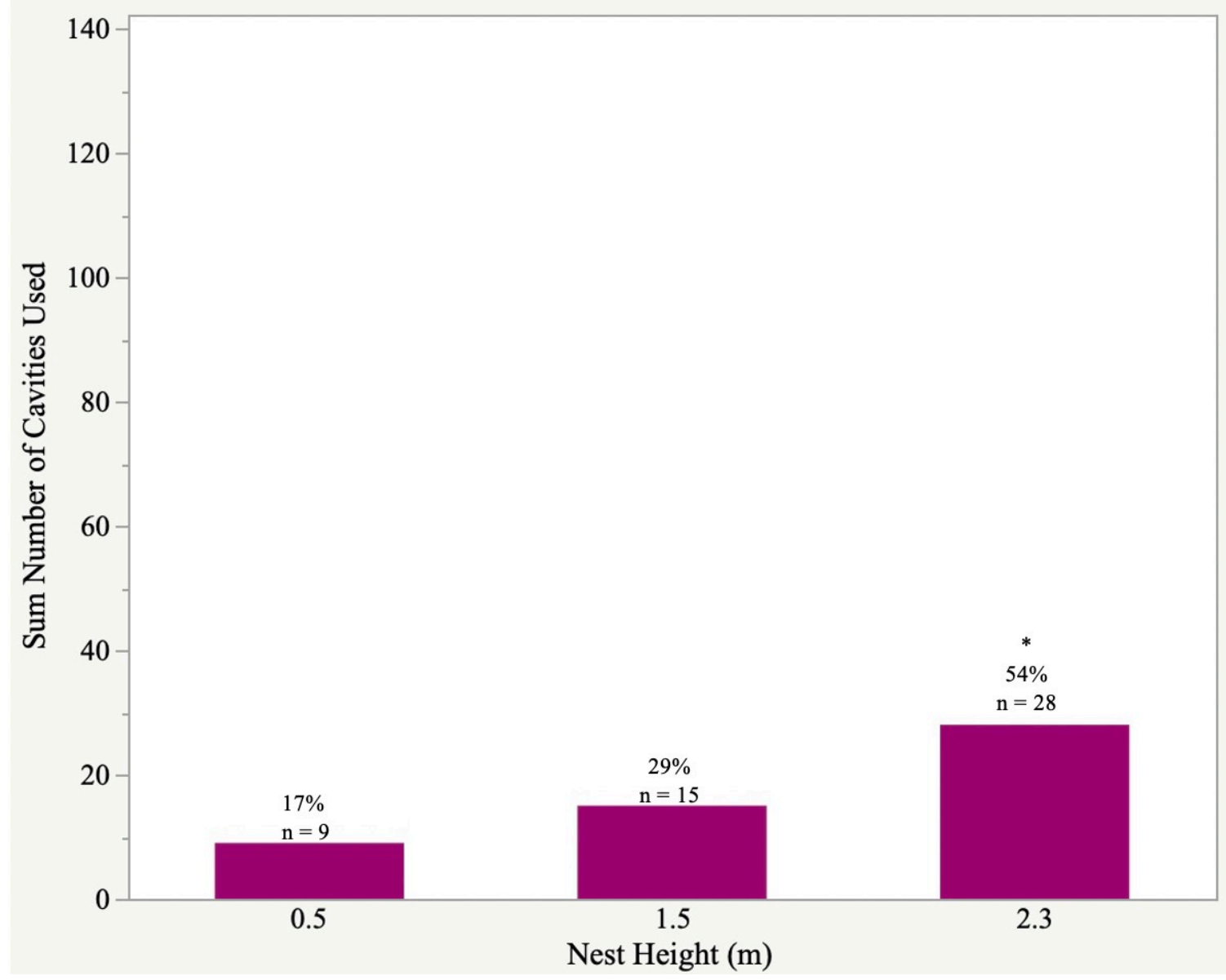

Figure 1.17: Nest heights used by Osmia lignaria propinqua. Nest height analysis using Poisson regression shows that compared to $0.5 \mathrm{~m}$, nest blocks at heights of $2.3 \mathrm{~m}(\mathrm{p}=0.003$; slope $=1.135)$ were occupied significantly more. Chi square test of independence supports that there was a significant difference in use between heights $X^{2}(2, n=52)=7.564, \mathrm{p}=0.023$. 


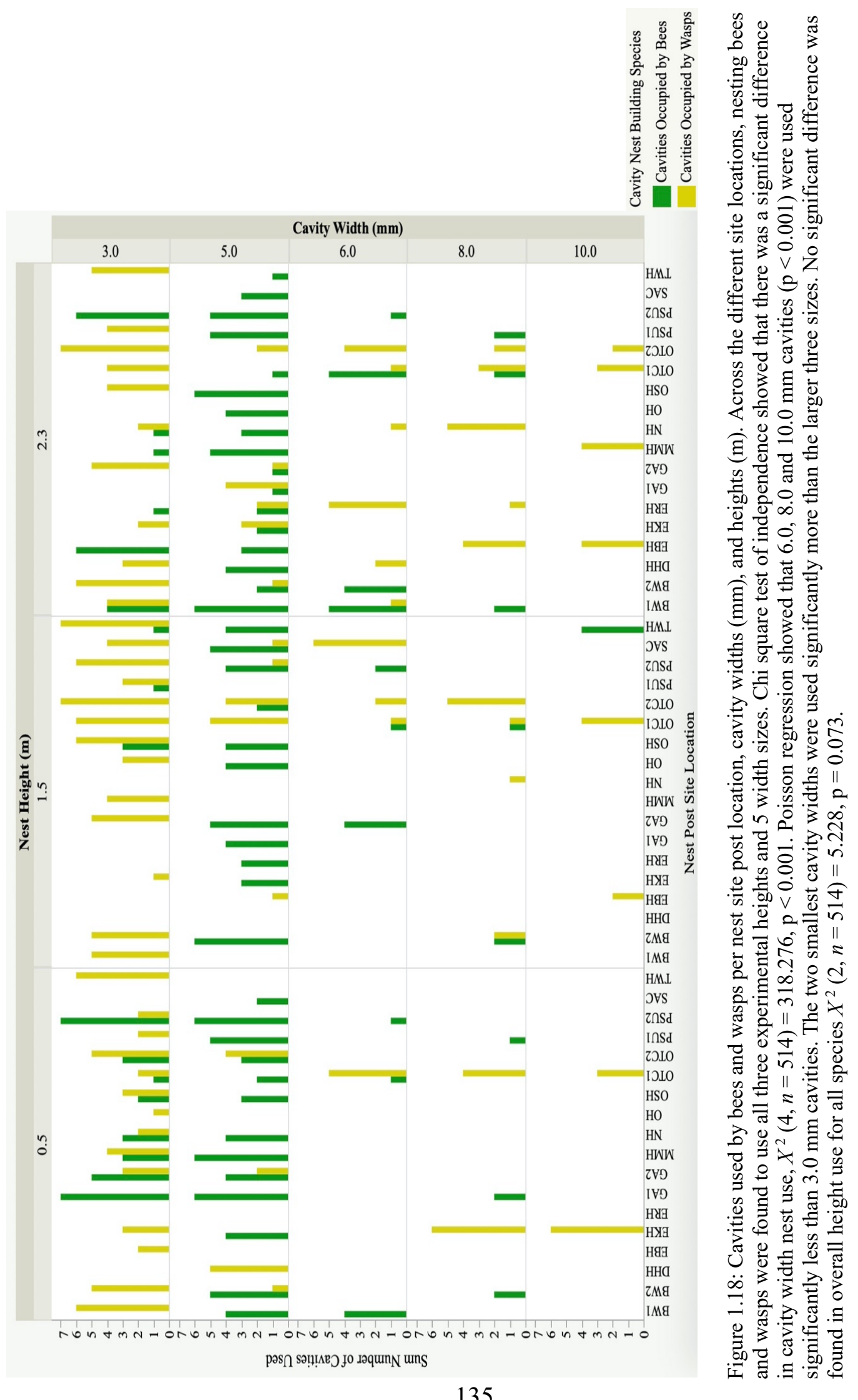




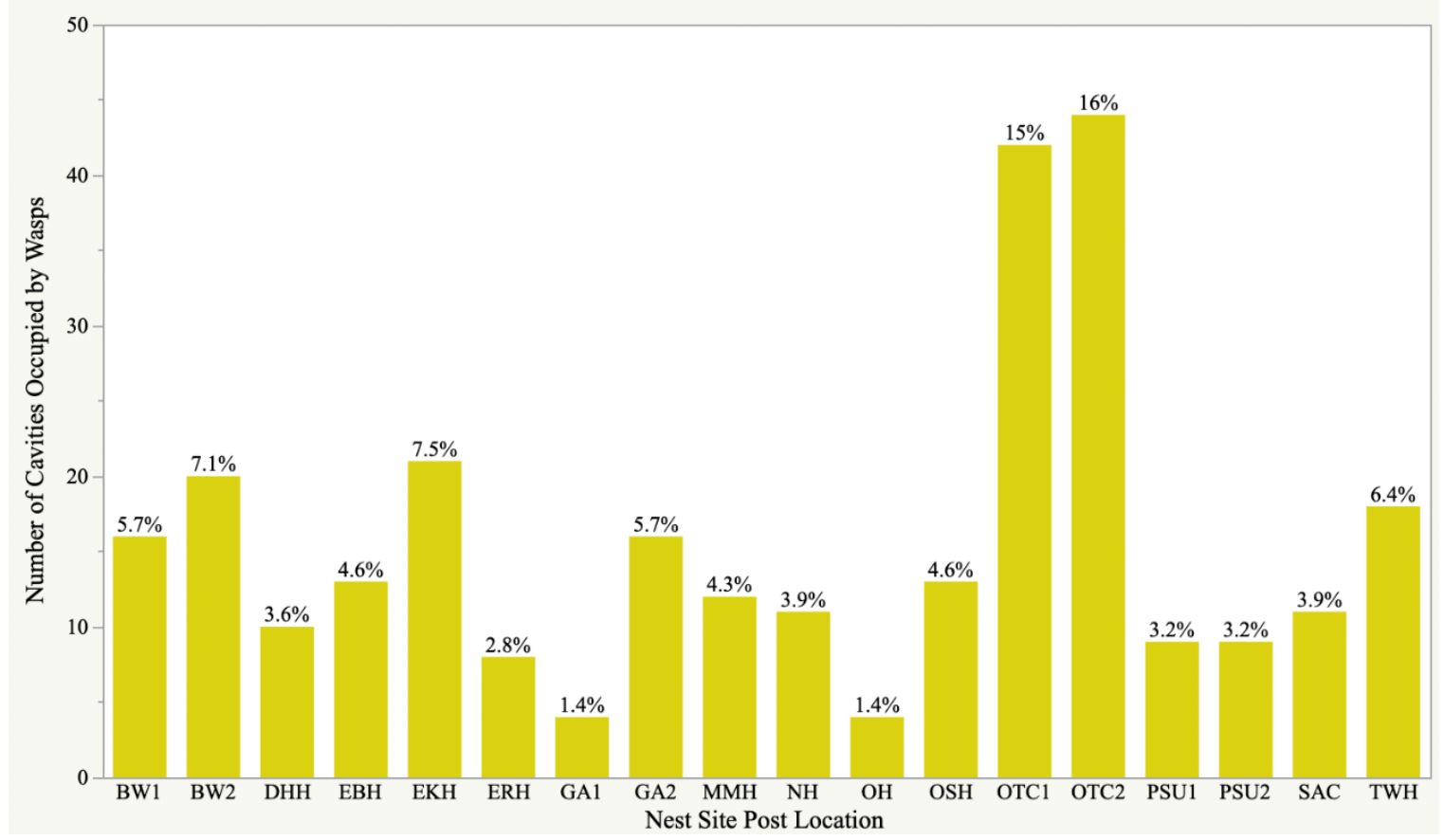

Figure 1.19: Number of cavities occupied by nest building wasps per nest site post location. The sum number of cavities wasps used are graphed and the percentages above are calculated out of the 281 cavities that these wasps occupied. 


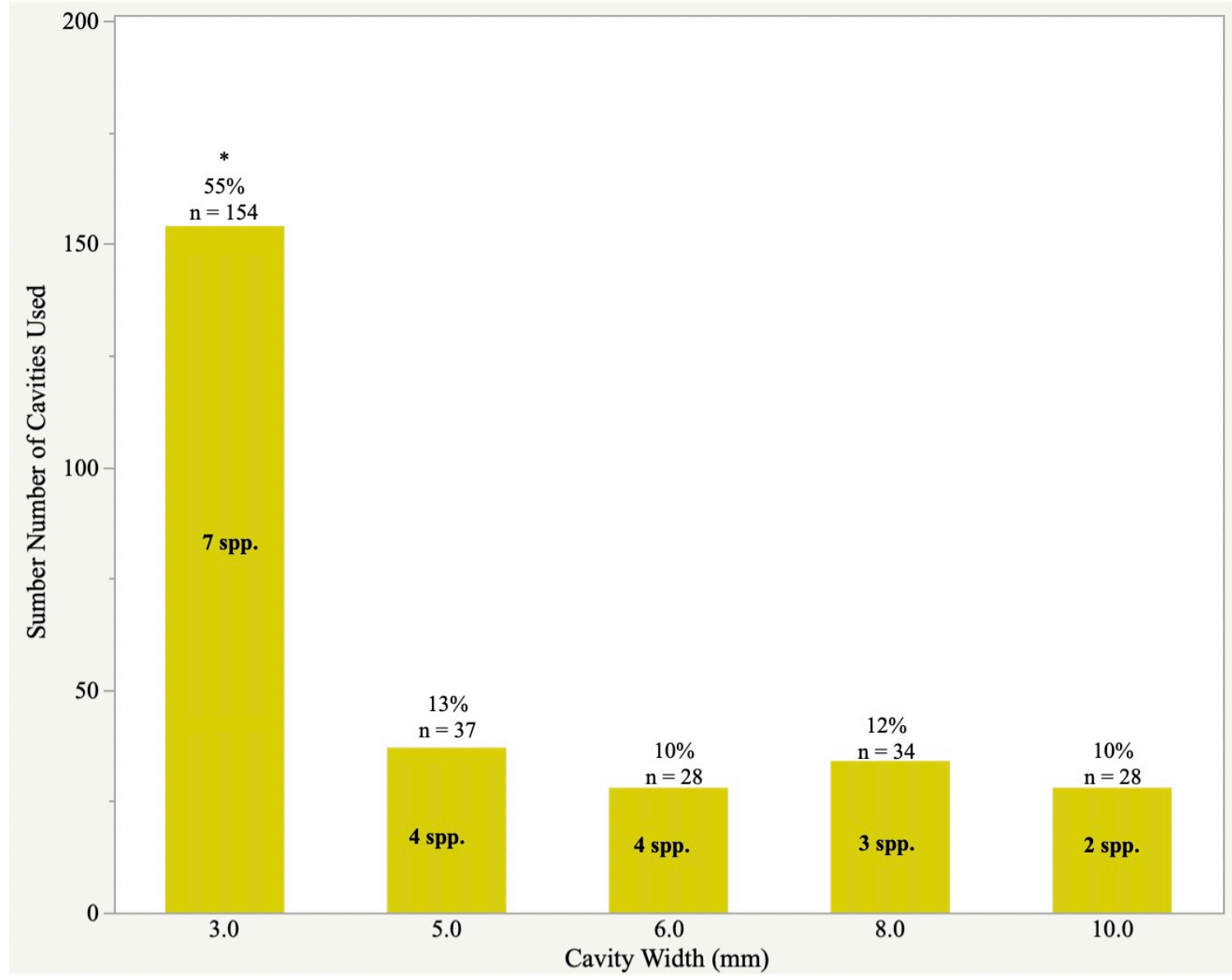

Figure 1.20: Cavity widths used by all nest building wasp species. Cavity diameter analysis using Poisson regression shows that compared to $3.0 \mathrm{~mm}$, that all other cavities were occupied significantly less ( $\mathrm{p}<$ $0.001)$. Chi square test of independence supports that there was a significant difference in use between cavity widths $X^{2}(4, n=281)=158.7335, \mathrm{p}<0.001$. 


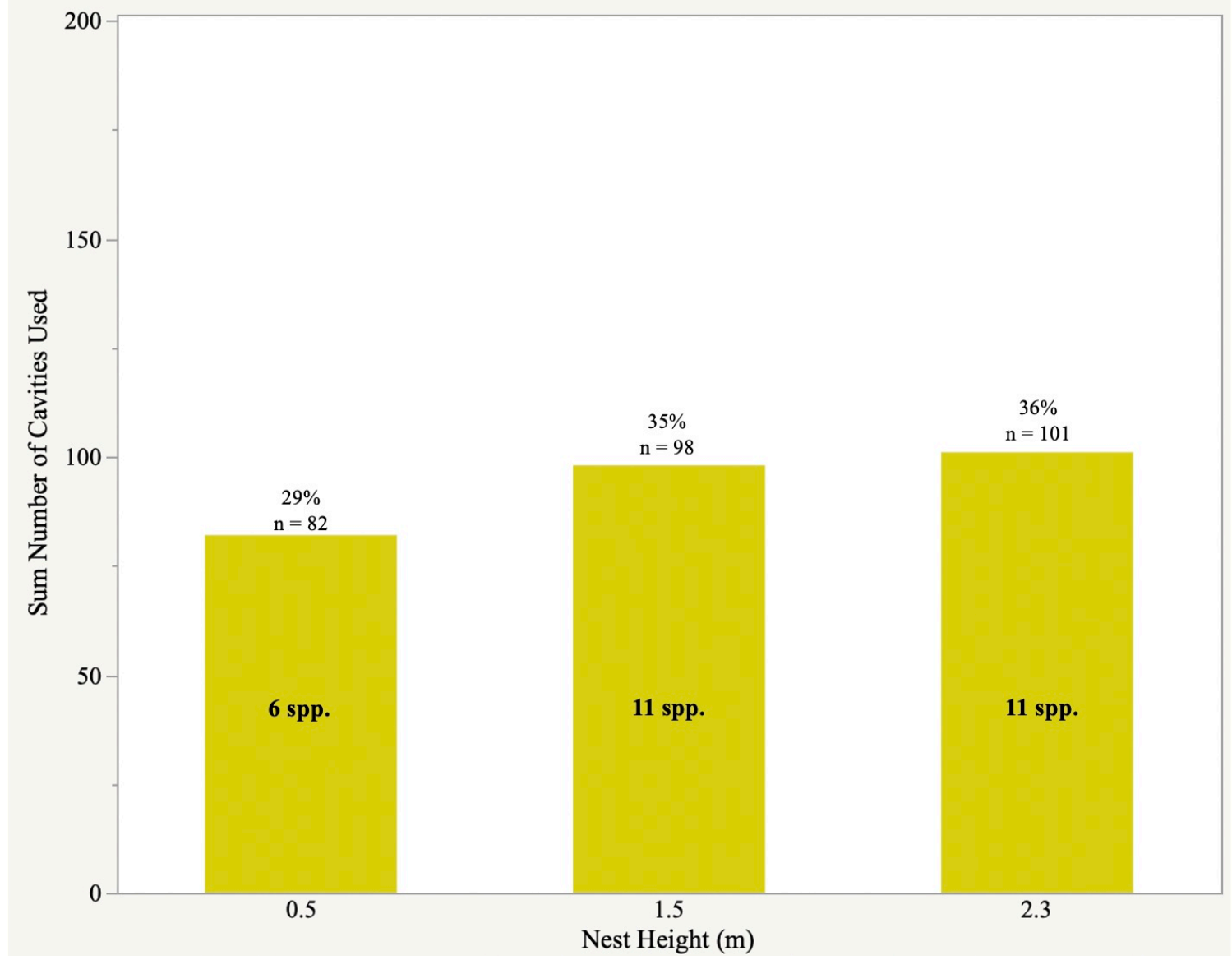

Figure 1.21: Nest heights used by all nest building wasp species. Nest height analysis using Poisson regression shows that compared to $0.5 \mathrm{~m}$, nest blocks at heights of $1.5 \mathrm{~m}$ and $2.3 \mathrm{~m}$ were not statistically different in their occupancy rates $(\mathrm{p}>0.10)$. Chi square test of independence supports that there was no significant difference in use between heights $X^{2}(2, n=281)=5.9146, \mathrm{p}=0.051959$. 


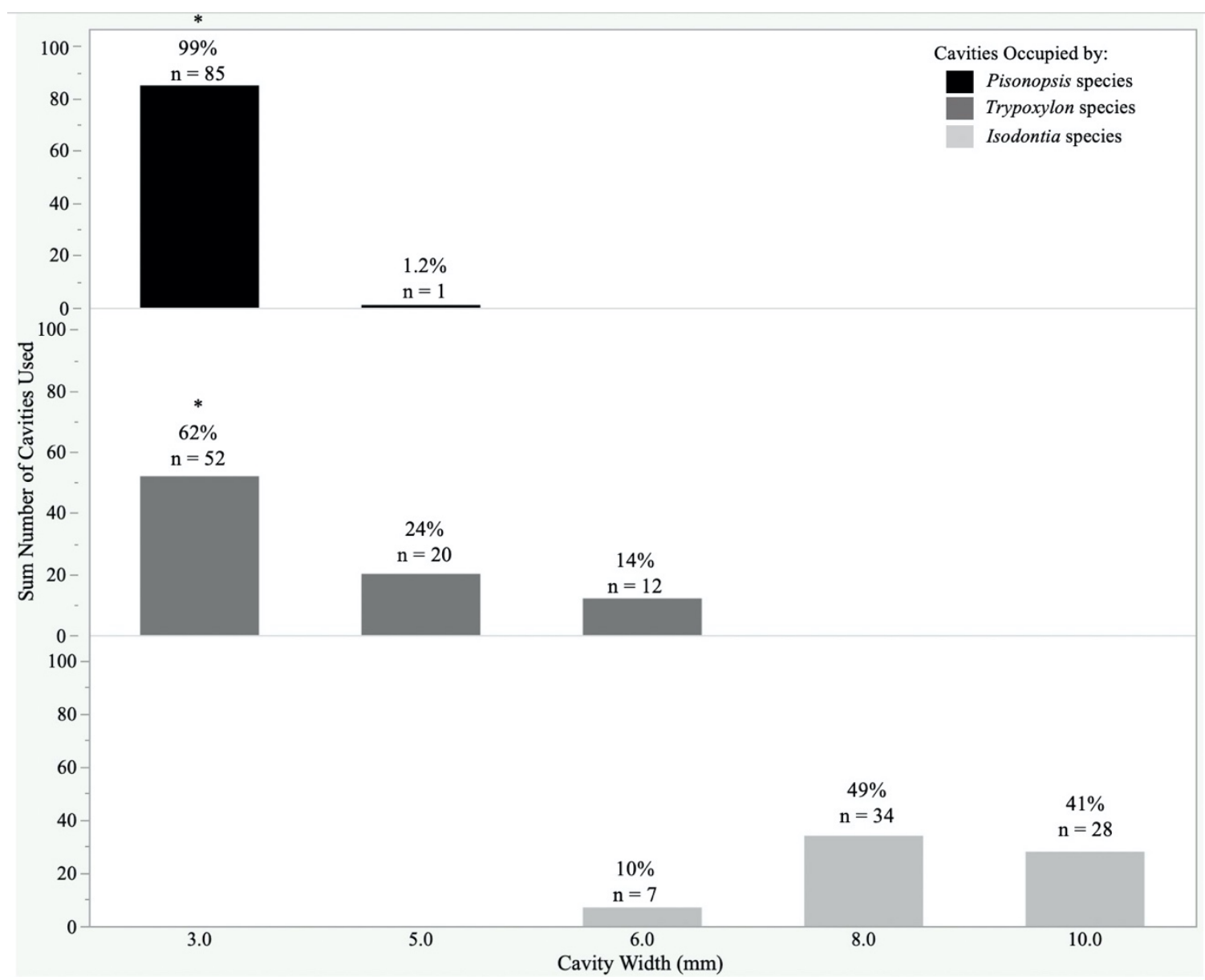

Figure 1.22: Cavity width used by common wasp genera including Pisonopsis sp., Trypoxylon spp., and Isodontia spp. Pisonopsis sp. wasps used $5.0 \mathrm{~mm}$ cavities significantly less than that of $3.0 \mathrm{~mm}$ (Poisson regression, $\mathrm{p}$ value $<0.001$ and slope $=-4.443)$ and chi square test of independence supports that there was a significant difference in use $X^{2}(1, n=86)=99.519, \mathrm{p}<0.001$. For Trypoxylon spp. cavity use, chi square test of independence supports that there was a significant difference, $X^{2}(2, n=84)=15.604, \mathrm{p}=0.0004$; and Poisson regression showed that $5.0 \mathrm{~mm}$ cavity widths $(\mathrm{p}=0.0003$ and slope $=-0.956)$ and $6.0 \mathrm{~mm}$ cavity widths $(\mathrm{p}<0.001$ and slope -1.466$)$, were used significantly less than $3.0 \mathrm{~mm}$. For Isodontia spp., chi square test of independence supports that there was a significant difference, $X^{2}(2, n=69)=62.483$, $\mathrm{p}<$ 0.001 . 


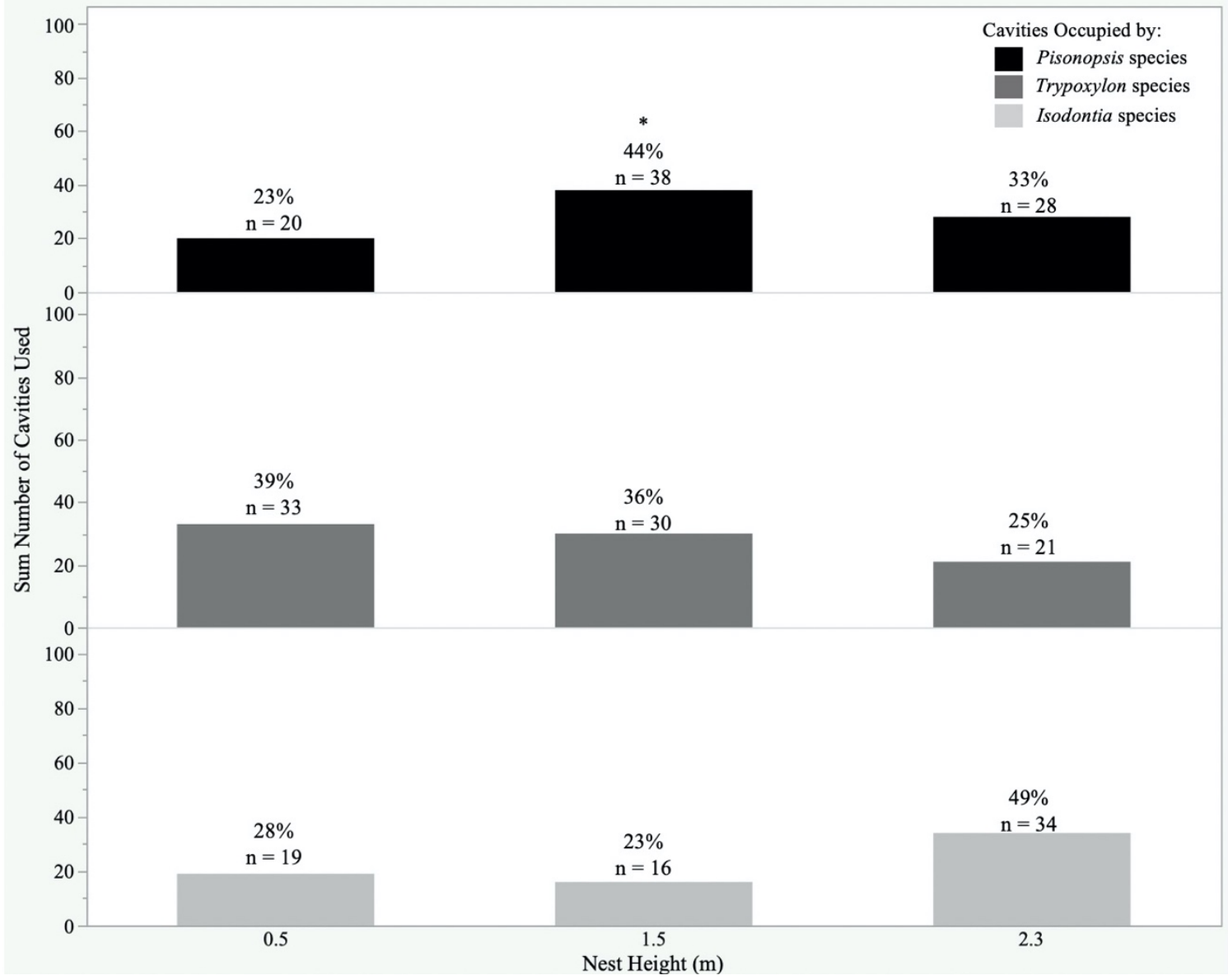

Figure 1.23: Nest height use by common wasp genera including Pisonopsis sp., Trypoxylon spp., and Isodontia spp. Pisonopsis $\mathrm{sp}$. nest heights at $1.5 \mathrm{~m}$ were used significantly more than $0.5 \mathrm{~m}$ (p value $=$ 0.0202 and slope $=0.642$ ) and chi square test of independence supports that there was a significant difference in use $X^{2}(1, n=86)=8.712, \mathrm{p}=0.013$. No significant difference in Trypoxylon spp. nest height use $(\mathrm{p}>0.10)$. No significant difference in nest height use by Isodontia spp. $(\mathrm{p}>0.05)$. 


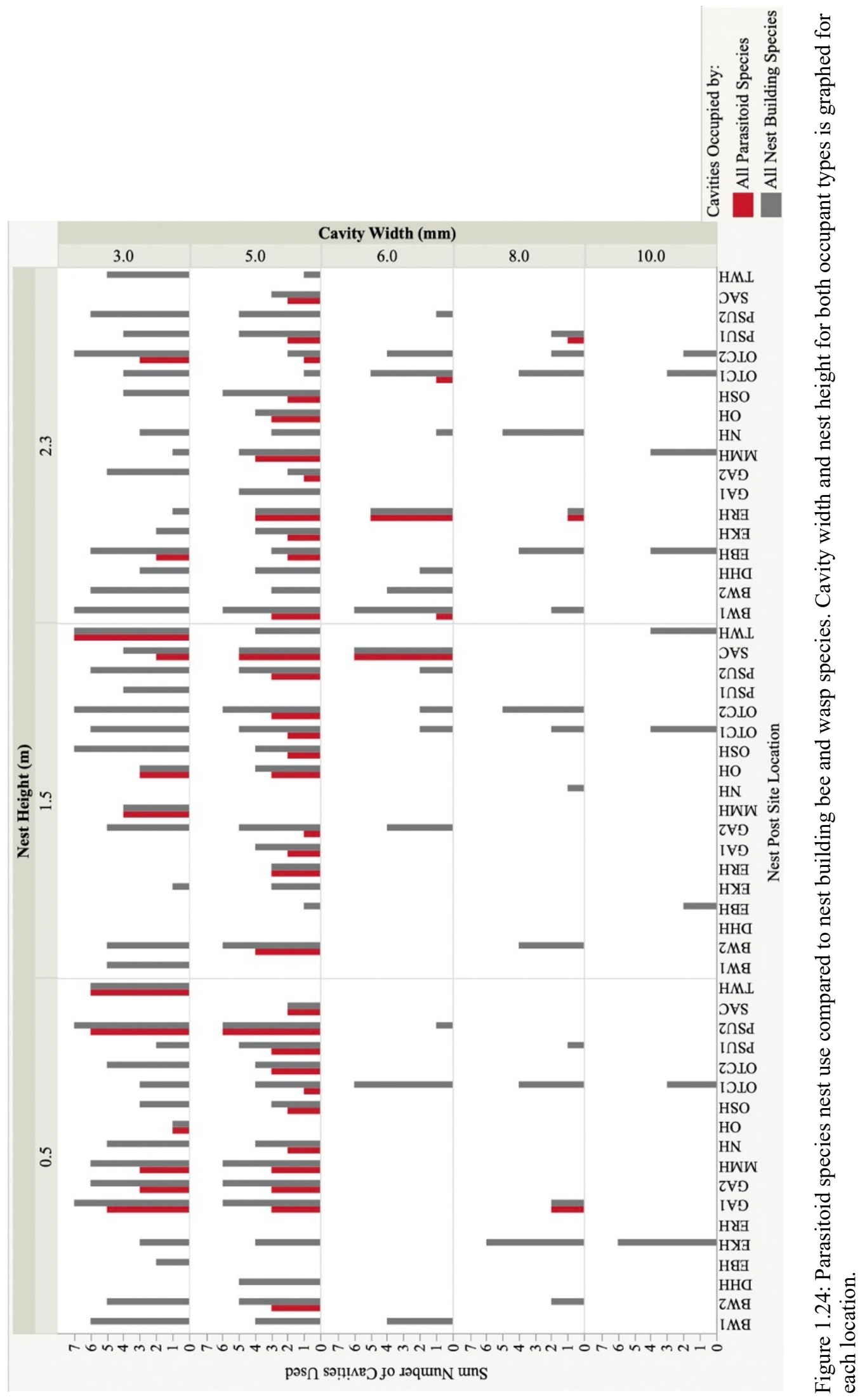




\section{Chapter 2}

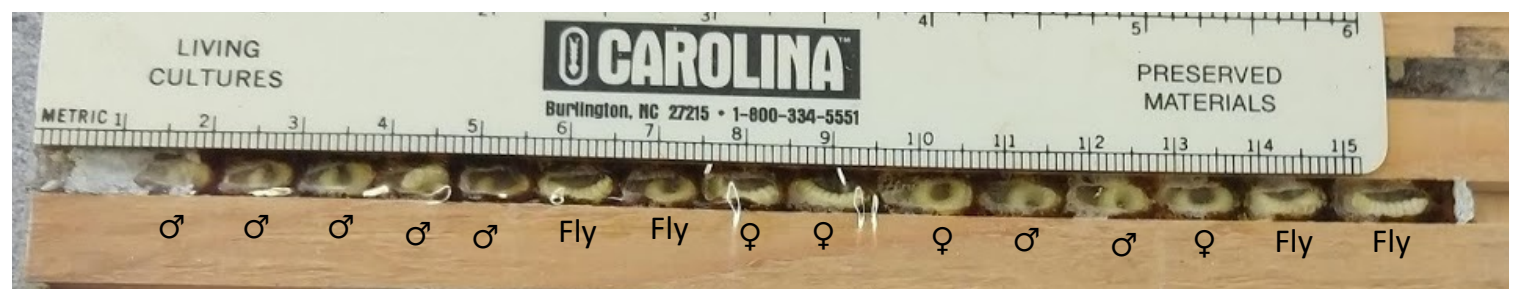

Figure 2.1: Cell position of Megachile angelarum. The position of female (ㅇ) and male ( $\left.\delta^{1}\right)$ Megachile angelarum, and parasitoid flies, Anthrax irroratus are shown under each cell. This is a $5.0 \mathrm{~mm}$ cavity nest from North Portland natural site, Baltimore Woods. Red resinous plant material was used as nesting material for the cell partitions separating the prepupa larvae. 


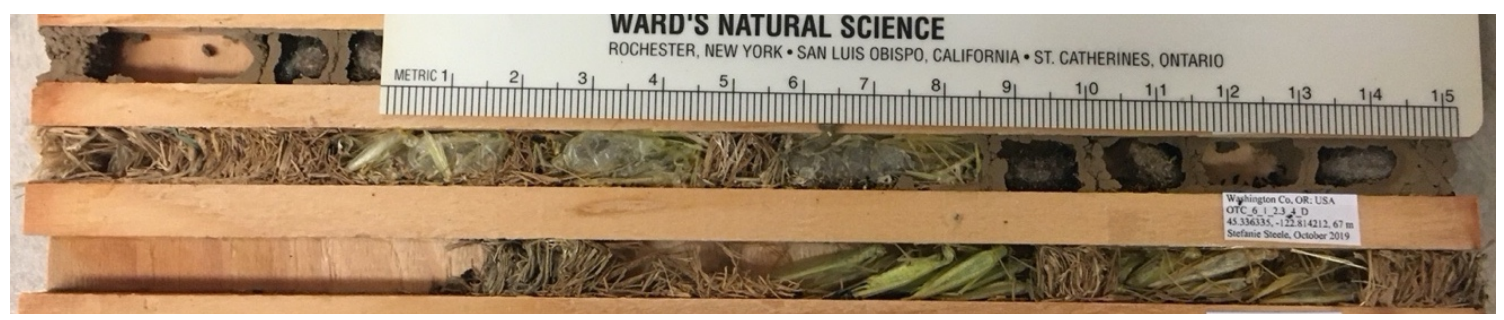

Figure 2.2. Osmia lignaria propinqua superseded by Isodontia elegans in an $8.0 \mathrm{~mm}$ cavity of a $2.3 \mathrm{~m}$ nest block at organic farm site OTC. O. l. propinqua built nest in row above the superseded nest and I. elegans in the row below.

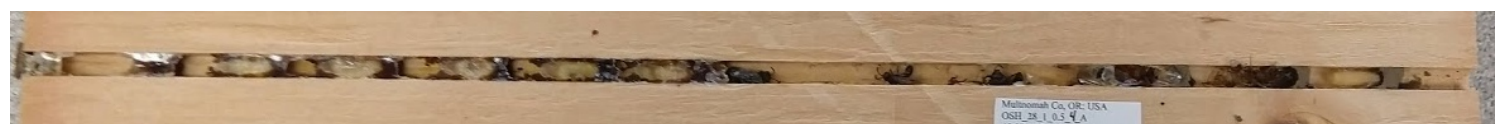

Figure 2.3. Megachile angelarum superseded two wasp species. Two wasp species, Trypoxylon frigidum and Pemphredoninae sp., nested in the first $2 / 3$ of the nest and Megachile angelarum in the final third, completing the $3.0 \mathrm{~mm}$ cavity nest in a 0.5 nest block at residential garden site $\mathrm{OSH}$. Three Pemphredoninae sp. adults in this nest appear to have emerged, but were likely trapped by the other nesting species.

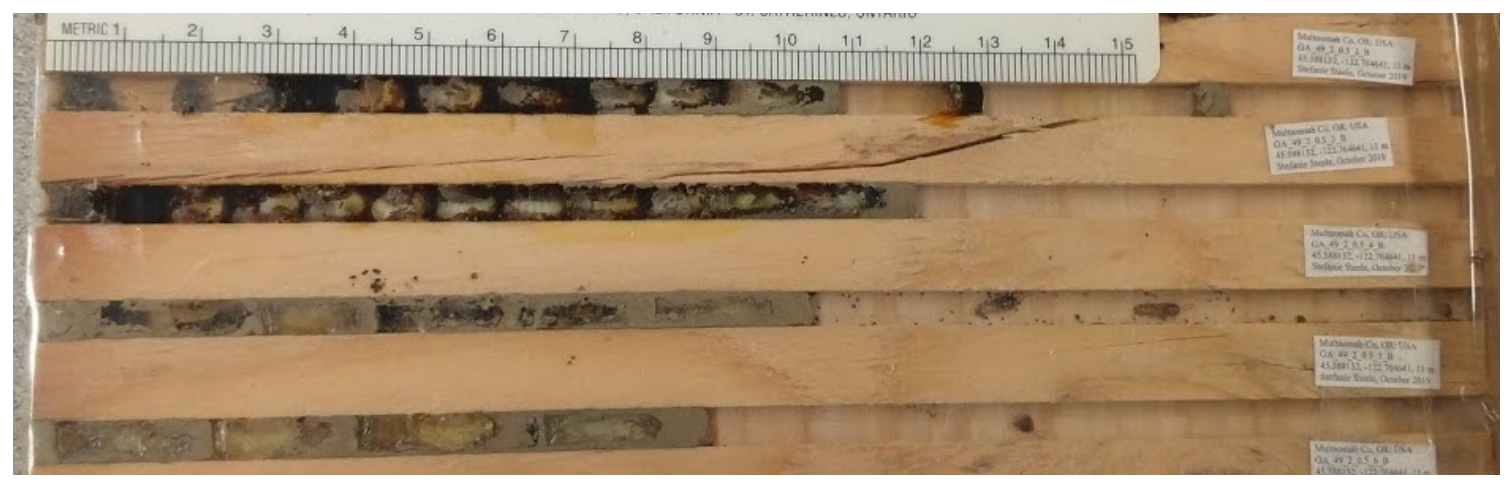

Figure 2.4. Evidence of nest competition between Eumeninae wasps and Megachile angelarum. M. angelarum nested in the above two cavity rows and Eumeninae sp. in the bottom two. Presence of mud preliminary plug and mud partitions mixed with resin is evidence that Eumeninae wasps attempted to build nests where $M$. angelarum nested. Cavities were $5.0 \mathrm{~mm}$ in nest blocks at $0.5 \mathrm{~m}$ at educational garden site GA.

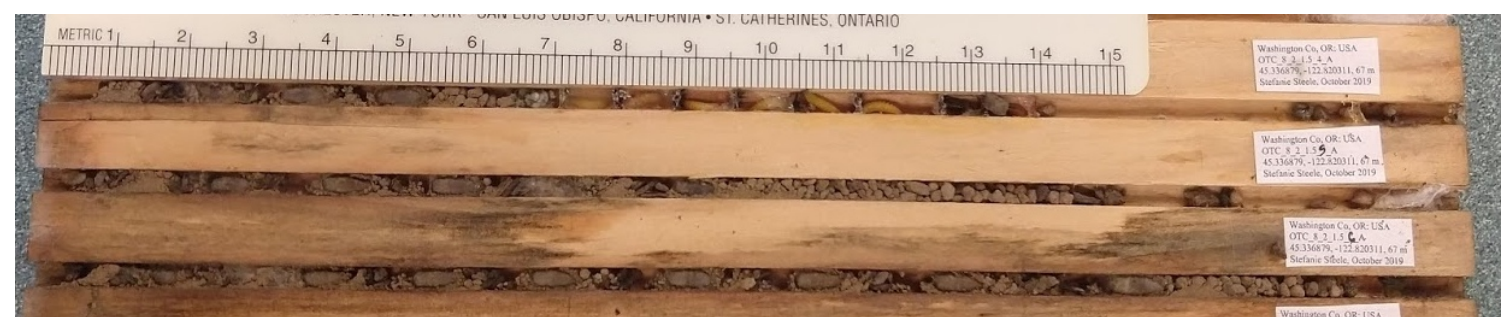

Figure 2.5. Evidence of nest competition between Pemphredoninae resin sp. and Pisonopsis sp. Two wasp species, Pemphredoninae sp. with thin resin and visible larvae and Pisonopsis sp. using loose balls of dirt and other detritus nested in the same $3.0 \mathrm{~mm}$ cavity in a nest block at $1.5 \mathrm{~m}$ at organic farm site OTC. Balls of dirt are sparsely visible in the back of nest, as if Pisonopsis sp. had initially begun the nest. 


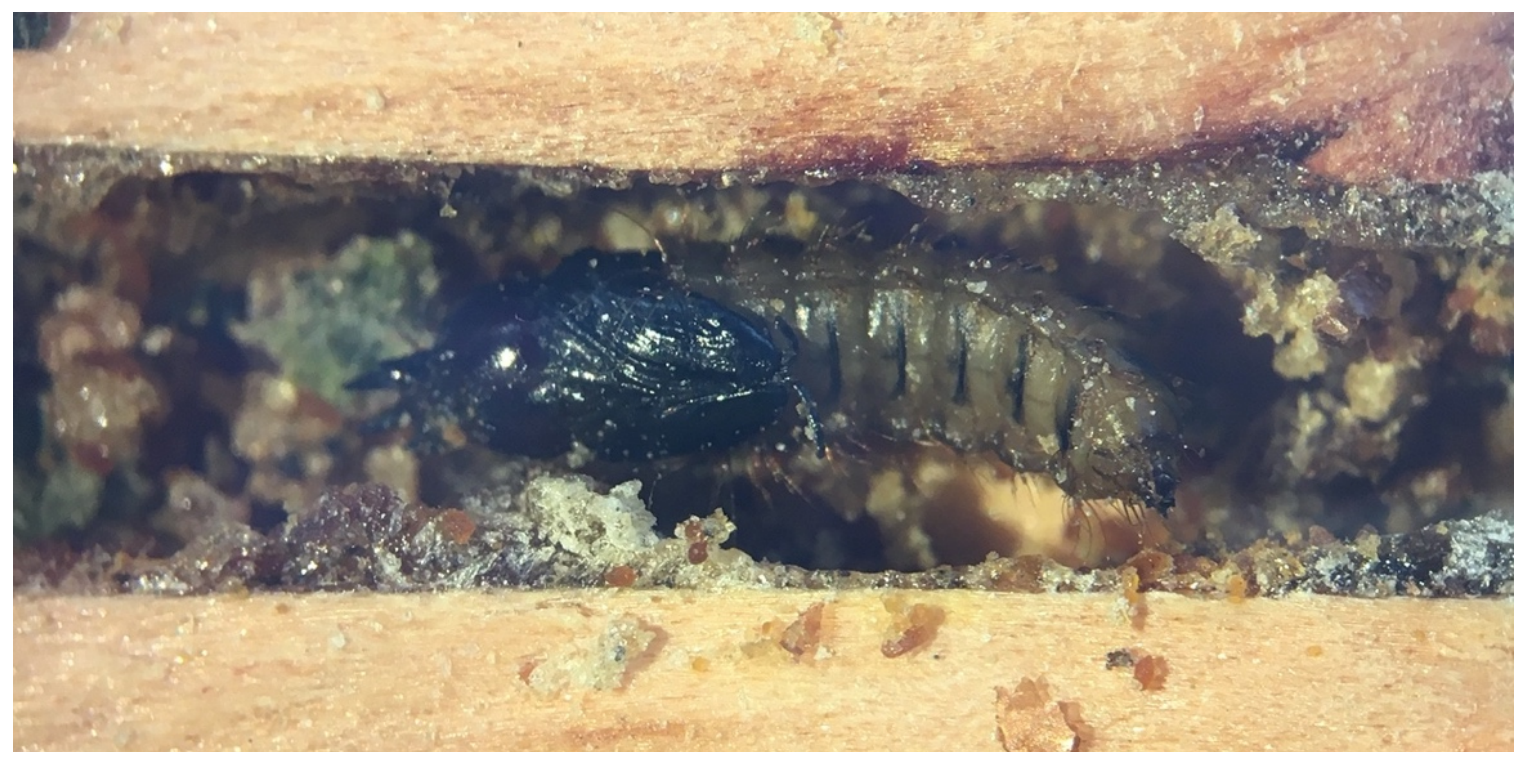

Figure 2.6: Parasitoid fly pupa of Anthrax irroratus moving through the resinous cell partitions built by host, Megachile angelarum in a $5.0 \mathrm{~mm}$ cavity.

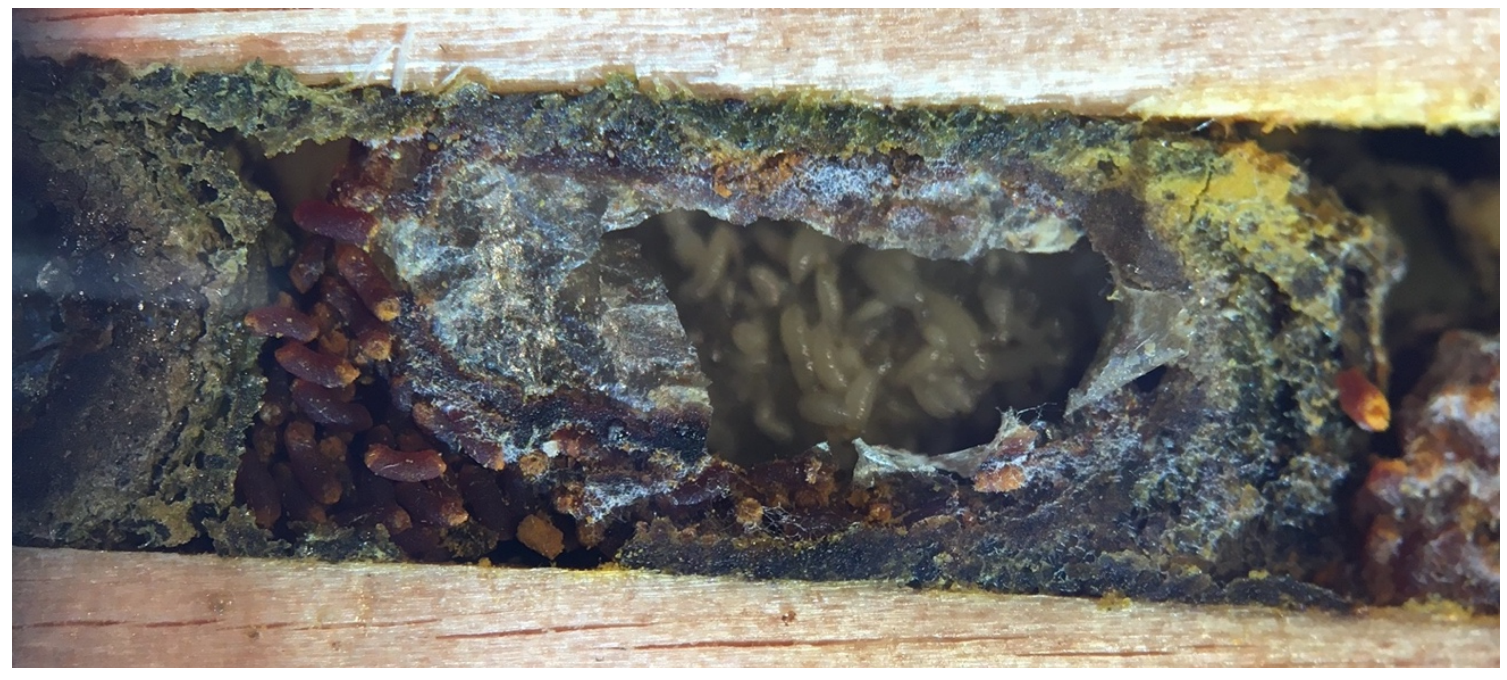

Figure 2.7: Parasitoid wasp larvae of Melittobia sp. on a Megachile fidelis larva host in a $5.0 \mathrm{~mm}$ cavity. 


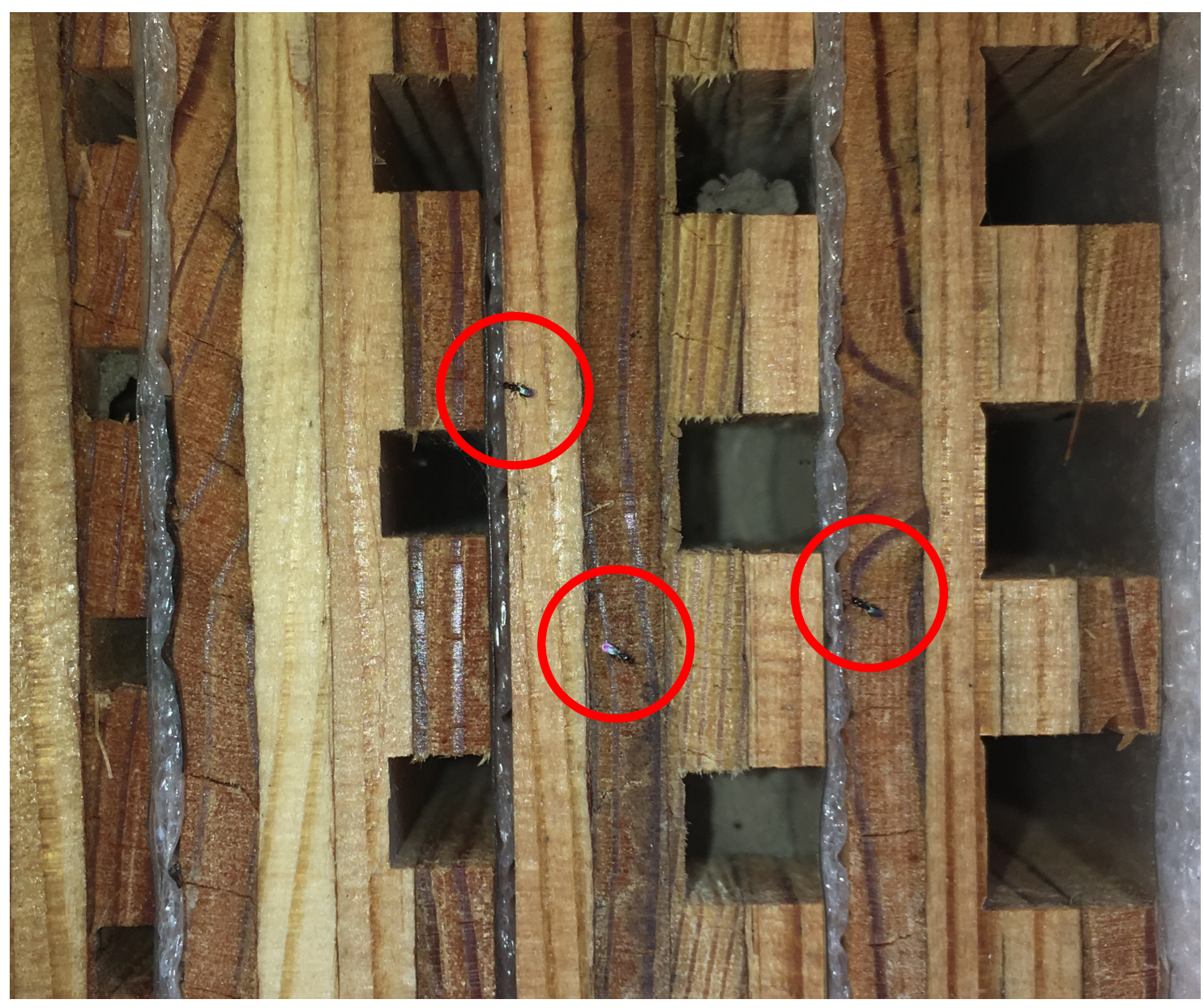

Figure 2.8: Parasitoid wasp adults, Melittobia sp. outside cavity nest entrances. 

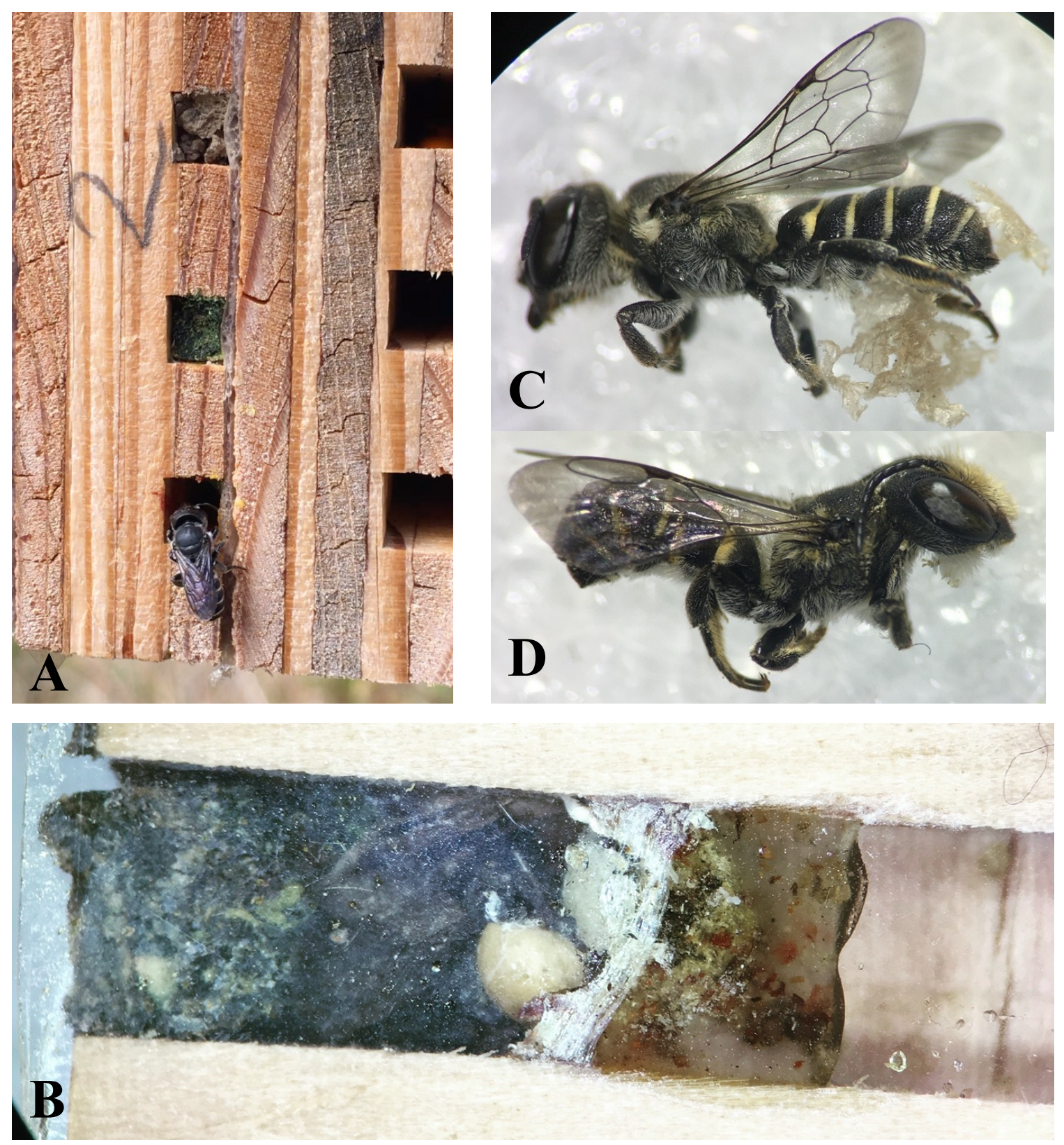

Figure 2.9: A.) Female Megachile angelarum returning to $5.0 \mathrm{~mm}$ cavity nest. Fresh green terminal plug material visible in cavity above this bee. B.) M. angelarum terminal nest plug showing innermost material plant resin, middle loose plant material, and outermost finely masticated leaves. C.) Female M. angelarum. D.) Male M. angelarum. 


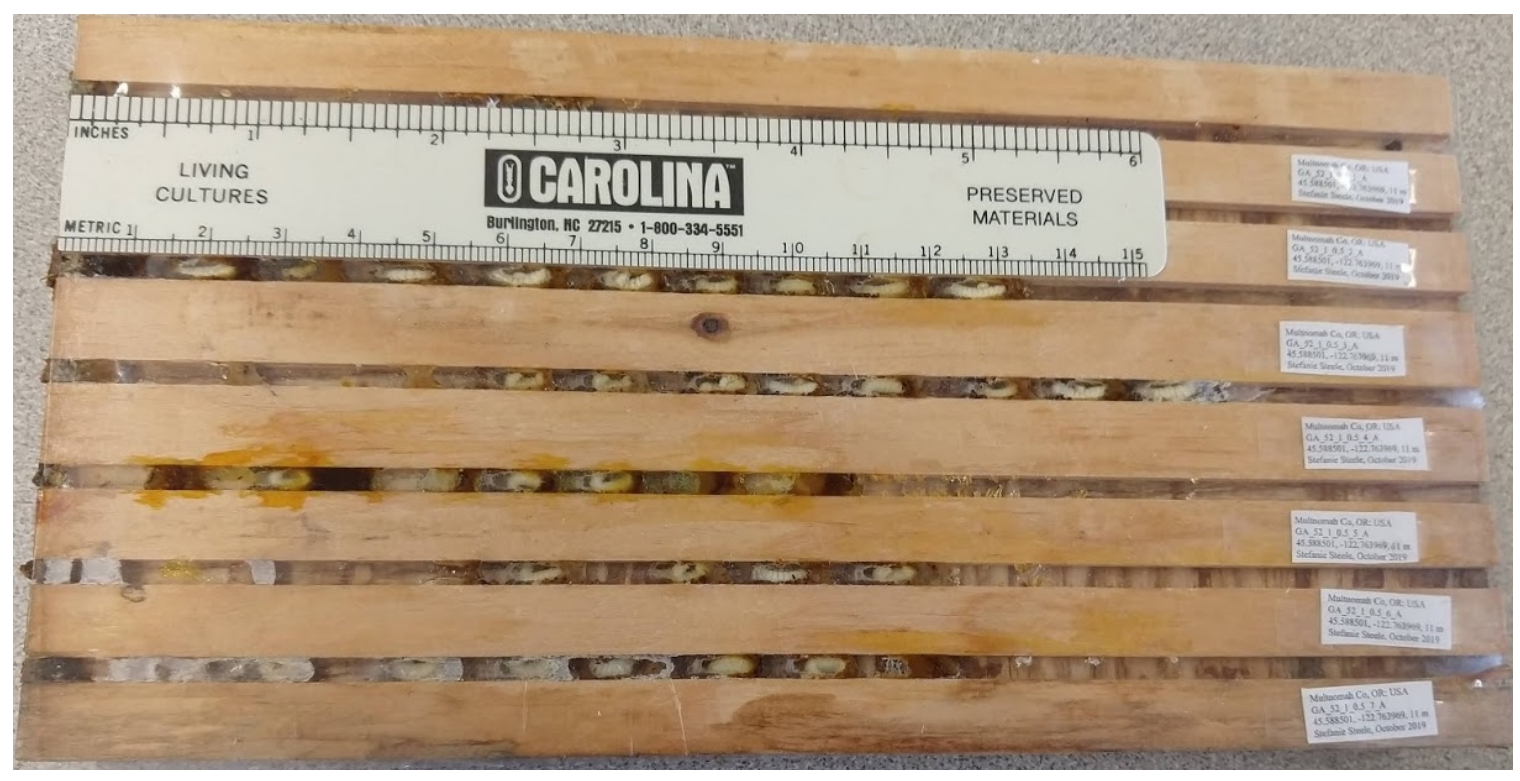

Figure 2.10: Megachile angelarum $3.0 \mathrm{~mm}$ cavity nests.

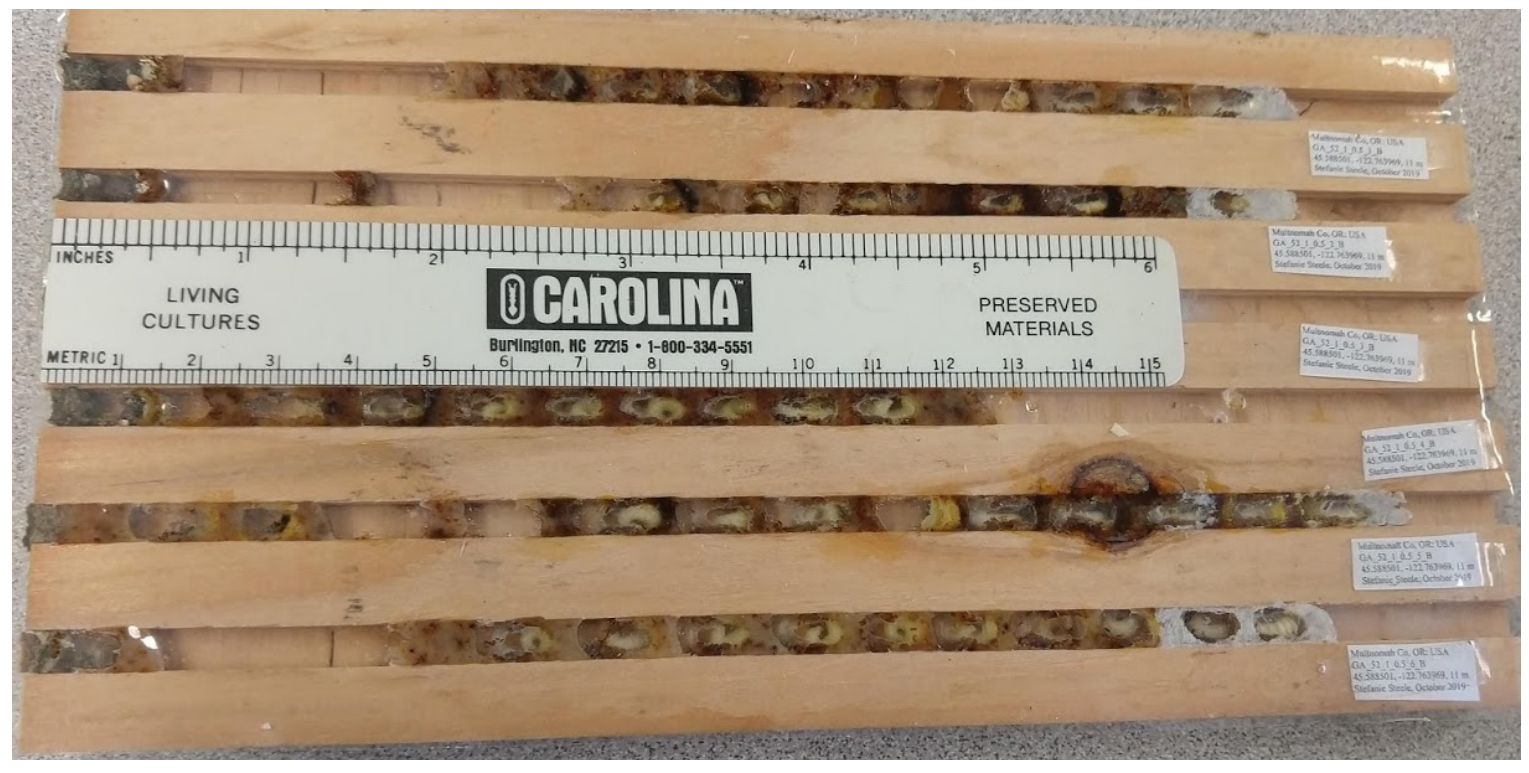

Figure 2.11: Megachile angelarum $5.0 \mathrm{~mm}$ cavity nests. 


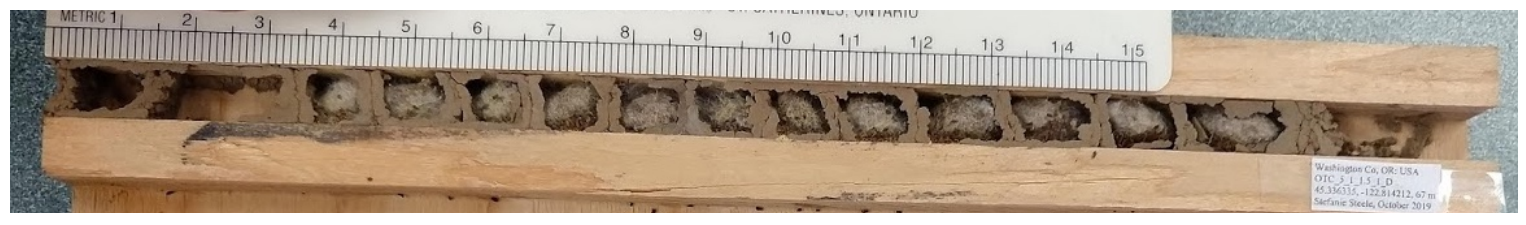

Figure 2.12: Osmia lignaria propinqua $8.0 \mathrm{~mm}$ cavity nest.

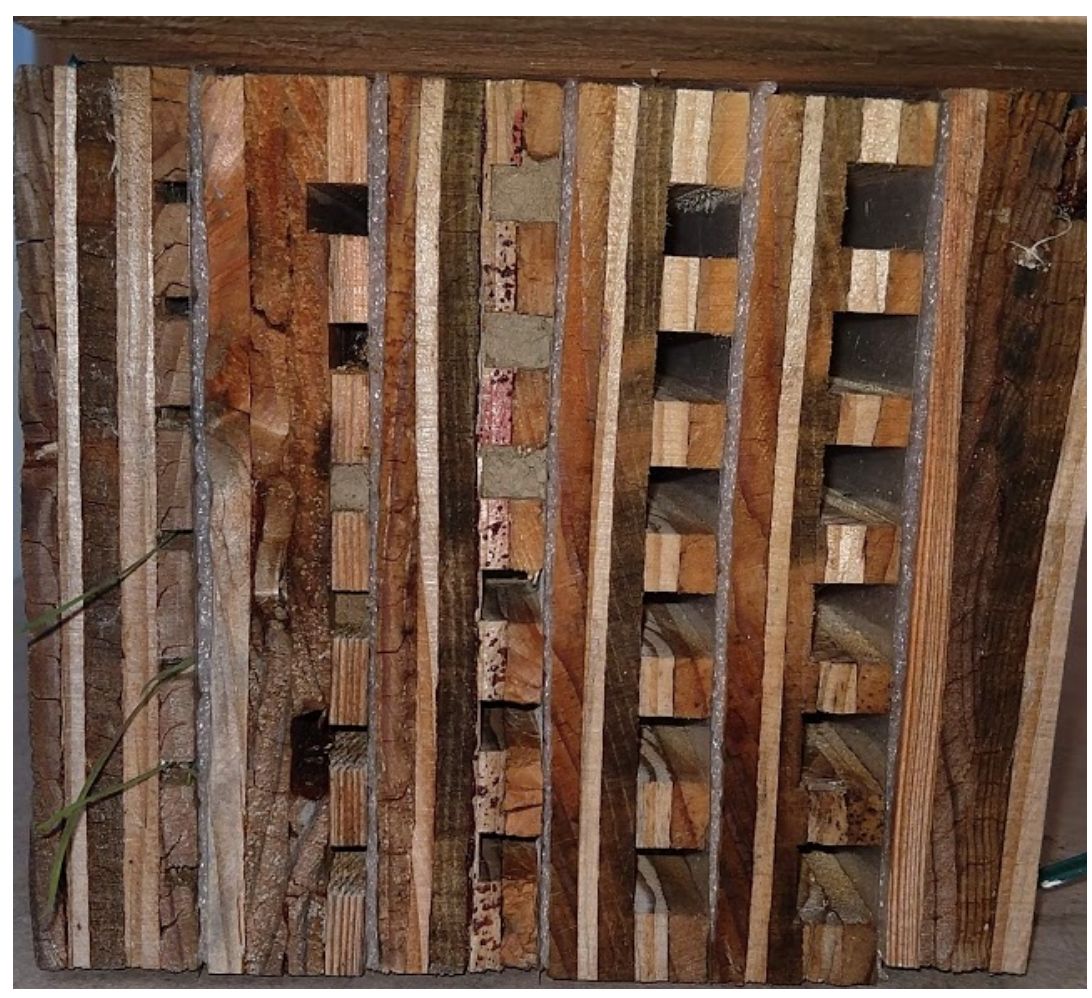

Figure 2.13: Osmia lignaria propinqua mud terminal plugs visible in 5.0 and $6.0 \mathrm{~mm}$ cavity widths. 


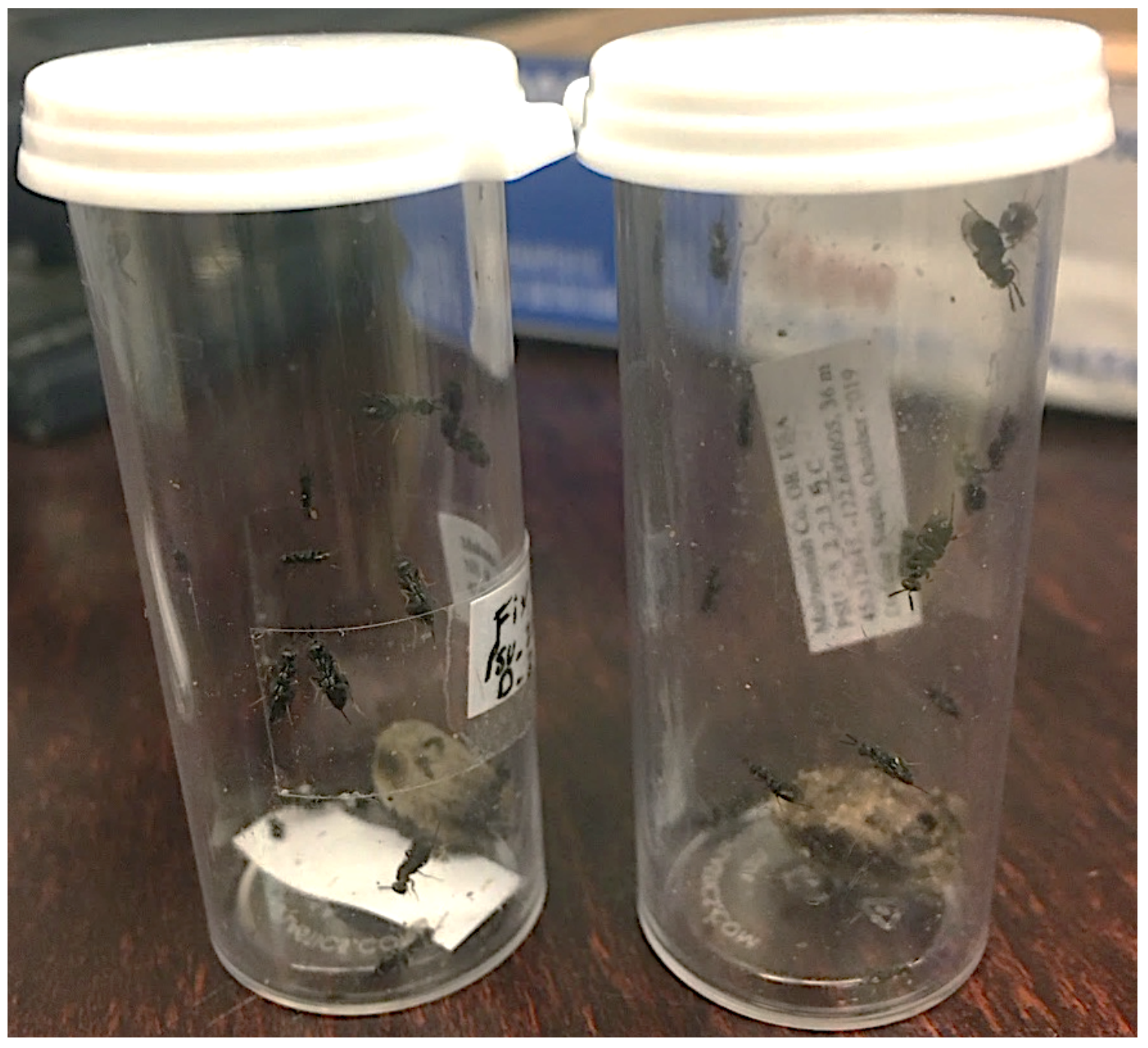

Figure 2.14: Parasitoid wasps, Monodontomerus sp. emerged from Osmia lignaria propinqua cocoons. 


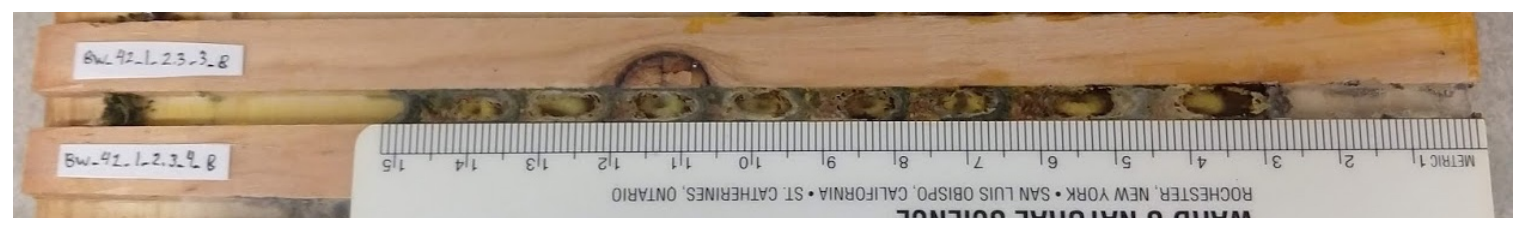

Figure 2.15: Megachile fidelis $5.0 \mathrm{~mm}$ cavity nest.

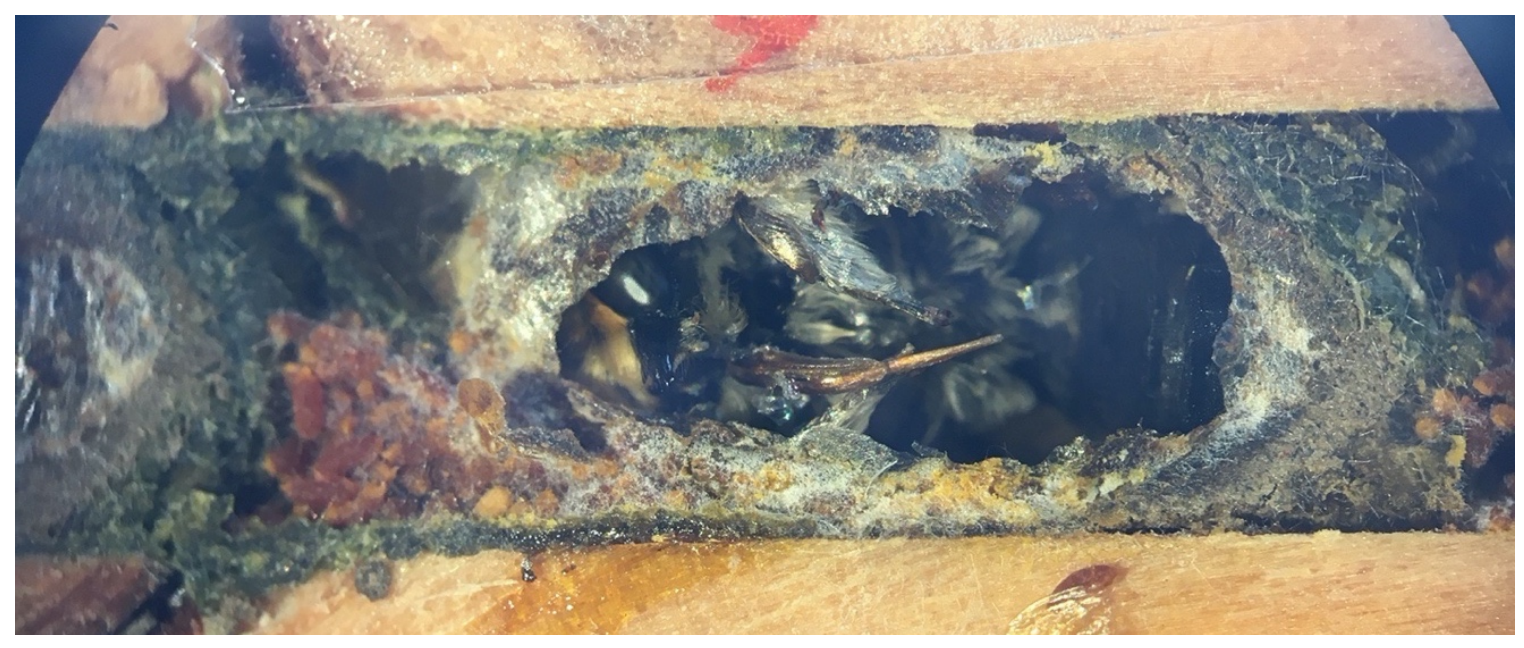

Figure 2.16: Close up of a Megachile fidelis brood cell with a male still inside. 


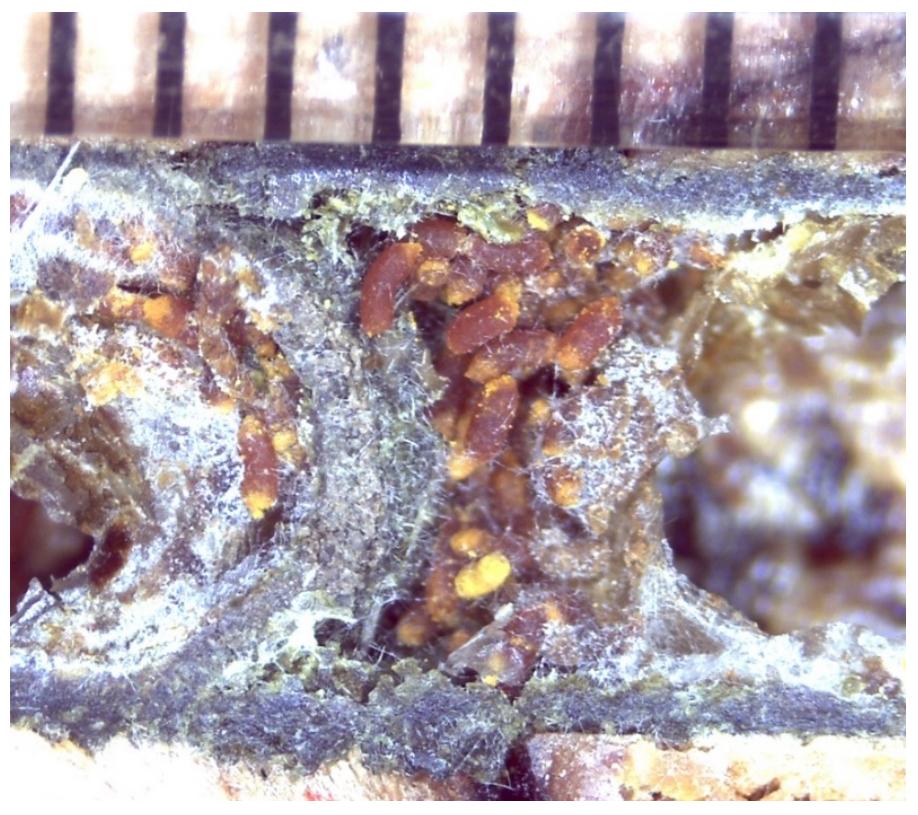

Figure 2.17: Finely masticated leaves and mud used for cell partitions and along edge of cavity row in Megachile fidelis nest.

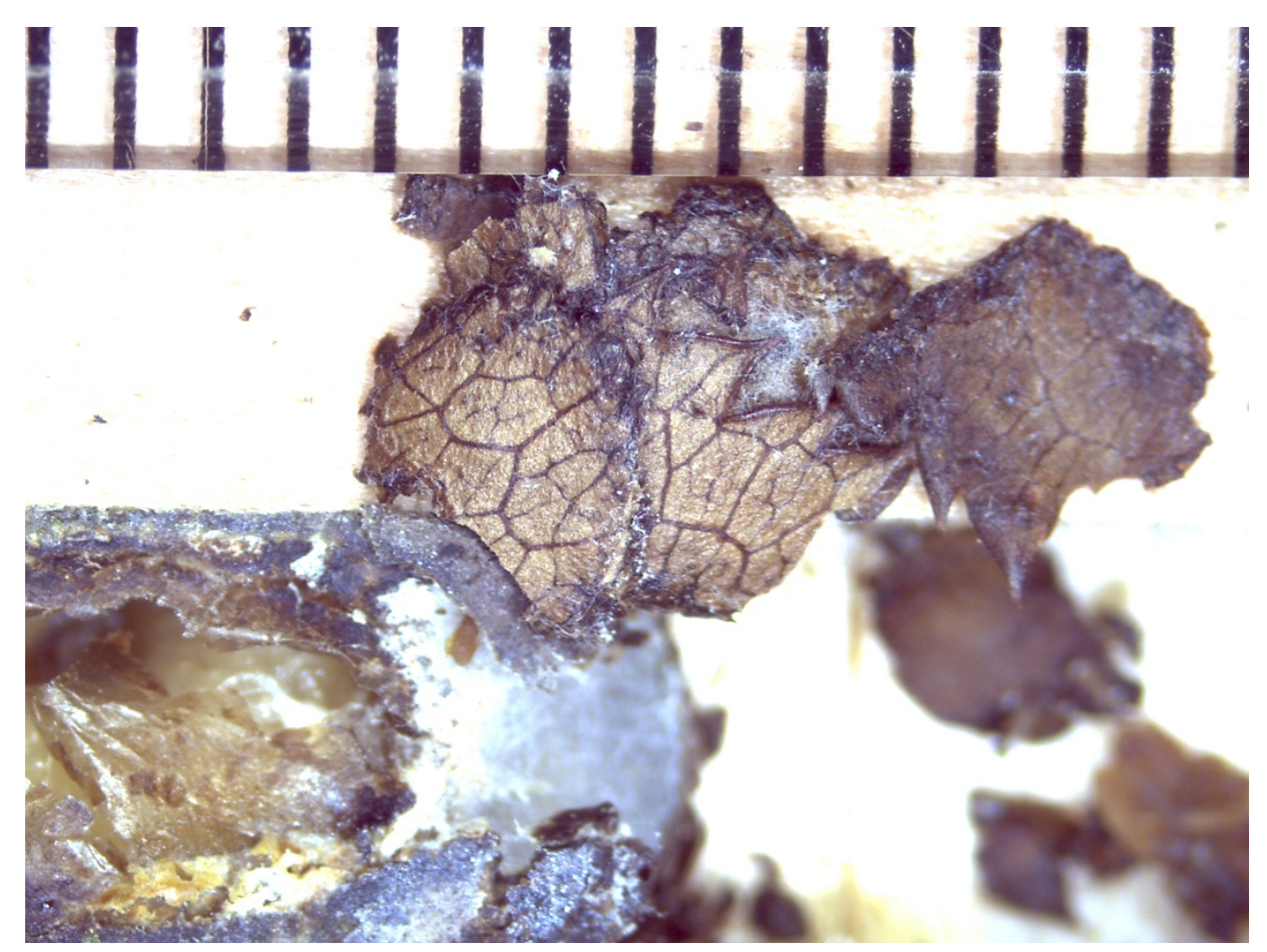

Figure 2.18: Megachile fidelis preliminary plug nest materials: brown toothed leaves partially coated with sticky resinous material. 


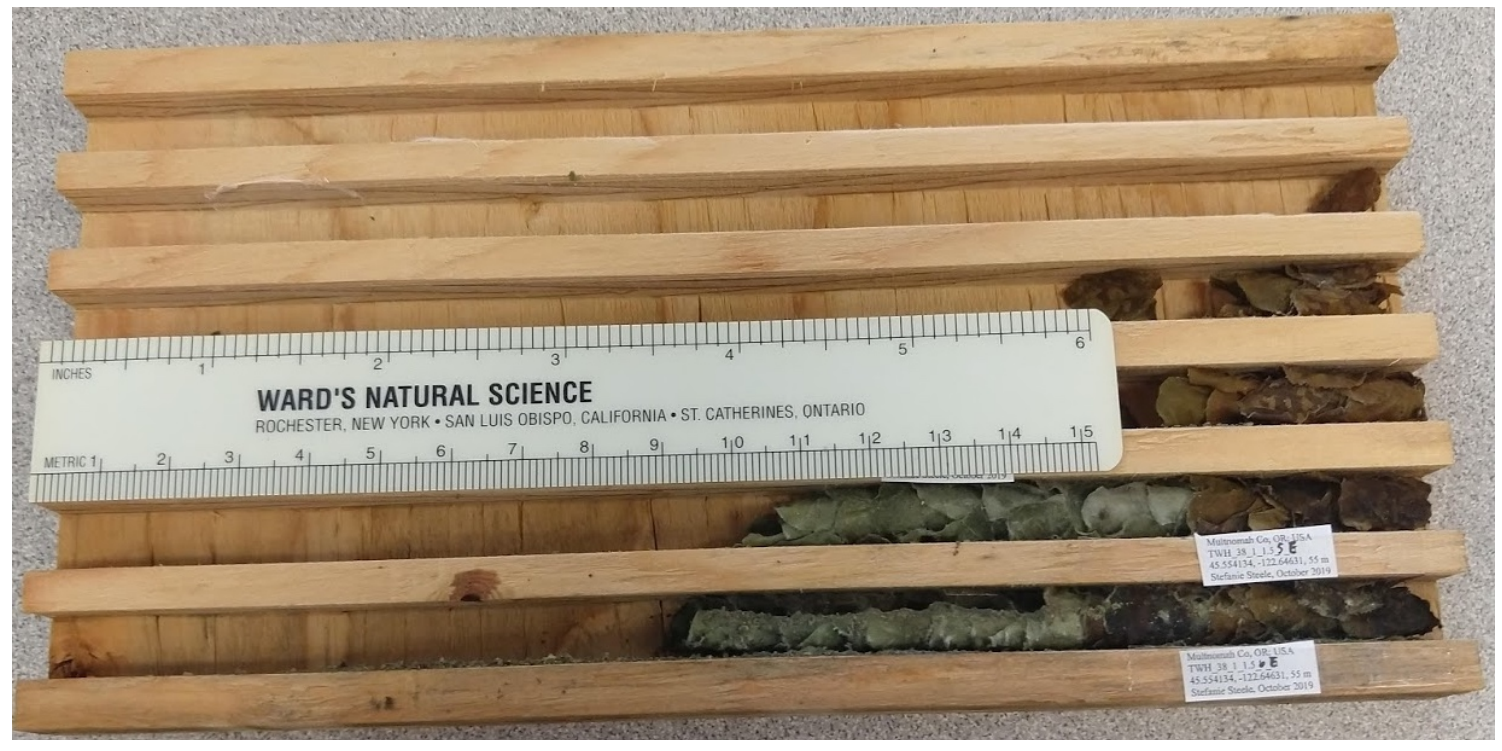

Figure 2.19: Megachile sp. A with overlapping cut green leaves in a $10.0 \mathrm{~mm}$ cavity nest. Fuzzy fungal growth visible on nest materials.

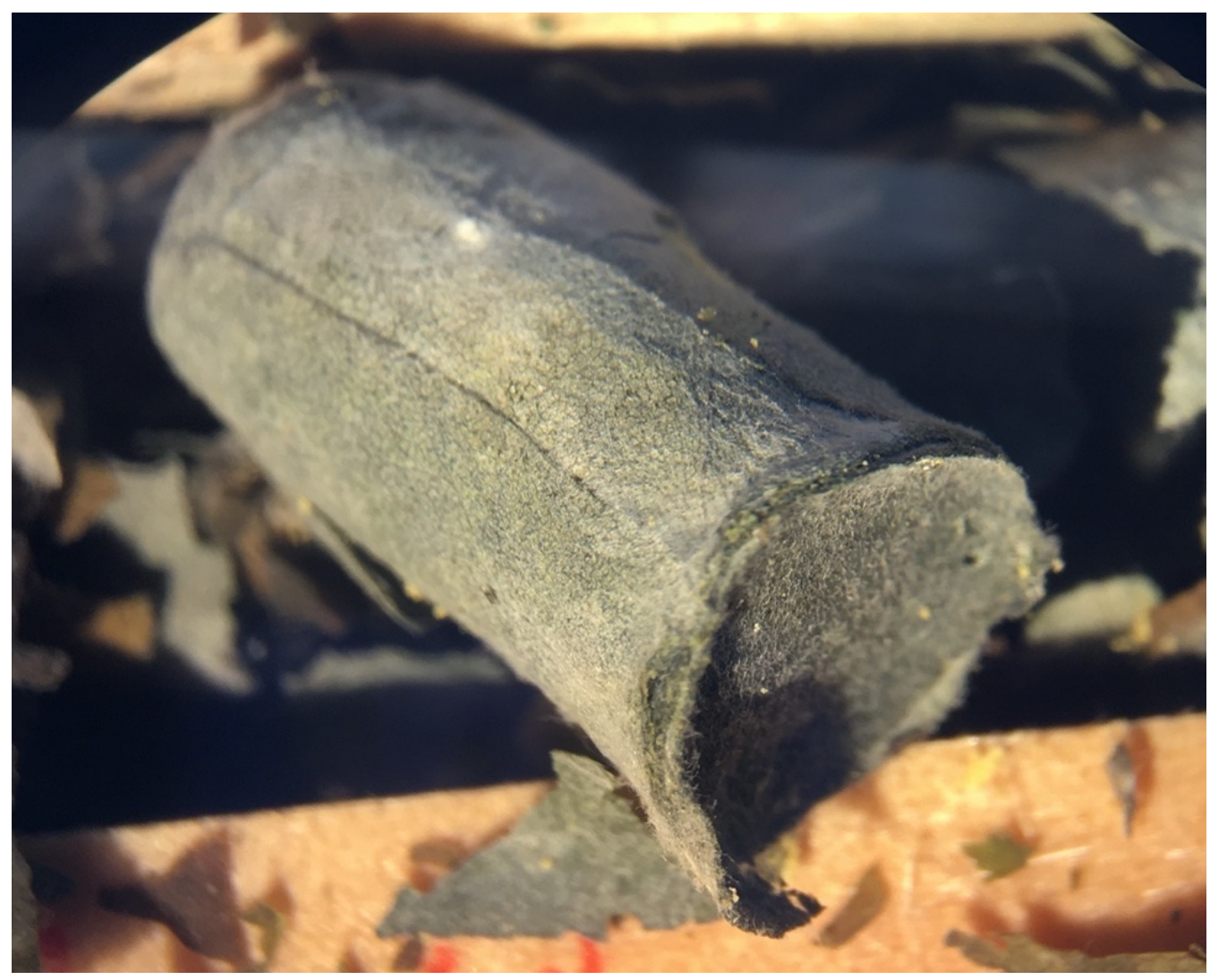

Figure 2.20: Megachile sp. A encapsulated green leaf cocoon. Fuzzy fungal growth visible on nest materials. 


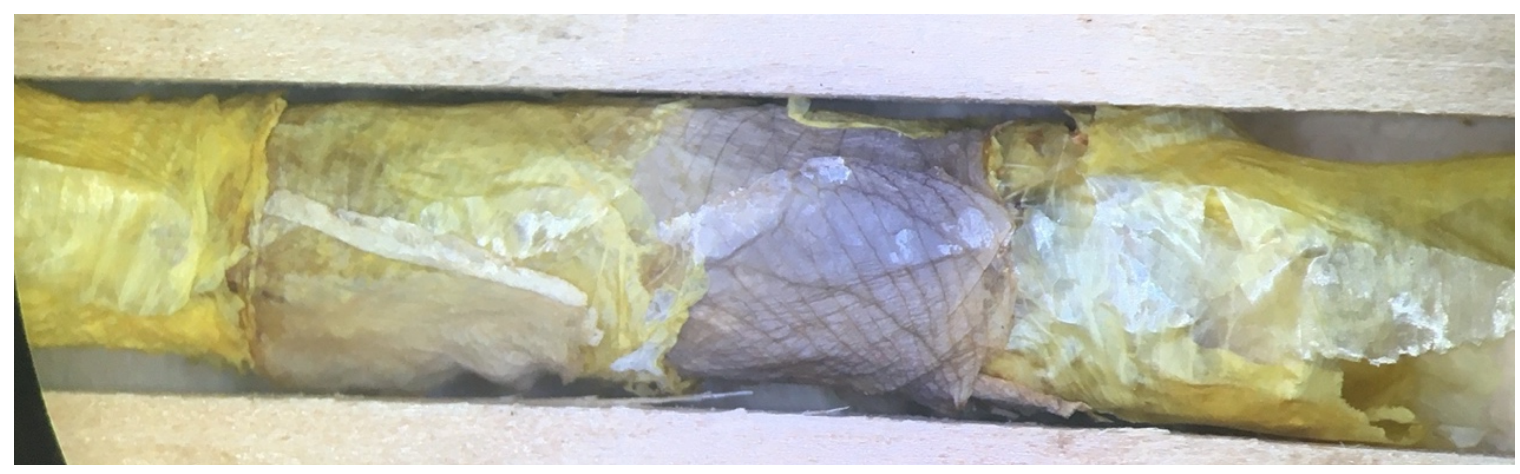

Figure 2.21: Megachile sp. B rolled petal nest in $8.0 \mathrm{~mm}$ cavity.

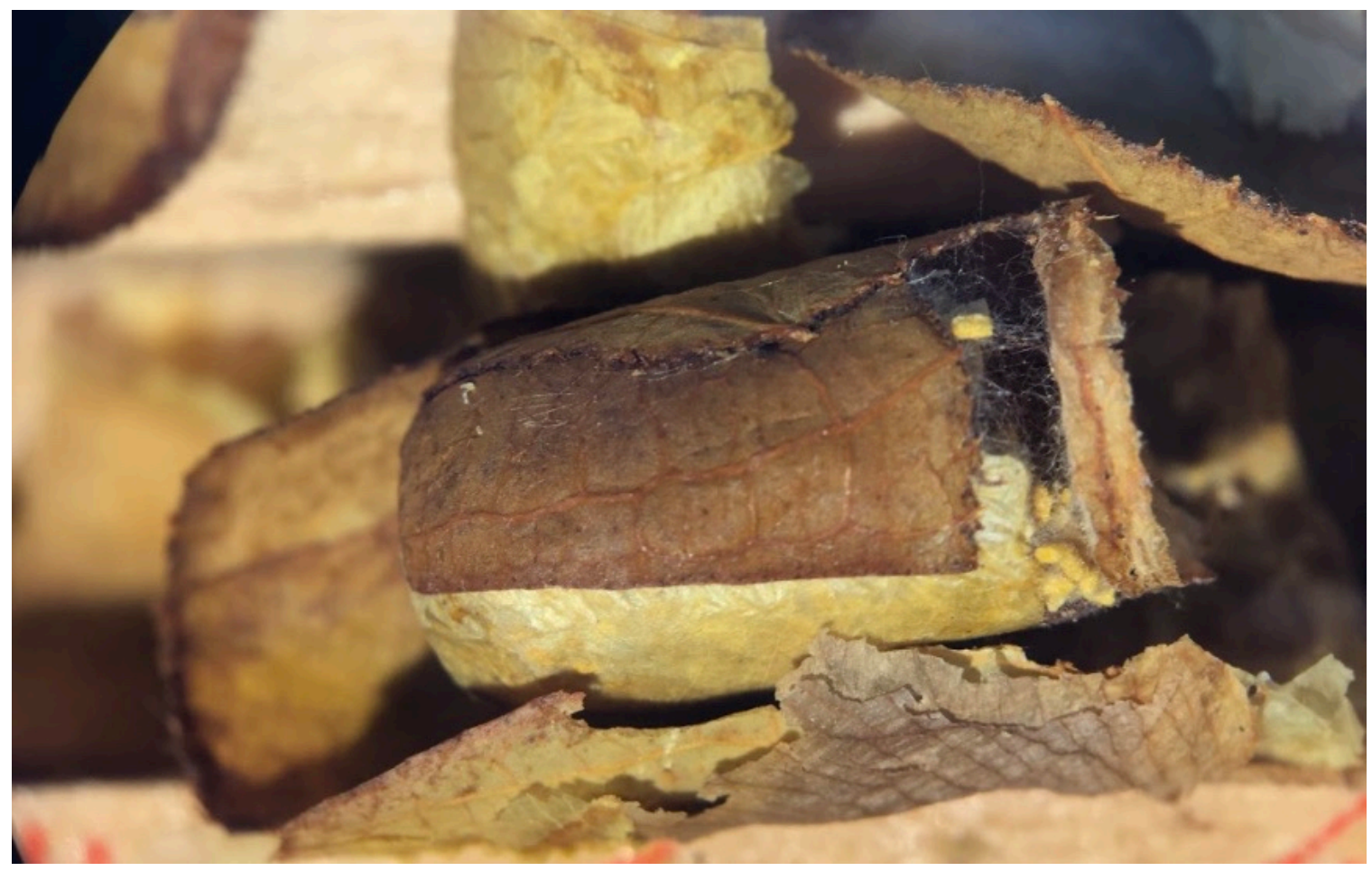

Figure 2.22: Cocoon of Megachile sp. B rolled petal nest in $8.0 \mathrm{~mm}$ cavity.

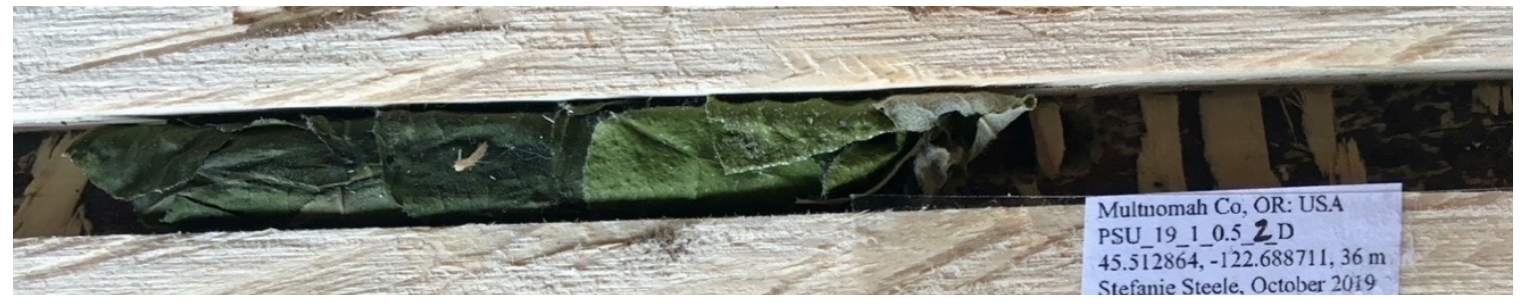

Figure 2.23: Megachile sp. C rolled leaf nest in $8.0 \mathrm{~mm}$ cavity. 


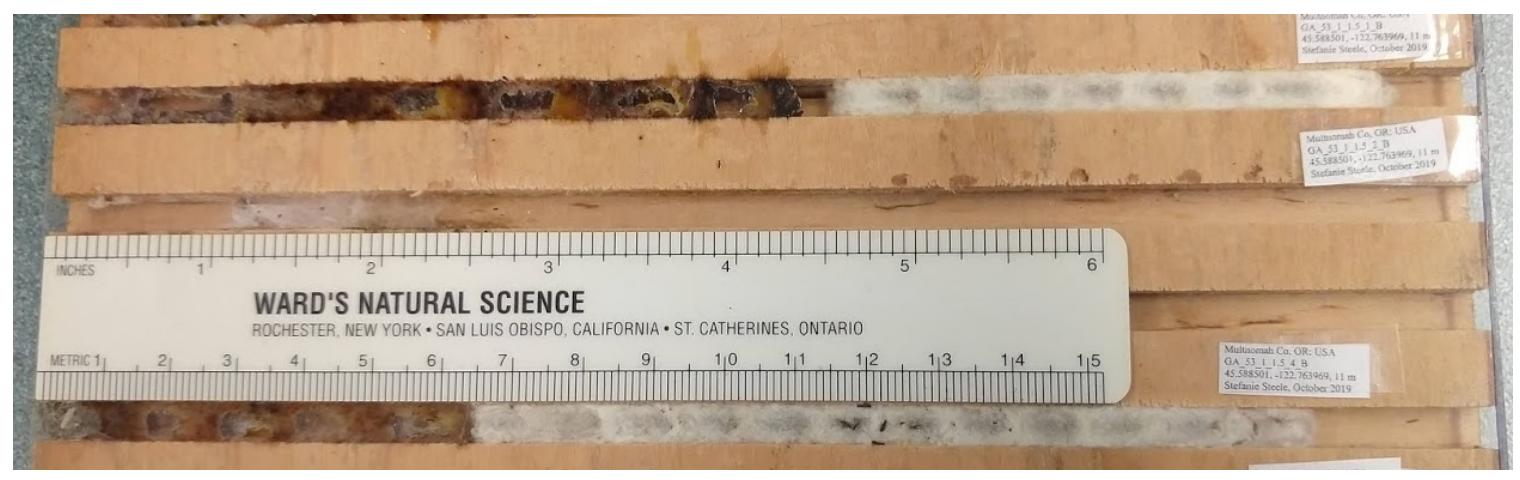

Figure 2.24: Pseudoanthidium nanum constructed two nests with white cottony plant fibers in $5.0 \mathrm{~mm}$ cavity width nests. Melittobia sp. are visible as small black specs on top of white cottony fibers of the bottom nest. Megachile angelarum superseded both $P$. nanum nests.

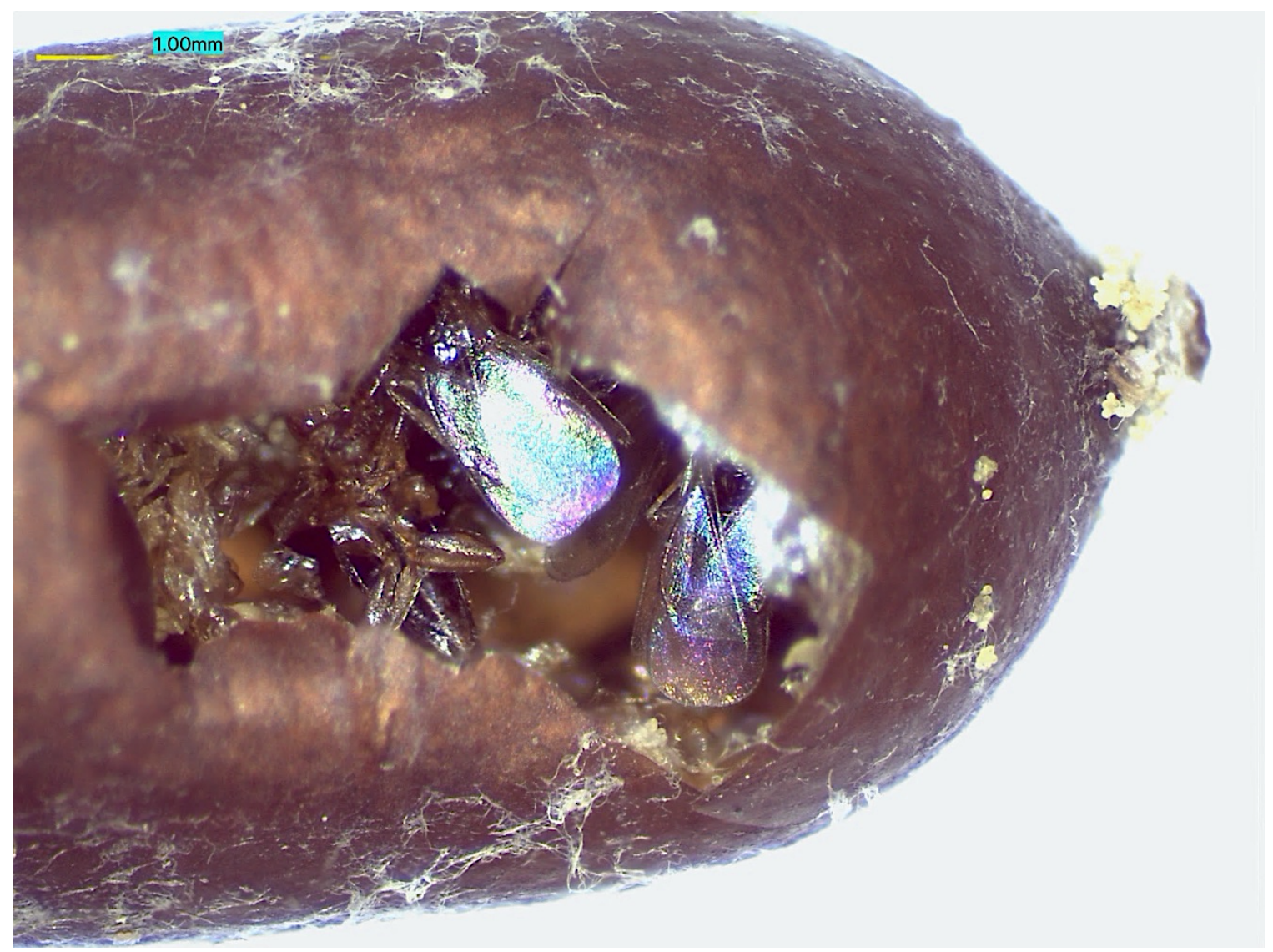

Figure 2.25: Melittobia species visible inside Pseudoanthidium nanum cocoon. 


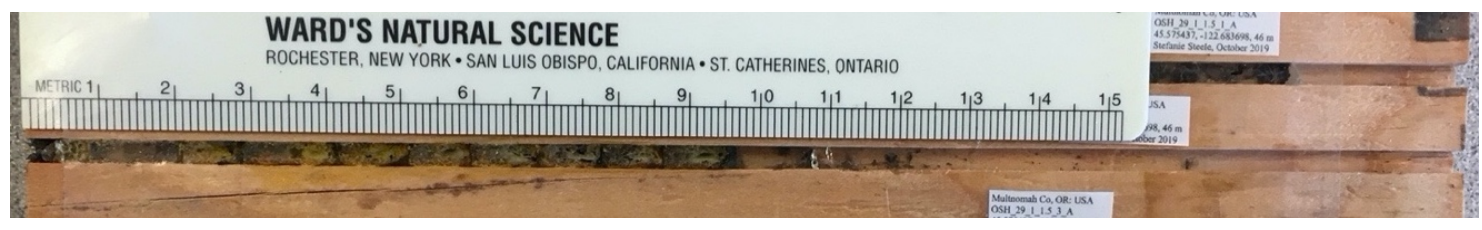

Figure 2.26: Heriades carinata $3.0 \mathrm{~mm}$ cavity nest.

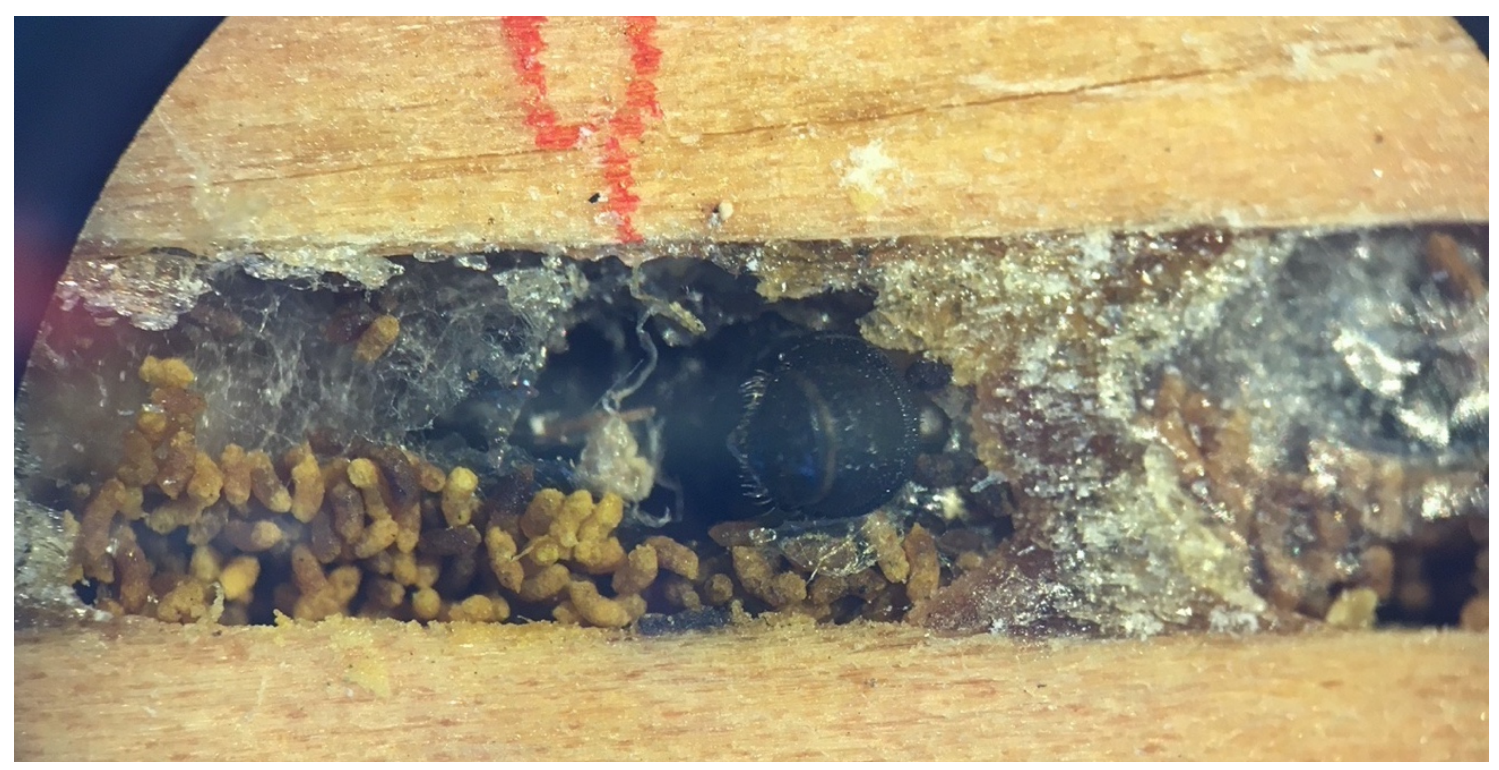

Figure 2.27: Male Heriades carinata visible in brood cell with whiteish colored plant resin partitions.

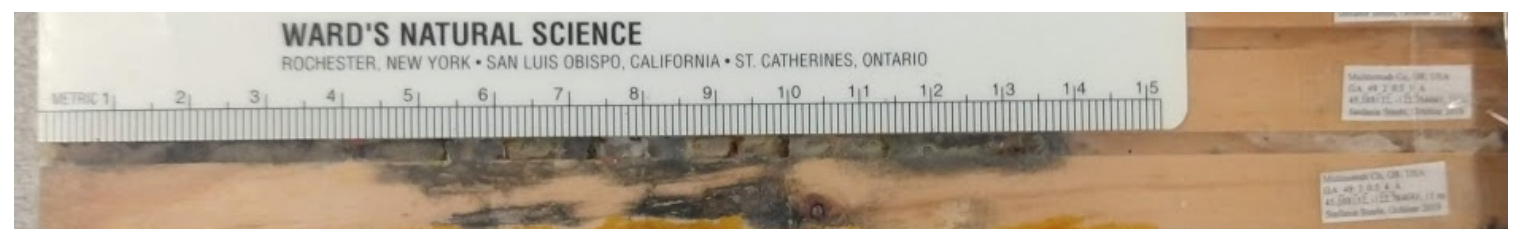

Figure 2.28: Ashmeadiella cactorum cactorum $3.0 \mathrm{~mm}$ cavity nest. Black staining evidence of fungal growth in this nest. 


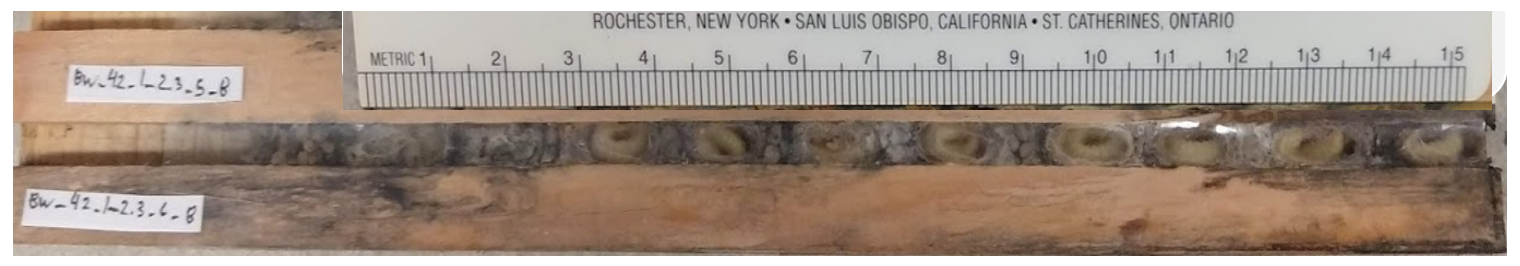

Figure 2.29: Hoplitis albifrons nest in $5.0 \mathrm{~mm}$ cavity.

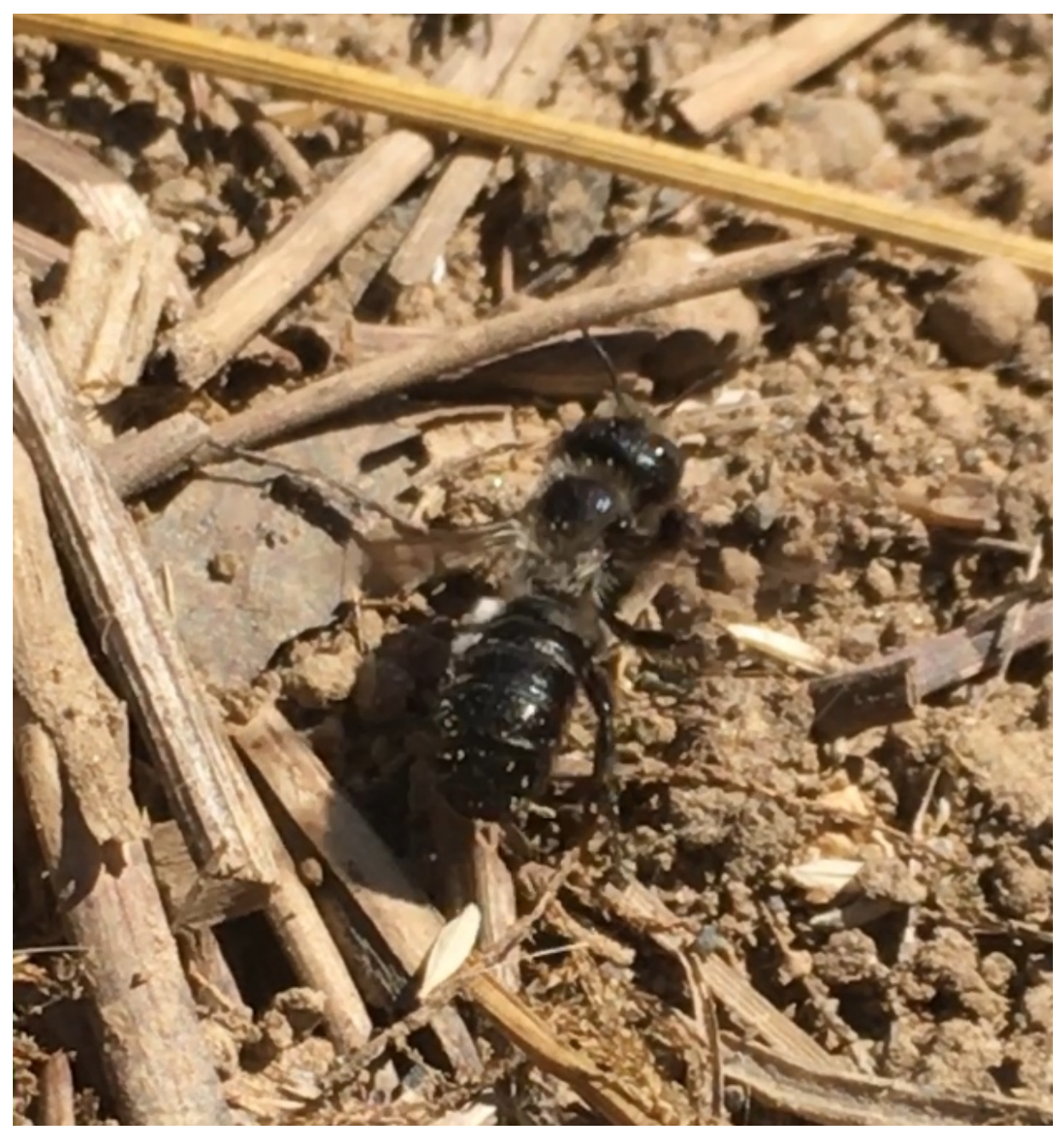

Figure 2.30: Hoplitis albifrons collecting balls of dirt to use as nesting material on 13 July 2019. 


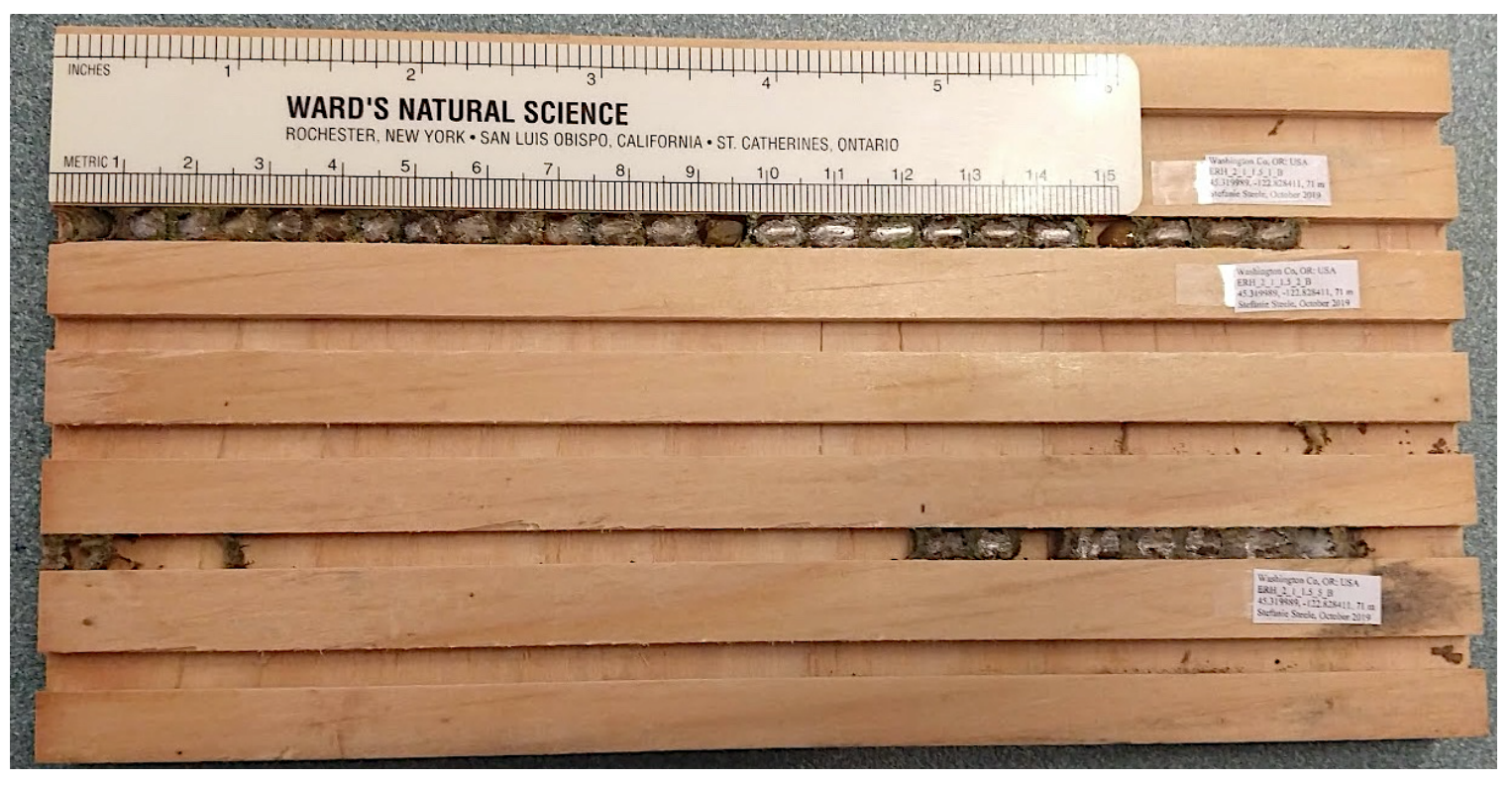

Figure 2.31: Osmia proxima $5.0 \mathrm{~mm}$ nest cavities.

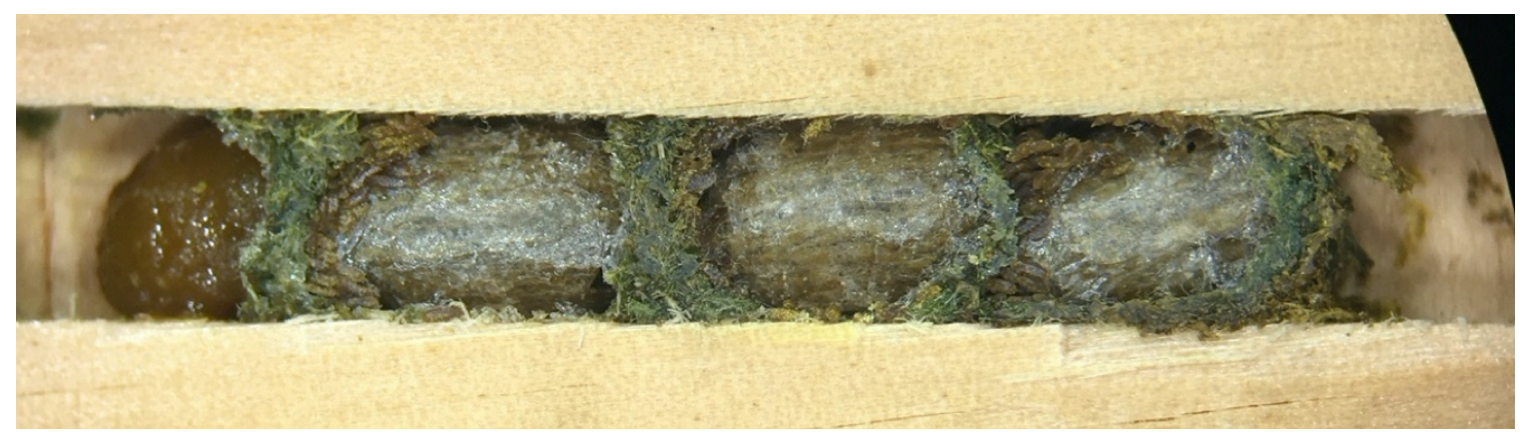

Figure 2.32: Close view of Osmia proxima brood cells, cocoons, cell partitions, and uneaten pollen ball mass. 


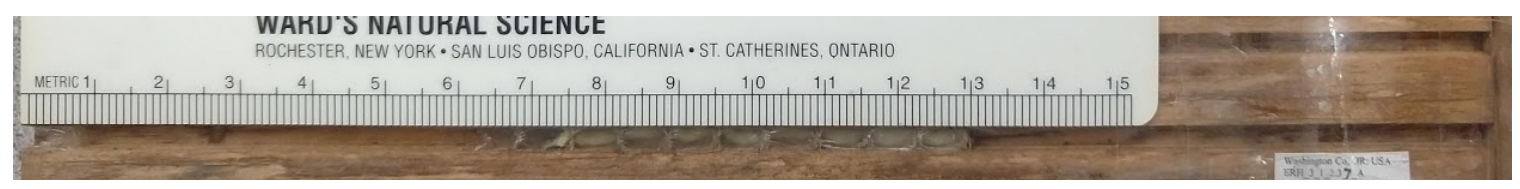

Figure 2.33: Hylaeus sp. nest in $3.0 \mathrm{~mm}$ cavity.

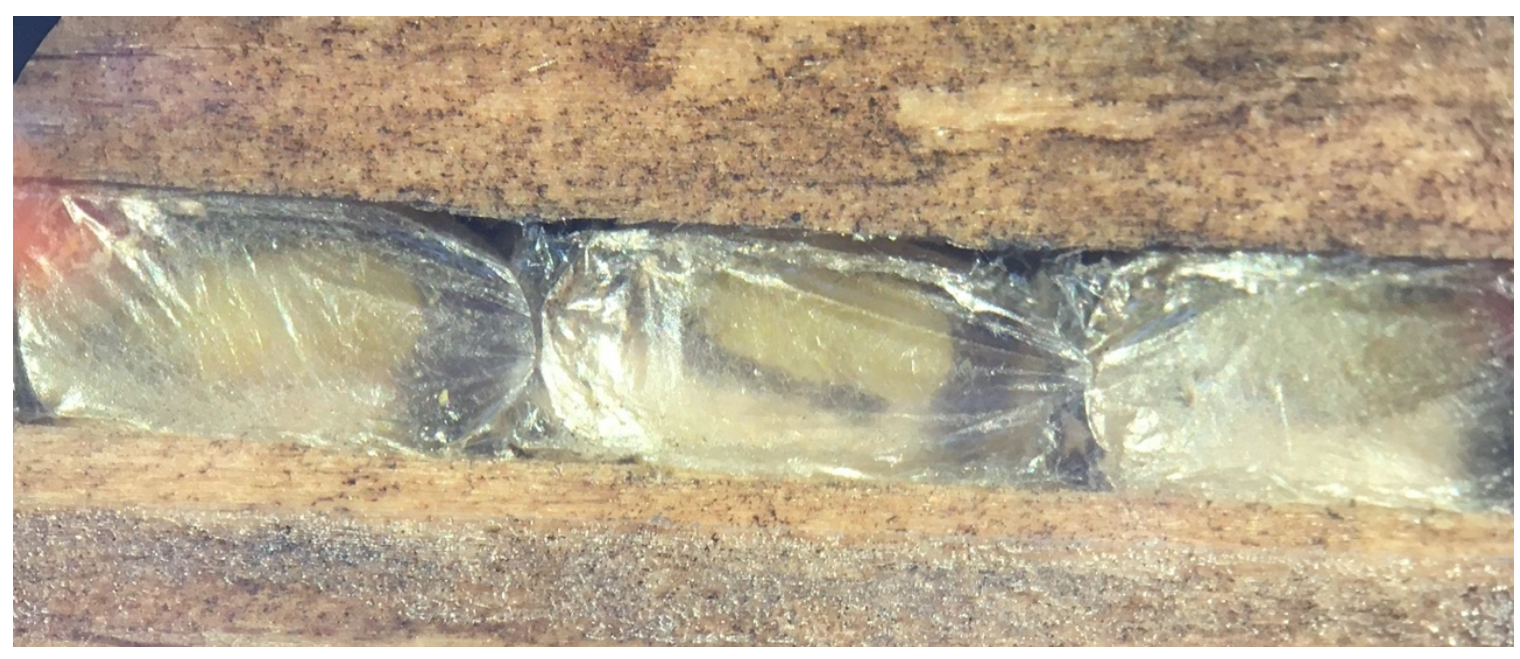

Figure 2.34: Close view of cellophane secretions from Hylaeus sp. nest. 


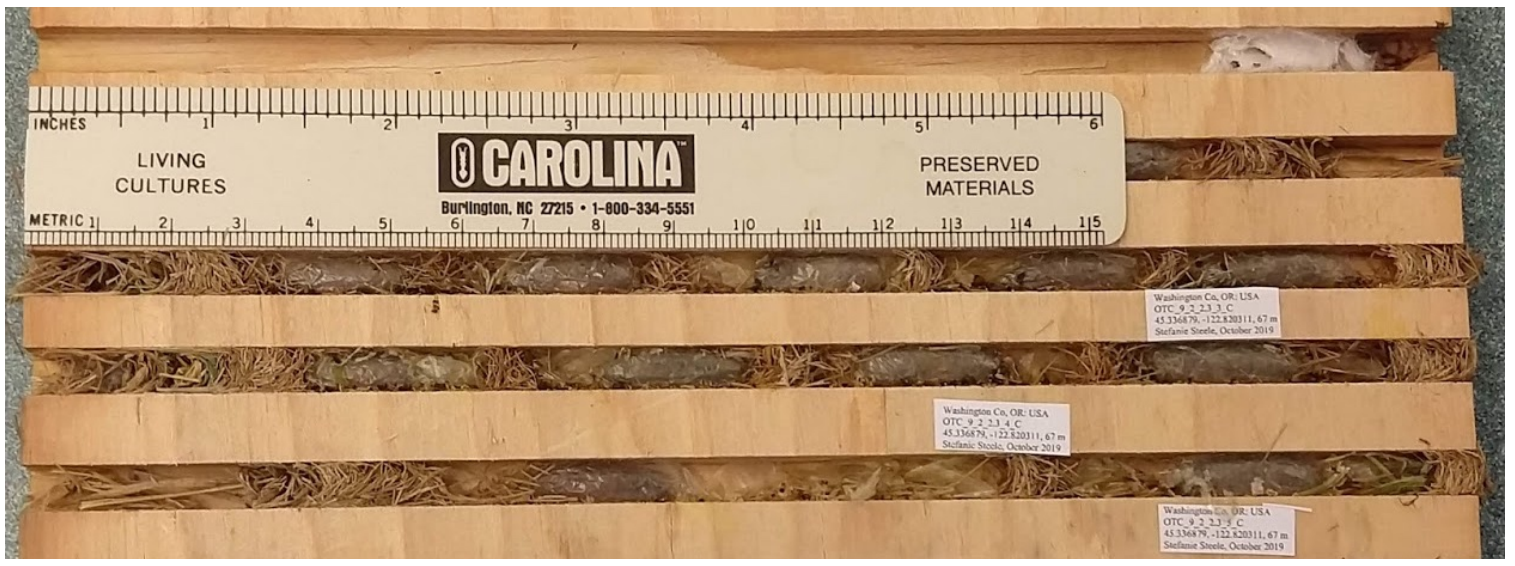

Figure 2.35: Isodontia elegans nest in $6.0 \mathrm{~mm}$ cavities.

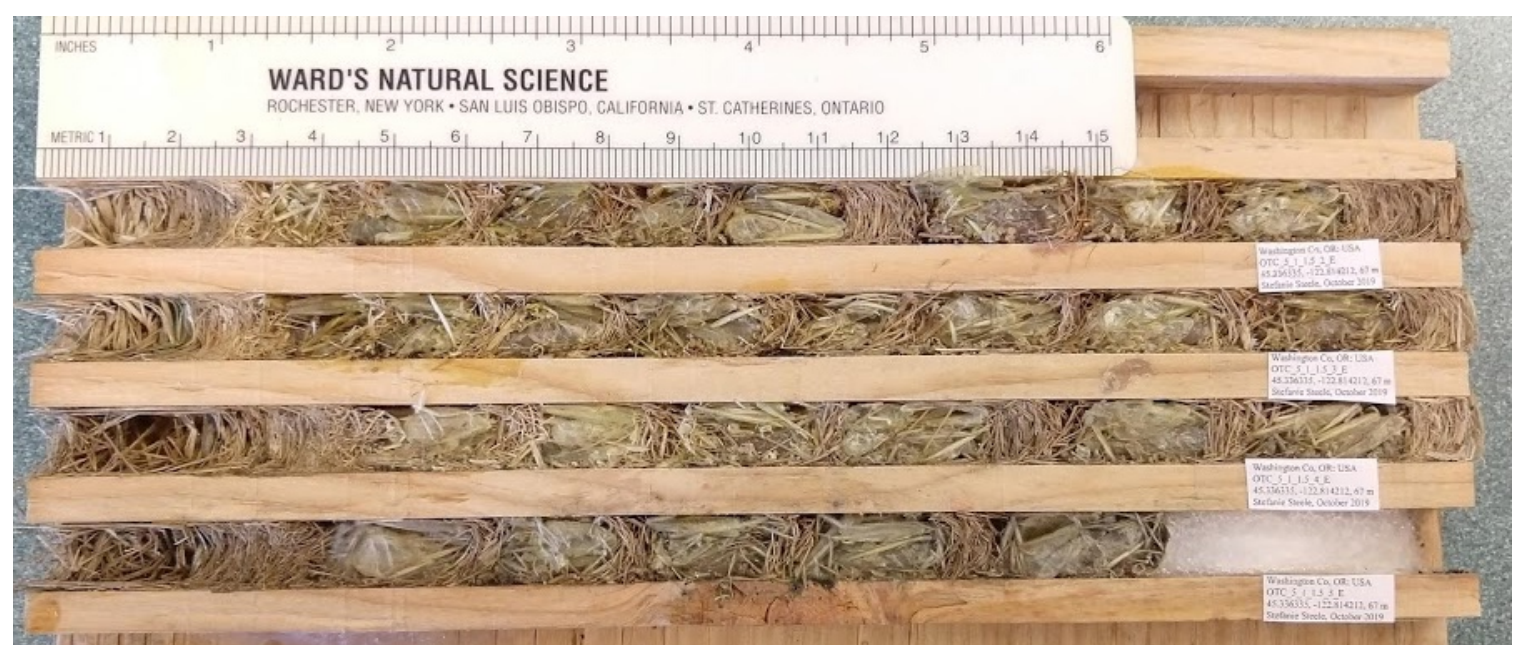

Figure 2.36: Isodontia elegans nest in $10.0 \mathrm{~mm}$ cavities.

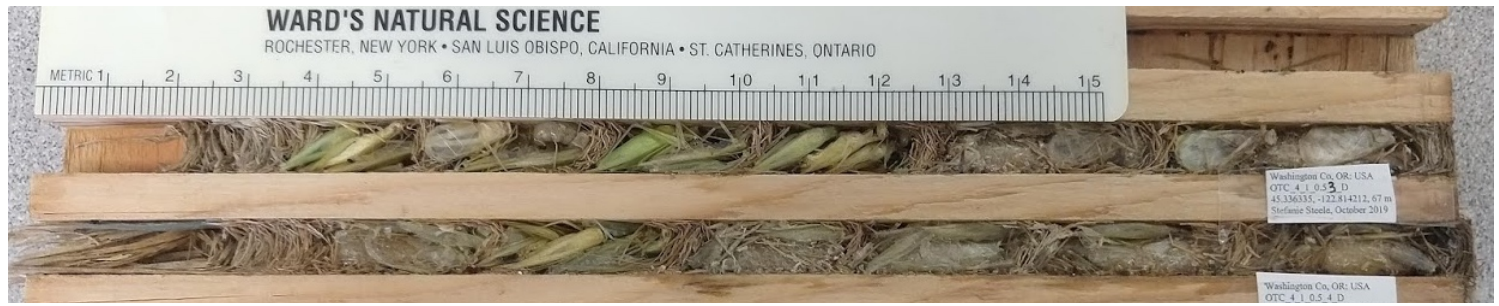

Figure 2.37: Isodontia elegans nest in $8.0 \mathrm{~mm}$ cavities with uneaten tree cricket prey visible. 


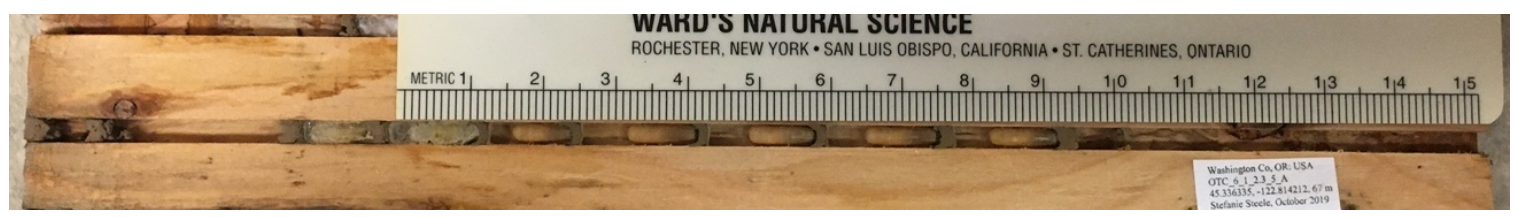

Figure 2.38: Trypoxylon (Trypoxylon) frigidum nest $3.0 \mathrm{~mm}$ cavity. Two Eumeninae cells are visible closest to the nest entrance and terminal plug.

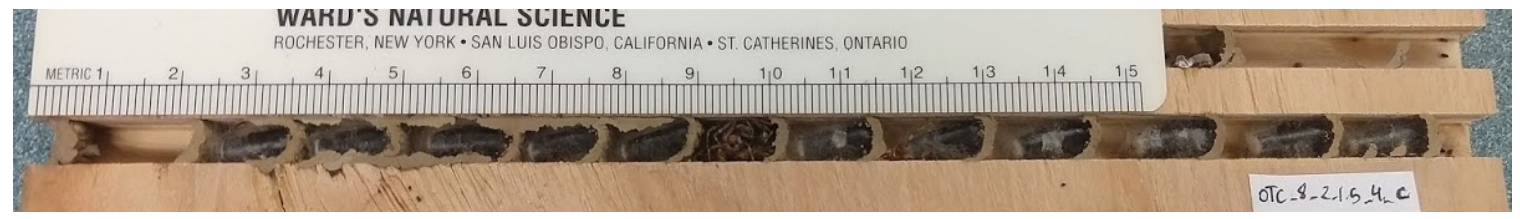

Figure 2.39: Trypoxylon (Trypargilum) sp. nest in $6.0 \mathrm{~mm}$ cavity. Uneaten spider prey provisions visible in center brood cell.

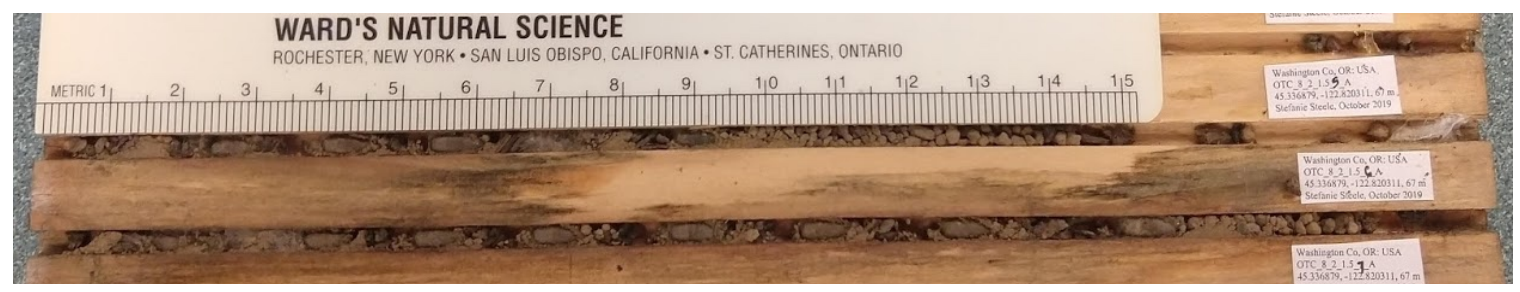

Figure 2.40: Pisonopsis sp. nests in $3.0 \mathrm{~mm}$ cavities.

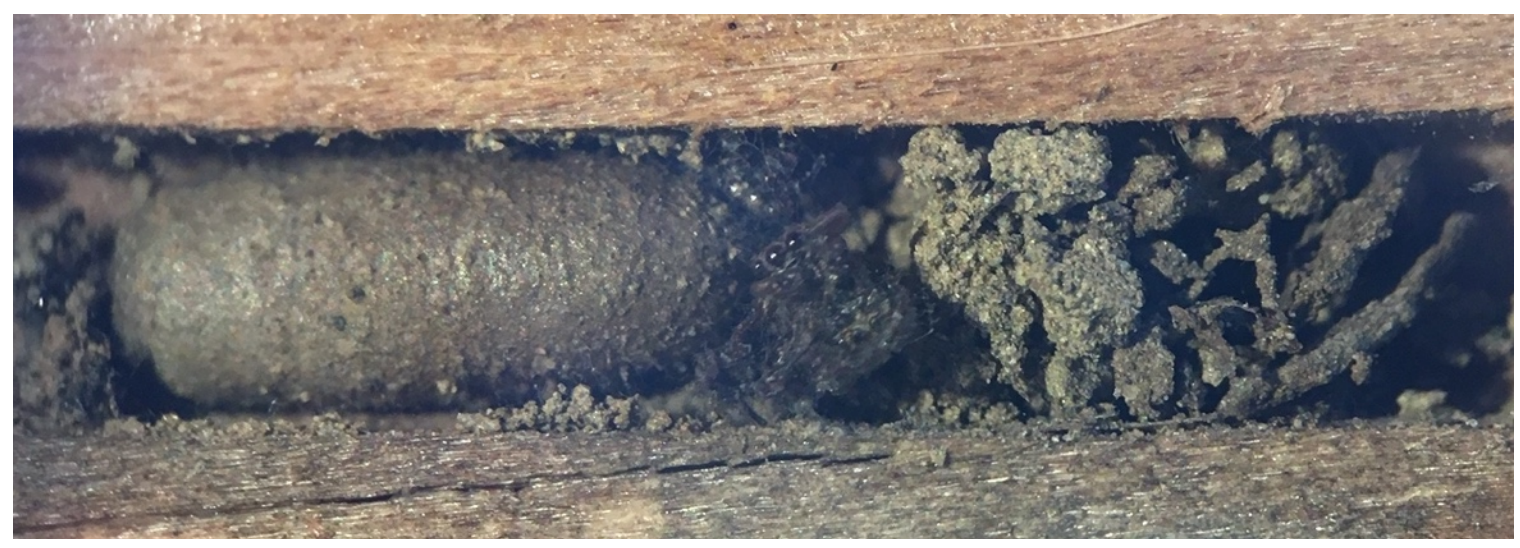

Figure 2.41: Close up of Pisonopsis sp. cocoon and uneaten spider prey provision. 


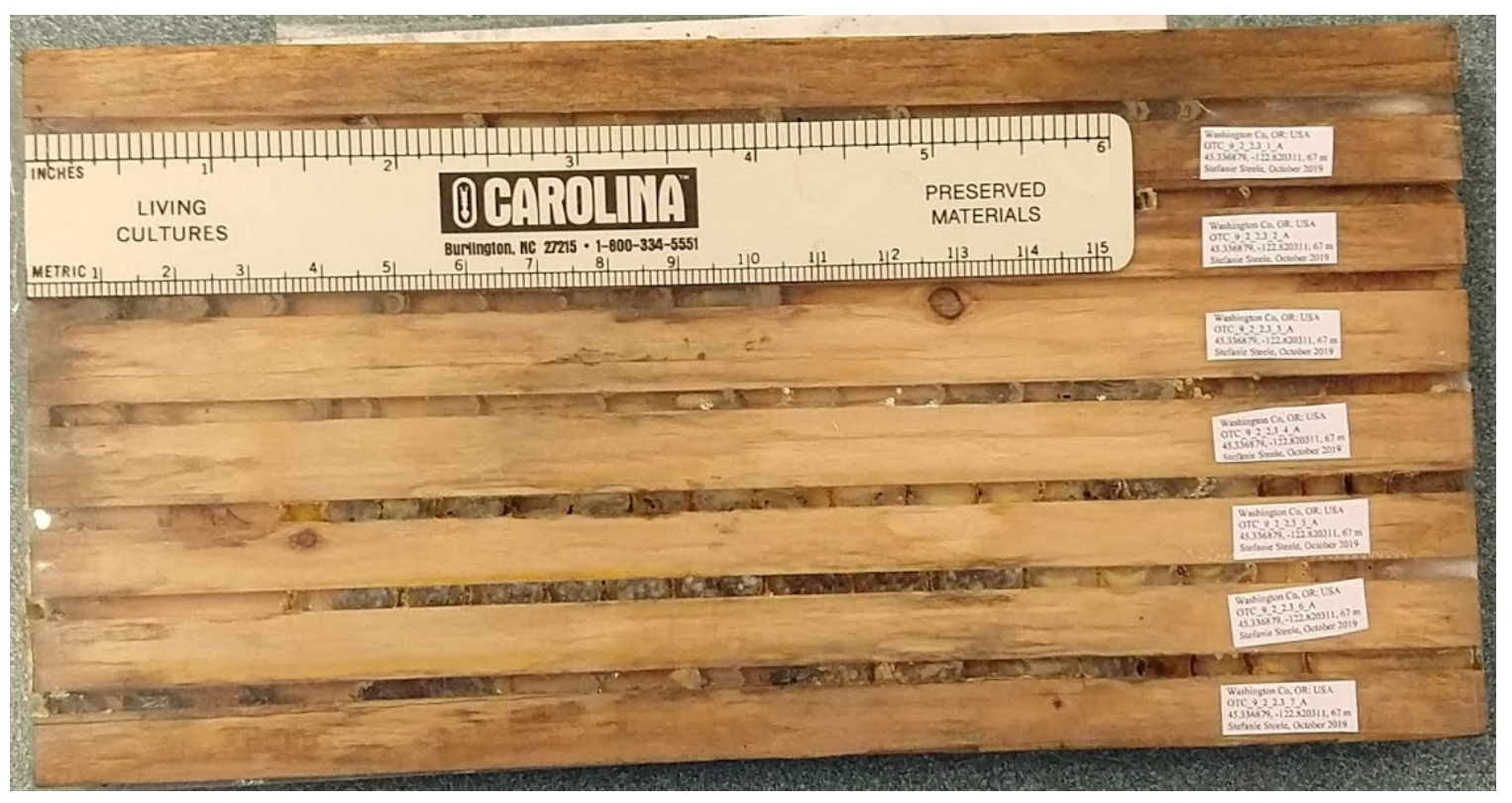

Figure 2.42: Resin Pemphredoninae sp. nest in $3.0 \mathrm{~mm}$ cavities.

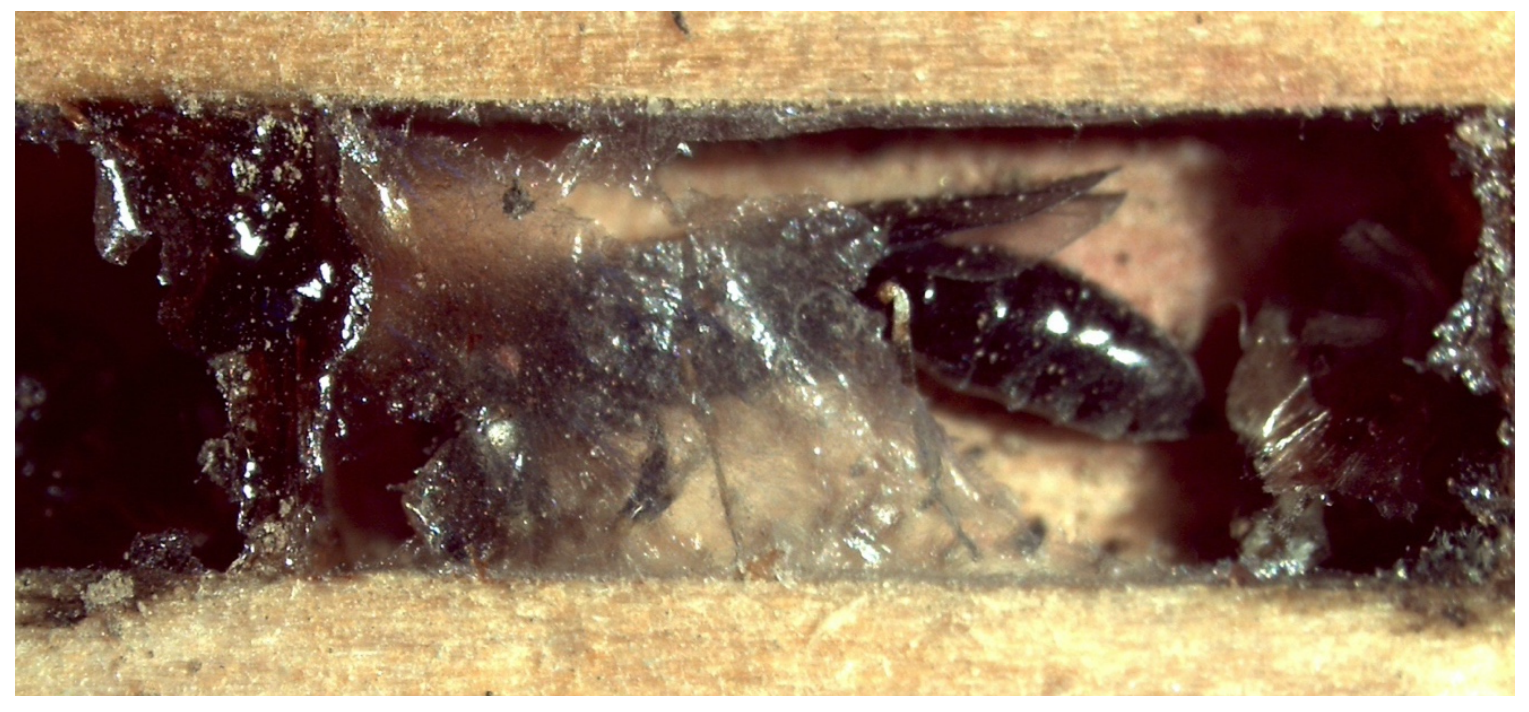

Figure 2.43: Close up of resin Pemphredoninae sp. in brood cell with resin partitions visible and cellophane material cell cover. 


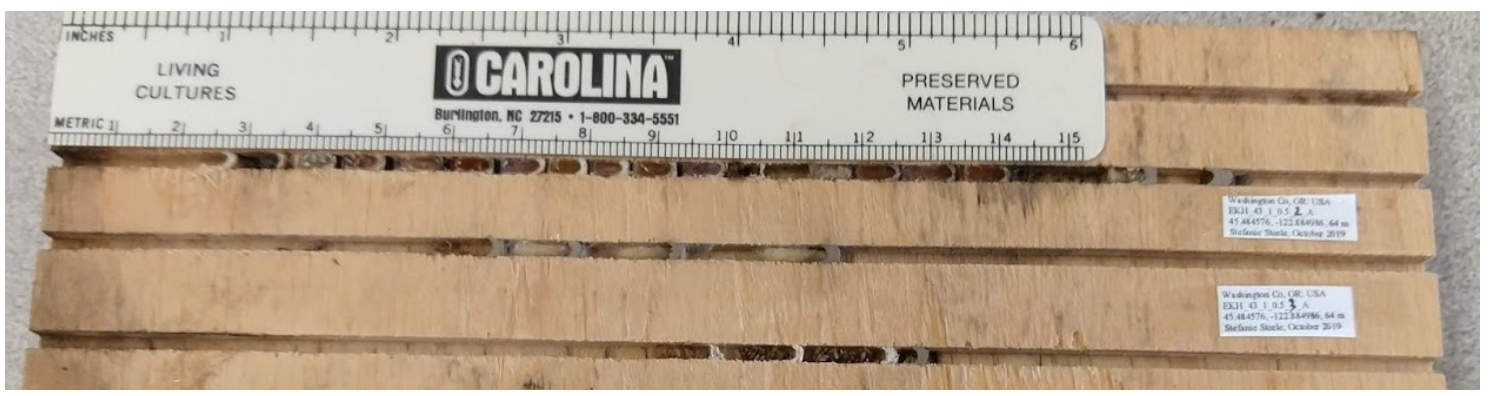

Figure 2.44: Wood chewing Pemphredoninae sp. nest in $3.0 \mathrm{~mm}$ cavities.

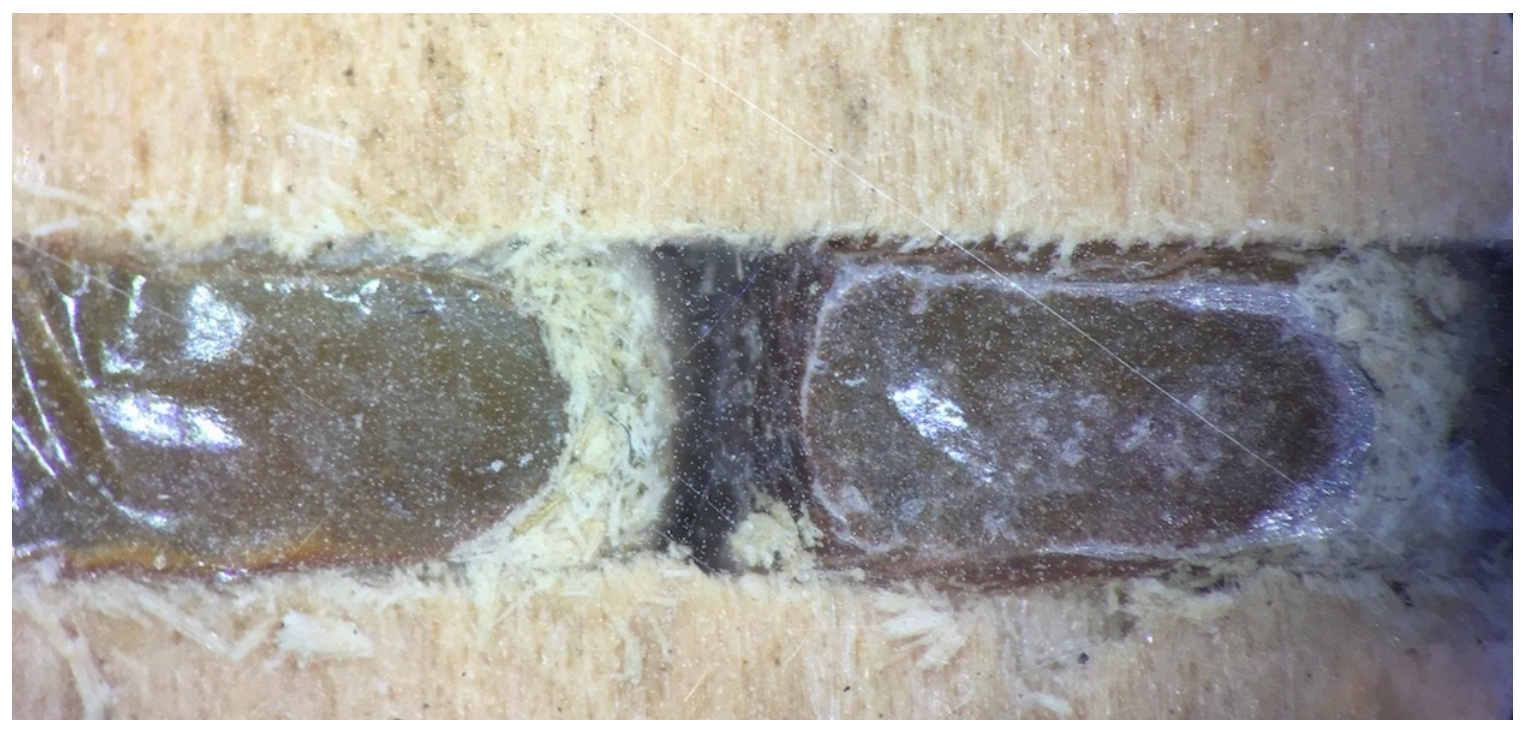

Figure 2.45: Wood chewing Pemphredoninae sp. brood cells. Wood was chewed from the sides of the cavity row. 


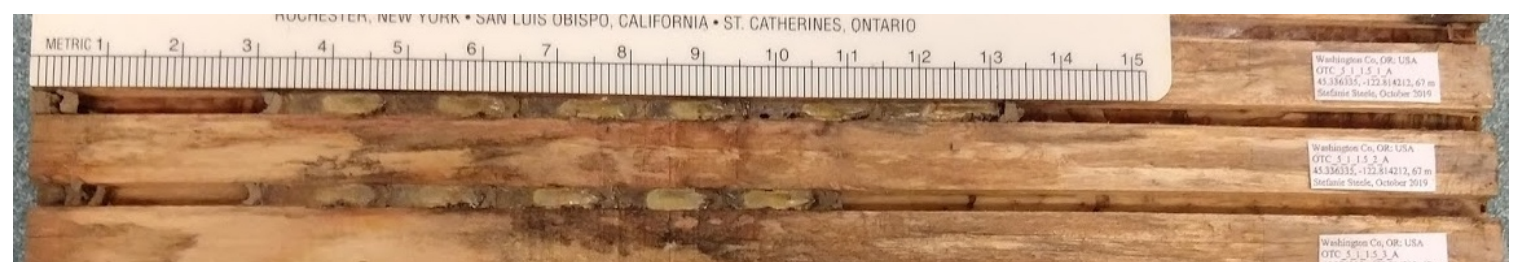

Figure 2.46: Eumeninae sp. nest in $3.0 \mathrm{~mm}$ cavities.

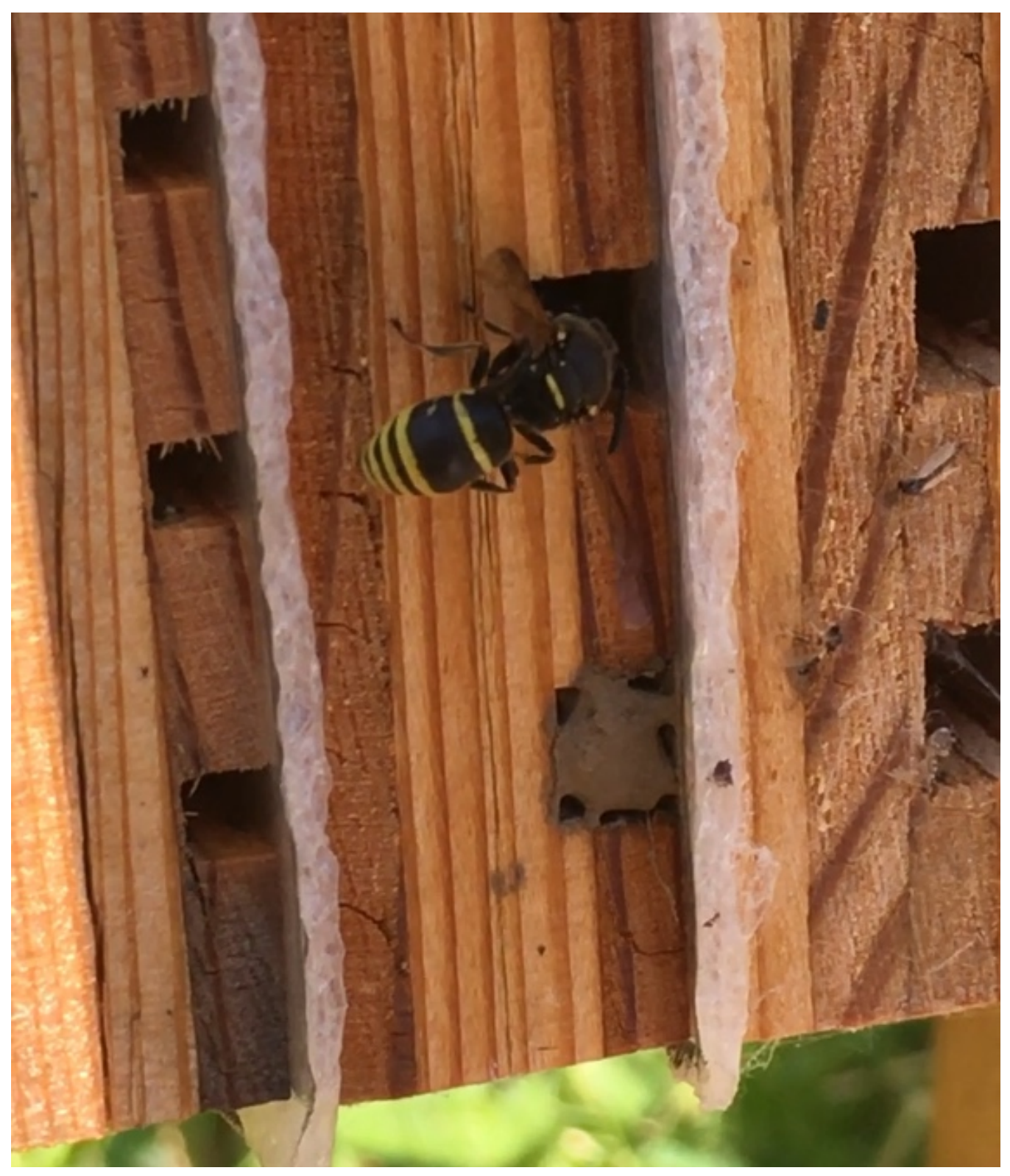

Figure 2.47: Eumenine sp. female returning to $5.0 \mathrm{~mm}$ cavity nest. Globular mud terminal plug is visible below female. 


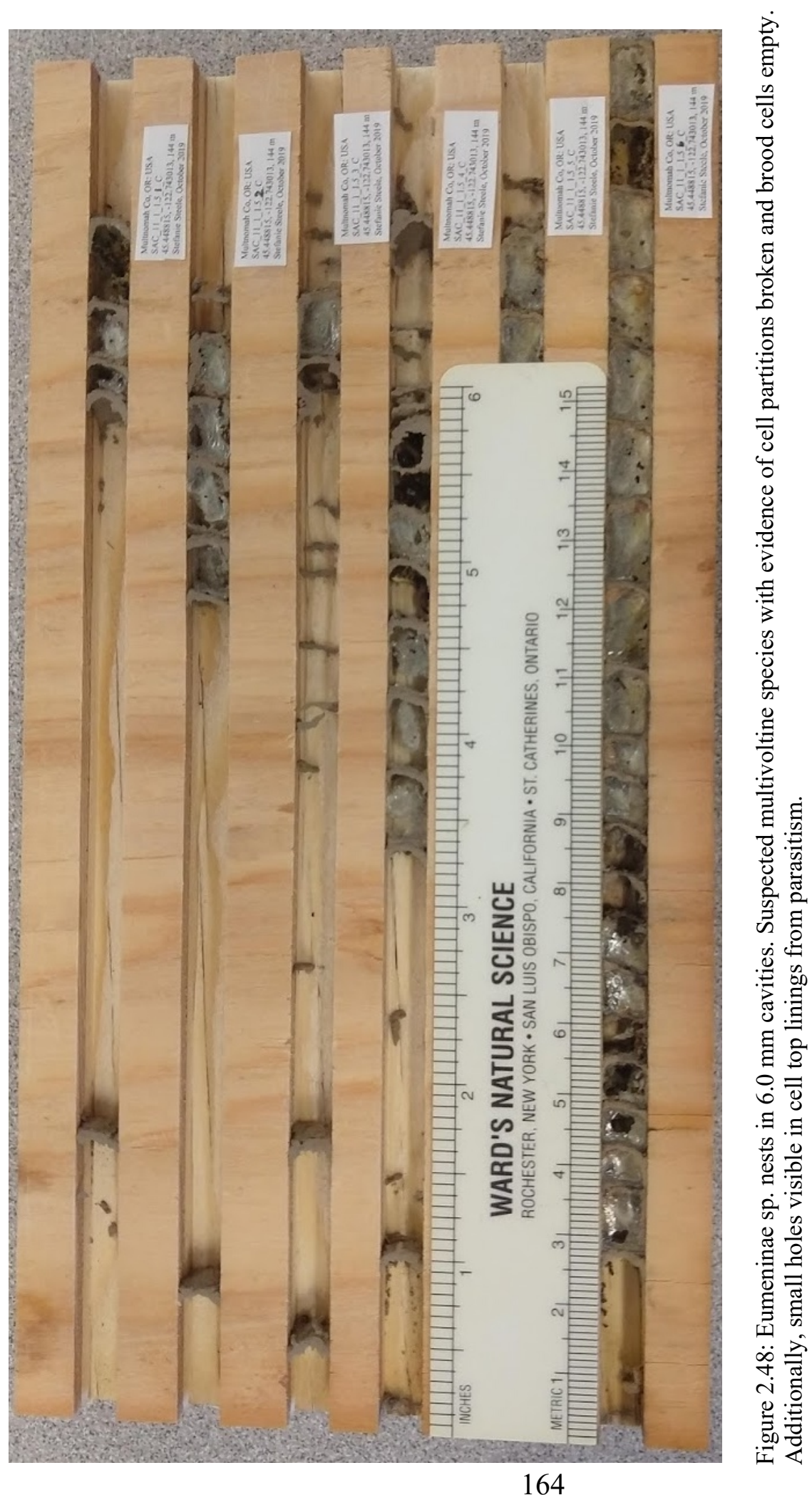




\section{References}

Araújo, P. C. S., Lourenço, A. P. and Raw, A. (2016) 'Trap-Nesting Bees in Montane Grassland (Campo Rupestre) and Cerrado in Brazil: Collecting Generalist or Specialist Nesters', Neotropical Entomology, 45(5), pp. 482-489. doi: 10.1007/s13744-016-0395-9.

Ascher, J. (2020) Information on record AMNH_BEES17382, Discover Life. Available at: https://www.discoverlife.org/mp/201?id=AMNH_BEES17382 (Accessed: 28 August 2020).

Ascher, J. S. (2009) Apoidea species guide, Checklist of World Bees. Available at: http://www.discoverlife.org/mp/20q?guide=Apoidea_species.

Ascher, J. S., Kornbluth, S. and Goelet, R. G. (2014) 'Bees (Hymenoptera: Apoidea: Anthophila) of Gardiners Island, Suffolk County, New York', Northeastern Naturalist, 21(1), pp. 47-71. doi: 10.1656/045.021.0105.

Ávalos-Hernández, O. et al. (2014) 'New records of bee flies (Diptera, Bombyliidae) from Cuatro Ciénegas, Coahuila, Mexico’, ZooKeys, 85(422), pp. 49-86. doi: 10.3897/zookeys.422.7598.

Baldock, K. C. R. et al. (2015) 'Where is the UK's pollinator biodiversity? The importance of urban areas for flower visiting insects', Proceedings: Biological Sciences, 282(1803), pp. 1-10.

Barthell, J. F., Frankie, G. W. and Thorp, R. W. (1998) 'Invader Effects in a Community of Cavity Nesting Megachilid Bees (Hymenoptera: Megachilidae)', Environmental Entomology, 27(2), pp. 240-247. doi: 10.1093/ee/27.2.240.

Bohart, G. E., Stephen, W. P. and Eppley, R. K. (1960) 'The Biology of Heterostylum robustum (Diptera: Bombyliidae), A Parasite of the Alkali Bee', Annals of the Entomological Society of America, 53(3), pp. 425-435. doi: 10.1093/aesa/53.3.425.

Bohart, R. M. and Menke, A. S. (1976) Sphecid Wasps of the World: A Generic Revision. Berkley: University of California Press. Available at: https://archive.org/details/bub_gb_FExMjuRhjpIC/page/n15/mode/2up.

Bosch, J., Kemp, W. P. and Peterson, S. S. (2000) 'Management of Osmia lignaria (Hymenoptera: Megachilidae) populations for almond pollination: Methods to advance bee emergence', Environmental Entomology, 29(5), pp. 874-883. doi: 
10.1603/0046-225X-29.5.874.

Boyle, N. K. and Pitts-Singer, T. L. (2019) 'Assessing blue orchard bee (Osmia lignaria) propagation and pollination services in the presence of honey bees (Apis mellifera) in Utah tart cherries', PeerJ, 2019(9). doi: 10.7717/peerj.7639.

Budriene, A., Budrys, E. and Nevronyte, Ž. (2004) 'Solitary Hymenoptera Aculeata inhabiting trap-nests in Lithuania: nesting cavity choice and nice overlap', Latvijas Entomologs, 41(January), pp. 19-31.

Cane, J. H., Griswold, T. and Parker, F. D. (2007) 'Substrates and materials used for nesting by North American Osmia bees (Hymenoptera: Apiformes: Megachilidae)', Annals of the Entomological Society of America, 100(3), pp. 350358. doi: 10.1603/0013-8746(2007)100[350:SAMUFN]2.0.CO;2.

Delphia, C. M. and O’Neill, K. M. (2012) 'Supersedure of Isodontia mexicana (Saussure) (Hymenoptera: Sphecidae) Nests by Megachile rotundata (F.) (Hymenoptera: Megachilidae): Do bees destroy wasp cocoons?', Journal of the Kansas Entomological Society, 85(4), pp. 380-383. doi: 10.2317/0022-8567-85.4.380.

Droege, S. W. and Shapiro, L. H. (2011) 'An August Survey of Wild Bees (Hymenoptera: Apoidea) in the Northeastern Port Areas of Baltimore, Maryland and the Second North American Record of Pseudoanthidium nanum (Mocsáry)', Maryland Entomological Society, 5(3), pp. 33-44.

Evans, H. E. (1969) 'Notes on the Nesting Behavior of Pisonopsis clypeata and Belomicrus forbesii (Hymenoptera, Sphecidae)', Journal of Kansas Enotomological Society, 42(2), pp. 117-125.

Everaars, J. et al. (2011) 'Microsite conditions dominate habitat selection of the red mason bee (Osmia bicornis, Hymenoptera: Megachilidae) in an urban environment: A case study from Leipzig, Germany', Landscape and Urban Planning. doi: 10.1016/j.landurbplan.2011.05.008.

Fateryga, A. V., Protsenko, Y. V. and Zhidkov, V. Y. (2014) 'Isodontia mexicana (Hymenoptera, Sphecidae), a new invasive wasp species in the fauna of Ukraine reared from trap-nests in the Crimea', Vestnik Zoologii, 48(2). doi: 10.2478/vzoo2014-0020.

Fortel, L. et al. (2014) 'Decreasing abundance, increasing diversity and changing structure of the wild bee community (Hymenoptera: Anthophila) along an urbanization gradient', PLoS ONE, 9(8). doi: 10.1371/journal.pone.0104679.

Fortel, L. et al. (2016) 'Use of human-made nesting structures by wild bees in an urban 
environment', Journal of Insect Conservation. Springer International Publishing, 20(2), pp. 239-253. doi: 10.1007/s10841-016-9857-y.

Frankie, G. W. et al. (1998) 'Monitoring Solitary Bees in Modified Wildland Habitats: Implications for Bee Ecology and Conservation', Environmental Entomology, 27(5), pp. 1137-1148. doi: 10.1093/ee/27.5.1137.

Fye, R. E. (1965a) 'Biology of Apoidea Taken in Trap Nests in Northwestern Ontario (Hymenoptera)', The Canadian Entomologist, 97(8), pp. 863-877. doi: 10.4039/Ent97863-8.

Fye, R. E. (1965b) 'The Biology of the Vespidae, Pompilidae, and Sphecidae (Hymenoptera) from Trap Nests in Northwestern Ontario', The Canadian Entomologist, 97(7), pp. 716-744. doi: 10.4039/Ent97716-7.

Grixti, J. C. and Packer, L. (2006) 'Changes in the bee fauna (Hymenoptera: Apoidea) of an old field site in southern Ontario, revisited after 34 years', Canadian Entomologist, 138(2), pp. 147-164. doi: 10.4039/N05-034.

Groulx, A. F. and Forrest, J. R. K. (2018) 'Nesting aggregation as a predictor of brood parasitism in mason bees (Osmia spp.)', Ecological Entomology. Blackwell Publishing Ltd, 43(2), pp. 182-191. doi: 10.1111/een.12484.

Guisse, J. K. and Miller, D. G. (2011) 'Distribution and habitat preferences of Osmia lignaria (Hymenoptera: Megachilidae) and associated cavity-nesting insects in California's Sierra Nevada foothills adjacent to the Sacramento Valley', PanPacific Entomologist, 87(3), pp. 188-195. doi: 10.3956/2007-45.1.

Hallett, P. E. (2011) Farmed Solitary Bees \& Wasps, Data Set (generations 1997-2008), University of Toronto TSpace. Available at: https://tspace.library.utoronto.ca/handle/1807/30434 (Accessed: 14 April 2021).

Hobbs, G. A. and Lilly, C. E. (1954) 'Ecology of Species of Megachile Latreille in the Mixed Prairie Region of Southern Alberta with Special Reference to Pollination of Alfalfa, Ecology, 35(4), pp. 453-462.

Hunter, D. (2020) Crown Bees. Available at: https://crownbees.com (Accessed: 27 July 2020).

Hurd, Jr., P. D. and Michener, C. D. (1955) 'The Megachiline bees of California', Bulletin of the California Insect Survey, 3(May 31, 1955), p. 247.

Jackson, A. (2019) 'The Bees of the Willamette Valley A Comprehensive Guide to Genera'. 
Jordan, S. F. et al. (2014) Pollinator Habitat Assessment Form and Guide: Natural Areas and Rangelands. Xerces Society for Invertebrate Conservation.

Jordan, S. F. et al. (2019) Habitat Assessment Guide for Pollinators in Yards, Gardens, and Parks, Xerces Society for Invertebrate Conservation.

Kemp, W. P. and Bosch, J. (2000) 'Development and emergence of the alfalfa pollinator Megachile rotundata (Hymenoptera: Megachilidae)', Annals of the Entomological Society of America. doi: 10.1603/0013-8746(2000)093[0904:daeota]2.0.co;2.

Kilpatrick, S. K. et al. (2020) 'An updated checklist of the bees (Hymenoptera, Apoidea, Anthophila) of Pennsylvania, United States of America', Journal of Hymenoptera Research, 77, pp. 1-86. doi: 10.3897/jhr.77.49622.suppl9.

Kits, J. H., Marshall, S. A. and Evenhuis, N. L. (2008) 'The Bee Flies (Diptera: Bombyliidae) of Ontario, with a Key to the Species of Eastern Canada', Canadian Journal of Arthropod Identification, 6, pp. 1-52. doi: 10.3752/cjai.2008.06.

Kline, O. and Joshi, N. K. (2020) 'Mitigating the effects of habitat loss on solitary bees in agricultural ecosystems', Agriculture (Switzerland), 10(4). doi: 10.3390/agriculture 10040115 .

Klostermeyer, E. C. and Gerber, H. S. (1969) 'Nesting Behavior of Megachile rotundata (Hymenoptera: Megachilidae) Monitored with an Event Recorder', Annals of the Entomological Society of America, 62(6), pp. 1321-1325. doi: 10.1093/aesa/62.6.1321.

von Königslöw, V. et al. (2019) 'Benchmarking nesting aids for cavity-nesting bees and wasps', Biodiversity and Conservation. Springer Netherlands, 28(14), pp. 38313849. doi: 10.1007/s10531-019-01853-1.

Kopec, K. and Burd, L. A. (2017) 'Pollinators In Peril: A systematic status review of North American and Hawaiian native bees', Center For Biological Diversity. doi: 10.1038/443893a.

Kraemer, M. E., Favi, F. D. and Niedziela, C. E. (2014) 'Nesting and Pollen Preference of Osmia lignaria lignaria (Hymenoptera: Megachilidae) in Virginia and North Carolina Orchards', Environmental Entomology, 43(4), pp. 932-941. doi: 10.1603/en13219.

Krombein, K. V. (1967) Trap-nesting wasps and bees: Life histories, nests, and associates, Smithsonian Press. doi: 10.5962/bhl.title.46295.

Langellotto, G. (2019) Megachile Bees from Portland-Area Gardens, Garden Ecology 
Lab. Available at:

https://blogs.oregonstate.edu/gardenecologylab/2019/12/05/megachile-bees-fromportland-area-gardens/ (Accessed: 7 February 2021).

Laurelby (2018) Pseudoanthidium nanum, iNaturalist. Available at: https://www.inaturalist.org/observations/14356133 (Accessed: 28 August 2020).

Litman, J. R. (2012) Phylogentic Systematics and the Evolution of Nesting Behavior, Host-plant Preference, and Cleptoparasitism in the Bee Family Megachilidae (Hymenoptera, Apoidea). Cornell Universtiy.

Loyola, R. D. and Martins, R. P. (2008) 'Habitat structure components are effective predictors of trap-nesting Hymenoptera diversity', Basic and Applied Ecology, 9(6), pp. 735-742. doi: 10.1016/j.baae.2007.06.016.

Loyola, R. D. and Martins, R. P. (2011) 'Small-scale area effect on species richness and nesting occupancy of cavity-nesting bees and wasps', Revista Brasileira de Entomologia, 55(1). doi: 10.1590/S0085-56262011000100011.

MacIvor, J. S. (2015) 'Building height matters: nesting activity of bees and wasps on vegetated roofs', Israel Journal of Ecology \& Evolution, 62(1-2), pp. 88-96. doi: 10.1080/15659801.2015.1052635.

MacIvor, J. S. (2017) 'Cavity-nest boxes for solitary bees: A century of design and research', Apidologie, 48(3), pp. 311-327. doi: 10.1007/s13592-016-0477-z.

MacIvor, J. S. (2019) 'Adult emergence order in a community of cavity-nesting bees and wasps, and their parasites', bioRxiv, pp. 1-26. doi: 10.1101/556456.

MacIvor, J. S. and Packer, L. (2015) "'Bee hotels" as tools for native pollinator conservation: A premature verdict?', PLoS ONE, 10(3), pp. 1-13. doi: 10.1371/journal.pone.0122126.

Macivor, J. S. and Salehi, B. (2014) 'Bee Species-Specific Nesting Material Attracts a Generalist Parasitoid: Implications for Co-occurring Bees in Nest Box Enhancements', Environmental Entomology, 43(4), pp. 1027-1033. doi: https://doi.org/10.1603/EN13241.

Mallinger, R. E., Werts, P. and Gratton, C. (2015) 'Pesticide use within a pollinatordependent crop has negative effects on the abundance and species richness of sweat bees, Lasioglossum spp., and on bumble bee colony growth', Journal of Insect Conservation. doi: 10.1007/s10841-015-9816-z.

Marston, N. L. (1970) 'Revision of New World species of Anthrax (Diptera: 
Bombyliidae), other than the Anthrax albofasciatus group', Smithsonian Contributions to Zoology, (43), pp. 1-148. doi: 10.5479/si.00810282.43.

Matteson, K. C., Grace, J. B. and Minor, E. S. (2013) 'Direct and indirect effects of land use on floral resources and flower-visiting insects across an urban landscape', Oikos, 122(5), pp. 682-694. doi: 10.1111/j.1600-0706.2012.20229.x.

Matthews, R. W. et al. (2009) 'Biology of the parasitoid Melittobia (Hymenoptera: Eulophidae)', Annual Review of Entomology, 54, pp. 251-266. doi: 10.1146/annurev.ento.54.110807.090440.

Matthews, W. R. (1965) The biology of Heridaes carinata Cresson (Hymenoptera: Megachilidae). Michigan State University. Available at: https://d.lib.msu.edu/etd/12000/datastream/OBJ/view.

Medler, J. T. (1967a) 'Biology of Osmia in Trap Nests in Wisconsin (Hymenoptera: Megachilidae)1', Annals of the Entomological Society of America, 60(2), pp. 338344. doi: 10.1093/aesa/60.2.338.

Medler, J. T. (1967b) 'Biology of Trypoxylon in Trap Nests in Wisconsin (Hymenoptera : Sphecidae)', The American Midland Naturalist, 78(2), pp. 344358.

Michener, C. D. (1947) 'A Character Analysis of a Solitary Bee, Hoplitis albifrons (Hymenoptera, Megachilidae)', Evolution, 1(3), p. 172. doi: 10.2307/2405493.

Michener, C. D. (1953) 'The Biology of a Leafcutter Bee (Megachile brevis) and Its Associates', The University of Kansas Science Bulletin, 35(3), pp. 1659-1748.

Michener, C. D. (2000) The Bees of the World. Baltimore, MD and London, UK: The Johns Hopkins University Press.

Michener, C. D. (2007) The Bees of the World. 2nd edn. Baltimore, MD: The Johns Hopkins University Press.

Minckley, R. L. and Danforth, B. N. (2019) 'Sources and frequency of brood loss in solitary bees', Apidologie, 50(4), pp. 515-525. doi: 10.1007/s13592-019-00663-2.

Minnesota Bee Atlas (2021). Available at:

https://apps.extension.umn.edu/environment/citizen-science/bee-atlas/ (Accessed: 16 May 2021).

Mitchell, T. B. (1962) 'Bees of the Eastern United States', North Carolina Agricultural Experiment Station Technical Bulletin, 152(2), pp. 1-557. Available at: 
https://projects.ncsu.edu/cals/entomology/museum/easternBees.php.

Moisset, B. B. and Buchmann, S. (2011) 'Bee Basics: An Introduction to Our Native Bees', USDA Forest Service and Pollinator Partnership, pp. 1- 40.

Morris, S. (2018) Teeny tiny Anthidiini, BugGuide. Available at: https://bugguide.net/node/view/1566202 (Accessed: 28 August 2020).

Musicante, M. L. and Salvo, A. (2010) 'Nesting biology of four species of Trypoxylon (Trypargilum) (Hymenoptera: Crabronidae) in Chaco Serrano Woodland, Central Argentina', Revista de Biologia Tropical, 58(4), pp. 1177-1188. doi: 10.15517/rbt.v58i4.5403.

Natter, J. R. (2021) A New Pest of Mason Bees: The "Houdini" Fly. Available at: https://blogs.oregonstate.edu/mgmetro/2021/01/10/a-new-pest-of-mason-bees-thehoudini-fly/.

Nether, M. C., Dudek, J. and Buschini, M. L. T. (2019) 'Trophic interaction and diversity of cavity-nesting bees and wasps (Hymenoptera: Aculeata) in Atlantic forest fragments and in adjacent matrices', Apidologie, 50(1), pp. 104-115. doi: 10.1007/s13592-018-0623-x.

O'Neill, K. M. et al. (2010) 'Offspring size and sex ratio variation in a feral population of alfalfa leafcutting bees (Hymenoptera: Megachilidae)', Annals of the Entomological Society of America, 103(5), pp. 775-784. doi: 10.1603/AN09183.

O’Neill, K. M. and O’Neill, J. F. (2010) 'Cavity-Nesting Wasps and Bees of Central New York State: The Montezuma Wetlands Complex', Northeastern Naturalist, 17(3), pp. 455-472. doi: 10.1656/045.017.0307.

O’Neill, K. M. and O’Neill, J. F. (2013) 'Cavity-Nesting Wasps and Bees (Hymenoptera) of Central New York State: The Roy H. Park Preserve and Dorothy McIlroy Bird Sanctuary', Proceedings of the Entomological Society of Washington, 115(2), pp. 158-166. doi: 10.4289/0013-8797.115.2.158.

O’Neill, K. M. and O’Neill, J. F. (2018) 'Cavity-Nesting Wasps and Bees (Hymenoptera) of Central New York State: Finger Lakes National Forest', Proceedings of the Entomological Society of Washington. doi: 10.4289/0013-8797.120.2.260.

O’Neill, K. M. and O'Neill, R. P. (2003) 'Sex Allocation, Nests, and Prey in the GrassCarrying Wasp Isodontia mexicana (Saussure) (Hymenoptera: Sphecidae)', Journal of the Kansas Entomological Society, 76(3), pp. 447-454.

O’Neill, K. M. and O’Neill, R. P. (2007) 'Nests and Prey of Isodontia elegans (F. Smith) 
(Hymenoptera: Sphecidae) in Montana, U.S.A.', Entomological News, 118(2), pp. 139-142. doi: 10.3157/0013-872X(2007)118[139:NAPOIE]2.0.CO;2.

Oram, R. J. (2018) Revision of the Genus Hylaeus fabricius (Hymenoptera: Colletidae) in Canada. University of Regina.

Oregon Bee Atlas (2020) Oregon State University Extension Service. Available at: https://extension.oregonstate.edu/bee-atlas (Accessed: 12 January 2021).

Parker, F. D. and Bohart, G. E. (1979) 'Dolichostelis, a New Genus of Parasitic Bees (Hymenoptera: Megachilidae)', Journal of the Kansas Entomological Society, 52(1), pp. 138-153.

Parker, F. D. and Bohart, R. M. (1966) 'Host-Parasite Association in some Twig-Nesting Hymenoptera from Western North America', The Pan-Pacific Entomologist, 42(2), pp. 91-98.

Peckham, G. W. and Peckham, Elizabeth, G. (1898) 'On the Instincts and Habits of the Solitary Wasps', Wisconsin Geological and Natural History Survey, 2(1), pp. 1245. doi: 10.1126/science.8.207.876.

Phillips, J. K. and Klostermeyer, E. C. (1978) 'Nesting Behavior of Osmia lignaria propinqua Cresson (Hymenoptera: Megachilidae)', Journal of the Kansas Entomological Society, 51(1), pp. 91-108.

Pickering, J. (2009) Database of Hymenoptera in America north of Mexico, Proceedings of Life. Available at: https://www.discoverlife.org/proceedings/0000/6/.

Pitts-Singer, T. L. and Cane, J. H. (2011) 'The alfalfa leafcutting bee, Megachile rotundata: The world's most intensively managed solitary bee', Annual Review of Entomology, 56, pp. 221-237. doi: 10.1146/annurev-ento-120709-144836.

Portman, Z. M. et al. (2019) 'First records of the adventive Pseudoanthidium nanum (Mocsáry) (Hymenoptera: Megachilidae) in illinois and Minnesota, with notes on its identification and taxonomy', Great Lakes Entomologist, 52(1-2), pp. 12-20.

Portman, Z. M., Bruninga-Socolar, B. and Cariveau, D. P. (2020) 'The State of Bee Monitoring in the United States: A Call to Refocus Away from Bowl Traps and towards More Effective Methods', Annals of the Entomological Society of America, 113(5), pp. 337-342. doi: 10.1093/aesa/saaa010.

Ratzlaff, C. (2015) 'Checklist of the Spheciform Wasps (Hymenoptera: Crabronidae \& Sphecidae) of British Columbia', Journal of the Entomological Society of British Columbia, 112, pp. 19-46. 
Rau, P. (1937) 'The Life-Histroy of Osmia lignaria and $O$. cordata with notes on $O$. conjuncta', Annals of the Entomological Society of America, 30(2), pp. 324-343.

Richards, K. W. (1984) 'Alfalfa leafcutter bee management in Western Canada', Agriculture Canada, (1945/E). Available at:

https://static1.squarespace.com/static/5a849d4c8dd041c9c07a8e4c/t/5aa1bb26816 5f552c51eb6a8/1520548655146/A53-1495-1984-eng.pdf.

Rubene, D., Schroeder, M. and Ranius, T. (2015) 'Estimating bee and wasp (Hymenoptera: Aculeata) diversity on clear-cuts in forest landscapes - an evaluation of sampling methods', Insect Conservation and Diversity, 8(3). doi: 10.1111/icad.12105.

Sánchez-Bayo, F. and Wyckhuys, K. A. G. (2019) 'Worldwide decline of the entomofauna: A review of its drivers', Biological Conservation, 232(September 2018), pp. 8-27. doi: 10.1016/j.biocon.2019.01.020.

Sandhouse, G. A. (1939) 'The North American bees of the genus Osmia (Hymenoptera: Apoidea)'. Washington, D.C.: The Entomological Society of Washington (Memoirs of the Entomological Society of Washington; no. 1). Available at: file://catalog.hathitrust.org/Record/008556273.

Sandhouse, G. A. (1940) 'A Review of the Nearctic Wasps of the Genus Trypoxylon (Hymenoptera: Sphecidae)', The American Midland Naturalist, 24(1), pp. 133176.

Satyshur, C. et al. (2020) How to create habitat for stem-nesting bees. Available at: https://www.beelab.umn.edu/sites/beelab.umn.edu/files/stem-nesting-beehandout-v5.pdf.

Satyshur, C. D. et al. (2020) 'Minnesota State Records for Osmia georgica, Megachile inimica, and Megachile frugalis (Hymenoptera, Megachilidae), Including a New Nest Description for Megachile frugalis Compared with Other Species in the Subgenus Sayapis', The Great Lakes Entomologist Volume, 53(2), pp. 109-118.

Scott, V. L. and Strickler, K. (1992) 'New Host Records for Two Species of Anthrax (Diptera: Bombyliidae)', Journal of the Kansas Entomological Society, 65(4), pp. 393-402.

Sgolastra, F. et al. (2016) 'Pre-wintering conditions and post-winter performance in a solitary bee: Does diapause impose an energetic cost on reproductive success?', Ecological Entomology. doi: 10.1111/een.12292.

Sheffield, C. S. et al. (2011) 'Leafcutter and Mason Bees of the Genus Megachile 
Latreille (Hymenoptera: Megachilidae) in Canada and Alaska', Canadian Journal of Arthropod Identification, (18), pp. 1-107. doi: 10.3752/cjai.2011.18.

Snelling, R. R. (1990) 'A review of the native North American bees of the genus Chalicodoma (Hymenoptera: Megachilidae)', Contributed Science, Los Angeles County Museum of Natural History, 421(421), pp. 1-39.

Stangroom, J. (2018) Chi-Square Test Calculator, Social Science Statistics. Available at: https://www.socscistatistics.com/tests/chisquare2/default2.aspx.

Stefaniesteele (2020) Tribe Trypoxylini, iNaturalist. Available at: https://www.inaturalist.org/observations/67382304 (Accessed: 14 April 2021).

Stephen, W. (1962) 'Propagation of the leaf-cutter bee for alfalfa seed production', Oregon State University Agricultural Experiment Station, 586(September), pp. 316.

Stephen, W. P. (1981) 'The Design and Function of Field Domiciles and Incubators for Leafcutting Bee Management', Oregon State University Agricultural Experiment Station Bulletin, 654(October), pp. 1-13.

Stephen, W. P. and Osgood, C. E. (1965) 'Influence of Tunnel Size and Nesting Medium on Sex Ratios in a Leaf-Cutter Bee, Megachile rotundata', Journal of Economic Entomology, 58(5), pp. 965-968. doi: 10.1093/jee/58.5.965.

Taki, H. et al. (2008) 'Artificial covering on trap nests improves the colonization of trapnesting wasps', Journal of Applied Entomology, 132(3), pp. 225-229. doi: 10.1111/j.1439-0418.2007.01237.x.

Torchio, P. F. (1976) 'Use of Osmia lignaria Say (Hymenoptera: Apoidea, Megachilidae) as a Pollinator in an Apple and Prune Orchard', Journal of the Kansas Entomological Society, 49(4), pp. 475-482.

Torchio, P. F. (1989) 'In-Nest Biologies and Development of Immature Stages of Three Osmia Species (Hymenoptera: Megachilidae)', Annals of the Entomological Society of America, 82(5), pp. 599-615. doi: 10.1093/aesa/82.5.599.

Torchio, P. F. and Tepedino, V. J. (1980) 'Sex Ratio, Body Size and Seasonality in a Solitary Bee, Osmia lignaria propinqua Cresson (Hymenoptera: Megachilidae)', Evolution, 34(5), p. 993. doi: 10.2307/2408004.

Vaughan, M. et al. (2009) Pollinator Habitat and Biology: New England Pollinator Handbook. 
Vaughan, M. et al. (2015) 'Farming for Bees: Guidelines for Providing Native Bee Habitat on Farms', The Xerces Society for Invertebrate Conservation, pp. 1-44.

Vaughan, M. and Black, S. H. (2007) 'Enhancing Nest Sites For Native Bee Crop Pollinators', USDA Agroforestry Notes, 34(February), pp. 1-4.

Vaughan, M. and Skinner, M. (2008) 'Using Farm Bill Programs for Pollinator Conservation', USDA Technical Note, (78), pp. 1-12.

Veddeler, D. et al. (2010) 'Natural enemy diversity reduces temporal variability in wasp but not bee parasitism', Oecologia, 162(3), pp. 755-762. doi: 10.1007/s00442009-1491-x.

Wcislo, W. T. (1996) 'Parasitism rates in relation to nest site in bees and wasps (Hymenoptera: Apoidea)', Journal of Insect Behavior, 9(4), pp. 643-656. doi: 10.1007/BF02213885.

Williams, F. X. (1954) 'The Wasps of the Genus Pisonopsis (Hymenoptera: Sphecidae)', Pan-Pacific Entomologist, 30(1), pp. 235-246.

Williams, N. M. et al. (2015) 'Native wildflower plantings support wild bee abundance and diversity in agricultural landscapes across the United States', Ecological Applications. doi: 10.1890/14-1748.1.

Wojcik, V. A. et al. (2008) 'Seasonality in Bees and Their Floral Resource Plants at a Constructed Urban Bee Habitat in Berkeley, California', Journal of the Kansas Entomological Society, 81(1), pp. 15-28.

Wratten, S. D. et al. (2012) 'Pollinator habitat enhancement: Benefits to other ecosystem services', Agriculture, Ecosystems and Environment. doi: 10.1016/j.agee.2012.06.020.

WSDA (2020) Houdini fly found in Washington. Available at: https://agr.wa.gov/departments/insects-pests-and-weeds/insects/apiarypollinators/pollinator-health/houdini-fly.

Yeates, D. K. and Greathead, D. (1997) 'The evolutionary pattern of host use in the Bombyliidae (Diptera): A diverse family of parasitoid flies', Biological Journal of the Linnean Society, 60(2), pp. 149-185. doi: 10.1006/bij1.1996.0097.

Yocum, G. D., Rinehart, J. P. and Kemp, W. P. (2014) 'Cell position during larval development affects postdiapause development in Megachile rotundata (Hymenoptera: Megachilidae)', Environmental Entomology, 43(4), pp. 10451052. doi: 10.1603/EN13222. 
Appendix: Nest Block Occupants

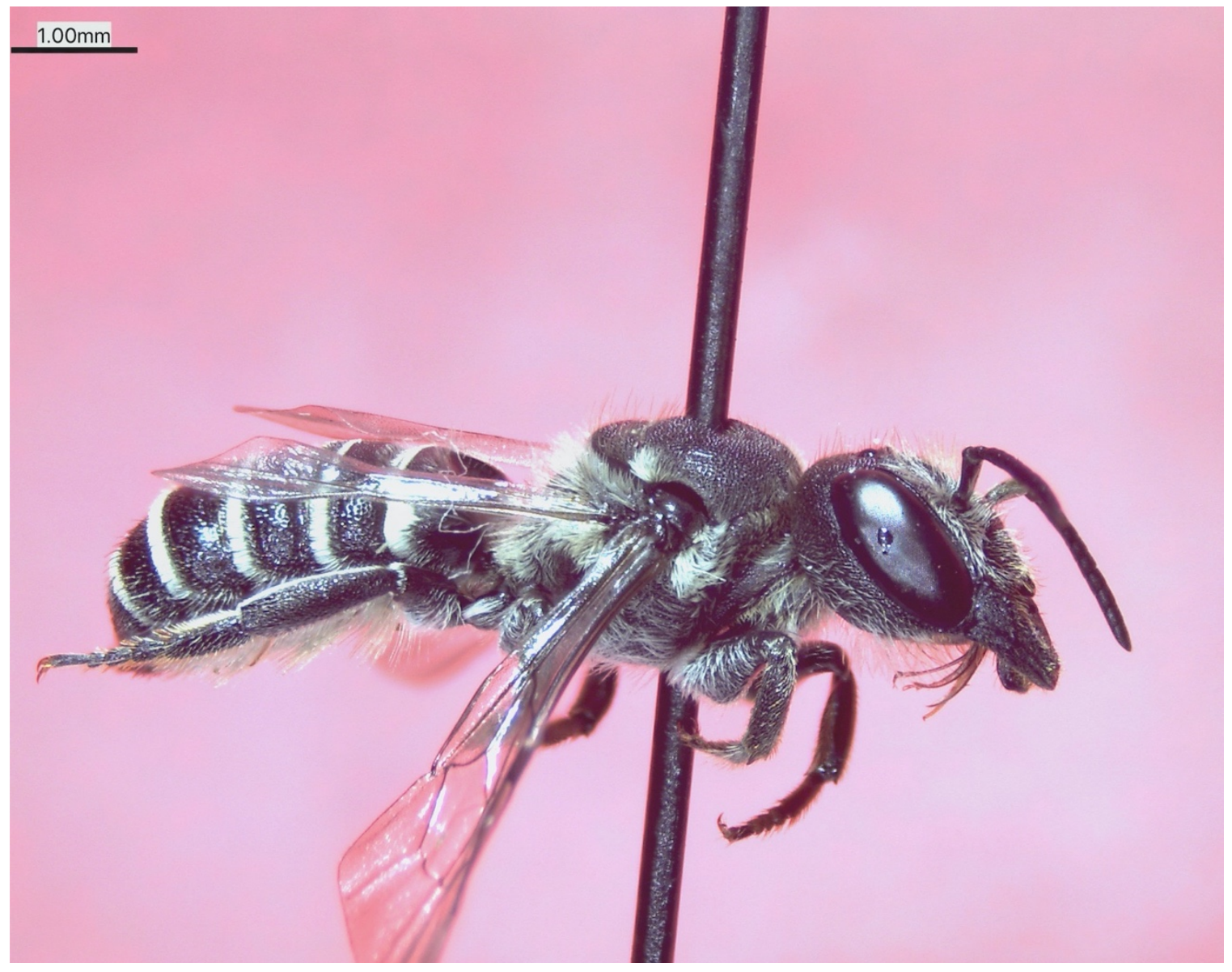

Figure 1: Female Megachile angelarum. 


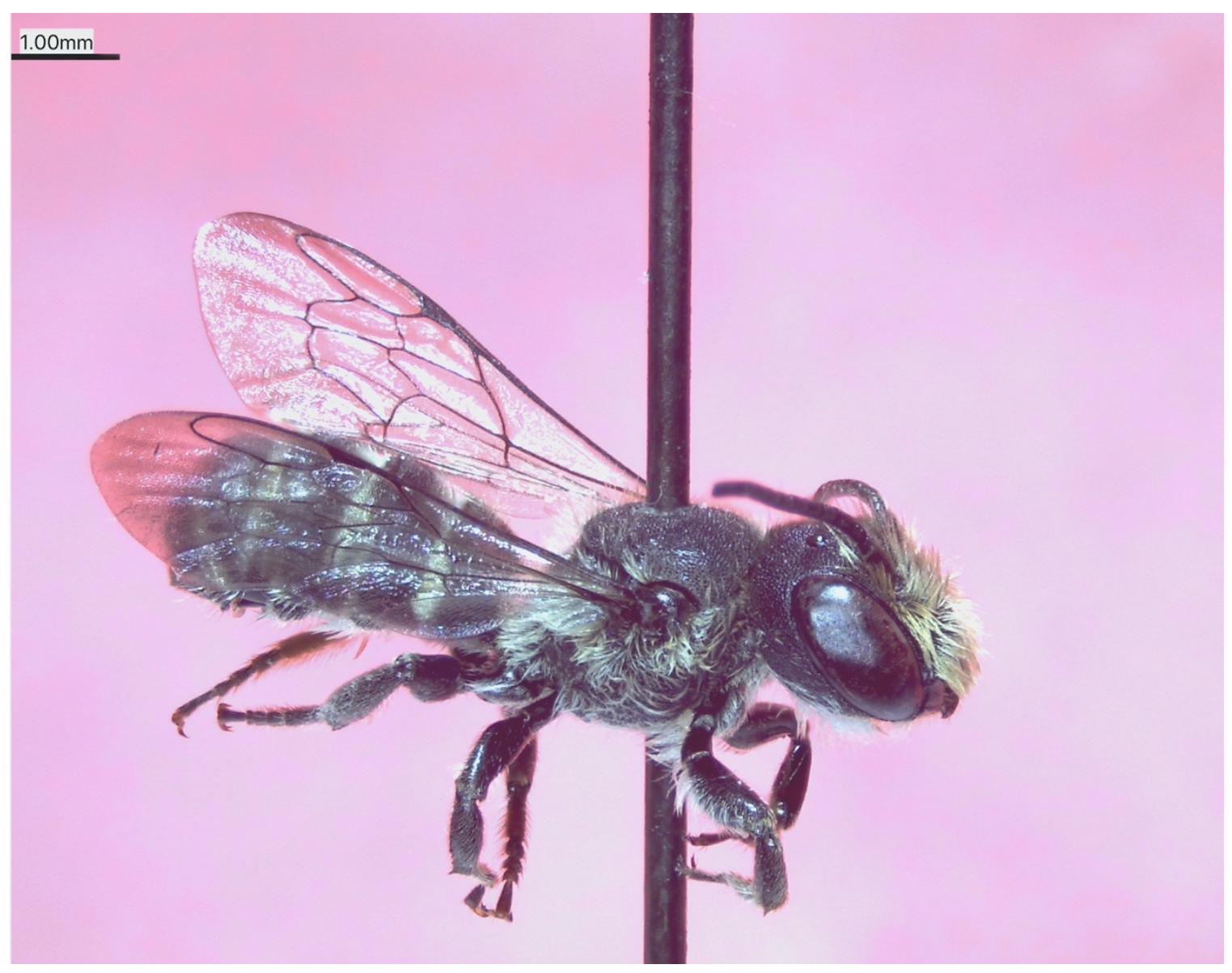

Figure 2: Male Megachile angelarum. 


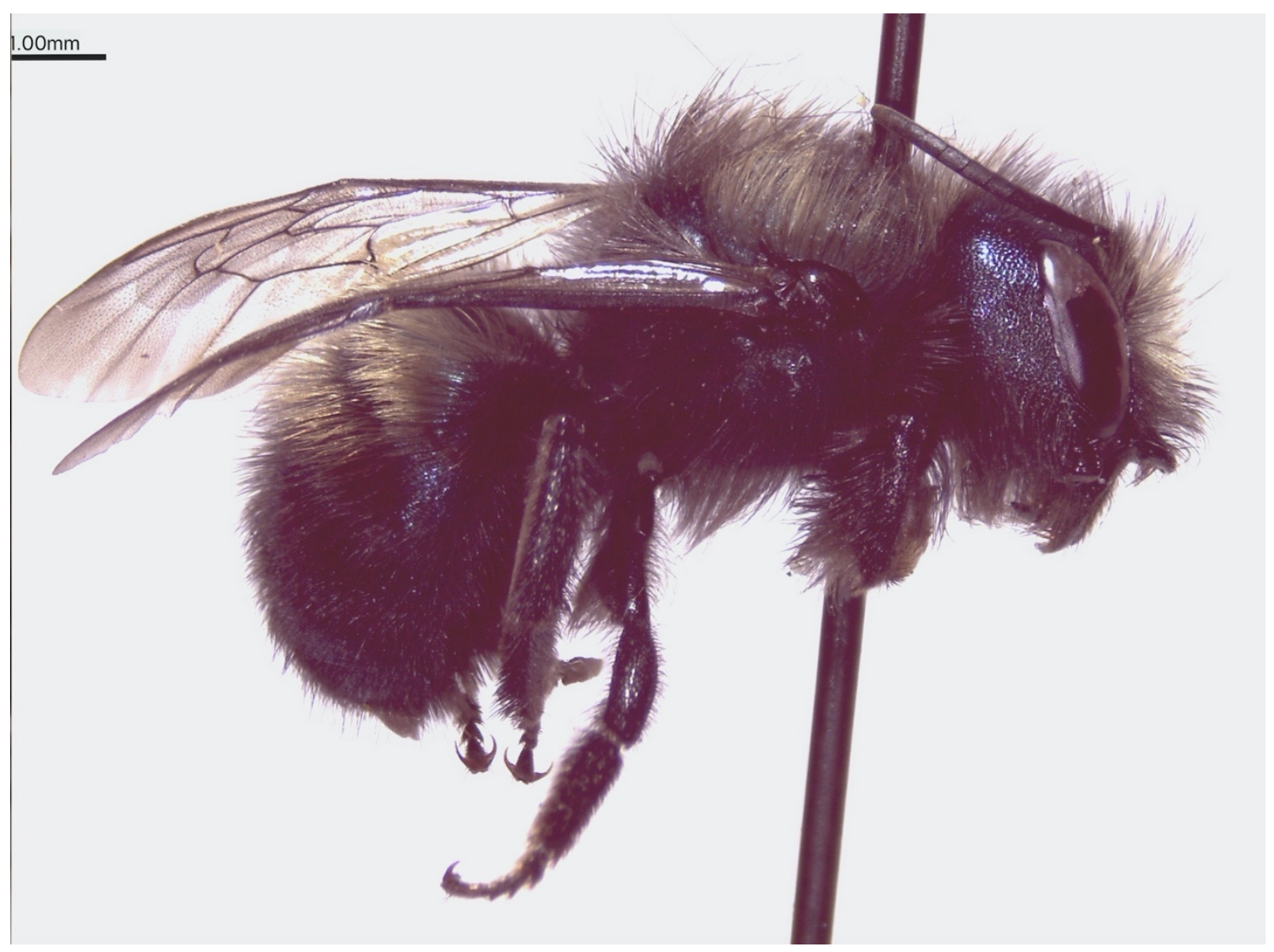

Figure 3. Female Osmia lignaria propinqua. 


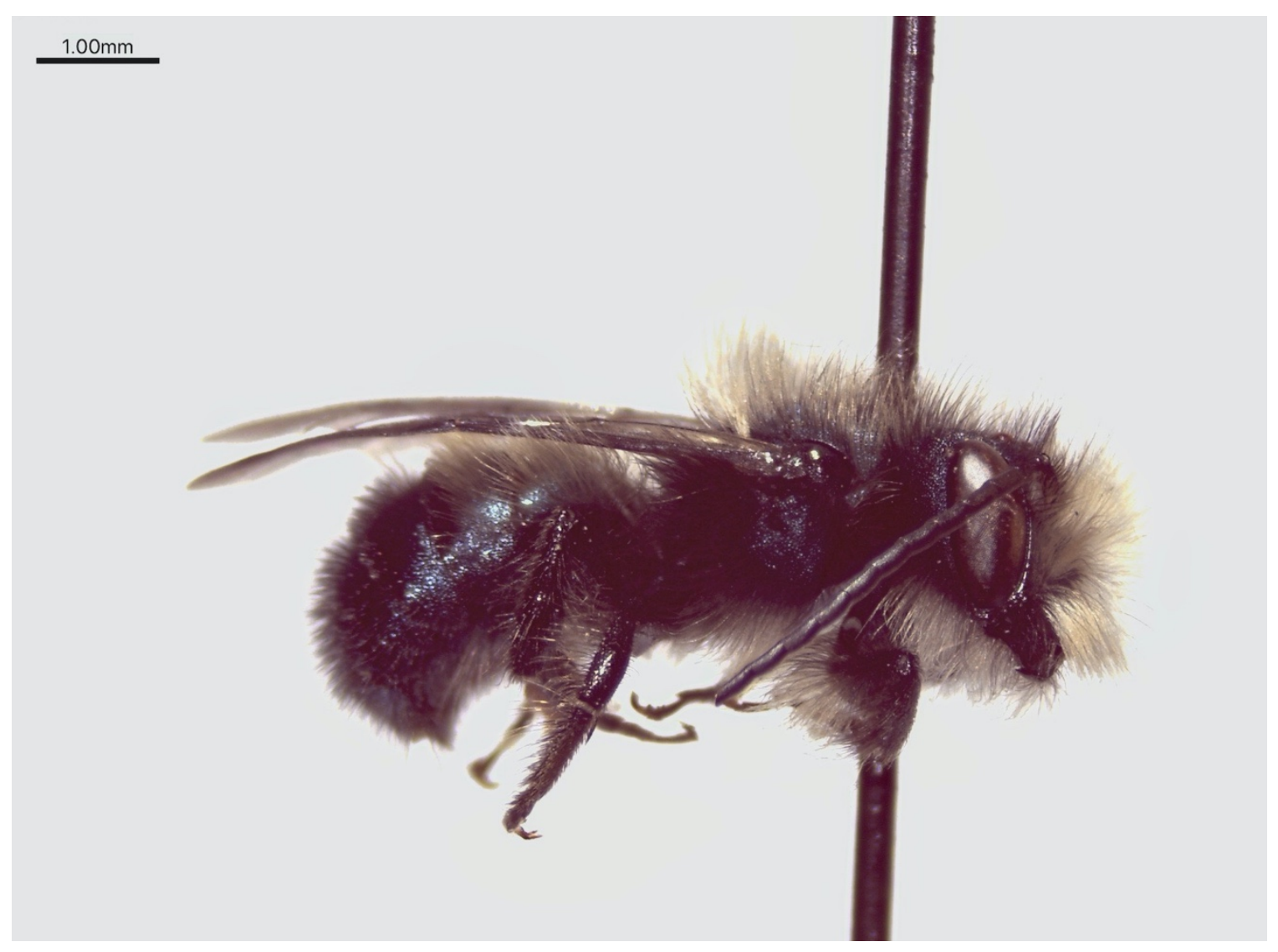

Figure 4. Male Osmia lignaria propinqua. 


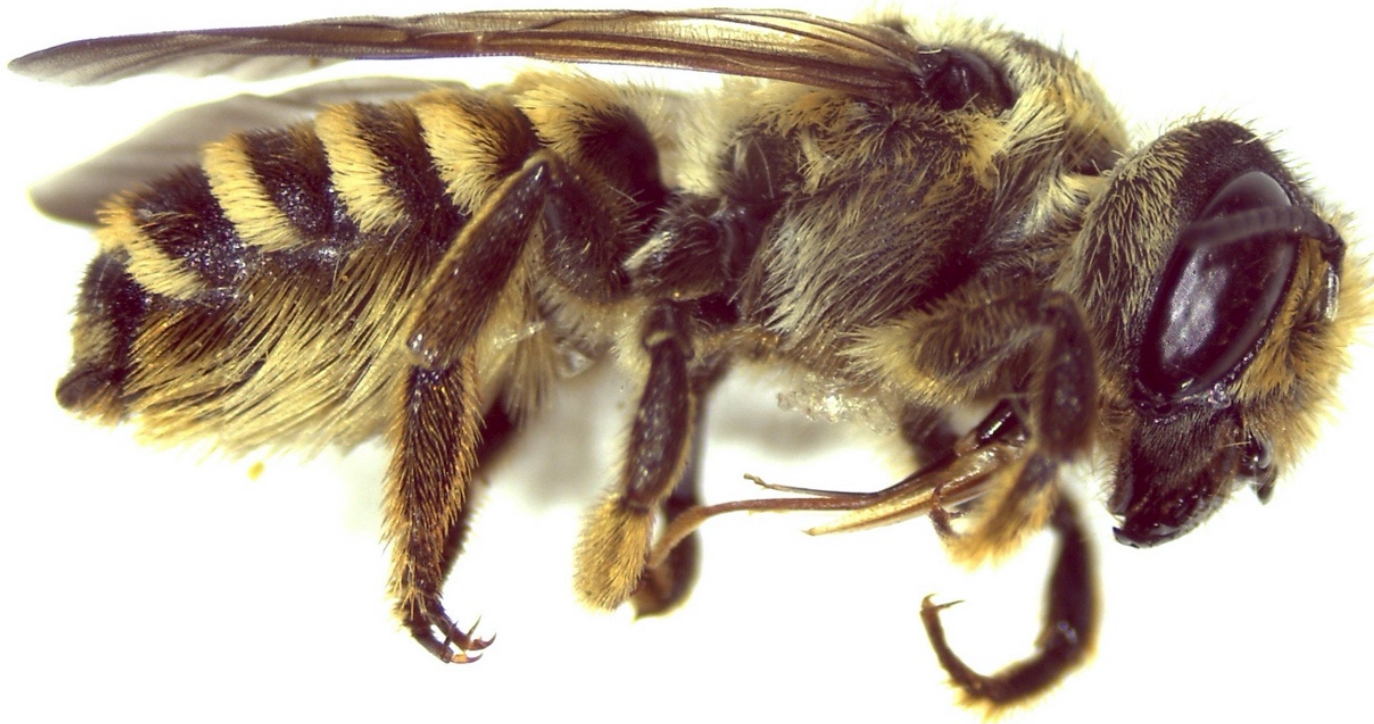

Figure 5: Female Megachile fidelis. 


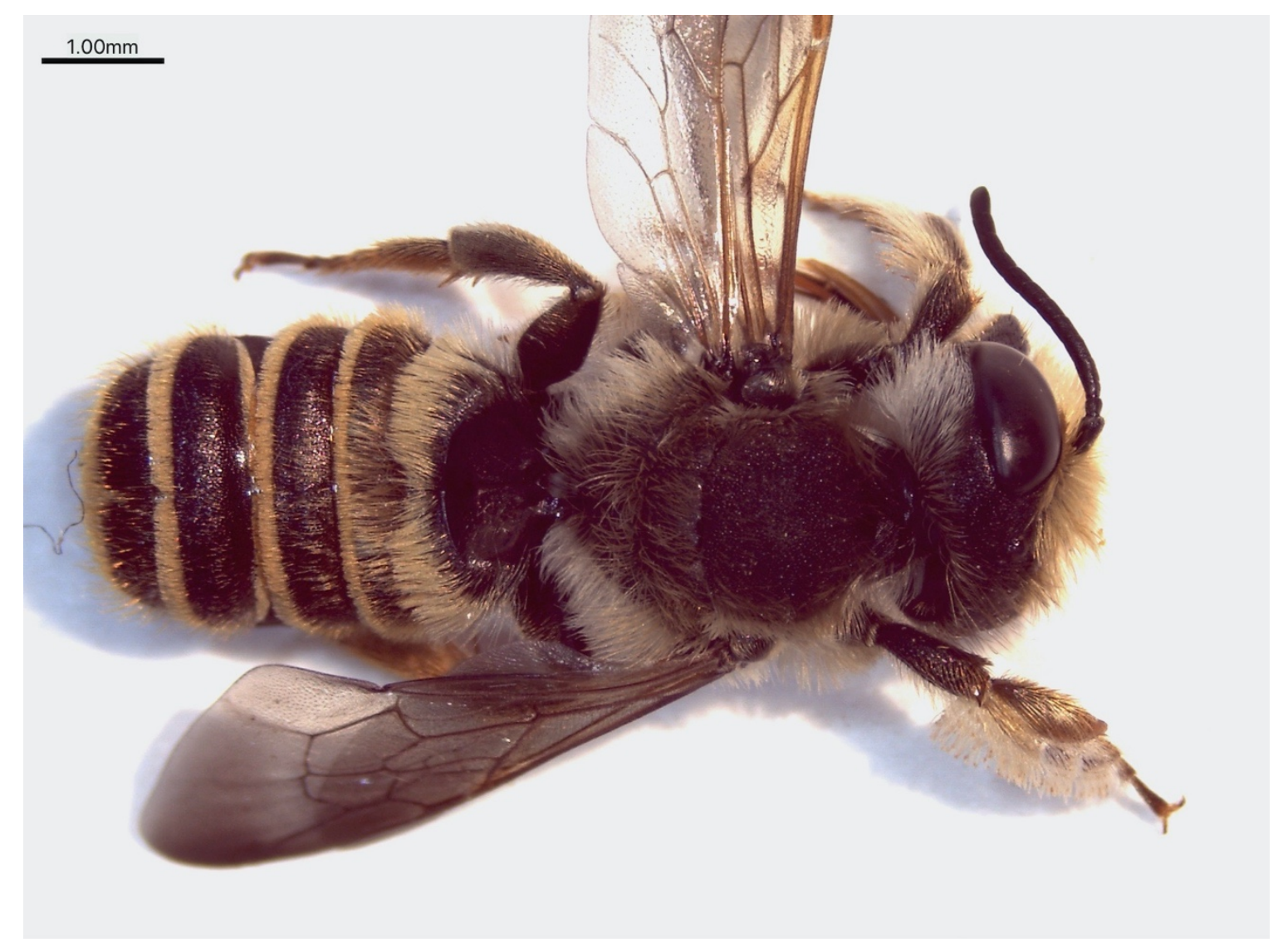

Figure 6: Male Megachile fidelis. 


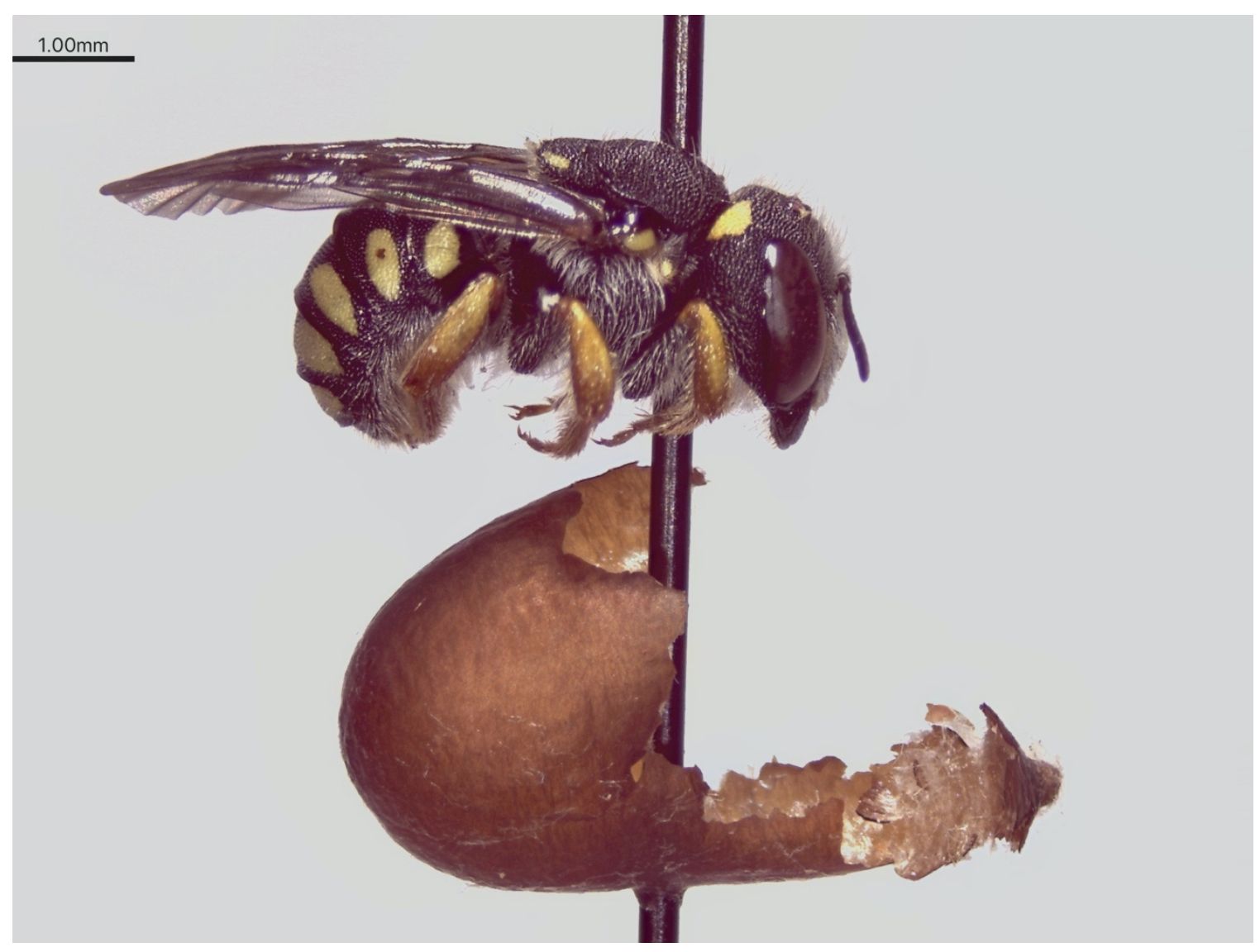

Figure 7. Female Pseudoanthidium nanum female. 


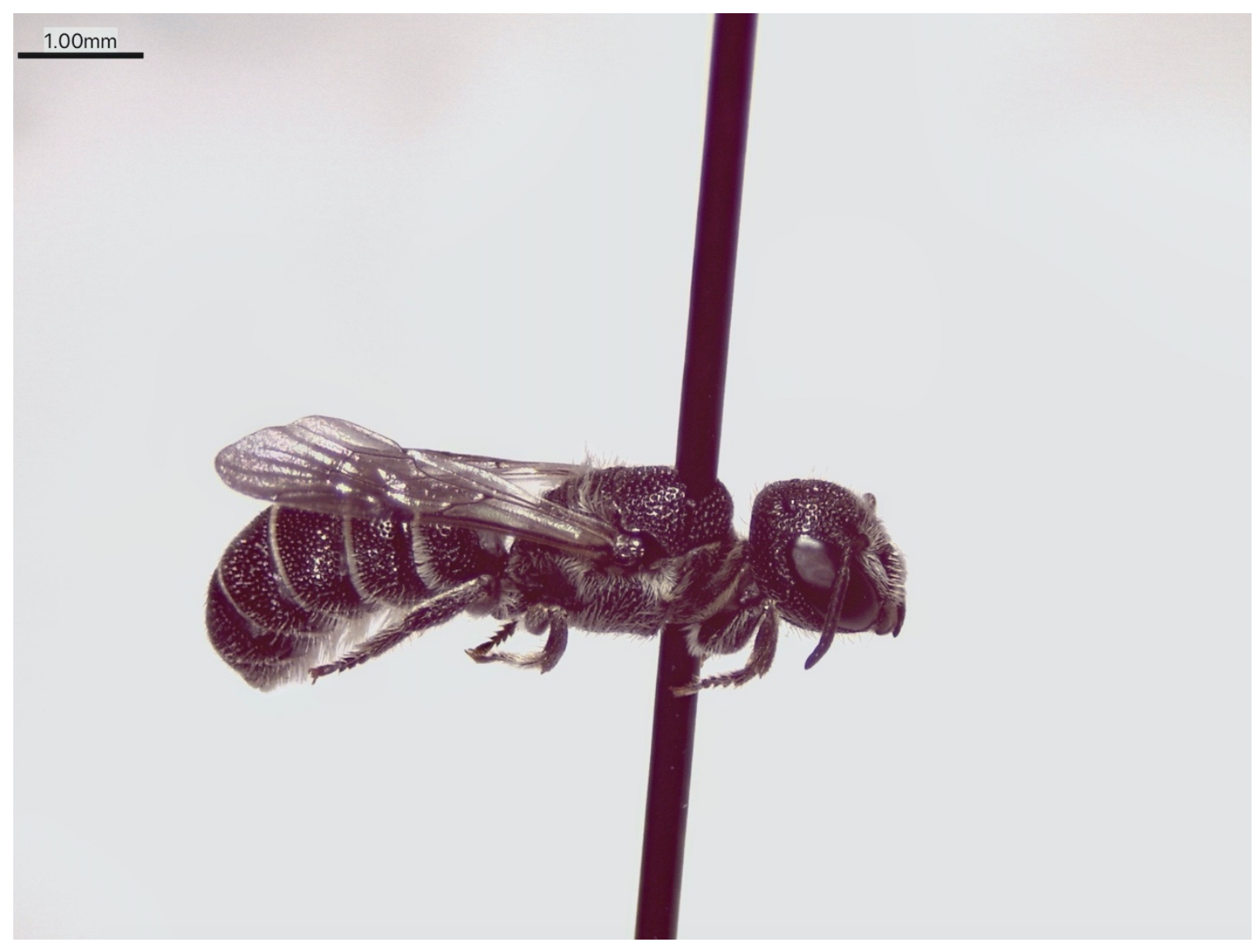

Figure 8: Female Heriades carinata. 


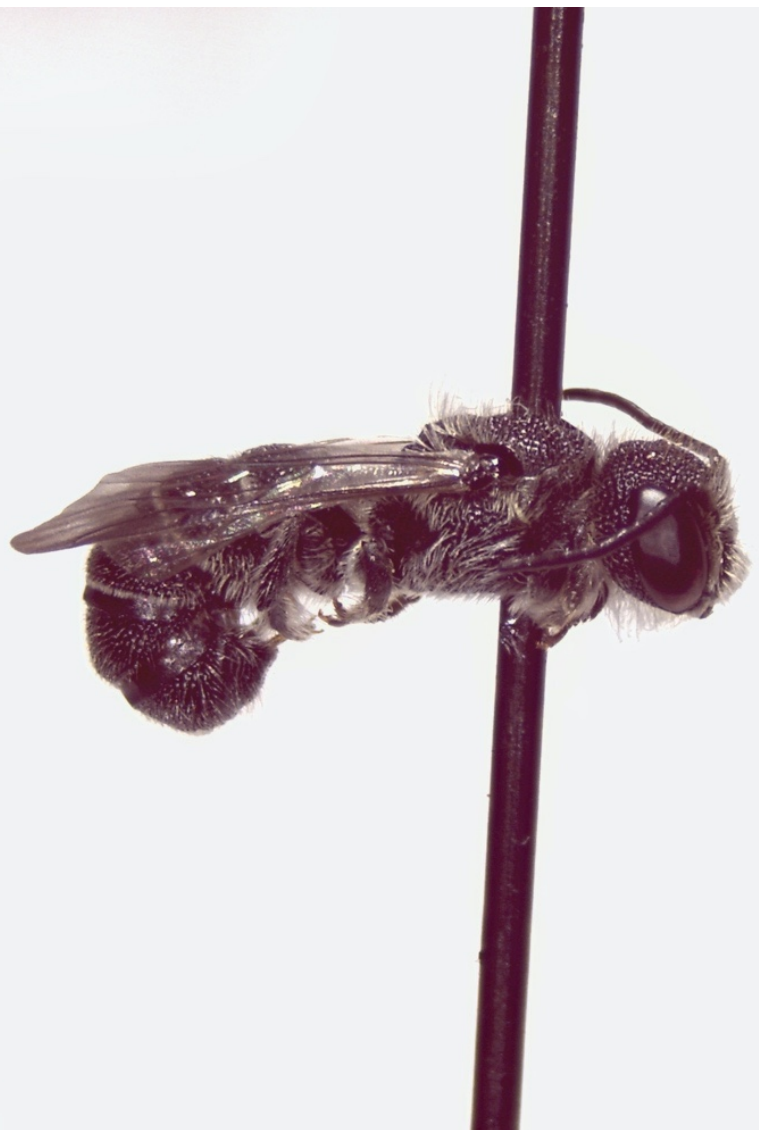

Figure 9: Male Heriades carinata. 


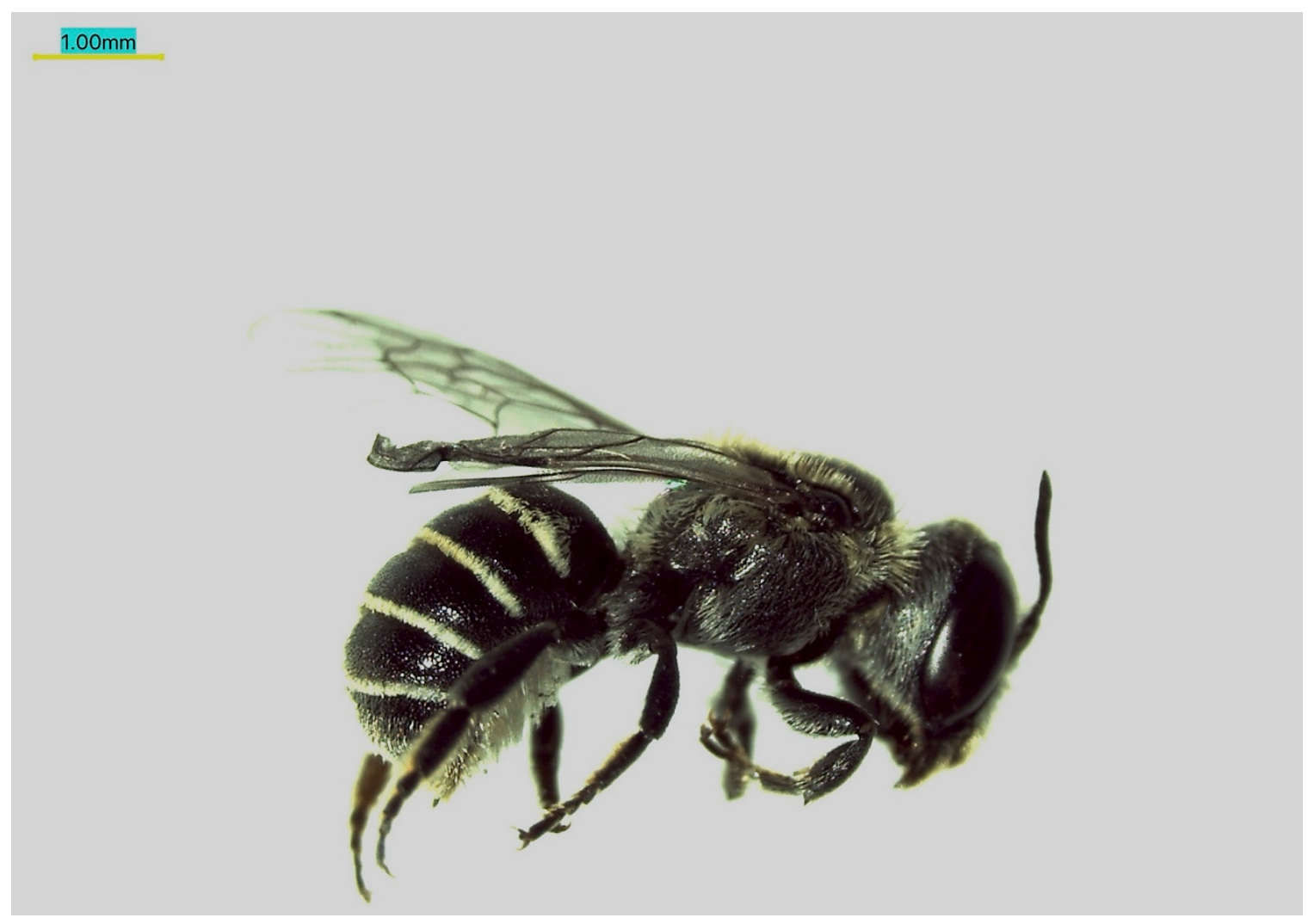

Figure 10: Female Ashmeadiella cactorum cactorum.

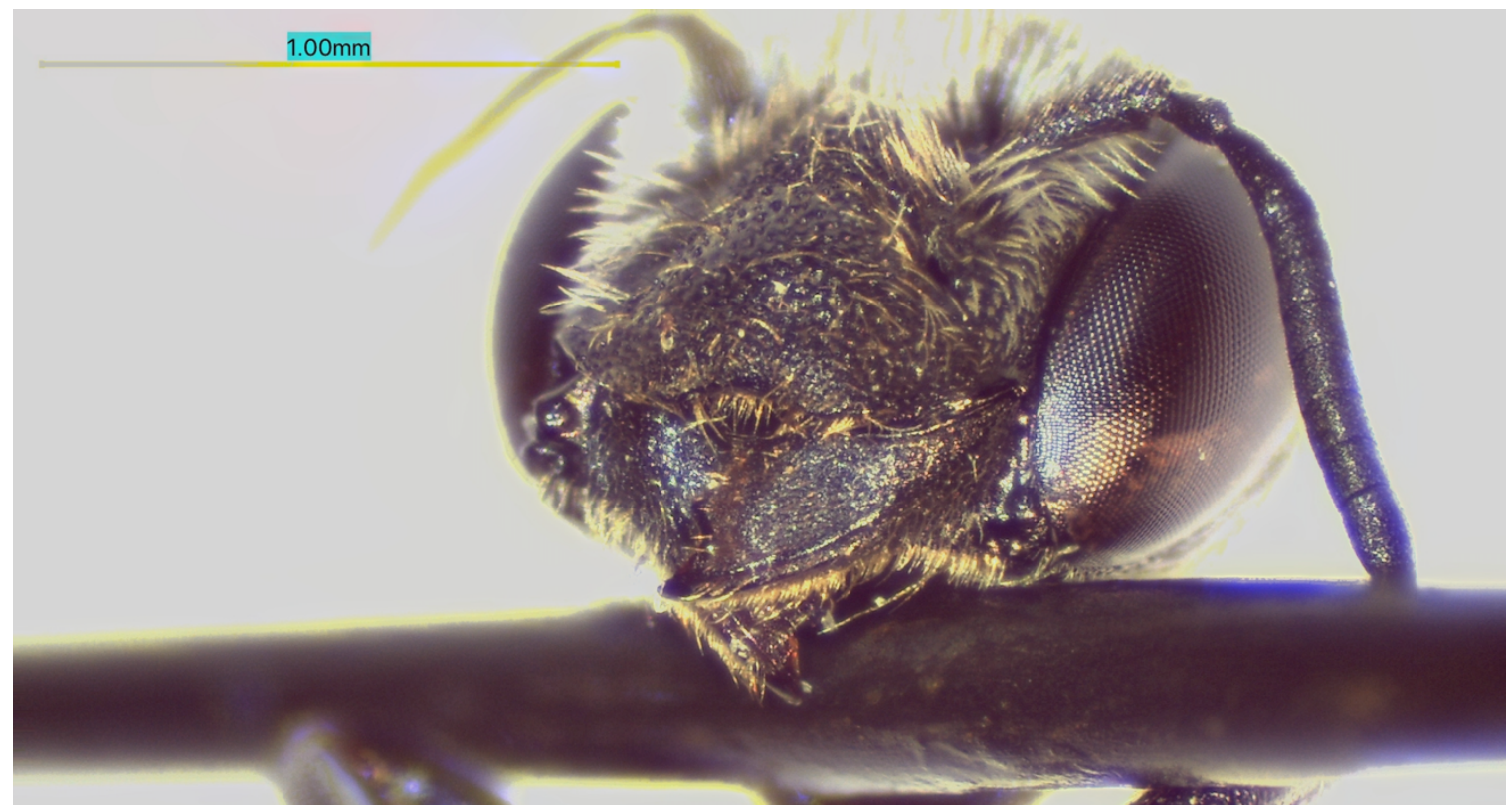

Figure 11: Female Ashmeadiella cactorum cactorum clypeal margin. 


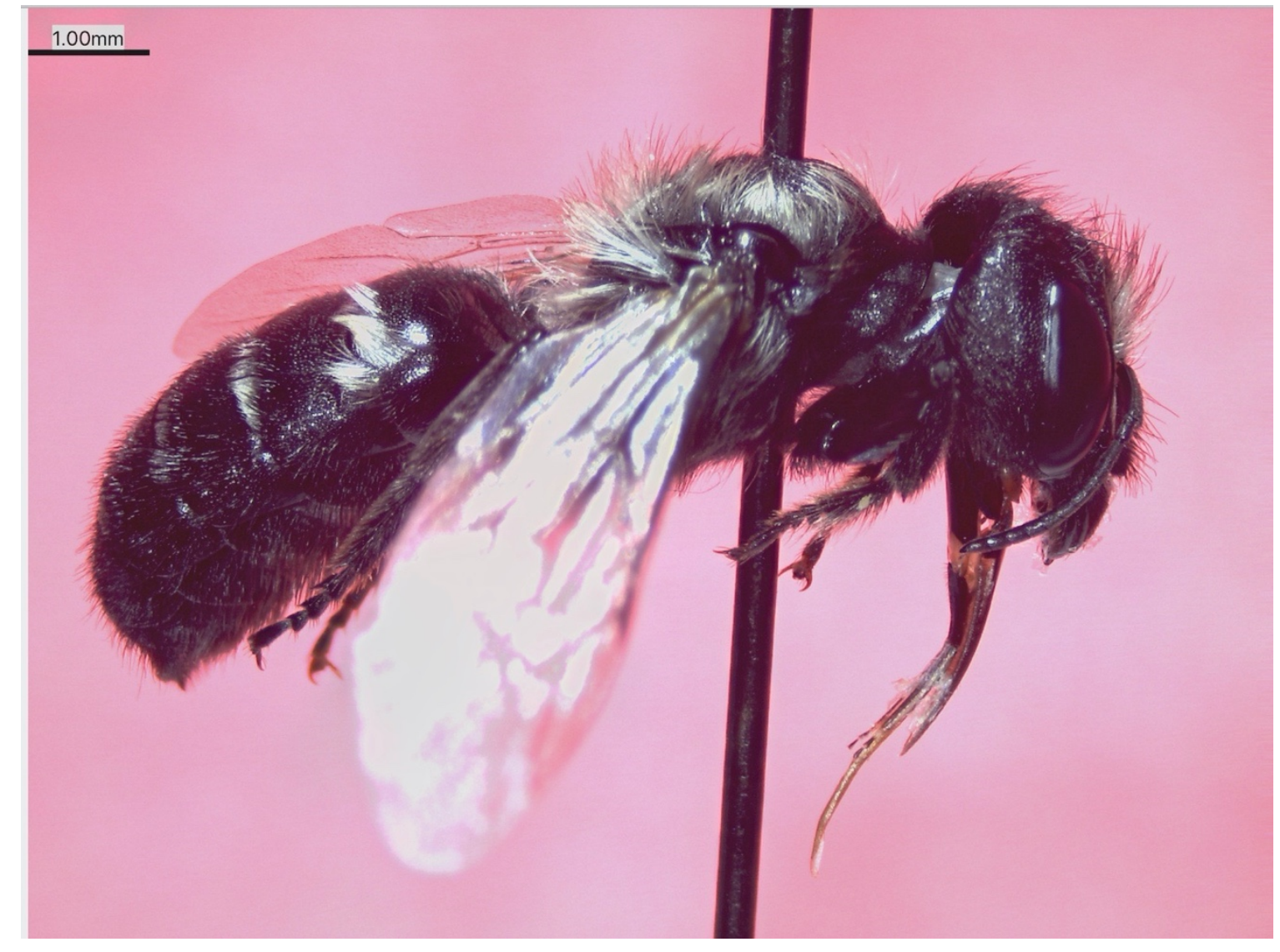

Figure 12. Female Hoplitis albifrons. 


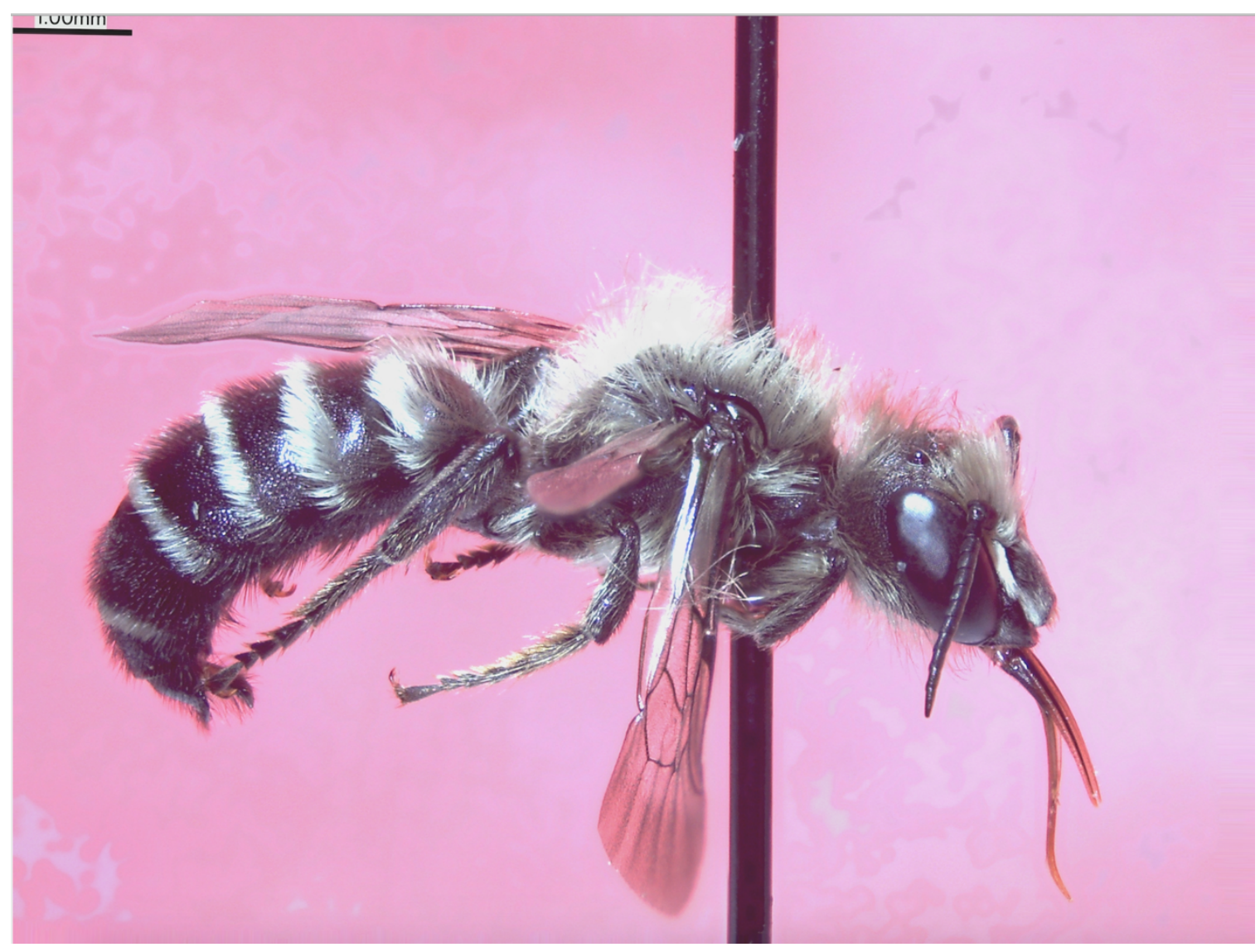

Figure 13: Male Hoplitis albifrons. 


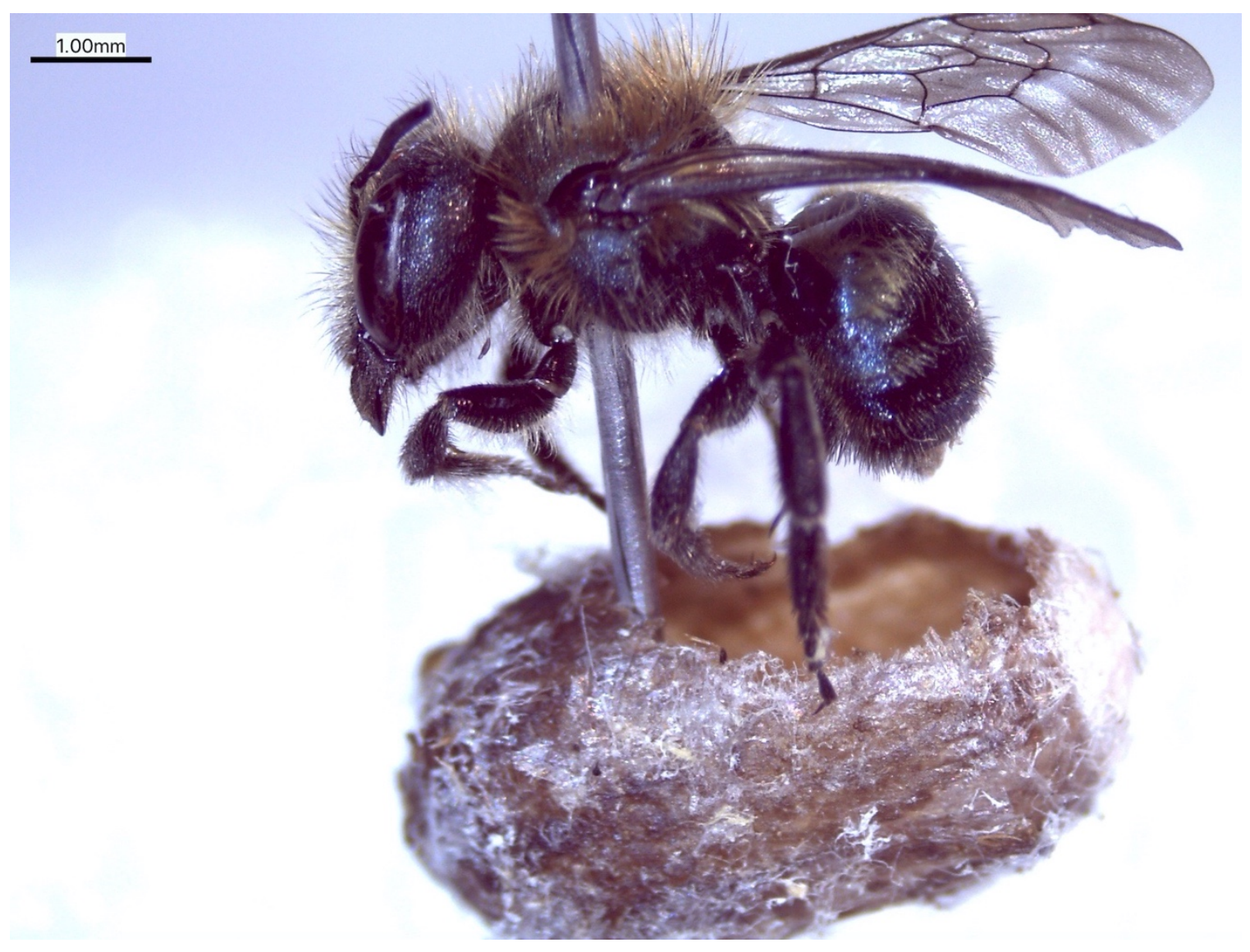

Figure 14: Female Osmia proxima with cocoon. 


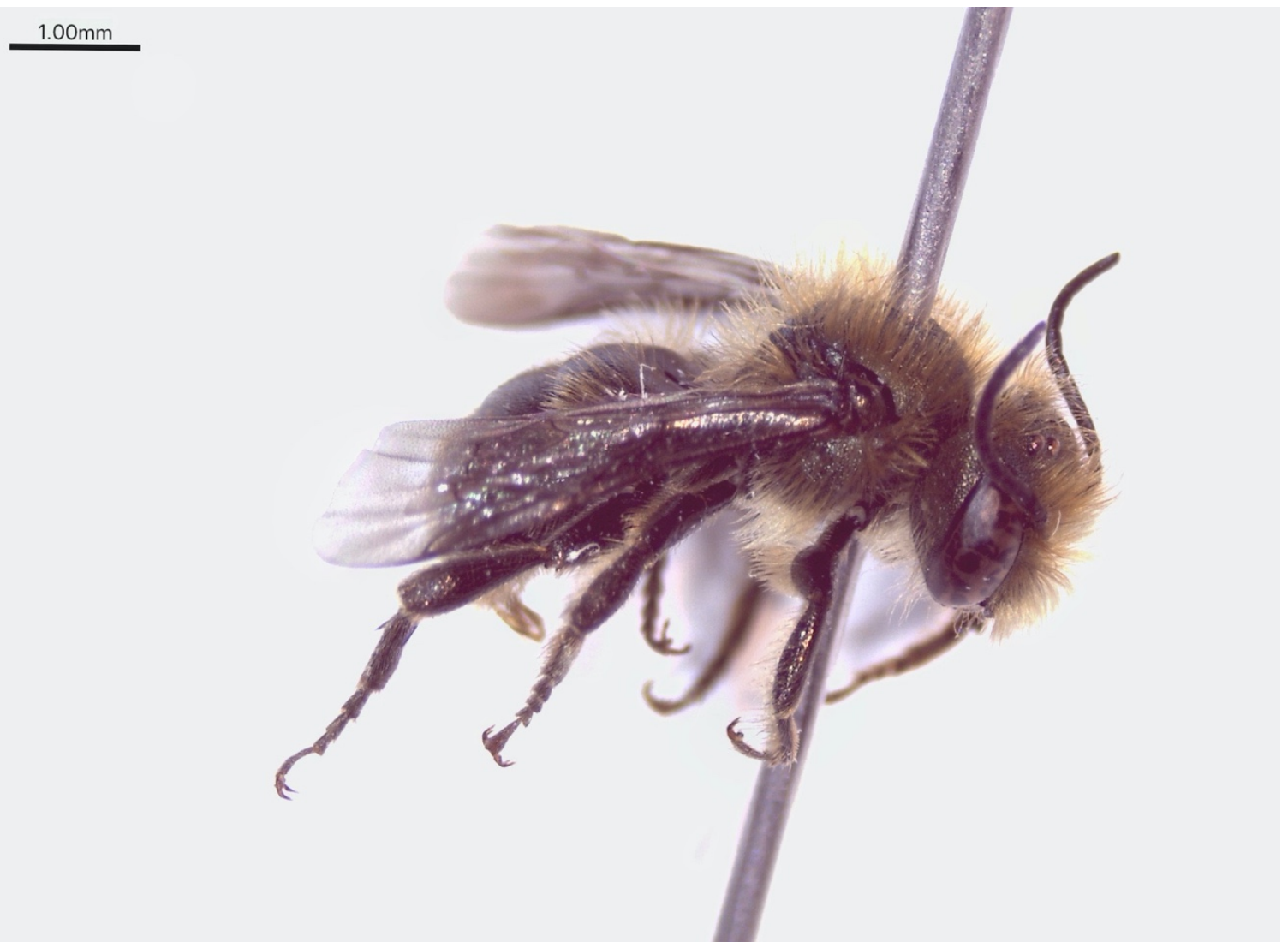

Figure 15: Male Osmia proxima. 


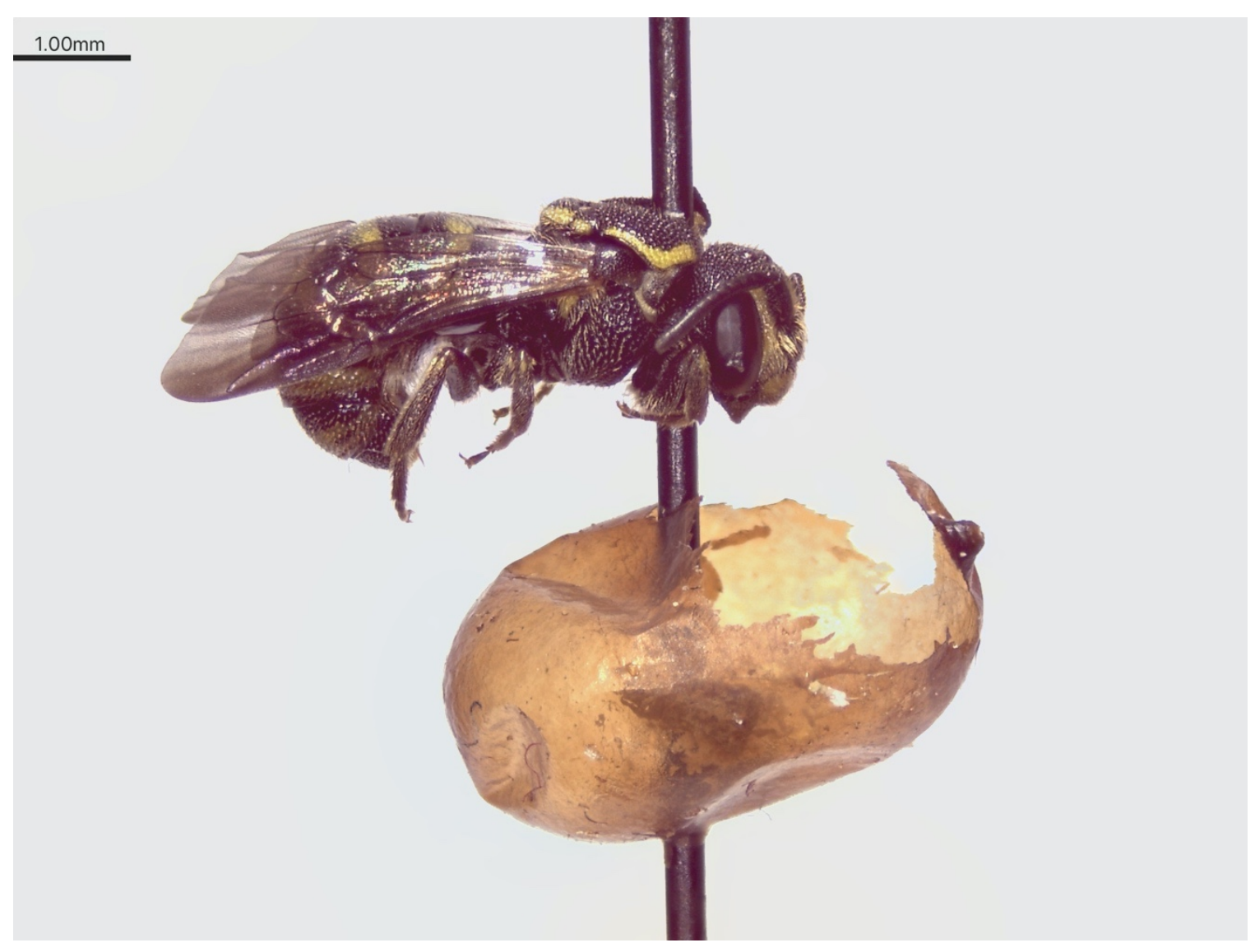

Figure 16: Male Stelis laticincta with cocoon. 


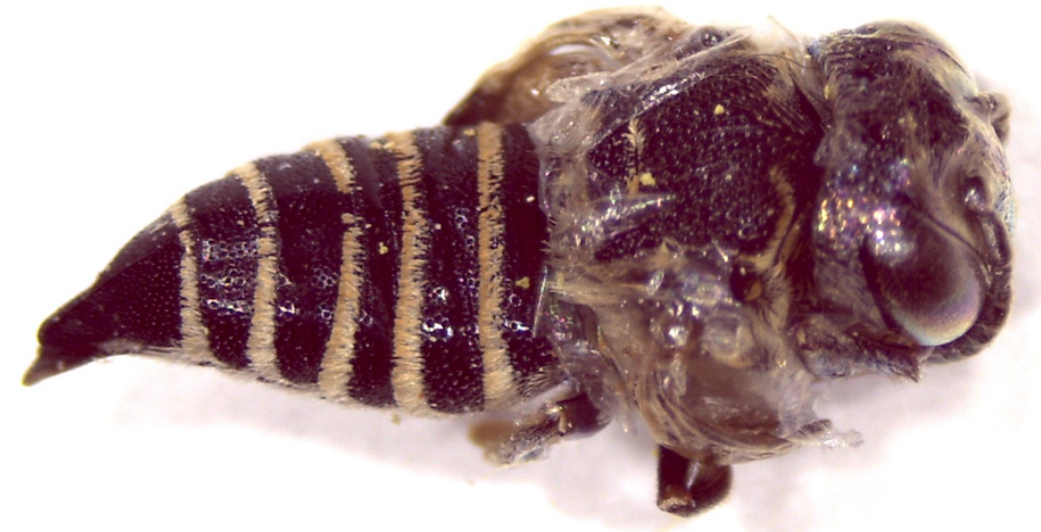

Figure 17: Underdeveloped female Coelioxys sp. 


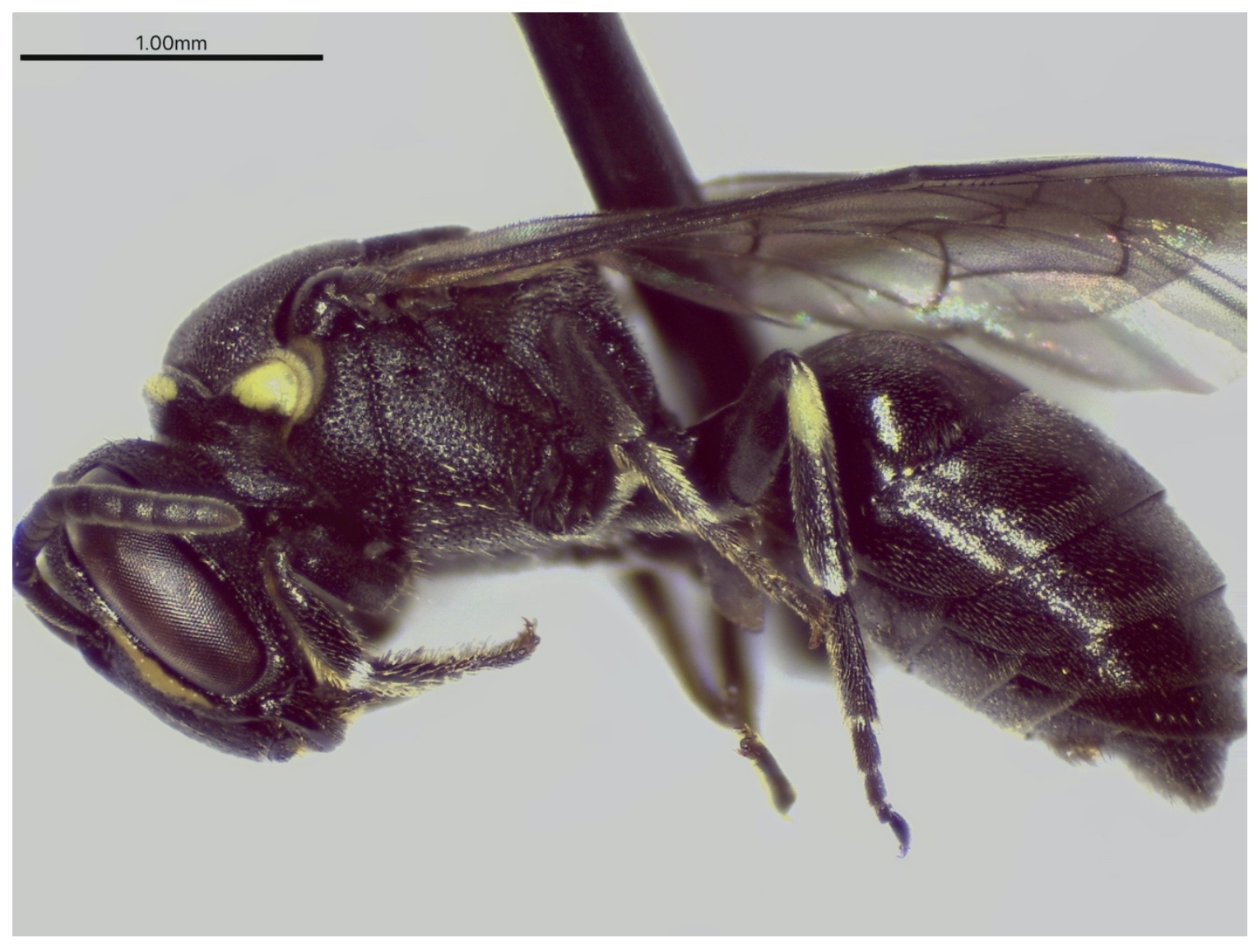

Figure 18: Female Hylaeus coloradensis. 


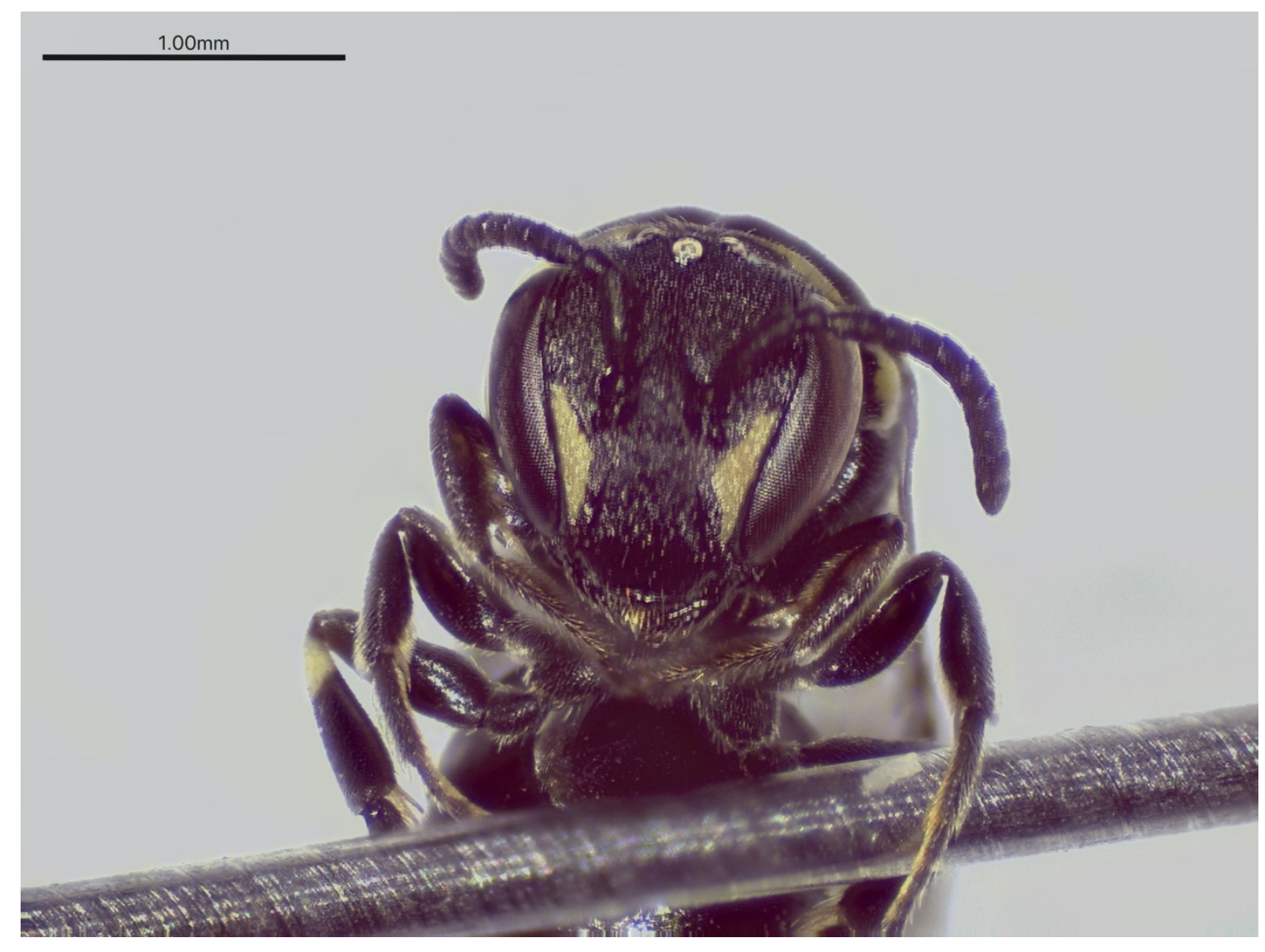

Figure 19: Female Hylaeus coloradensis view head on. 


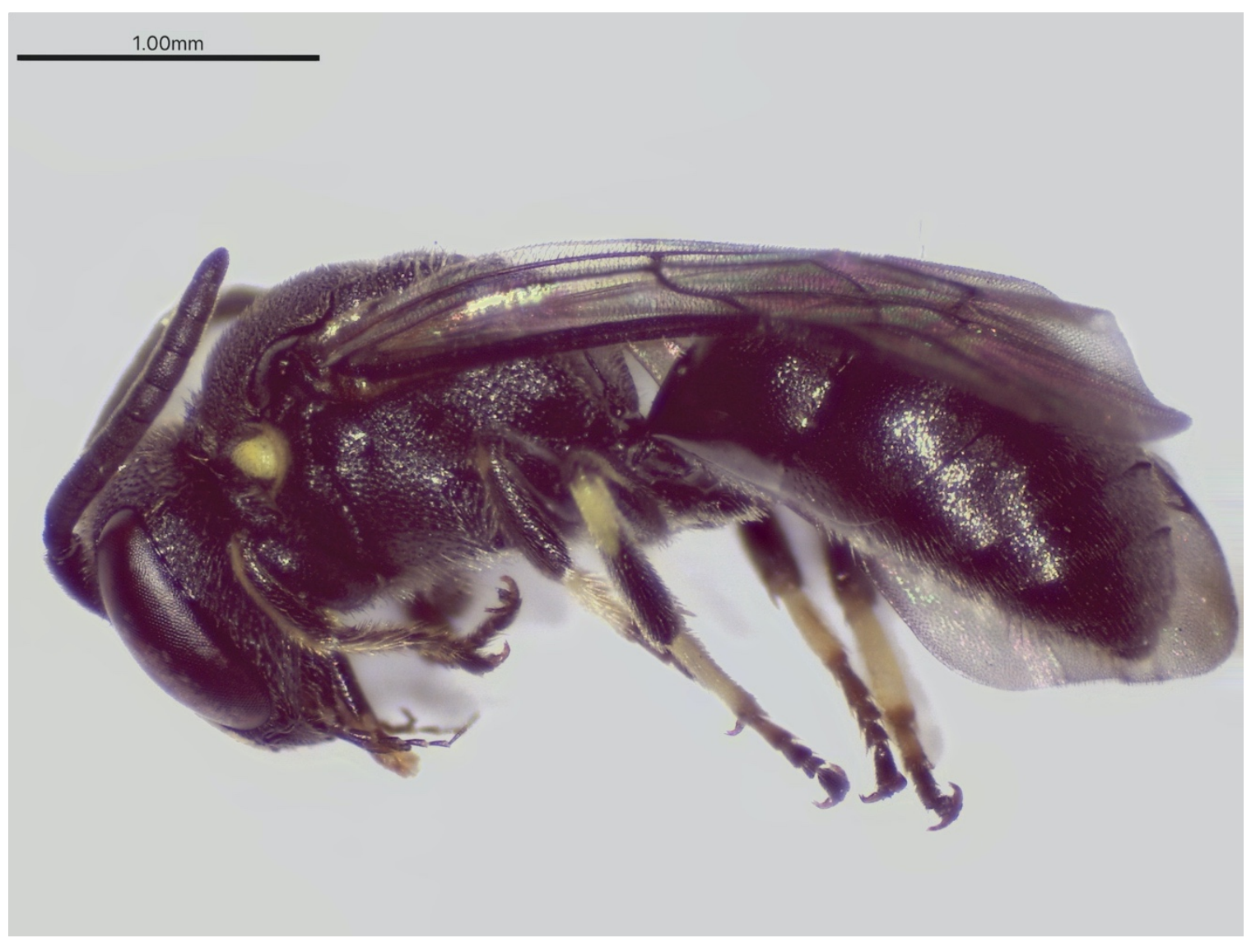

Figure 20: Male Hylaeus coloradensis. 


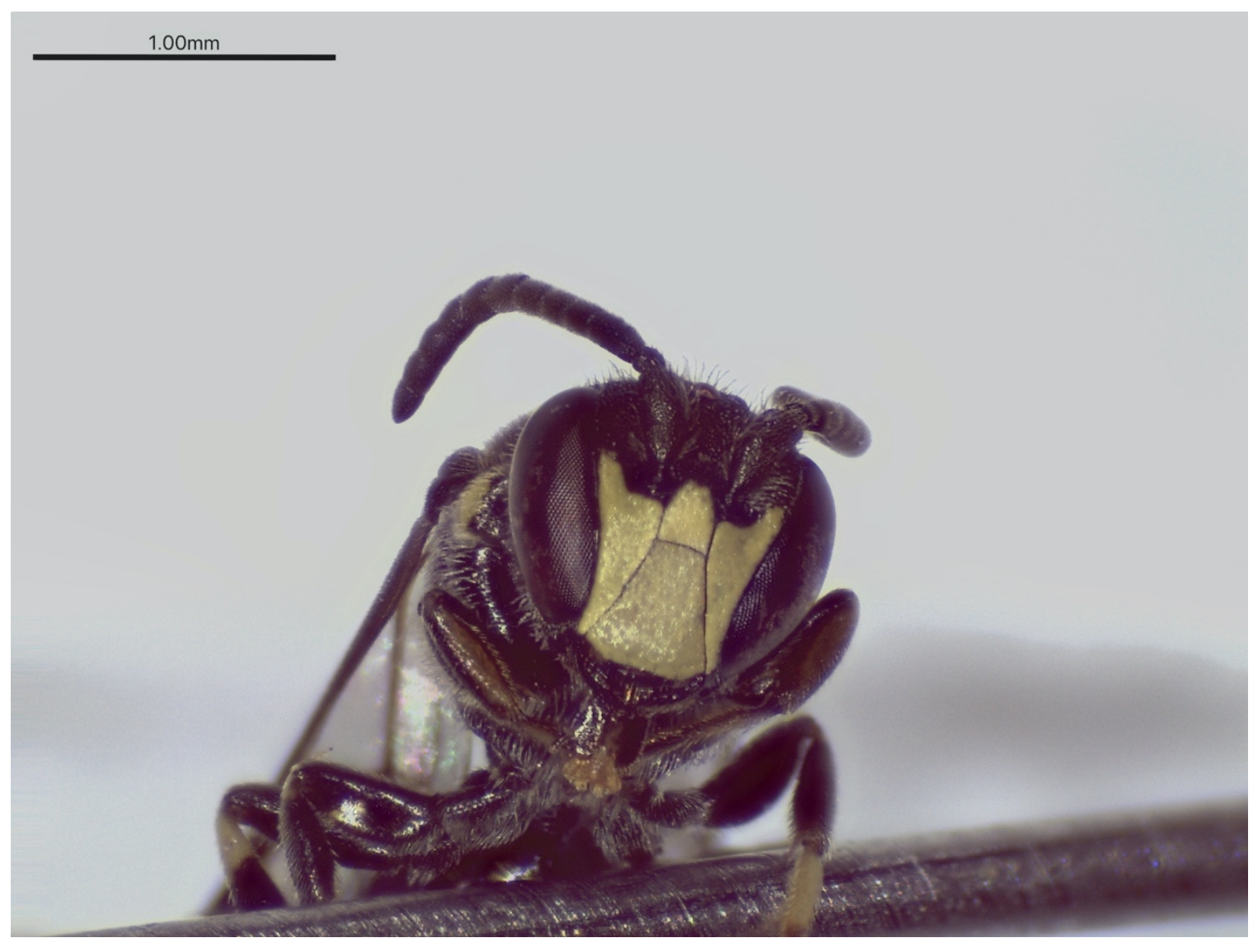

Figure 21: Male Hylaeus coloradensis view head on. 
$1.00 \mathrm{~mm}$
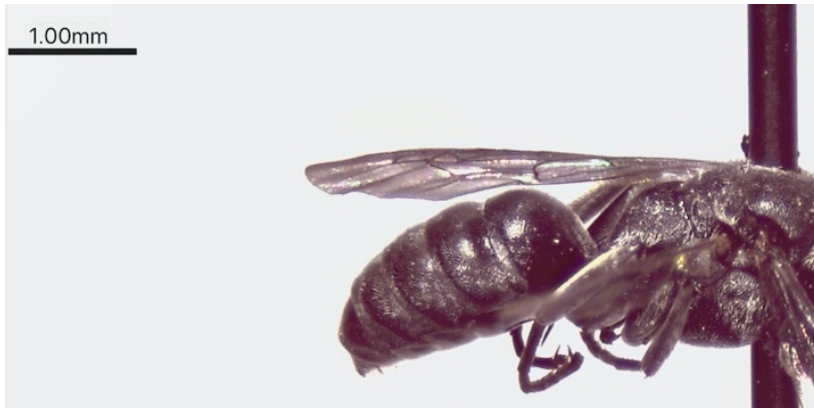


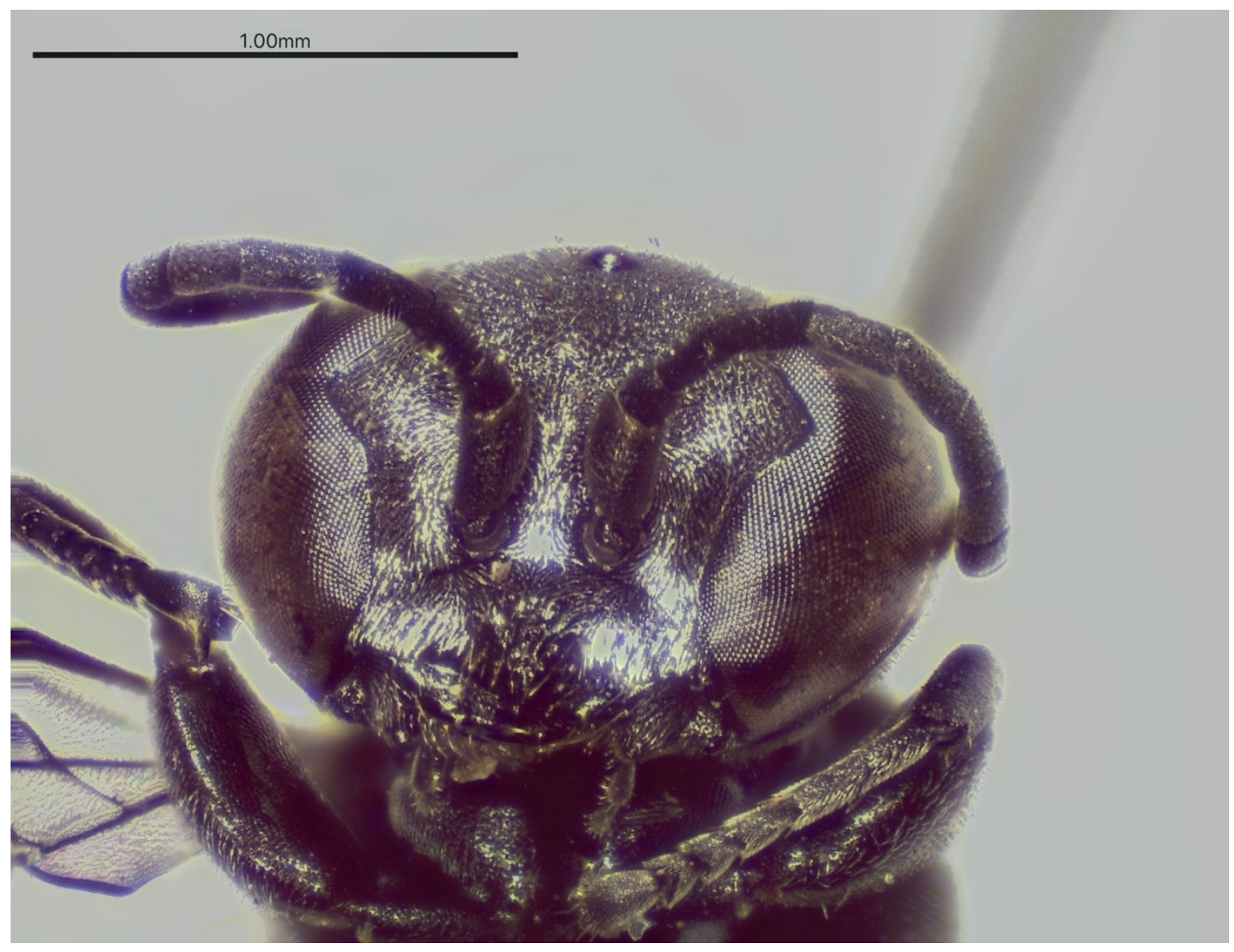

Figure 23: Pisonopsis species view head on. Notch in mandible visible. 


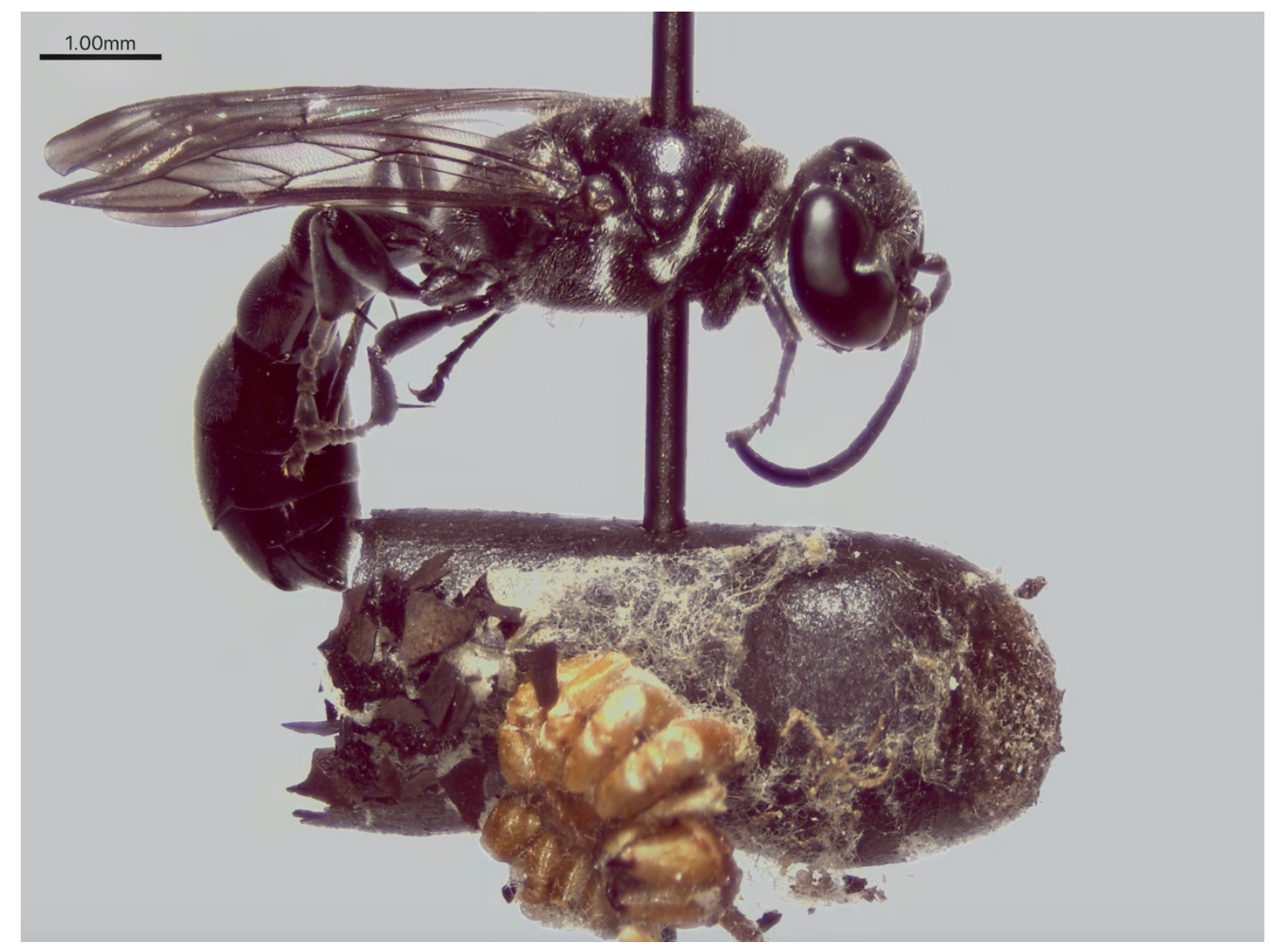

Figure 24: Trypoxylon (Trypargilum) and cocoon with a piece of food provisions (spider) attached. 


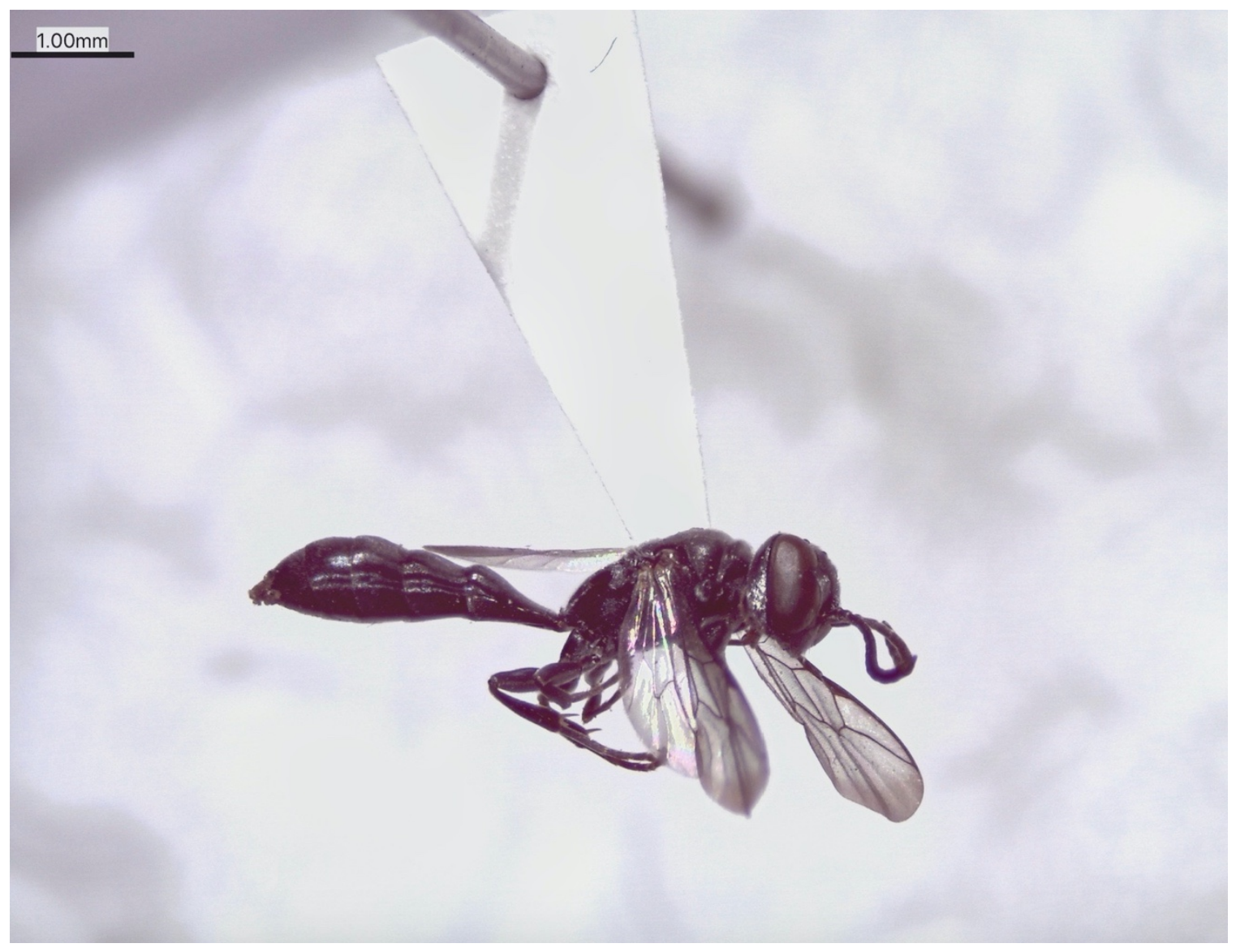

Figure 25: Trypoxylon (Trypoxylon) frigidum. 


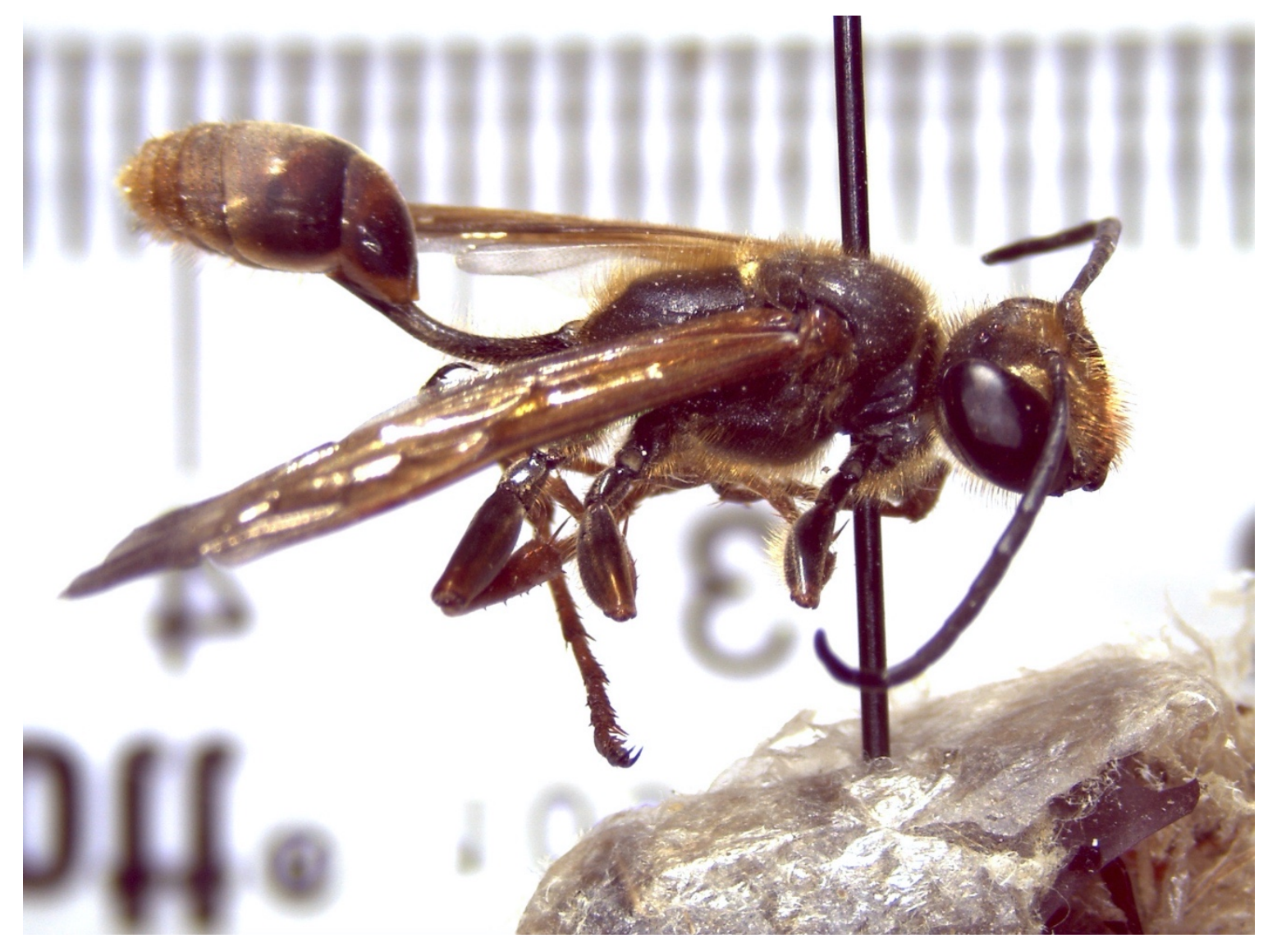

Figure 26: Isodontia elegans with partial view of cocoon below. Each line in the background is $1 \mathrm{~mm}$. 


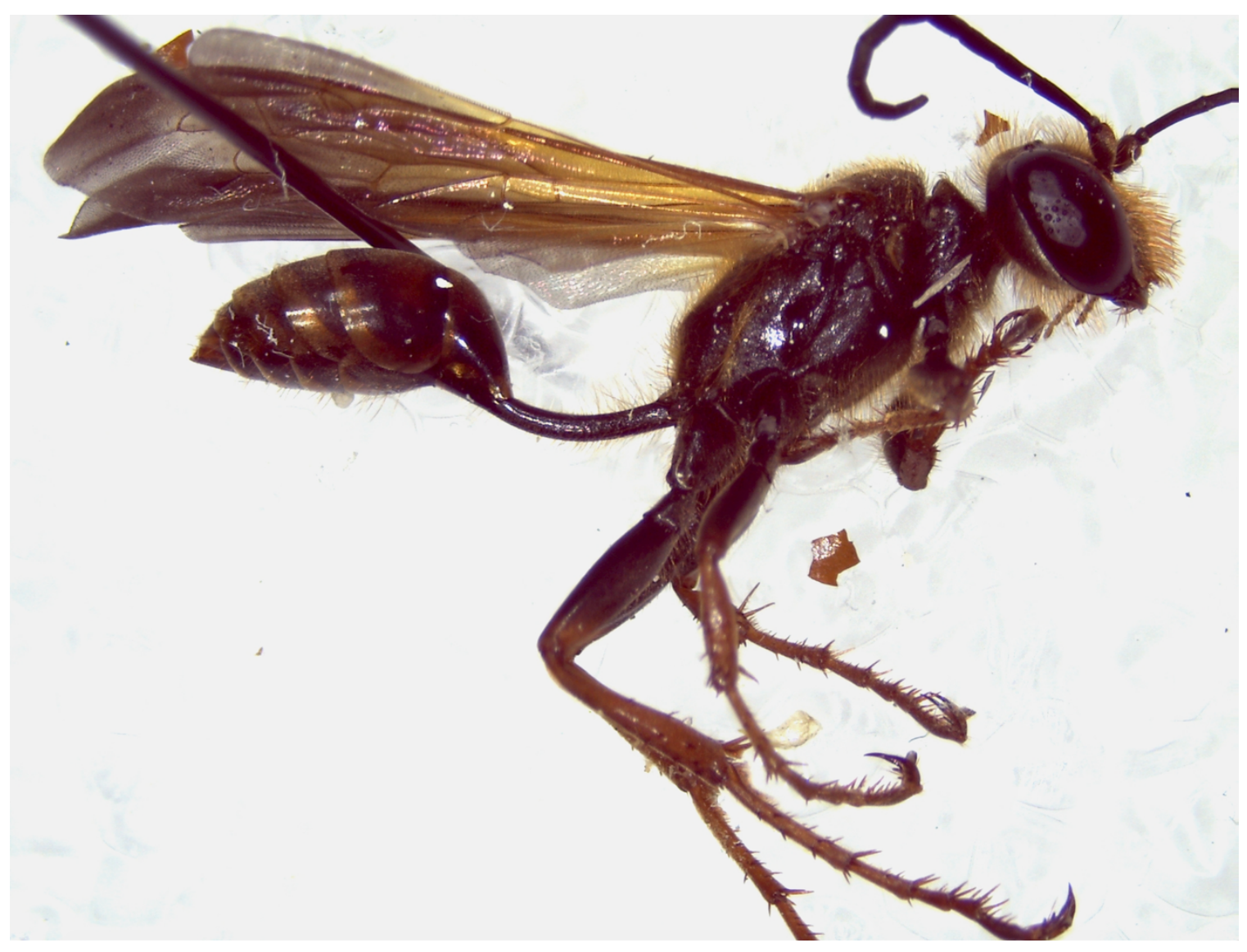

Figure 27: Isodontia elegans. 


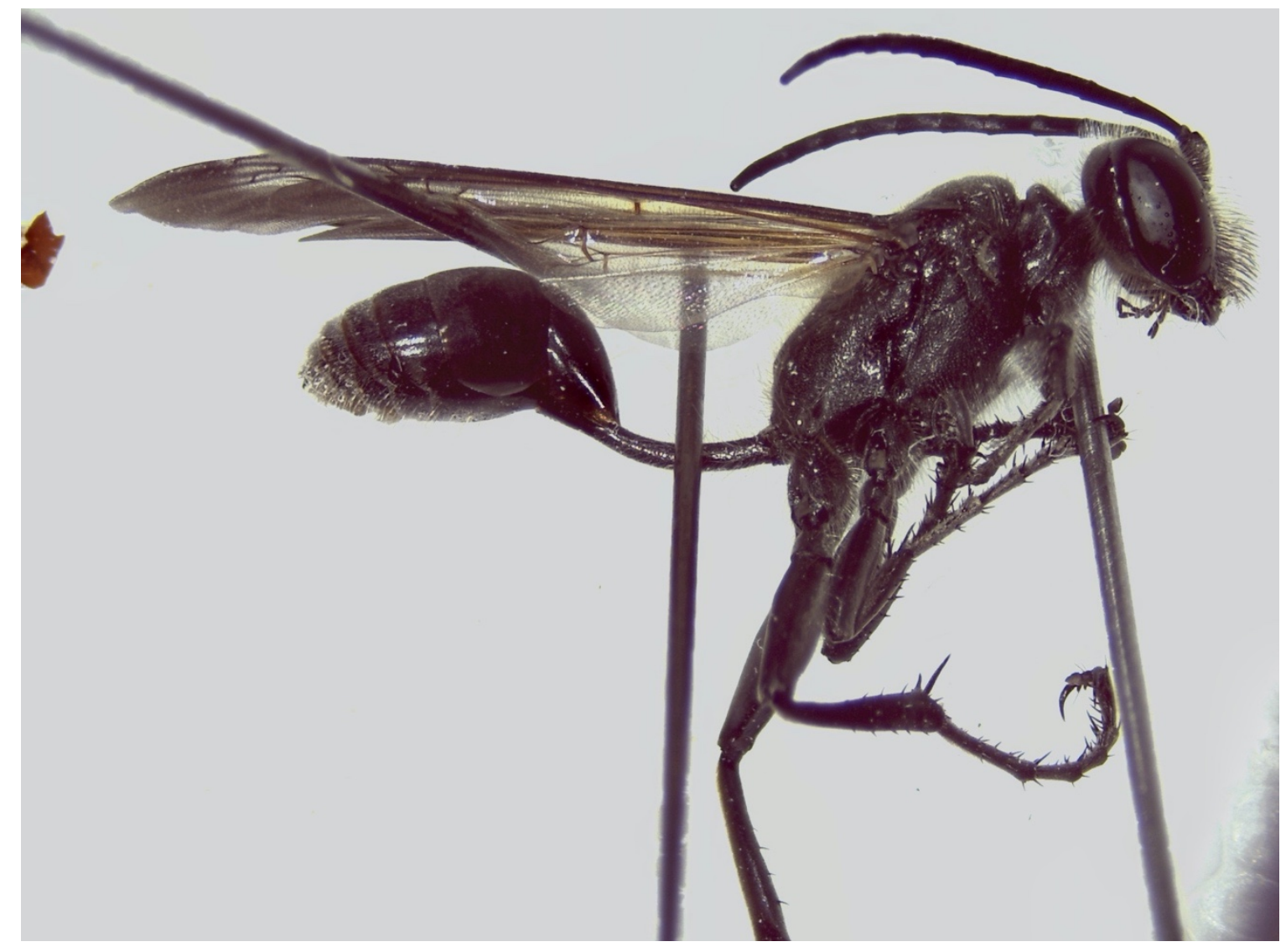

Figure 28. Isodontia mexicana. 


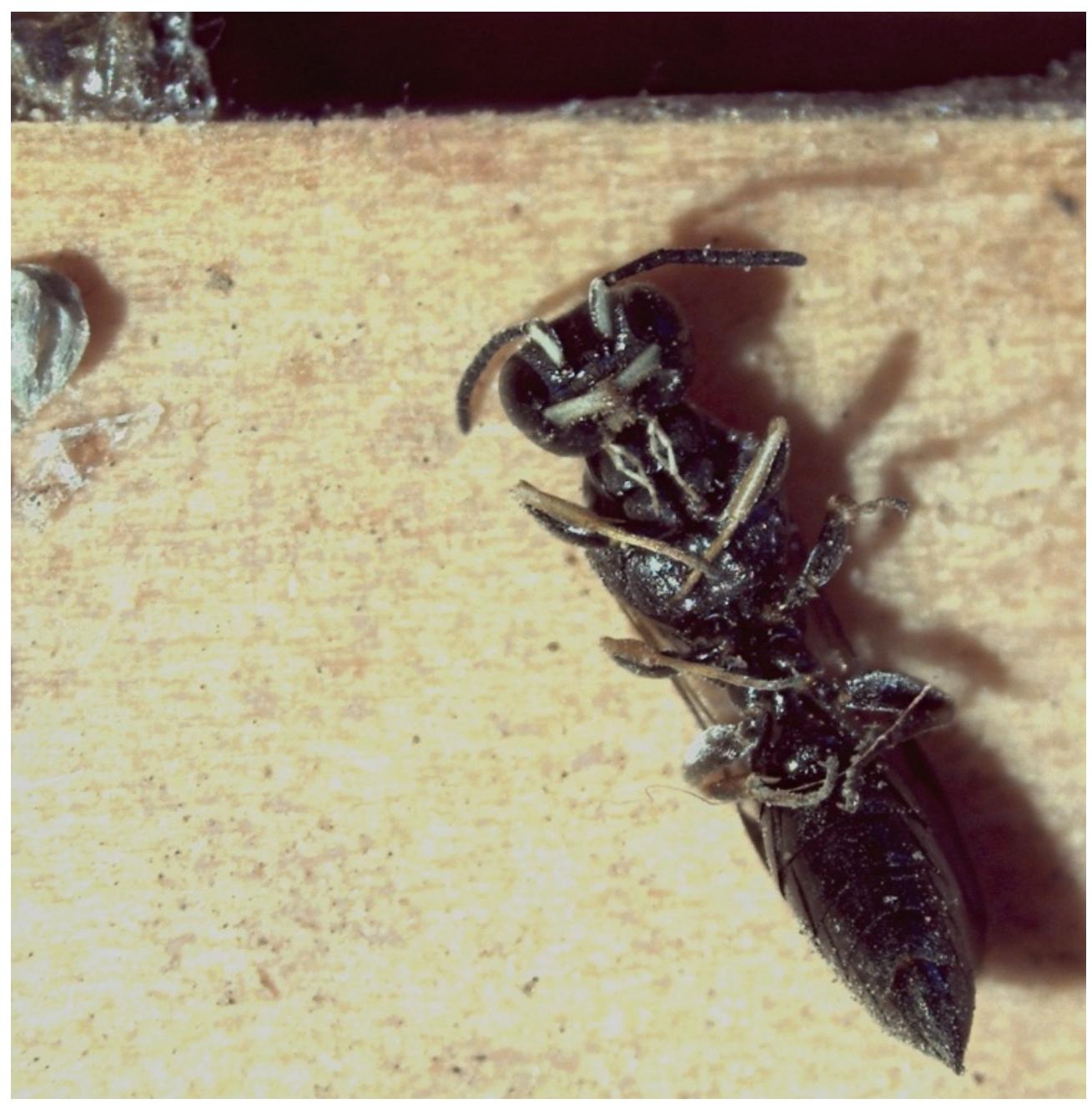

Figure 29: Resin Pemphredoninae wasp species. 


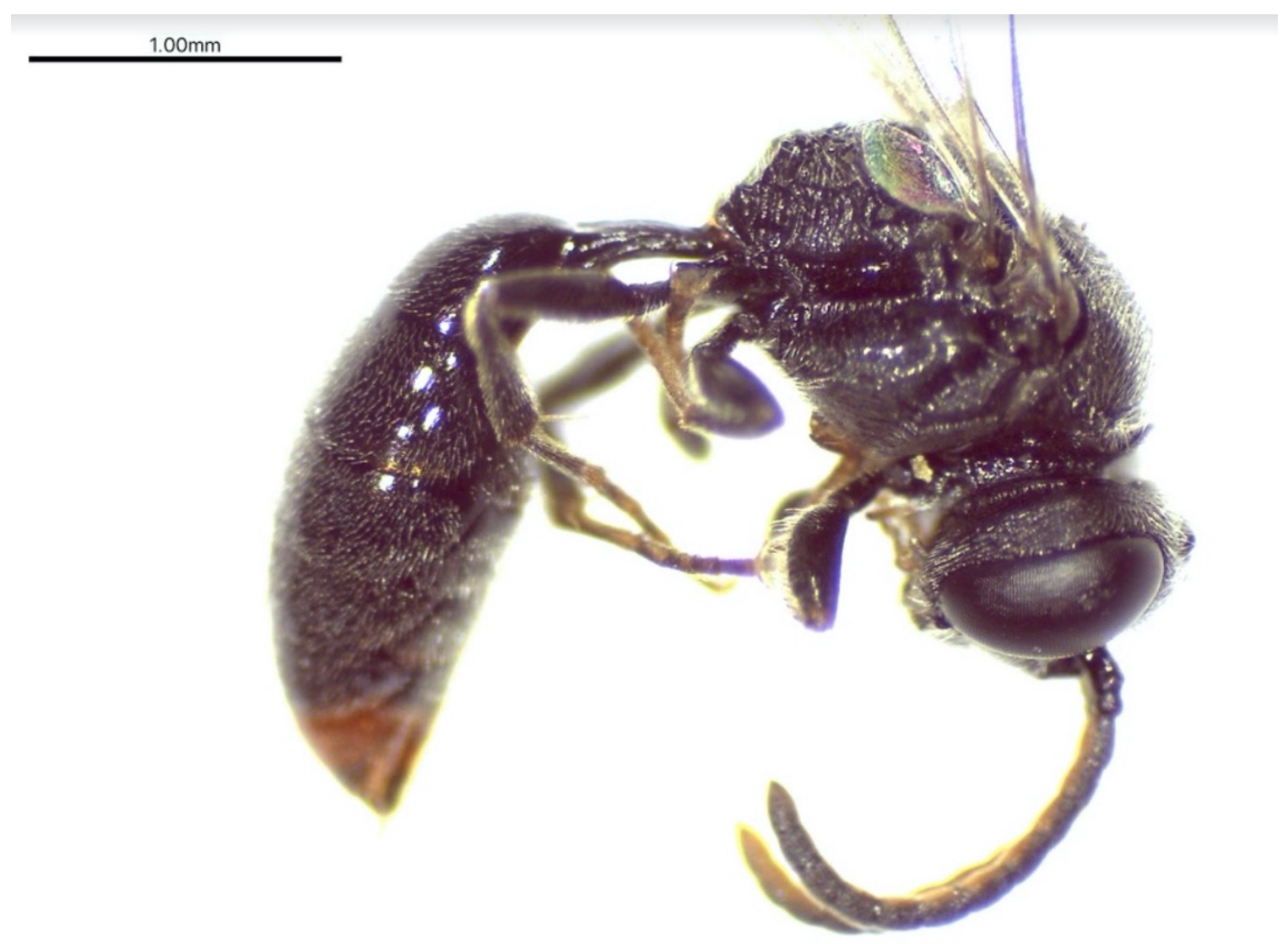

Figure 30: Wood chewing Pemphredoninae wasp species.

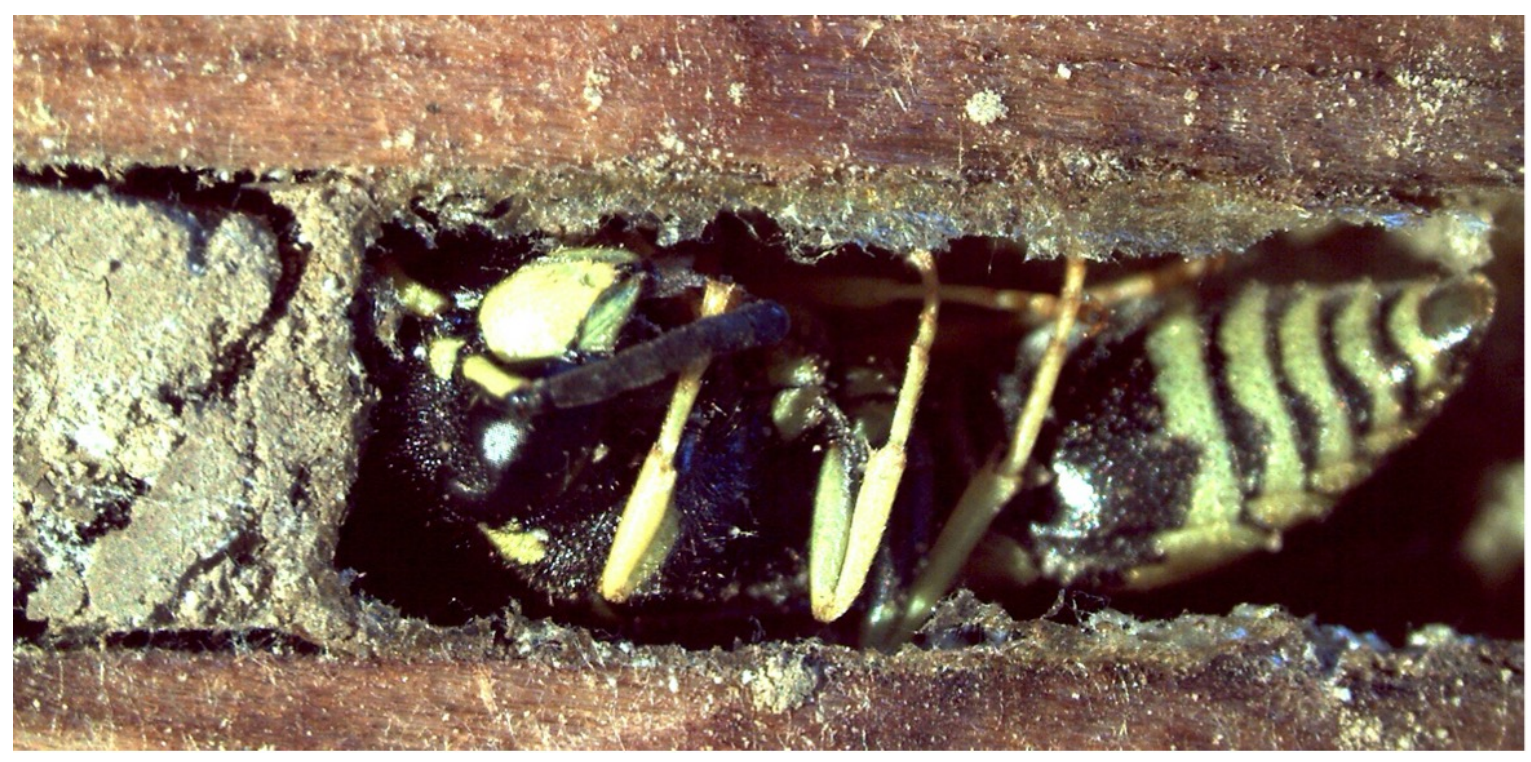

Figure 31. Eumeninae wasp species from $3.0 \mathrm{~mm}$ cavity. 


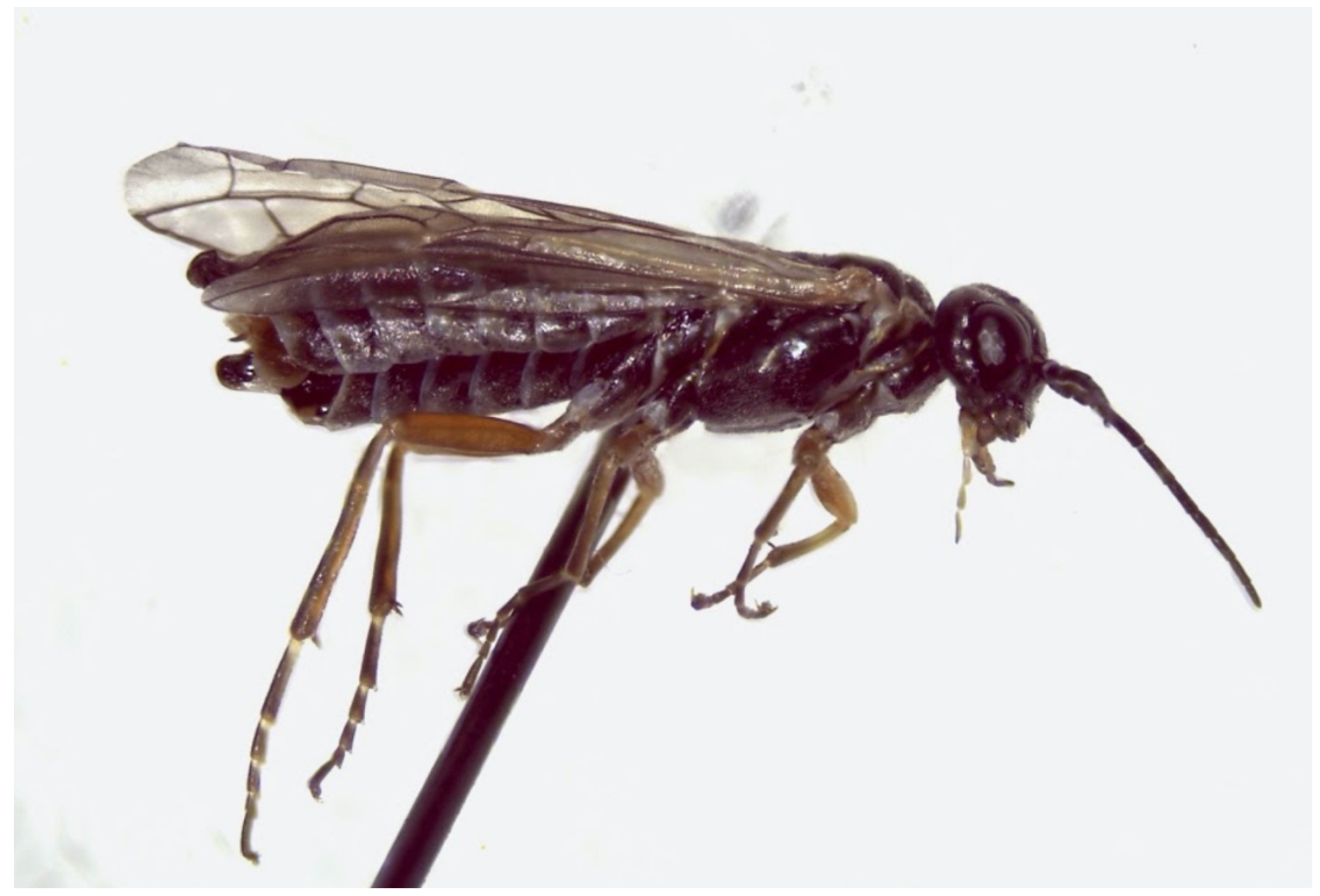

Figure 32: Sawfly species. 

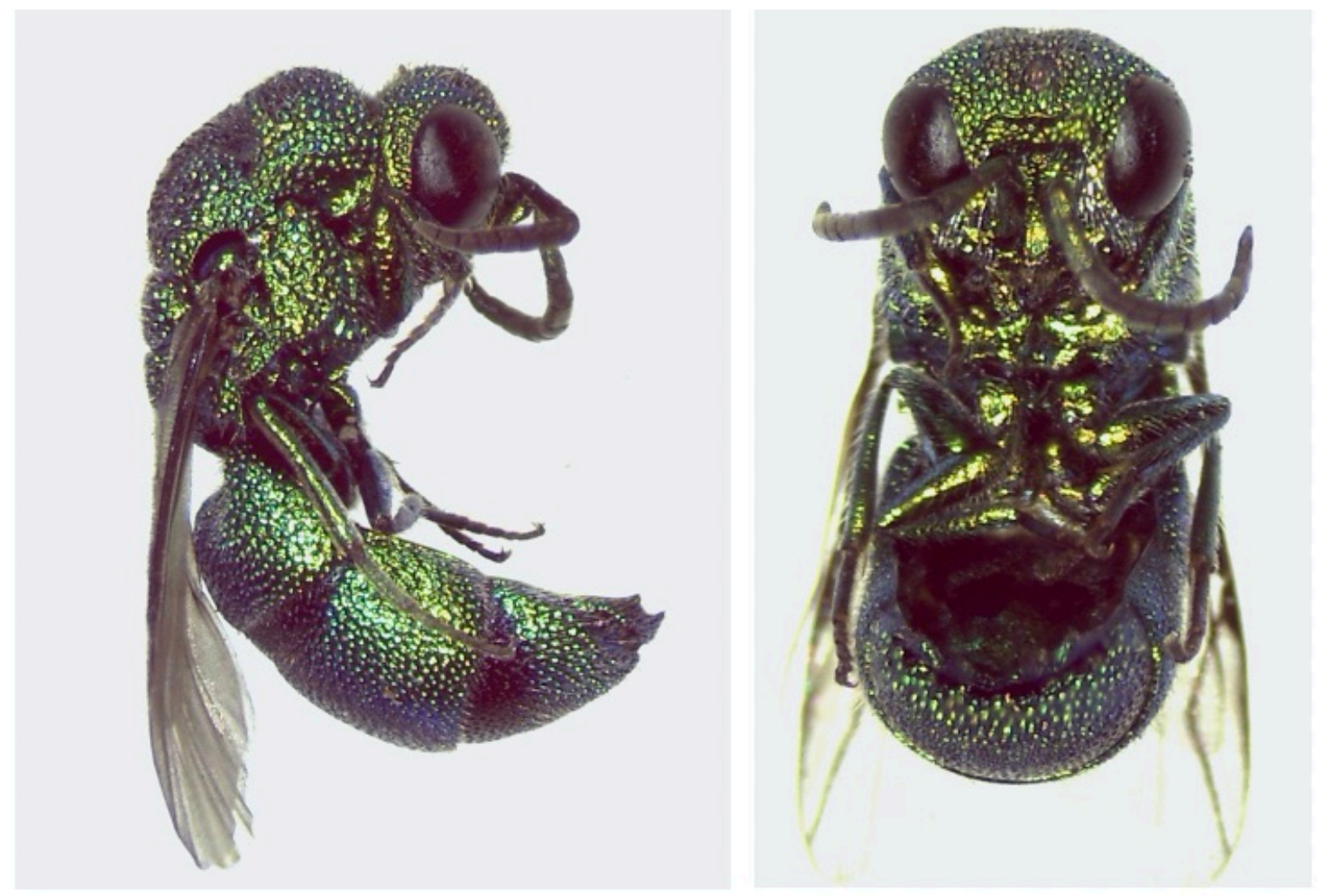

Figure 33: Chrysididae wasp species. 


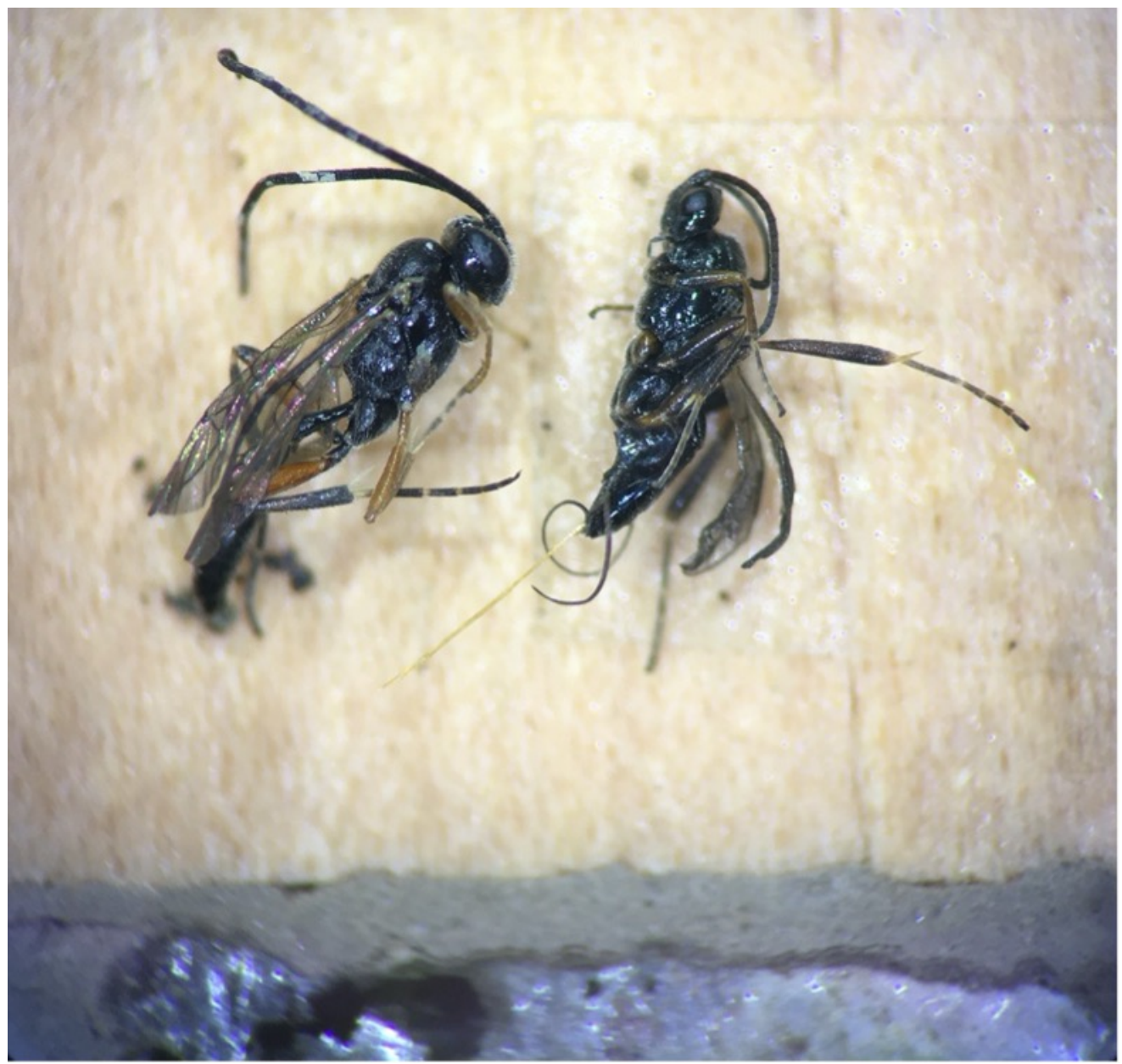

Figure 34: Ichneumonidae wasp male and female with long antennae. 


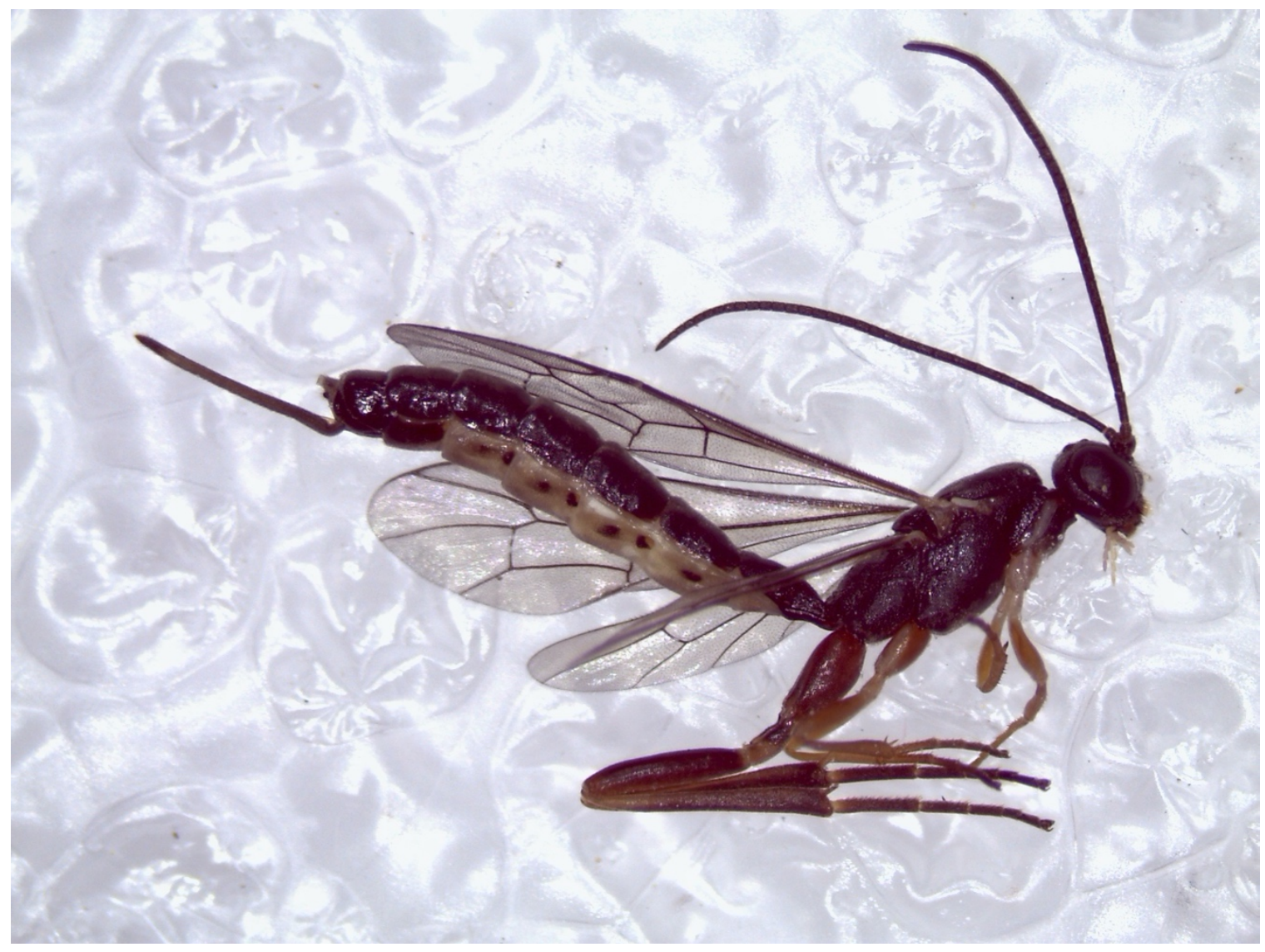

Figure 35: Ichneumonidae wasp male and female with long abdomen. 


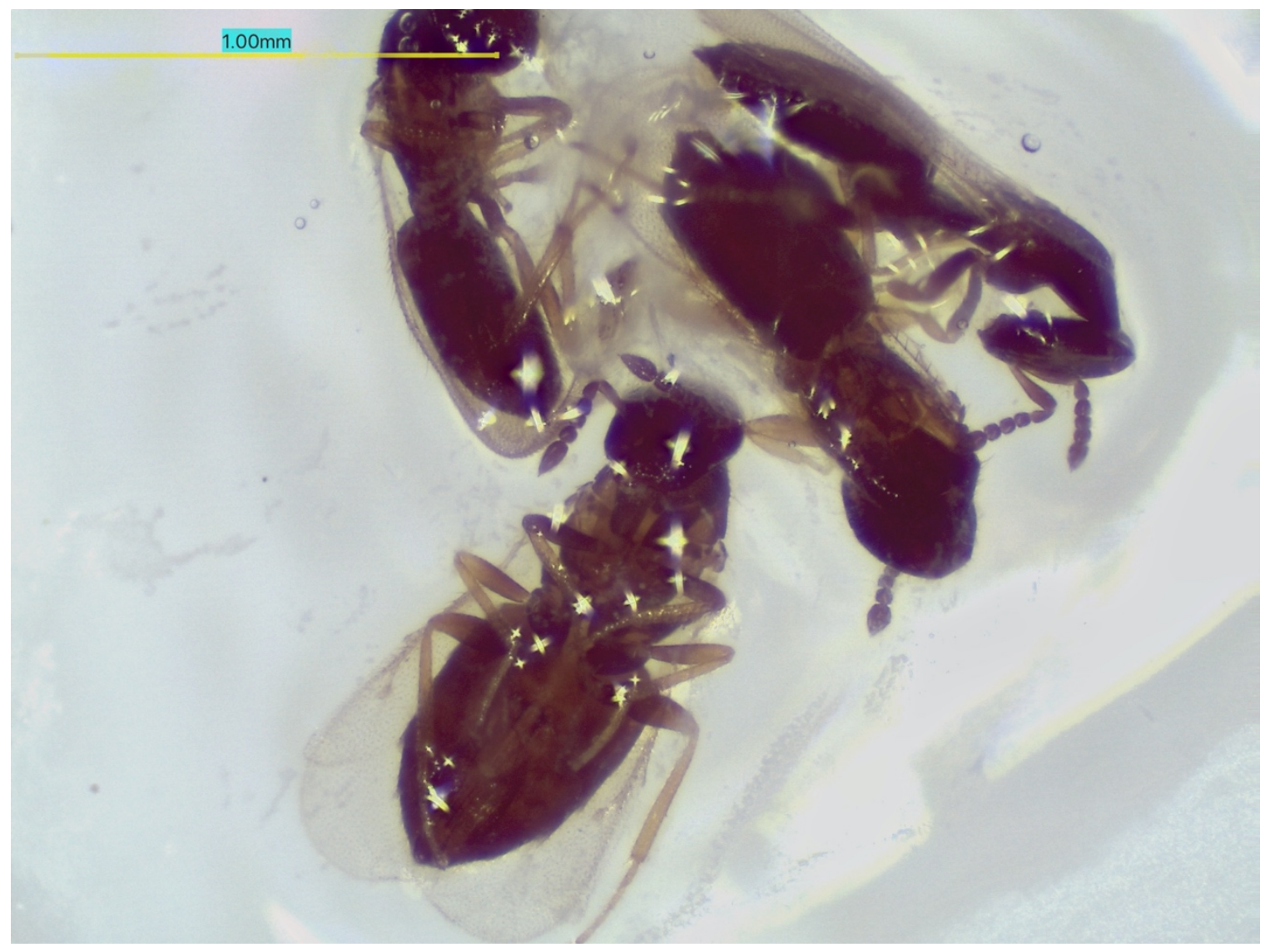

Figure 36: Melittobia species (in EtOH) from Pseudoanthidium nanum nests. 


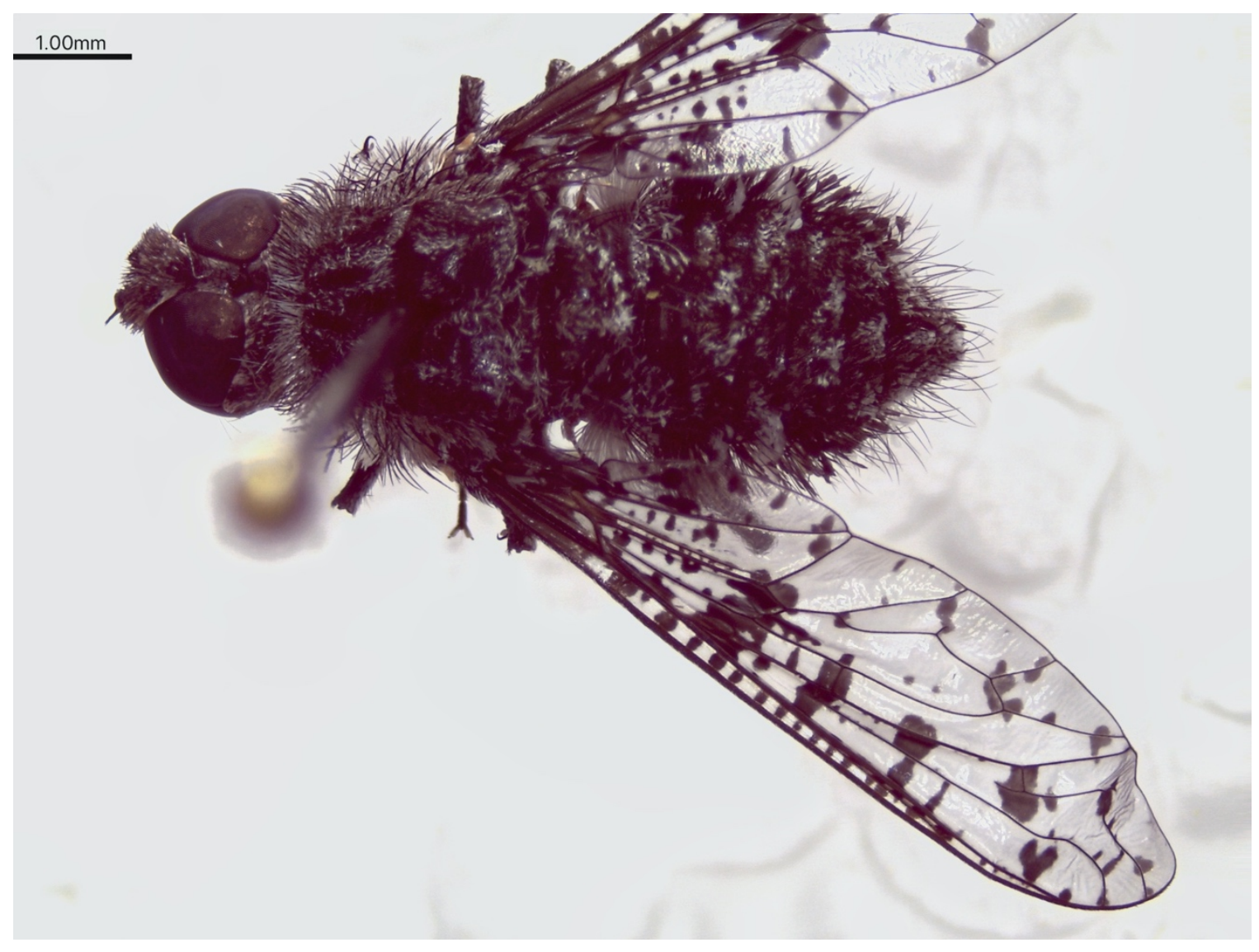

Figure 37: Bombyliidae parasitoid fly, Anthrax irroratus. 